Florida International University FIU Digital Commons

$2-22-2013$

\title{
Gender Differences in the Influence of Protective Factors, Risk Factors, and Health Risk Behaviors on HIV Risk Behaviors Among Youth in South Florida
}

Christi M. Navarro

Florida International University, cnava009@fiu.edu

DOI: $10.25148 /$ etd.FI13042305

Follow this and additional works at: https://digitalcommons.fiu.edu/etd

\section{Recommended Citation}

Navarro, Christi M., "Gender Differences in the Influence of Protective Factors, Risk Factors, and Health Risk Behaviors on HIV Risk Behaviors Among Youth in South Florida" (2013). FIU Electronic Theses and Dissertations. 845.

https://digitalcommons.fiu.edu/etd/845 


\section{FLORIDA INTERNATIONAL UNIVERSITY}

Miami, Florida

GENDER DIFFERENCES IN THE INFLUENCE OF PROTECTIVE FACTORS, RISK FACTORS, AND HEALTH RISK BEHAVIORS ON HIV RISK BEHAVIORS

AMONG YOUTH IN SOUTH FLORIDA

A dissertation submitted in partial fulfillment of

the requirements for the degree of

DOCTOR OF PHILOSOPHY

in

PUBLIC HEALTH

by

Christi M. Navarro

2013 
To: Dean Michele Ciccazzo

Robert Stempel College of Public Health \& Social Work

This dissertation, written by Christi M. Navarro, and entitled Gender Differences in the Influence of Protective Factors, Risk Factors, and Health Risk Behaviors on HIV Risk Behaviors Among Youth in South Florida, having been approved in respect to style and intellectual content, is referred to you for judgment.

We have read this dissertation and recommend that it be approved.

William W. Darrow

Jessy G. Dévieux

Changwon Yoo

H. Virginia McCoy, Major Professor

Date of Defense: February 22, 2013.

The dissertation of Christi M. Navarro is approved.

Dean Michele Ciccazzo Robert Stempel College of Public Health \& Social Work

Dean Lakshmi N. Reddi University Graduate School

Florida International University, 2013 
(C) Copyright 2013 by Christi M. Navarro

All rights reserved. 


\title{
DEDICATION
}

\author{
To Sam I Am
}

A smart left-handed man I once knew

Said "A Ph.D. you must pursue"

So we started this journey

But he left me too early

So Grandpa, I say this one's for you.

Forever in your debt.

1922-2009 


\section{ACKNOWLEDGMENTS}

"Our willingness to wait reveals the value we place on the object we're waiting for."

- Charles Stanley

This journey has been truly rewarding and would not have been possible without the support and guidance of several individuals who in one way or another contributed to this process. First, I would like to express my sincere gratitude to the members of my committee for their time, expertise, and scholarly critique. I would also like to extend a special appreciation to my committee chair, Dr. Virginia McCoy, for making my doctoral experience both productive and motivating. Her encouragement and advice were of great value to me, especially during the tough times.

I gratefully acknowledge the funding sources that have made the successful and timely completion of my Ph.D. work possible. I am honored to be a McKnight Doctoral Fellow and would like to thank Dr. Lawrence Morehouse and the Florida Education Fund for providing financial support, professional development, and unlimited encouragement. A special thanks to Charles Jackson at the FEF for his unwavering dedication to the MDF fellows. My final year of support as a Dissertation Year Fellow was received from the Florida International University Graduate School. My deepest thanks to the generous guidance of the UGS staff, both past and present.

The Centers for Disease Control and Prevention, Division of Adolescent and School Health and the School District of Palm Beach County provided me with the data for my research, and I am very grateful to them.

These past few years were made both enjoyable and bearable due in large part to my fantastic cohort. To Team Awesome, your encouragement, e-mails, study sessions, 
venting episodes, rolling-on-the-floor type laughter, in-class giggles, baked goods, wine toasts, and other distractions kept me sane on this journey. Stay awesome, my incredibly over-qualified friends.

Lastly, I would like to share the joy of successfully completing this degree with the people who helped me emotionally, intellectually, and spiritually. In particular, I would like to thank my family for loving me so effortlessly and willingly. To my grandparents, your belief in my abilities is a wonder to me, and is the push that keeps me going. To my parents, I am blessed to have been raised with a passion for knowledge and always encouraged to reach past my potential. To my brother, for always being right there for me, regardless of your post, whether in Iraq, Afghanistan, Japan, or Hawaii. To Jayden and Naomi, may your life be filled with the love of learning as mine has been. Jioia, you are my sunshine.

And most of all, to my patient husband Eligio, from Jouvert mornings to afternoons in the library to late night writing sessions, you were there for it all. Thank you for taking this huge adventure with me. Our journey continues... 


\section{ABSTRACT OF THE DISSERTATION \\ GENDER DIFFERENCES IN THE INFLUENCE OF PROTECTIVE FACTORS, RISK \\ FACTORS, AND HEALTH RISK BEHAVIORS ON HIV RISK BEHAVIORS \\ AMONG YOUTH IN SOUTH FLORIDA \\ by}

Christi M. Navarro

Florida International University, 2013

Miami, Florida

Professor H. Virginia McCoy Major Professor

Adolescents engage in a range of risk behaviors during their transition from childhood to adulthood. Identifying and understanding interpersonal and socioenvironmental factors that may influence risk-taking is imperative in order to meet the Healthy People 2020 goals of reducing the incidence of unintended pregnancies, HIV, and other sexually transmitted infections among youth. The purpose of this study was to investigate gender differences in the predictors of HIV risk behaviors among South Florida youth. More specifically, this study examined how protective factors, risk factors, and health risk behaviors, derived from a guiding framework using the Theory of Problem Behavior and Theory of Gender and Power, were associated with HIV risk behavior.

A secondary analysis of 2009 Youth Risk Behavior Survey data sets from MiamiDade, Broward, and Palm Beach school districts tested hypotheses for factors associated with HIV risk behaviors. The sample consisted of 5,869 high school students (mean age 16.1 years), with $69 \%$ identifying as Black or Hispanic. Logistic regression analyses 
revealed gender differences in the predictors of HIV risk behavior. An increase in the health risk behaviors was related to an increase in the odds that a student would engage in HIV risk behavior. An increase in risk factors was also found to significantly predict an increase in the odds of HIV risk behavior, but only in females. Also, the probability of participation in HIV risk behavior increased with grade level.

Post-hoc analyses identified recent sexual activity (past 3 months) as the strongest predictor of condom nonuse and having four or more sexual partners for both genders. The strongest predictors of having sex under the influence of drugs/alcohol were alcohol use in both genders, marijuana use in females, and physical fighting in males. Gender differences in the predictors of unprotected sex, multiple sexual partners, and having sex under the influence were also found.

Additional studies are warranted to understand the gender differences in predictors of HIV risk behavior among youth in order to better inform prevention programming and policy, as well as meet the national Healthy People 2020 goals. 


\section{TABLE OF CONTENTS}

CHAPTER

PAGE

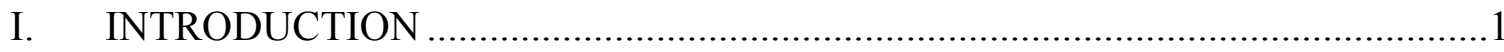

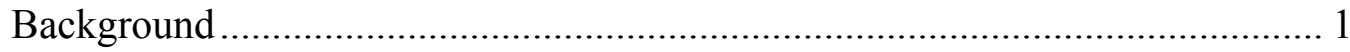

Statement of the Problem................................................................................. 14

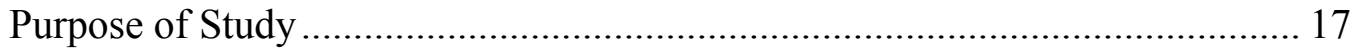

Public Health Significance............................................................................. 17

Conceptual Definitions ............................................................................... 17

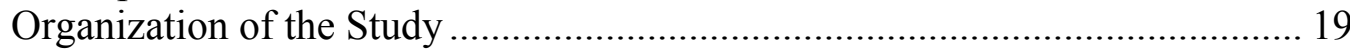

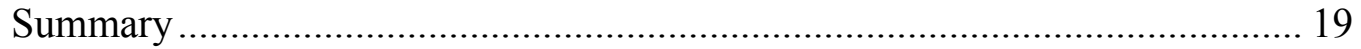

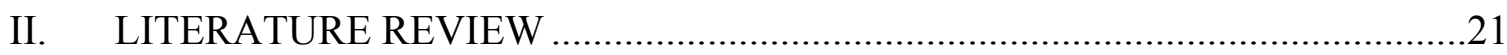

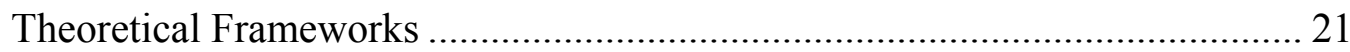

Conceptual Framework for the Study …………………................................. 34

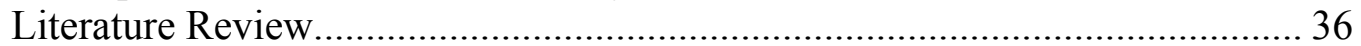

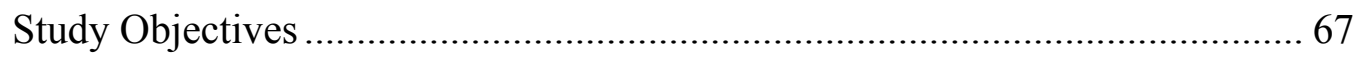

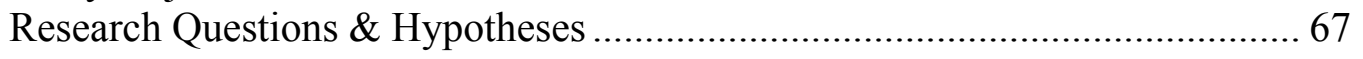

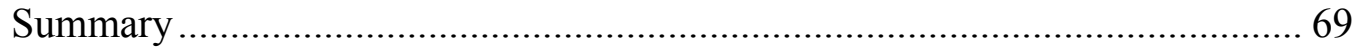

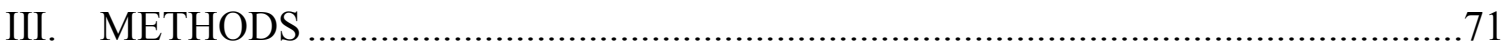

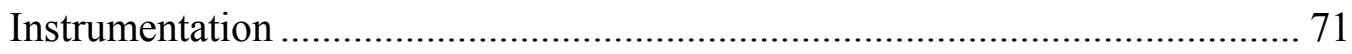

Data Collection Procedures............................................................................. 74

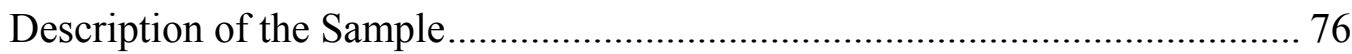

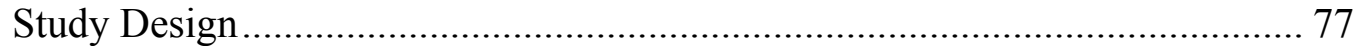

Variables and Measures .............................................................................. 78

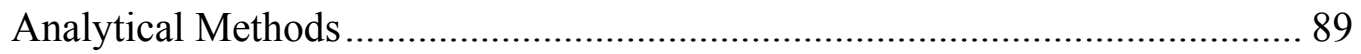

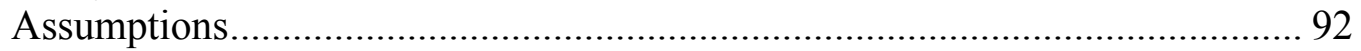

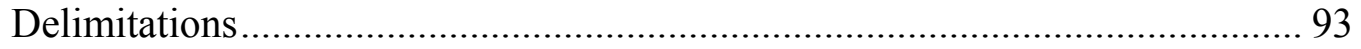

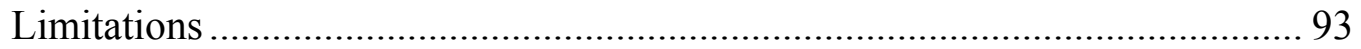

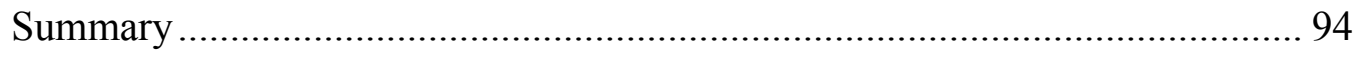

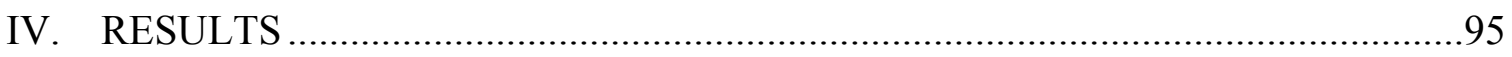

Description of the Sample............................................................................. 95

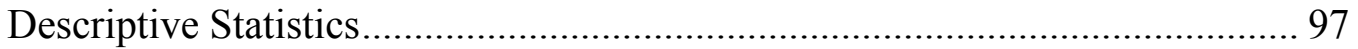

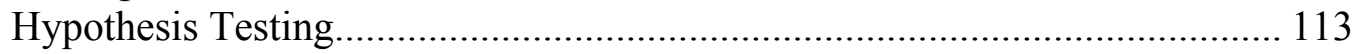

Post-Hoc Analyses …………................................................................. 140

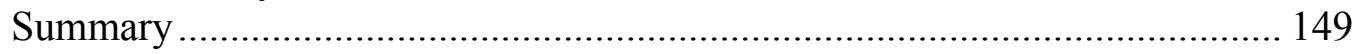

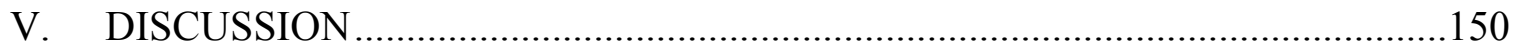

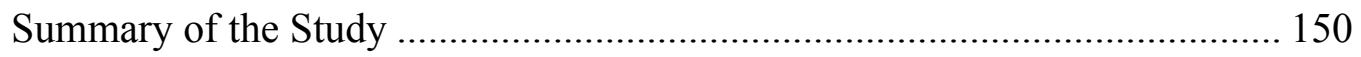

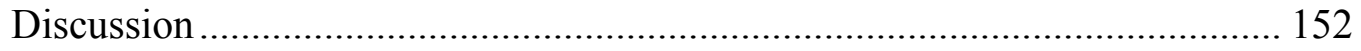

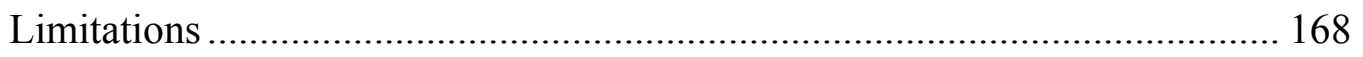

Implications for Public Health .................................................................... 172 
Implications for Theory Development.................................................... 174

Recommendations for Future Research .................................................... 175

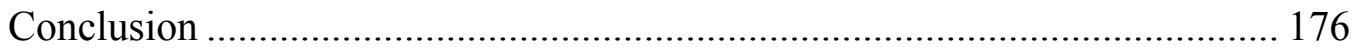

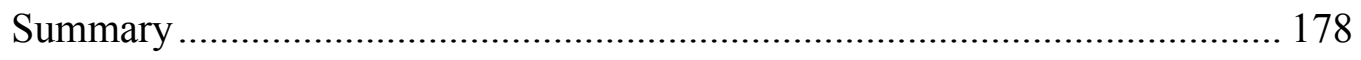

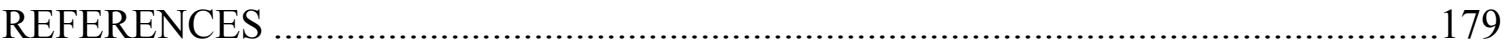

VITA 


\section{LIST OF TABLES}

TABLE

PAGE

1. Theory of Gender and Power: Exposures and Risk Factors for Increased HIV Risk Among Women.

2. Percentage of High Schools in South Florida That Taught HIV/STD and Pregnancy Prevention Topics, 2007-2008 .............................................................................5

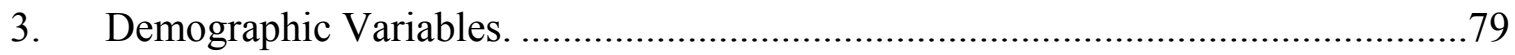

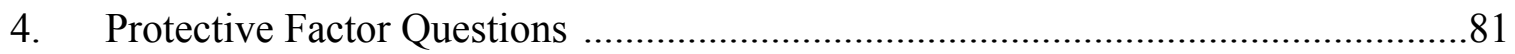

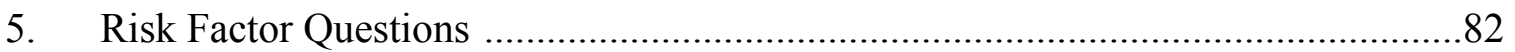

6. Health Risk Behavior Questions: Sexual Risk and Violence-Related Behaviors ...84

7. Health Risk Behavior Questions: Tobacco, Alcohol, and Illicit Drug Use ............85

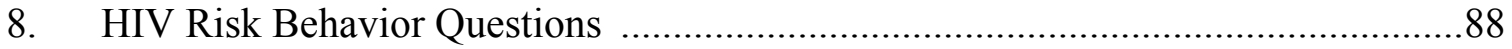

9. Demographic Characteristics of Survey Participant...........................................96

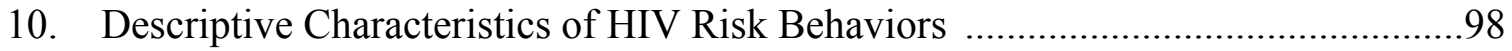

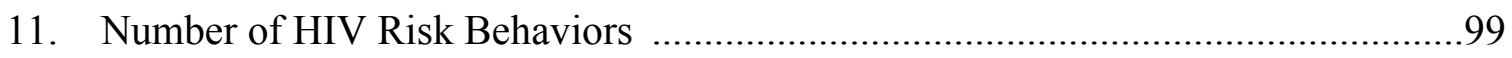

12. HIV Risk Behaviors for Females by Demographics Characteristics ...................100

13. HIV Risk Behaviors for Males by Demographics Characteristics ......................101

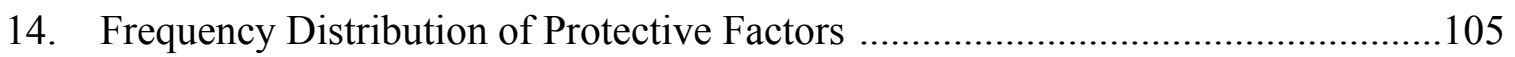

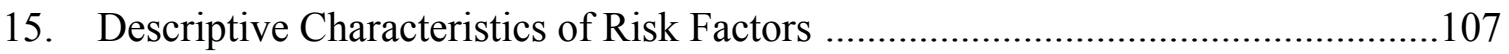

16. Age at First Sexual Intercourse Among Students Who Reported Ever Having Sex

17. Descriptive Characteristics of Health Risk Behaviors ........................................111

18. Bivariate Associations between Protective Factors and HIV Risk Behaviors .......114

19. Bivariate Associations between Risk Factors and HIV Risk Behaviors ................115 
20. Bivariate Associations between Health Risk Behaviors and HIV Risk Behaviors 117

21. Binary Logistic Regression Analyses Predicting Participation in At Least One HIV Risk Behavior from Safe School Index ..............................................................119

22. Binary Logistic Regression Analyses Predicting Participation in At Least One HIV Risk Behavior from Sports Team Membership

23. Binary Logistic Regression Analyses Predicting Participation in At Least One HIV Risk Behavior from Receipt of Sex Education in School

24. Binary Logistic Regression Analyses Predicting Participation in At Least One HIV Risk Behavior from the Risk Factor Index

25. Binary Logistic Regression Analyses Predicting Participation in At Least One HIV Risk Behavior from the Health Risk Behavior Index

26. Binary Logistic Regression Analyses Predicting Participation in HIV Risk Behavior from Interactions for Protective Factors and RFI/HRBI

27. Descriptive Characteristics of Sex Education Policy Implementation Among 9th10th Grade Students Who Reported Receipt of HIV/AIDS Education in School .132

28. Bivariate Associations of Characteristics of Sex Education Policy Implementation and HIV Risk Behavior for 9th-10th Grade Students Who Reported Receipt of HIV/AIDS Education

29. Binary Logistic Regression Analyses Predicting Lifetime Injection Drug Use from Course of Instruction for 9th-10th Grade Males Who Received Sex Education....135

30. Female Logistic Regression Analyses of Predictors of Participation in At Least One HIV Risk Behavior

31. Male Logistic Regression Analyses of Predictors of Participation in At Least One HIV Risk Behavior .138

32. Significant Predictors of Unprotected Sex at Last Sexual Intercourse 141

33. Significant Predictors of Four or More Sexual Partners 143

34. Significant Predictors of Sex Under the Influence of Drugs/Alcohol at Last Sexual Intercourse 


\section{LIST OF FIGURES}

FIGURE

PAGE

1. Annual Federal Funding for Abstinence-Only Education in the United States, 1982-

2011

2. Problem Behavior Theory's Interrelated Domains of Risk Factors and Protective

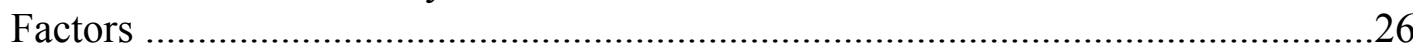

3. Associations Between the Three Domains of the Theory of Gender and Power:

Exposures, Risk Factors, and Risk Outcomes

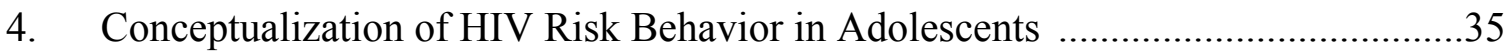

5. Conceptual Model of Factors Influencing HIV Risk Behavior .............................38

6. Logistic Regression for the Conceptual Model of Factors Influencing Adolescent

Participation in HIV Risk Behaviors 


\section{CHAPTER I}

\section{INTRODUCTION}

Adolescents and young adults have been disproportionately affected by the sexually transmitted infections (STIs) and the human immunodeficiency virus (HIV) epidemics, compared to older adults (Centers for Disease Control and Prevention [CDC], 2011d; Scott et al., 2011). Previous research has identified several behaviors that place individuals at risk for contracting HIV: engaging in unprotected sexual intercourse, having multiple sexual partners, engaging in sex while under the influence of alcohol or drugs, and using injection drugs (CDC, 1992, 2006; Niyonsenga, Hlaing, \& McCormack Brown, 2008). Investigators suggest that HIV risk behaviors may be part of a syndrome of health-compromising behaviors (DiClemente et al., 2008; Donovan \& Jessor, 1985; Donovan, Jessor, \& Costa, 1988; Jessor, 1991; Jessor \& Jessor, 1977). Identifying and understanding the individual and environmental factors that may influence youth decision-making and risk-taking are important for developing relevant HIV prevention programs.

\section{Background}

Adolescence is a transitional period between childhood and adulthood where, beginning with biological maturation at puberty, youth experience complex changes in the development of self, not only physically, but intellectually, emotionally, and socially (Biro \& Dorn, 2006; Choudhury, Blakemore, \& Charman, 2006). It also marks a time for exploration with a wide range of behaviors, but opportunities for growth and development are often associated with a dramatic increase in risk-taking behavior, and, as a result, negative health outcomes and even death. 


\section{Developmental Considerations of Adolescence}

The adolescent years are a unique stage of transition in the human lifespan, and pose a particularly high-risk period for many (Doljanac \& Zimmerman, 1998). Youth reach their physical and sexual maturity, during this time, as well as develop sophisticated reasoning skills, establish both sexual and moral identities, adopt peer codes and lifestyles, make decisions about their educational and career endeavors, and achieve independence from parents as they prepare for adulthood (Neinstein, 1996). Changes that occur during adolescence are often confusing and adolescents may experience a high degree of "transitional stress" (Adler \& Rosengard, 1996; Montemayor, 1983).

Adolescents are not a homogenous group, but instead display a wide variability in their physical, mental, and emotional growth (Centers for Population Options, 1989; DiClemente et al., 2008; Salazar et al., 2010). Patterns of changes in behavior are often recognizable at three distinct developmental stages. The American Academy of Pediatrics recognizes the age ranges for these stages as early adolescence (12-13 years); middle adolescence (14-16 years), and late adolescence (17-21 years) (Greydanus, Bashe, \& American Academy of Pediatrics, 2003), although age at which each stage is reached may vary from child to child (Haffner, 1995).

In early adolescence, youth begin to develop and assert their value system in the context of strong peer influences (Allensworth \& Symons, 1989). During middle adolescence, youth become more invested in peer group influence and participate in peerrelated activities (O’Donnell et al., 2006). Adolescents also conform to peer expectations in order to be accepted into a group, which may result in conflict between youth and their parents. Studies have found an increase in susceptibility to peer influence between 
childhood and early adolescence, with a peak in susceptibility around age 14 and a decline during late adolescence (Gruber, 2001; Steinberg \& Cauffman, 1996).

Late adolescence is dominated by establishing one's identity while maintaining peer relationships and preparing for the responsibilities of adulthood. Older adolescents are more likely to understand the consequences of their actions and recognize the risks and future consequences of decisions than their younger counterparts (Haffner, 1995; Lewis, 1981).

\section{Adolescent Risk Behaviors}

From a developmental perspective, experimentation with a wide range of behaviors is considered a normal part of adolescent exploration and transition into adulthood (Bishai, Mercer, \& Tapales, 2005; Centers for Population Options, 1989; Gonzalez et al., 1994; Igra \& Irwin, 1996; Jessor \& Jessor, 1977), especially during middle adolescence (Jessor, Van Den Bos, Vanderryn, Costa, \& Turbin, 1995). Adolescence is often associated with a dramatic increase in risk-taking behavior for youth, such as tobacco, alcohol, and drug use, as well as other problem behaviors that are socially proscribed for youth (Allensworth \& Symons, 1989).

Another area of adolescent experimentation is sexual intercourse. Previous research indicates that adolescent risk behaviors tend to co-occur, and that sexual risk behaviors may be associated with other behaviors that negatively affect decision-making and well-being (Jessor \& Jessor, 1977; Jessor, 1991; Smart, Adlaf, \& Walsh, 1994). Recent national survey data show that among high school students, $46 \%$ have already had intercourse, $5.9 \%$ before the age of 13 (CDC, 2010b). More than one-third (34.2\%) of 
adolescents were recently sexually active (past 3 months), $13.8 \%$ had four or more sexual partners in their lifetime, and less than $40 \%$ had used a condom at last sexual intercourse.

Investigators have tried to determine why adolescents initiate risky sexual behaviors at such early ages (Elkind, 1967; Gonzalez et al., 1994). Since adolescents do not yet have the necessary skills to effectively label or describe their feelings, they may use sex as a coping mechanism to express or satisfy emotional and interpersonal needs which, in actuality, may have little or nothing to do with sex (Hajcak \& Garwood, 1988). They may also be trying to demonstrate their maturity by becoming sexually active (Keogh, 1988). According to Jessor and Jessor (1977), adolescents engage in risky behavior in order to (a) take control of their lives; (b) express opposition to authority; (c) deal with anxiety, frustration, or failure; (d) identify with and gain admission to peer groups; (e) confirm a personal identity; (f) affirm maturity; and (g) seek fun or pleasure.

The challenge of preventing sexual risk behaviors among young people is that their developmental processes are ongoing and incomplete, and adolescents may not yet possess the knowledge, skills, or motivation to practice safer sex behaviors (Malow, Rosenberg, Donenberg, \& Dévieux, 2006). Exploring adolescent risk behavior and factors that affect their decisions are important for developing effective preventative services and policy implementation (Kirby, 2002a; O'Donnell et al., 2006).

Outcomes Associated with Adolescent Risky Sexual Behaviors. The sexual and reproductive health of adolescents is an important issue of concern in the United States, with responsible sexual behavior as a leading health indicator (Institute of Medicine $[\mathrm{IOM}], 2011)$. The majority of young men and women have their first sexual intercourse during adolescence, and epidemiological data have shown the risk of acquiring sexually 
transmitted diseases accompanies this initial sexual experience (Salazar et al., 2010). Adolescents run the risk of having unintended pregnancies or contracting HIV or other STIs (Malhotra, 2008; Adler \& Rosengard, 1996), which can have negative implications for mental health, missed opportunities, financial burdens, or even loss of life. These consequences affect individuals as well as communities as a whole.

In 2010, adolescents between the ages of 10 and 19 years made up $14 \%$ of the U.S. population (U.S. Census Bureau, 2011a). Although 15- to 24-year-olds represent only $25 \%$ of the sexually experienced population, they acquire nearly half of the 18 million annual cases of STIs (Crosby \& Danner, 2008; Guttmacher Institute, 2012a; Malhotra, 2008; Weinstock, Berman, \& Cates, 2004). Adolescents are at especially high risk of infection for several reasons: (a) immature reproductive and immune systems that make them more vulnerable to infection (Cates \& McPheeters, 1997); (b) earlier age at first sexual experience which may increase the number of lifetime partners (DuRant et al., 1999; Mane \& Lawson, 2007); (c) barriers to preventative services (CDC, 2011d; Bersamin, Todd, \& Remer, 2011); and (d) contextual factors such as poverty, lower social status, cultural expectations, and, gender roles (DiClemente et al., 2002; Wingood \& DiClemente, 2000). Each year, nearly four million U.S. youth experience STIs (Florida Department of Health [DOH], 2007). The most common infections include bacterial infections like Chlamydia, gonorrhea, and syphilis, and viral infections like HIV and the human papilloma virus (HPV) (Cothran \& White, 2002).

Of the total number of Acquired Immunodeficiency Syndrome (AIDS) cases reported in 2009, 542 were among adolescents (13-19 years) (CDC, 2011c). These cases represent $1.4 \%$ of all diagnosed cases for males and $2.2 \%$ for females, however, due to 
the long latency period of AIDS, the proportion of diagnosed cases in the 20-24 age group should be considered (DiClemente, 1996). Combining cases in the two age groups, adolescents and young adults aged 13-24 years make up $8.0 \%$ of all male cases and $6.8 \%$ of all female cases. Although the proportion of adolescent cases is small in comparison to the total number of AIDS cases, the proportion of young adults-who probably contracted HIV as adolescents-is much larger.

The social and financial burdens of preventable health problems due to risky adolescent behavior are large and possibly long-lasting (U.S. Department of Health and Human Services [HHS], 2012a). Each year, STIs, including HIV, result in significant public health costs (American Social Health Association, 1998; Dariotis, Sifakis, Pleck, Astone, \& Sonenstein, 2011; HHS, 2012a). Some of the most common STIs are linked to health complications like infertility and cervical cancer, and a number of STIs can also increase the risk of acquiring HIV (Forhan et al., 2009; Sexuality Information and Education Council of the United States [SIECUS], 2003). In 2000, the total estimated financial burden of the nine million new cases of STIs among adolescents and young adults aged 15-24 years was $\$ 6.6$ billion. HIV and HPV were by far the most costly, accounting for $90 \%$ of the total burden (Chesson, Blandford, Gift, Tao, \& Irwin, 2004).

\section{Monitoring Adolescent Sexual Risk Behaviors}

Since 1979, the Healthy People initiative has provided a public health prevention framework for the nation which identifies specific goals and objectives in order to measure the progress in improving our society's wellness (HHS, 2012a). Fourteen national health objectives are relevant to sexual behaviors among adolescents (Morris, Warren, \& Aral, 1993). The Healthy People 2020 Initiative set goals to reduce the 
proportion of adolescents with STIs and HIV/AIDS diagnoses, decrease the pregnancy rate among adolescent females aged 15 to 19 years, and increase the proportion of adolescents who abstain from sexual intercourse, use effective methods of contraception, and receive HIV/AIDS, STI, and pregnancy prevention information in school (HHS, 2012a).

Many of these national objectives are measured by the Youth Risk Behavior Surveillance System (YRBSS), a system designed by the CDC to monitor six categories of health risk behaviors associated with the leading causes of death and disability among youth. The categories include: (a) behaviors that contribute to unintentional injuries and violence; (b) alcohol and other drug use; (c) tobacco use; (d) sexual behaviors that contribute to unintended pregnancy and sexually transmitted diseases; (e) unhealthy dietary behaviors; and (f) physical inactivity (CDC, 2010b). The YRBSS is the only national surveillance system that continually generates information about adolescent sexual behaviors and related health outcomes throughout the United States (Morris et al., 1993).

\section{School-based Sex Education}

To reduce the incidence of unintended pregnancies, HIV, and other STIs among youth, experts in the social, behavioral, and public health fields have employed programs to reduce sexual risk behaviors among youth (Salazar et al., 2010). Behavior-change interventions designed to prevent and reduce adolescent sexual risk-taking behaviors have emerged slowly over the course of the HIV epidemic, since adolescents were not initially considered a population at risk (Haffner, 1988). Risk reduction strategies vary from providing accurate information, motivating behavior changes and developing skills 
to deal with real-life situations (DiClemente \& Wingood, 2003; Kirby, 2000; Johnson, Scott-Sheldon, Huedo-Medina, \& Carey, 2011; Rotheram-Borus, Mahler, \& Rosario, 1995).

Numerous studies have attempted to reduce adolescent sexual risk-taking by employing a variety of prevention interventions to reach adolescents at different levels, however, much hope for the prevention of unintended pregnancies, HIV, and other STIs, as well as the promotion of healthy sexuality, has been placed in the hands of the schools (Constantine, 2008), and many parents rely on public schools to provide their children with accurate information (Cox, Scharer, \& Clark, 2009). Sex education is defined as a continual process of acquiring information about sexual behavior and forming attitudes, beliefs, and values about gender identities, sex roles, relationships, and intimacy (Broering, 1991; SIECUS, 2001a).

History of sex education in the United States. Over the past few decades, the curriculum and agenda of sex education have experienced four generations of profound changes (Darroch, Landry, \& Singh, 2000; Kendall, 2008b; Stout \& Kirby, 1993). Focus has shifted from pregnancy prevention to STI prevention to loss of life prevention with the advent of the HIV/AIDS epidemic. The 1980s brought awareness of the threat of HIV infection and AIDS, and one of the most controversial issues in the history of the epidemic has involved educating the nation's youth about HIV-related topics and prevention (Wierson \& Bright, 1996). First generation sex education programs in the 1970s focused on reproductive health and were designed to impart knowledge about sexuality and the consequences of pregnancy (Dunn, 1982). 
Second generation programs emphasized knowledge content from first generation programs, but mainly focused on clarifying values and improving both decision-making and communication skills as a mode of prevention. Evaluations of first and second generation programs found that knowledge was increased, but did not demonstrate changes in behavior (Kirby, 1985; Kirby, Barth, Leland, \& Fetro, 1991; Stout \& Kirby, 1993). Evidence has shown that risk reduction efforts based on increasing knowledge alone are not enough to ensure that adolescents will engage in safe behaviors (Hillier, Harrison, \& Bowditch, 1999; Nsuami, Sanders, \& Taylor, 2010; Obstfeld \& Meyers, 1984; Risisky, Caldwell, \& Fors, 1997; Weinstein \& Rosen, 1991).

Rather than rising from the first two generations, third generation sex education programs were designed in opposition to them. Abstinence-only-until-marriage (AOUM) education, also referred to as abstinence-only, emphasized that sexual abstinence until marriage was the expected standard for school-aged children (Trenholm et al., 2007) and the only way to prevent unintended pregnancies and sexually transmitted diseases (DeLamater, 2007; Wierson \& Bright, 1996). To avoid contradicting messages, most AOUM programs exclude discussions of condoms, birth control, and other contraceptive methods (Starkman \& Rajani, 2002), and some even highlighted their failures (Stout \& Kirby, 1993). From 1995 to 2002, formal instruction about contraceptive methods declined as abstinence education increased (Lindberg, Santelli, \& Singh, 2006).

Currently, fourth generation programs are built on a theoretical foundation of behavioral change that takes into consideration adolescent cognitive development, decision-making, and motivation. Comprehensive sex education programs (also called abstinence-plus) stress the value of abstinence, but also emphasize the importance of 
effective contraception methods for sexually-active youth (Kirby, 2001). Advocates of these programs assert that youth need accurate information and decision-making skills in order to make realistic, informed decisions about their sexual activity (Solomon-Fears, 2004). A distinct transition from third to fourth generation programs does not exist since both types of programs are still employed today. Despite abstinence being a fundamental part of both programs, the two are often characterized as opposites, although today's school sex education programs actually exist on a continuum due to the variances in format, scope, and content (Jeffries, Dodge, Bandiera, \& Reece, 2010).

Douglas Kirby, a leading researcher in sexuality education, assessed the effectiveness of curriculum-based sex education programs on changing adolescent sexual risk-taking behavior (Kirby \& Laris, 2009). He found that most abstinence-only programs did not delay first sexual intercourse and few had any significant positive effects on any sexual behavior, such as increasing the return to abstinence, reducing the number of sexual partners, or increasing condom or contraceptive behaviors. Contrary to AOUM programs, most comprehensive sex education programs have shown strong evidence that they positively affected adolescent sexual behavior (Hubbard, Giese, \& Rainey, 1998; Kirby, 2002b, 2008; Kirby \& Laris, 2009; Mueller, Gavin, \& Kulkarni, 2008) and were twice as likely as abstinence-only education programs (66\% vs. $33 \%)$ to delay first sexual experience and increase condom use (Kirby, 2008). These results are consistent with other evaluation research by Kirby (2001, 2002b, 2008, 2011; Kirby, Laris, \& Rolleri, 2007) and others (Dworkin \& Santelli, 2007; Kohler, Manhart, \& Lafferty, 2008; Stout \& Kirby, 1993; Underhill, Operario, \& Montgomery, 2009). 
Sex education policy and federal funding. No federal mandate to teach sex education in public schools exists and less than half (40\%) of all U.S. public schools teach adolescents about prevention using condoms and other contraceptives (Guttmacher Institute, 2012b). The decision to teach sex education is left to state legislatures and individual school districts. Southern states are almost five times as likely as states in the Northeast to have an abstinence-only policy (Landry, Kaeser, \& Richards, 1999). Although southeastern states tend to have the highest rates of syphilis and other STIs in the United States (CDC, 2011d; Corbie-Smith et al., 2010), the some of the highest proportions of abstinence-only policies are found in southeastern states (54\%) (e.g., Florida, Georgia, etc.),

The shift in focus to AOUM was fueled by federal funding for programs emphasizing abstinence (Duffy, Lynch, \& Santelli, 2008; Lindberg et al., 2006). Three major funding sources were implemented since the early 1980s and have received significant funding for grants: The Adolescent Family Life Act (AFLA), Title V of the Welfare Act, and Community-Based Abstinence Education (CBAE) (Figure 1). By 2006, this funding had totaled over $\$ 178$ million (Ott \& Santelli, 2007a), and estimates of federal and state-matched funds totaled roughly $\$ 1$ billion dollars (Kirby, 2006). 


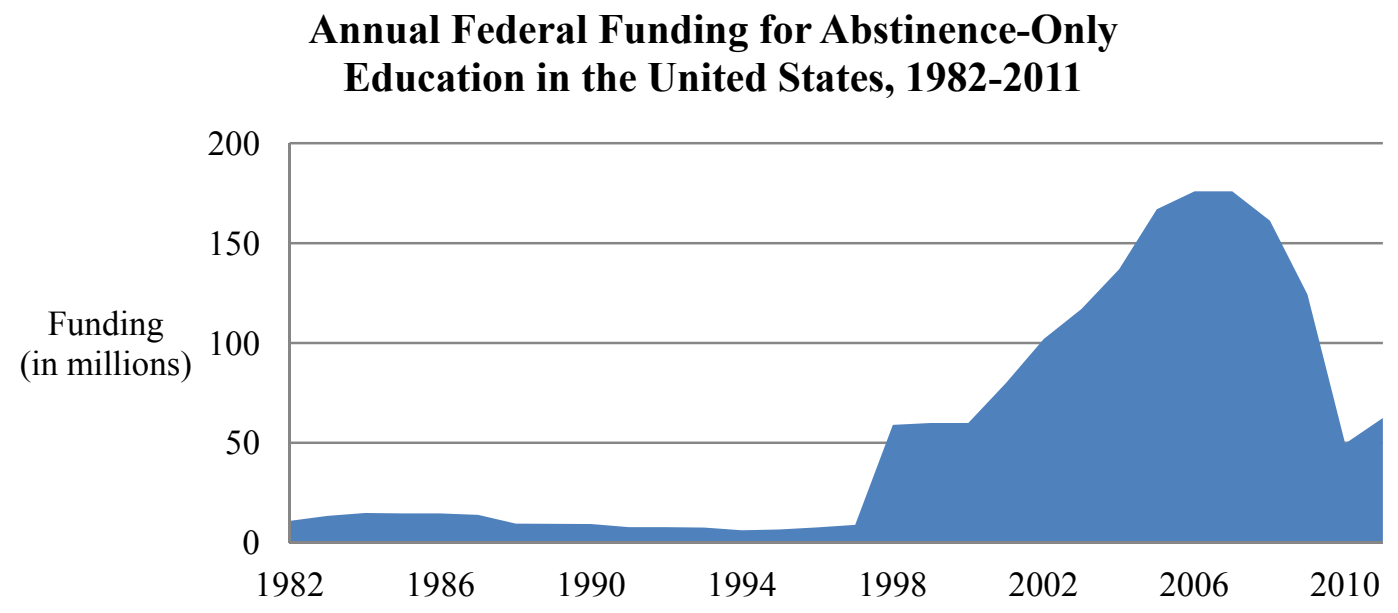

Figure 1. Adapted from HHS (2012b) and Howell (2007).

Due to the large amount of state and federal dollars invested in AOUM, public health professionals and policy makers became interested in the long-term benefits of these programs. Evaluation studies revealed that over $80 \%$ of the AOUM curricula contained false, misleading, or distorted information (U.S. House of Representatives Committee on Government Reform, 2004) and had no beneficial impact on young people's sexual behavior (Trenholm et al., 2007). Taken as a whole, the lack of evidence supporting the benefits of AOUM did not justify the widespread replication of abstinence sex education programs, and its continued funding came into question (Kirby, 2008). Researchers purport that if a particular intervention is found to support a particular outcome (e.g., reduced adolescent risk behaviors), then it should be adopted as broadly as possible; If not effective, as was the case with AOUM, it should be defunded (Kendall, 2008a).

A congressional hearing held before the House Committee on Oversight and Government Reform called for an end to federal funding for the AOUM programs in 2008 (Boonstra, 2009). By that time, 17 states had already declined AOUM funding 
(Duffy et al., 2008; Raymond et al., 2008), and by 2009, 25 states and the District of Columbia were no longer accepting Title V funds (Boonstra, 2009; Doan \& McFarlane, 2012). California is the only state that has never accepted funds for AOUM programs (SIECUS, 2010a). With almost two-thirds of federal funding for AOUM programs eliminated, the federal government ushered in a new era of sex education in the United States, providing $\$ 190$ million in funding for two initiatives that support evidence-based teen pregnancy prevention and more comprehensive approaches to sex education (HHS, 2011).

Public support for sex education. There is overwhelming support for sex education in schools by the American public (DeLamater, 2007; Howard-Barr, Wiley, Moore, Lang, \& Zipperer, 2011; Kirby, 2006; Lindley et al., 1998; Ott \& Santelli, 2007b). Many agree that youth should be given the information they need to protect themselves (Haffner \& Wagoner, 1999; SIECUS, 2001b) and that withholding information from adolescents about sexual realities like contraception, STI risk, and the complexities of sexual relationships is like "putting them behind the wheel without a seatbelt" (Epstein, 2006; Rickenback, 2006). International human rights standards recognize access to accurate and appropriate health information and services, including that of HIV/AIDS and sexual health, as a basic human right for adolescents, and governments have an obligation to provide accurate information and avoid the provision of misinformation (Finklea, Gruendemann, \& Harris, 2004; United Nations, 2003, 2010).

Sex education is taught as part of a number of different courses, including health, science, and even religion (Clark \& Yarber, 1993; Denson, Voight, \& Eisenman, 1993), although some assert it should be a part of health education curriculum so the 
interrelationship of health behaviors can be examined (American School Health Association, 1995; Neutens, Drolet, DuShaw, \& Jubb, 1991). The American Public Health Association (APHA) (2005), among others (DiClemente, 1989; Cull-Wilby et al., 1985; Kirby, 2006; Ott \& Santelli, 2007b; Santelli, 2008; Brooks, 2004; Wattleton, 1987), recommended that age-appropriate, evidence-based, comprehensive sexuality education should be an integral part of K-12 health education and is necessary to lower the prevalence of health problems among the adolescent population. Others have added that gender-specific (Miller et al., 2000) and feminist-informed (Askew, 2007; BayCheng \& Lewis, 2006) approaches to sexuality education were also needed, and more attention to whether program outcomes differ for males and females were necessary (DeLamater, 2007).

Many students receive inadequate instruction on how to protect themselves-an unfortunate and unacceptable trend in a time of increasing birth rates and STI epidemics among youth (CDC, 2008c, 2009a, 2011d, 2012c; Middleman, 1999; Wilson, 2000). Although research and public opinion support more comprehensive approaches to sex education, the disconnect between empirical research, public opinion, and policy described above should be noted.

\section{Statement of the Problem}

Florida's rates of adolescent sexual activity are higher than comparable national rates for high school students who reported ever having sex (50.6\% vs. $46.0 \%$ ), having sex before age 13 ( $8.3 \%$ vs. 5.9\%), and having four or more lifetime sexual partners $(16.6 \%$ vs. $13.5 \%)(\mathrm{CDC}, 2010 \mathrm{~b})$. As a result of risky sexual activity, Florida adolescents and young adults have been disproportionately affected by the STI and HIV epidemics. 
The state ranks first for rates of new HIV cases among 13-19 year-old adolescents with 15.5 diagnoses per 100,000 people, almost twice the national rate (8.7) (CDC, 2012c).

The South Florida region includes Miami-Dade, Broward, and Palm Beach counties - the top three areas for number of HIV/AIDS and STI cases in Florida (Bandiera, Jeffries, Dodge, Reece, \& Herbenick, 2008). Young people living in this region have been especially hit hard by the HIV/AIDS epidemic. Of the 3,840 reported HIV/AIDS cases among the state's adolescents and young adults through 2010, almost half (47.4\%) were from South Florida (DOH, 2011a, 2011b, 2011c). Despite high prevalence rates among youth, research on sexual risk behaviors in South Florida has generally focused on adults as a whole, particularly among the Hispanic population (Weiss \& Tillman, 2009).

Florida currently participates in the YRBSS to monitor the health risk behaviors of youth, including sexual risk behaviors, but it does not include county-level data (DOH, 2011d). However, the CDC directly funds six counties in Florida-including MiamiDade, Broward, and Palm Beach—to conduct the Youth Risk Behavior Survey (YRBS) at the county-level (CDC, 2012e).

To address increasing rates of sexual activity, teen pregnancies, and STIs, several school districts in Florida—including the three South Florida counties—-have adopted comprehensive sex education policies. Although Florida law [§ 1003.42(2)(n)] mandates health education in public schools to teach abstinence from sexual activity as the expected standard for all school-aged children (Florida Legislature, 2011a, 2011b), it does not prohibit comprehensive sexual health curricula from being implemented (Florida Department of Education, n.d.). 
The CDC's Division of Adolescent and School Health (DASH) currently funds Miami-Dade, Broward, and Palm Beach to provide HIV education as an aspect of their health education program (CDC, 2012d; SIECUS, 2010b), although policies, practices, and implementation of these programs vary by location. The YRBS data provides a unique window through which to examine the relationship between sex education and HIV-related risk behaviors of adolescents within and across the contiguous borders of South Florida, the most highly HIV and STI-prevalent region of Florida.

Few studies have evaluated the effect of sex education programs on sexual risk behaviors at a population level (Armstrong, Ashford, López, \& Brown, 2009; Kirby, 2011; Kohler et al., 2008; Sabia, 2006; Halpern et al., 2004), and even fewer have examined the role of gender on these behaviors and the ability to prevent disease (Amaro, 1995; Raj et al., 2007). Gender differences in sexual risk behaviors have been observed among U.S. adolescents (CDC, 2010b; Epstein \& Spirito, 2010; Krantz, Lynch, \& Russell, 2002; Kreiter et al., 1999; March \& Atav, 2010; Puente et al., 2011; Sacco, Rickman, Thompson, Levine, \& Reed, 1993; Schepis et al., 2011; Shrier, Pierce, Emans, \& DuRant, 1998; Tevendale, Lightfoot, \& Slocum, 2009), but research among Florida youth is limited (Hlaing, de la Rosa, \& Niyonsenga, 2007; Niyonsenga et al., 2008).

There is a need for research that explores the role of gender, sex education, personal and environmental factors, and their relation to HIV-risk behaviors. Doing so will enable researchers, educators, and practitioners to better inform sex education and prevention programming and policy. 


\section{Purpose of Study}

The purpose of the current study was threefold. The first purpose was to investigate the role of risk factors, protective factors, and participation in health risk behaviors on students' self-reports of HIV-related risk behaviors as measured by the YRBS. The current study also explored the relationship between participation in HIV risk behaviors and characteristics of sex education received. Finally, the third purpose analyzed gender differences in the predictors of HIV risk behaviors among adolescents in three South Florida school districts.

\section{Public Health Significance}

This study addresses some of the limitations of previous research by drawing its sample from an understudied region and using a conceptual framework to investigate the HIV risk behaviors of youth there. The study has implications for educators who teach HIV prevention and can help explain the relationships between adolescent HIV risk behaviors and associated and protective factors, risk factors, and health-risk behaviors. Findings can also advise state and local policy makers to implement prevention programs that address these individual and socio-environmental factors addressed in the study. Modifying existing or future programs in order to incorporate evidence-based research can help reduce the spread of HIV/AIDS, STIs, as well as unintended pregnancies among youth.

\section{Conceptual Definitions}

For the purpose of this study, the following words and phrases have special meaning as set out below. Other terms, which are not frequently used but which require definitions are explained as they are introduced. 
1. Adolescence: The period of transition from late childhood to early adulthood that corresponds to the period between the ages of 12 and 21 (Greydanus et al., 2003).

2. Black race: For the purpose of this study, this race refers to people of who identify as Black or African Americans (CDC, 2010a).

3. Health risk behaviors: For the purpose of this study, health risk behaviors are defined as: sexual behaviors, the use of tobacco, alcohol, and illicit drugs, and violence-related behaviors (CDC, 2010b).

4. Ethnicity: In this study ethnicity was defined as either Hispanic/Latino or nonHispanic/Latino (CDC, 2010a).

5. HIV risk behaviors: For the purpose of this study, HIV risk behaviors refer to behaviors that place an individual at risk for contracting or transmitting HIV: unprotected sex with multiple sexual partners, the use of alcohol and other illicit substances, and injection drug use (IDU) (CDC, 1992, 2006, 2008c; Niyonsenga et al., 2008).

6. Problem behavior: Undesirable, socially proscribed behaviors that may cause some form of social control response or sanction (Donovan, 2005; Turbin, Jessor, $\&$ Costa, 2000).

7. Protective factor: The role of a protective factor is to reduce the impact of a risk behavior and enhance the likelihood of socially desirable and positive outcomes.

8. Risk factor: A risk factor is any factor associated with the increased likelihood of a problem behavior. 
9. Sexually transmitted infection (STI): An infection spread from one person to another through sexual contact. It is commonly known as sexually transmitted disease (STD) and may be used interchangeably in the text.

10. South Florida: For the purpose of this study, the South Florida region refers to the three contiguous counties: Miami-Dade, Broward, and Palm Beach.

\section{Organization of the Study}

The remaining sections of this research study are divided into the following chapters. Chapter 2 contains the theoretical and conceptual frameworks for the study, the review of related literature, as well as the research objectives and hypotheses. Chapter 3 discusses the YRBS instrument, study design, and data analysis plan used in the study. Chapter 4 presents the findings, analyses, and evaluation of the data, and Chapter 5 provides a discussion of findings, conclusions drawn from the results, and implications for practice and future studies.

\section{Summary}

In this introductory chapter, the problem was defined and the purpose of this study was explained. Adolescents engage in a range of risk behaviors during their transition from childhood to adulthood. Of special concern are sexual behaviors that have health and life-compromising outcomes such as unintended pregnancies and sexually transmitted infections, including HIV/AIDS. To address this problem, sex education programs have been employed in the nation's schools to attempt to change students' risky behaviors. The purpose of this study was to examine gender differences in the association between self-reported HIV-related risk behaviors and protective factors, risk factors, and health risk behaviors among adolescents in a highly HIV and STI-prevalent region of 
Florida. The present study also examined the role of sex education on HIV-risk behaviors.

In the next chapter, both theoretical and conceptual frameworks used to guide the study will be presented, as well as a review of the current literature related to adolescent sexual risk behavior, as guided by the conceptual model. 


\section{CHAPTER II}

\section{THEORETICAL FRAMEWORKS AND LITERATURE REVIEW}

This purpose of this chapter was twofold: (1) to present the theoretical frameworks used in this research study and (2) to discuss the current state of the literature related to adolescent HIV-related risk behaviors as guided by the conceptual framework. The guiding framework for this study was derived from Problem Behavior Theory (Jessor \& Jessor, 1977) and the Theory of Gender and Power (Connell, 1987; Wingood \& DiClemente, 2000). Figures 2 and 3 present the constructs of each theory, and the conceptual framework is illustrated in Figure 4. The concept map (Figure 5) logically organizes the variables identified by the literature review as related to adolescent HIV risk behaviors. Research objectives and hypotheses were discussed at the conclusion of this chapter.

\section{Theoretical Frameworks}

Jessor's Problem Behavior Theory (1977) and Wingood and DiClemente's adaptation of the Theory of Gender and Power (2000) were selected as guiding frameworks for the current study. Several other theoretical models relevant to HIV prevention (Ajzen, 1991; Becker, 1974; Catania, Kegeles, \& Coates, 1990; C.

DiClemente \& Prochaska, 1982; Janz \& Becker, 1984) and adolescent risk behavior change (Bandura, 1992, 2001) were considered, but, after careful review, were discarded for three reasons. First, models that were individualistic in nature failed to acknowledge how social norms, power differentials, adolescent development, and other contextual factors affect sexual behaviors and decision-making among youth (Amaro, 1995; Harvey, 2000; Jessor, Turbin, \& Costa, 1998a; Lightfoot \& Milburn, 2009; Marín, Gomez, 
Tschann, \& Gregorich, 1997; Pedlow \& Carey, 2003, 2004; Weinstein \& Rosen, 1991).

Second, these theoretical approaches assumed that an individual's behaviors were under their volitional control and excluded the impact of emotions, irrational behaviors (Brewer \& Rimer, 2008; Edberg, 2007), and the behaviors of others (e.g., sexual partners) - an important consideration when studying adolescents who engage in unplanned, impulsive risk-taking behavior (Schaalma, Abraham, Gillmore, \& Kok, 2004; van den Akker, Andre, Lees, \& Murphy, 1999). Finally, the basic constructs of these theories lacked gender as an important determinant of sexual risk behavior. Gender is a fundamental part of adolescent sexual health (Tolman, Striepe, \& Harmon, 2003), and although gender differences have been observed in HIV risk behaviors, many studies do not provide an explanation for why these differences occur (Krantz et al., 2002; Kreiter et al., 1999; March \& Atav, 2010; Puente et al., 2011; Sacco et al., 1993; Schepis et al., 2011; Shrier et al., 1998; Epstein \& Spirito, 2010; Tevendale et al., 2009; Werner-Wilson, 1998).

A multi-level approach that incorporated both individual and socio-environmental factors was necessary to study the phenomena of adolescent sexual risk behavior. In addition, since gender is an important determinant of sexual and risk behaviors, attention to the way behavior differs by gender was also warranted. The theories of Problem Behavior and Gender and Power were most relevant and allowed the current study to incorporate a broader spectrum of determinants of adolescent sexual risk.

\section{Problem Behavior Theory}

Problem Behavior Theory (PBT) is a useful theoretical framework for the study of risk behaviors among and the interrelationships between environmental, personal, and behavioral factors (Smith, Canter, \& Robin, 1989). The target population of this theory is 
adolescents, a group that is often marginalized and has a vulnerable status in an agegraded society (March \& Atav, 2010). Risk behaviors encompass two main subsets of behaviors: problem behaviors and health-risk behaviors. The former includes such socially proscribed behaviors for youth as alcohol and illicit drug use which may cause some form of social control response or sanction (Donovan, 2005; Turbin et al., 2000). Health-risk behaviors (e.g., cigarette smoking) may compromise health, but may not necessarily violate social or legal norms like other problem behaviors (Donovan, Jessor, $\&$ Costa, 1991). PBT attempts to predict adolescent involvement in a variety of behaviors, including prosocial behaviors (Basen-Engquist, Edmundson, \& Parcel, 1996; Jessor, 1991; Jessor, Donovan, \& Costa, 1991; Jessor, Turbin, \& Costa, 1998b; Jessor et al., 1995; Smith et al., 1989; Turbin et al., 2000).

The earliest formulation of PBT was developed in the 1960s (Jessor, Graves, Hanson, \& Jessor, 1968), and has been revised and extended since then (Jessor \& Jessor, 1977). A later version expanded PBT to include health-related behaviors (Jessor, 1991; Jessor et al., 1991), and the most recent reformulation reorganizes the main constructs from the theory into protective and risk factors (Jessor et al., 1998b).

Conceptual framework of PBT. According to the original formulation of PBT, there are three separate but interrelated systems that produce behaviors that are considered either conforming or deviant: personality, perceived environment, and behavior (Jessor \& Jessor, 1977). Each system is comprised of instigations for and controls against involvement in problem behaviors (Costa, 2008). Within each system, the balance of instigation and control forces determines the proneness for involvement in problem behavior, and the combined effects of these forces across the three systems 
result in an overall proneness toward or away from problem behavior (Donovan, 2005; March \& Atav, 2010).

The personality system consists of individual level variables including an adolescent's values, expectations, beliefs, and attitudes towards themselves and others around them. The concepts that constitute the perceived environment system include social controls, models, and support. Variables under this system are distinguished on the basis of conceptual closeness of their relations to problem behavior: proximal variables directly implicate a particular behavior and distal variables are more remote on the causal chain. The behavior system includes both problem and prosocial behaviors.

The social environment instructs social norms for behavior, including the behavior relevant to avoiding health risks (Romer \& Hornik, 1992). Many problem behaviors, like cigarette smoking and having unprotected sex, can also be considered health-compromising behaviors. Like problem behaviors, health risk behaviors are also subject to society's approval or disapproval (Costa, 2008). In the early 1990s, Jessor revised the early PBT framework to include health behaviors (Donovan et al., 1991; Jessor, 1991; Jessor et al., 1991). Research on adolescent health behavior supported the extension of PBT to the health behavior domain (Basen-Engquist et al., 1996; Carvajal, Hanson, \& Romero, 2002; DuRant et al., 1999), and variables originally designed to predict problem behaviors have been found to predict of involvement in health-enhancing behaviors as well.

Interrelated conceptual domains of risk factors and protective factors. The most recent version of PBT reorganizes the conceptual variables into categories of risk and protection (Jessor et al., 1998a, 1998b). Conceptually, the role of protective factors is 
to enhance the likelihood of socially desirable and positive outcomes, whereas risk factors have the reverse effect (Jessor et al., 1998b). The revised framework encompasses more variables than the original version, including individual-level variables and a variety of measures of the multiple social contexts (e.g., family, peers, school, community etc.) relevant to the life of an adolescent (Figure 2). The first domain groups the original systems (i.e., personality, behavior etc.) into overall areas of risk and protective factors, and a new system was created to account for biological and genetic factors. The second domain includes adolescent risk behaviors and lifestyles which included problem, health-related, and school behaviors. The final domain relates to outcomes of behaviors related to four systems: health, social roles, personal, and preparation for adulthood. The interrelationships of the variables in both the protective and risk factor domain and the risk behavior domain are illustrated, as well as their influence on health outcomes.

PBT studies. PBT has been used in a wide range of studies to investigate a broad variety of behaviors in childhood, adolescence, and young adulthood, including alcohol and illicit drug use, cigarette smoking, and early sexual activity. Research has shown that there is a significant co-variance among problem behaviors, what Jessor and colleagues refer to as a "problem behavior syndrome" (DiClemente et al., 2008; Donovan \& Jessor, 1985; Donovan et al., 1988; Jessor, 1991; Jessor \& Jessor, 1977). Problem behaviors tend to be positively correlated to other problem behaviors and negatively correlated to prosocial and health-enhancing behaviors (Lugoe, Klepp, Rise, Skutle, \& Biswalo, 1995). Additionally, problem behaviors that tend to cluster are related to the same set of psychosocial antecedents (Basen-Engquist et al., 1996; Kirby, 2002a). Recent research 


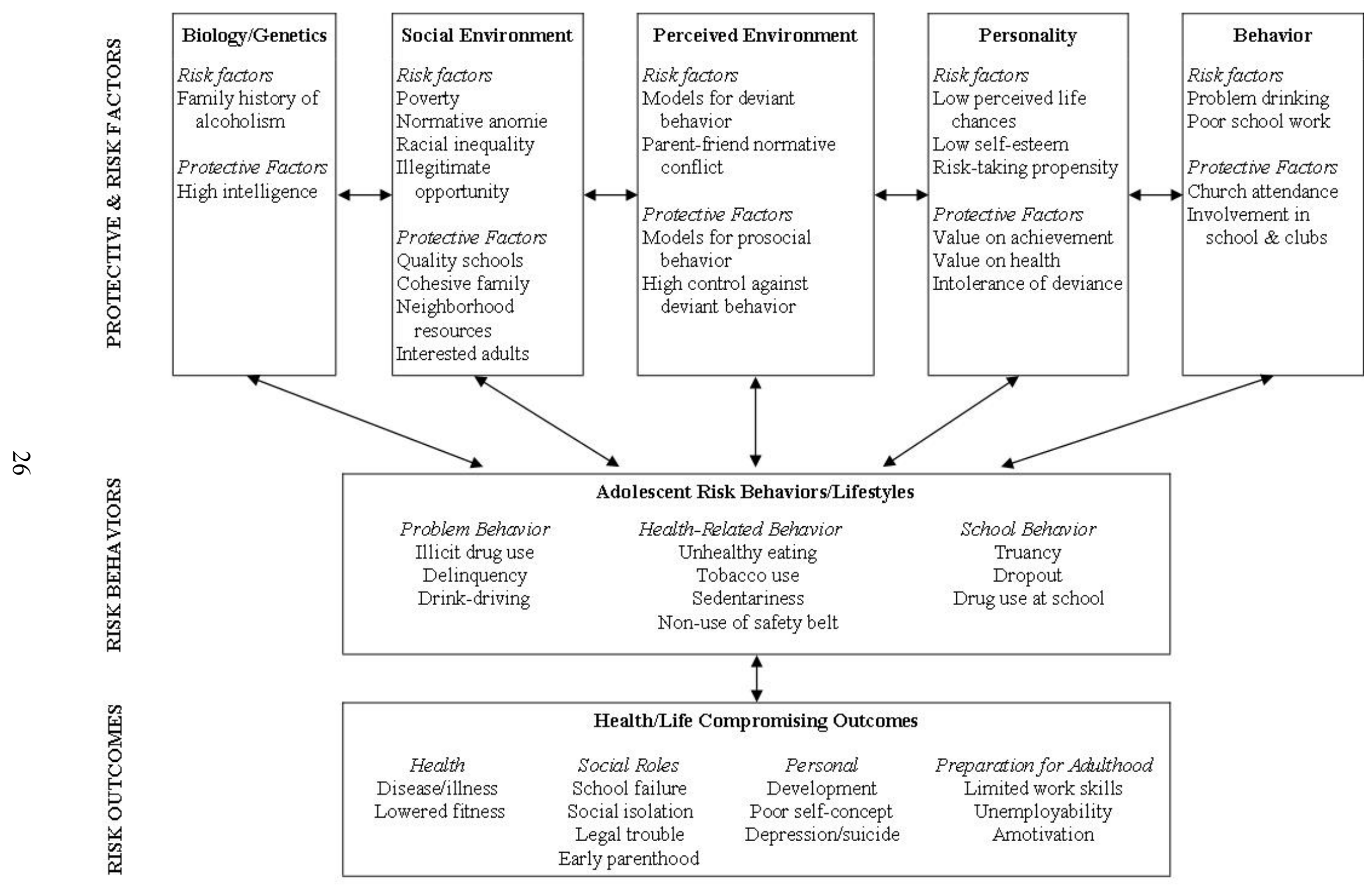

Figure 2. Problem Behavior Theory's interrelated domains of risk factors and protective factors, adapted from Jessor, 1991. 
has expanded PBT to explore the effects that culture (Carvajal et al., 2002) and gender (Zamboanga, Carlo, \& Raffaelli, 2004) have on problem behaviors as well.

PBT studies. PBT has been used in a wide range of studies to investigate a broad variety of behaviors in childhood, adolescence, and young adulthood, including alcohol and illicit drug use, cigarette smoking, and early sexual activity. Research has shown that there is a significant co-variance among problem behaviors, what Jessor and colleagues refer to as a "problem behavior syndrome" (DiClemente et al., 2008; Donovan \& Jessor, 1985; Donovan et al., 1988; Jessor, 1991; Jessor \& Jessor, 1977). Problem behaviors tend to be positively correlated to other problem behaviors and negatively correlated to prosocial and health-enhancing behaviors (Lugoe, Klepp, Rise, Skutle, \& Biswalo, 1995). Additionally, problem behaviors that tend to cluster are related to the same set of psychosocial antecedents (Basen-Engquist et al., 1996; Kirby, 2002a). Recent research has expanded PBT to explore the effects culture (Carvajal et al., 2002) and gender (Zamboanga, Carlo, \& Raffaelli, 2004) have on problem behaviors as well.

The current PBT model has been shown to account for substantial amounts of variance (30\% to $50 \%)$ in adolescent problem behaviors, prosocial behaviors, and health behaviors (Costa, 2008; Jessor et al., 1995; Ramirez-Valles, Zimmerman, \& Newcomb, 1998). One limitation of PBT is that the model may exclude other contextual variables (e.g., socio-economic status, gender, family structure, etc.) that may that account for the remaining variance of measures of adolescent behavior. The next section presents an additional theoretical framework that includes the impact of gender, power, and culture on HIV risk behavior, and will be used to expand conceptual framework for this study. 


\section{Theory of Gender and Power}

In her plenary speech at the XIIIth International AIDS conference, Geeta Rao Gupta (2000) outlined the many ways that power differentials in the social and historical constructions of gender have enhanced women's risk and vulnerability for HIV and other health disparities. The Theory of Gender and Power (TGP), originally developed by Connell (1987), is a framework used to understand how the impact of gender, power, and culture affect risk behavior. It is based on the idea that social rules about sexual behavior are determined by established social norms, including unequal gender and power differentials (Harrison, 2002). According to TGP, three social mechanisms characterize the social structures of gender: the sexual division of labor, the sexual division of power, and the structure of cathexis (emotional component of relationships). Conceptually, it is proposed that economic dependence, male dominance in society, and relational attachments are related to sexual practices and risk behaviors.

From a public health perspective, gender inequalities are observable as risk factors that adversely influence women's health and vulnerability to diseases. Wingood and DiClemente (2000) extended Connell's theory to include factors that influence women's risk for disease, and is the only theory focused exclusively on women and HIV (Noar, Carlyle, \& Cole, 2006). This version has been applied to examine HIV-related risks and used to design prevention interventions within a gender framework. In addition to its focus on women, TGP emphasizes the increase risk for HIV that youth and ethnic minorities face since constructions of adolescent sexuality are further complicated by gender and culture (Bay-Cheng \& Lewis, 2006). 
The application of the TGP to HIV defines the theory's original constructs as domains of risk, and further describes the constructs as exposures (or acquired risks) and risk factors within those domains (Wingood \& DiClemente, 2000) (Figure 3). Exposures are economic, physical, and social constraints that relate to sexual behavior. Risk factors are psychosocial constructs associated with participation in risk-taking behaviors. A history of physical and sexual violence, substance abuse, and depression, as well as high risk partners, poor negotiation skills, conservative gender and socio-cultural norms, and limited access to HIV education and control of barrier methods have all shown to increase HIV risk in women (Higgins, Hoffman, \& Dworkin, 2010; Sobo, 1993; Wingood \& DiClemente, 2000; Worth, 1989).

Conceptual framework of TGP. The sexual divisions of labor and power address gender relations, and the structure of cathexis addresses the affective component of relationships. These three structures exist at two different levels: the societal level (historical and sociopolitical forces that ascribe social norms and gender roles) and the institutional level (schools, families, religious institutions, health systems, and the media) (Connell, 1987; Wingood \& DiClemente, 2000). Table 1 presents the exposures and risk factors that increase HIV risk in women for each of the following TGP domains.

The sexual division of labor. At the societal level, the sexual division of labor refers to the allocation of certain genders to particular occupations and the inequalities of women's positions relative to men. Women often are often employed in clerical, service, or teaching jobs that have been given low status and as a result, low pay. This constraint limits women's economic potential and confines their career paths. 


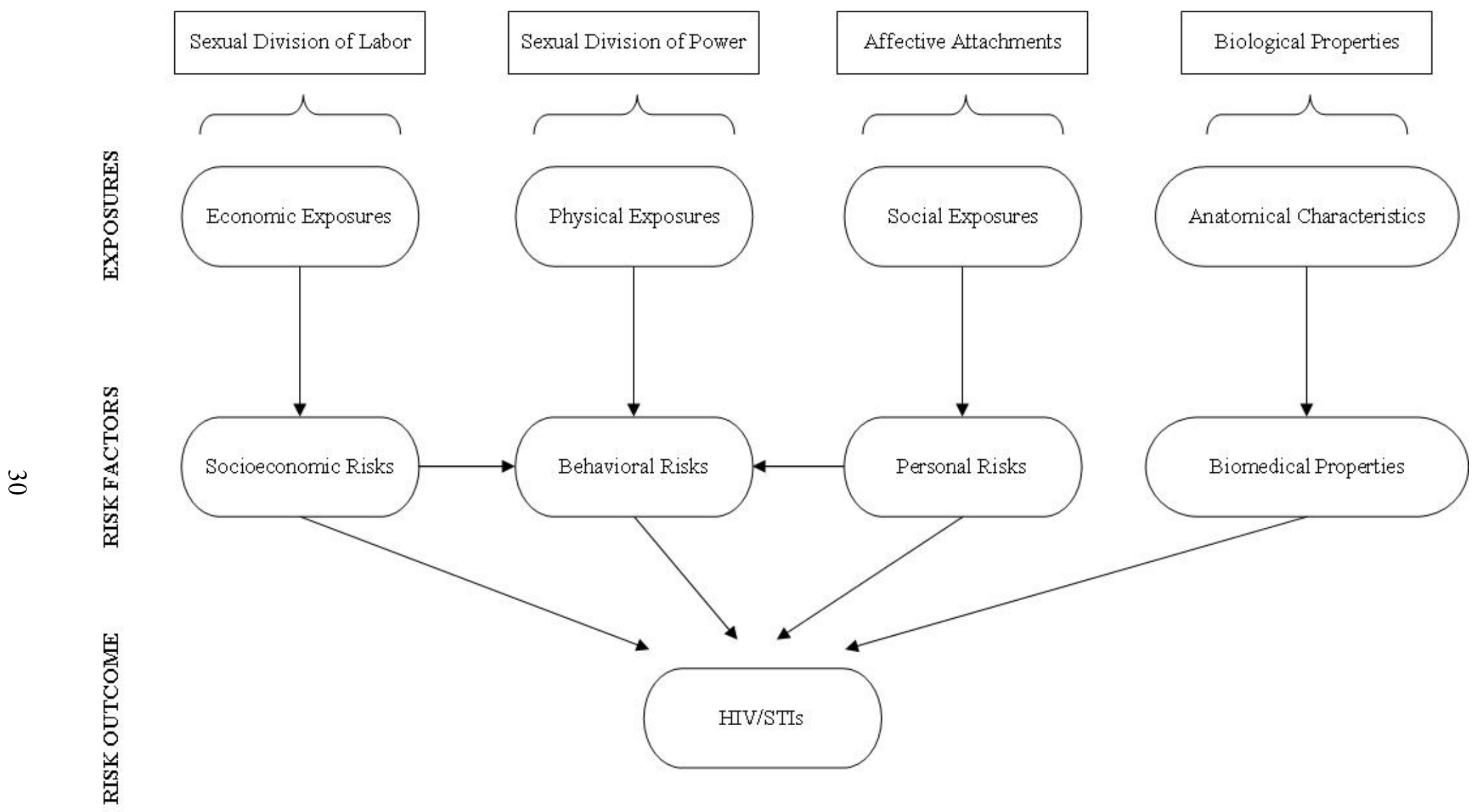

Figure 3. Associations between the three domains of the Theory of Gender and Power: exposures, risk factors, and risk outcomes. 
At the institutional level, this system is maintained by social mechanisms like child care, elderly care, and other domestic work that are often unpaid and undervalued. The low value that society places on "women's work" is an important part of a genderbased division of labor. Gender imbalances in the work environment create economic exposures and socioeconomic risk factors increase the likelihood of poorer health outcomes.

The sexual division of power. The sexual division of power is another fundamental structure of TGP. Inequalities in power and control exist in society, and power imbalances are maintained by abuse of authority and control in relationships. Women with physical exposures, like a history of rape or domestic violence, and behavioral risk factors, like poor condom negotiation skills, will encounter more power differentials and experience poorer health outcomes than women not having these exposures and risk factors.

Social norms and affective attachments. The structure of cathexis was used by Connell (1987) to address affective and emotional components of relationships, and was later renamed to affective and social exposures (Wingood \& DiClemente, 2002). This domain is characterized by gendered expectations regarding sexual behavior, including culturally-normative gender roles, stereotypes, and taboos that may further weaken women's roles and inequalities in relationships (Raj, Silverman, Wingood, \& DiClemente, 1999). Social exposures (e.g., conservative culture and gender norms) and personal risk factors (e.g., a history of depression) increase the likelihood of adverse health outcomes for women. 
Biological factors. Biological differences in susceptibility increase women's vulnerability to HIV (Higgins et al., 2010), and were therefore added to the HIV-tailored extension of the TGP. HIV and other STIs are transmitted more efficiently to the receptive partner, and many STIs are asymptomatic in women (Wingood \& DiClemente, 2000). Adolescent girls are especially at high risk since their immature reproductive and immune systems make them more vulnerable to infection (Cates \& McPheeters, 1997).

TGP studies. This theoretical framework has been used in a variety of studieslongitudinal, cross-sectional, and randomized control trials - to examine the gendered and social dynamics of risk for STI and HIV (DePadilla, Windle, Wingood, Cooper, \& DiClemente, 2011; DiClemente et al., 2002, 2008; Harrison, 2002; Shannon et al., 2012; Wingood, Seth, DiClemente, \& Robinson, 2009). SISTA (Sisters Informing Sisters about Topics on AIDS) (Wingood \& DiClemente, 2006), SiHLE (Sistas Informing, Healing, Living, and Empowering) (DiClemente et al., 2004), and WiLLOW (Wingood et al., 2004) are three successful gender and culturally-relevant sexual risk reduction interventions that utilize TGP. Results from these programs indicate that social skills training delivered in a community setting can increase condom use (CDC, 2009b) and women report fewer episodes of unprotected sex, had lower incidence of bacterial infections, and reported fewer partner-related barriers to condom use (DiClemente et al., 2008). 
Table 1

Theory of Gender and Power: Exposures and Risk Factors for Increased HIV Risk Among Women

\begin{tabular}{|c|c|c|}
\hline Domain & Economic Exposures & Socioeconomic Risk Factors \\
\hline \multirow{6}{*}{ Sexual Division of Labor } & Poverty and homelessness & Ethnic minority \\
\hline & Less than a high school education & Younger (<18 yrs. old) \\
\hline & Unemployed or under-employed & \\
\hline & High demand/low control at work & \\
\hline & Limited or no health insurance & \\
\hline & $\begin{array}{r}\text { Physical Exposures } \\
\end{array}$ & Behavioral Risk Factors \\
\hline \multirow{6}{*}{ Sexual Division of Power } & History of sexual or physical abuse & History of alcohol and drug abuse \\
\hline & High-risk partners & Poor assertive communication skills \\
\hline & Exposure to sexually explicit media & Poor condom use skills \\
\hline & Limited access to HIV prevention & Low self-efficacy to avoid HIV \\
\hline & & Limited perceived control over condom use \\
\hline & Social Exposures & Personal Risk Factor \\
\hline \multirow{7}{*}{$\begin{array}{l}\text { Affective and Social } \\
\text { Exposures }\end{array}$} & Older partner & Limited HIV prevention knowledge \\
\hline & Desire to get pregnant & Negative beliefs about safer sex \\
\hline & Conservative cultural and gender norms & Perceived vulnerability to HIV/AIDS \\
\hline & Religion that forbids contraception & History of depression or psychological distress \\
\hline & Mistrust of the medical system & \\
\hline & Family influences not supportive of HIV prevention & \\
\hline & Anatomical Characteristics & Biomedical Properties \\
\hline \multirow{4}{*}{ Biological Properties } & Immature cervix among younger women. & Sex while menstruating \\
\hline & HIV/ STIs transmitted more efficiently from to women & Oral contraceptive use \\
\hline & STIs more asymptomatic in women & History of cervical ectopy \\
\hline & Women may be less likely to seek treatment for STIs & \\
\hline
\end{tabular}

Note. Adapted from Wingood \& DiClemente, 2000. 


\section{Conceptual Framework for the Present Study}

Psychosocial, behavioral, and biological risk and protective factors are core constructs of both Jessor's Problem Behavior Theory (1998b) and the Theory of Gender and Power as applied by Wingood and DiClemente (2000). Both theories also emphasize the wider social and environmental issues that affect vulnerable populations such as women, minorities, and youth. Therefore, a combined model is appropriate for examining the way sexual risk behaviors differ by gender among adolescents (Figure 4).

The three domains include risk and protective factors, health risk behaviors, and risk outcomes. The social environment category in the model included the relevant PBT variables, as well as the economic exposure variables in the TGP framework. The acquired social and physical exposure variables from TGP were both added to the perceived environment system since they consist of interpersonal relationship variables

from family, peers, and social networks. Constructs from the personality, behavioral, and biological systems of PBT were combined with TGP's personal, behavioral, and biological risk factors, respectively. Demographic factors (i.e., gender, race, and age) describe the socioeconomic risk factors that are described by both theories. The domain of adolescent risk behaviors was expanded to include sexual risk behaviors. 


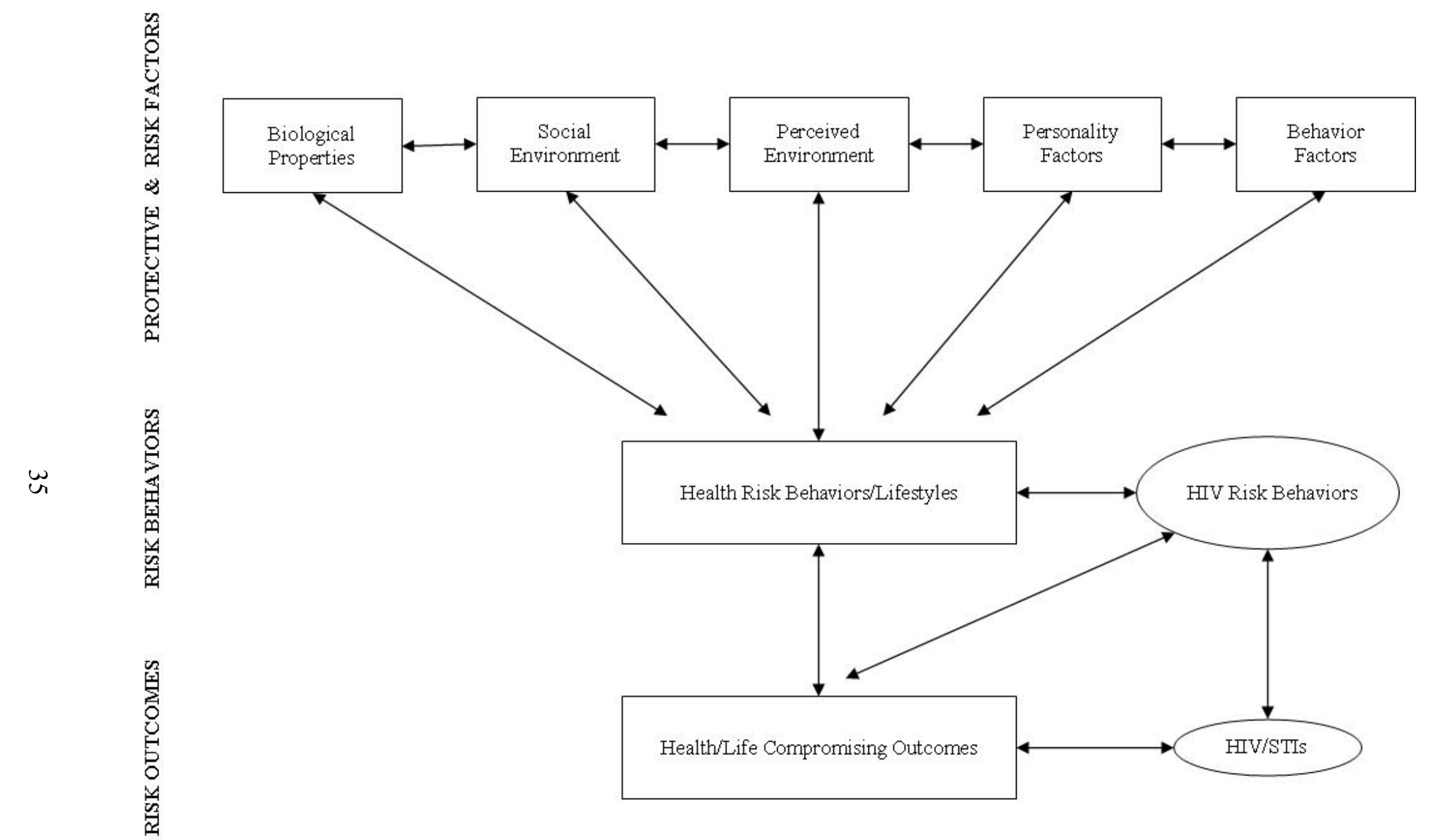

Figure 4. Conceptualization of HIV risk behavior in adolescents, adapted from Problem Behavior Theory (Jessor et al., 1998b) and the Theory of Gender and Power (Wingood \& DiClemente, 2000). 


\section{Literature Review}

The current state of the literature on adolescent HIV risk behaviors, as guided by the conceptual framework, is reviewed in this chapter. A comprehensive set of variables was derived from and organized by the conceptual framework. The literature reviewed, appropriate for the framework, included investigations of variables that were consistent with identified protective factors, risk factors, and health risk behaviors.

The concept map (Figure 5) of factors affecting HIV risk behaviors identified protective factors (school involvement, safe schools, and sex education exposure) and risk factors (history of sexual and physical abuse, depression, models for health risk behavior, and opportunity to participate in health risk behaviors). Health risk behaviors examined included sexual behaviors, drug and alcohol use, tobacco use, weapon carrying, and violence. The current chapter also includes information concerning important antecedent background variables such as gender and culture of the student population used in this study. Gender and location of residence served as controlling factors to examine the relationships between HIV-related risk behaviors, and the protective factors, risk factors, and health risk behaviors for which data from the 2009 Youth Risk Behaviors Survey was available. The measurement of each of these variables is described in Chapter 3.

\section{Literature Review Methodology}

Relevant research concerning protective factors, risk factors, and health risk behaviors on adolescent HIV risk behaviors was identified by employing several search methods. First, electronic databases in the health sciences were used to search for publications dated between January 1990 and January 2012, with articles obtained 
primarily from MEDLINE, CINAHL, and Health Source. In order to ensure that relevant studies were not missed, combinations of the following broad search terms were used: (a) adolescents, adolescence, youth and teenagers; (b) sexual risk behaviors, risky sexual behaviors, sexuality, HIV risk behaviors, HIV risk factors, HIV risk and STD or STI risk; (c) sex education, sexual health education, sexuality education, and HIV education; and (4) United States, Florida, South Florida, Miami, Broward, and Palm Beach. Initial searches produced more than 1,000 articles, but were significantly reduced after filtering articles that did not meet the inclusion criteria. Studies were eligible for inclusion if: (a) they were peer-reviewed, relevant to the current study, and able to be obtained by the researcher; (b) participants in the study were from the general Englishspeaking, U.S. adolescent population; and (c) studies included measures of HIV-related risk behavior and their correlates, as guided by the theoretical and conceptual frameworks of this study.

In addition to searching electronic databases, literature review methods included cross-referencing articles obtained in the searches and manual searches of leading public health journals likely to publish relevant articles (e.g., Adolescence, AIDS Education and Prevention, American Journal of Public Health, Journal of Adolescent Health, Pediatrics, Perspectives on Sexual and Reproductive Health, etc.). All studies that matched the selection criteria and were available as of July 9, 2012, were included. 


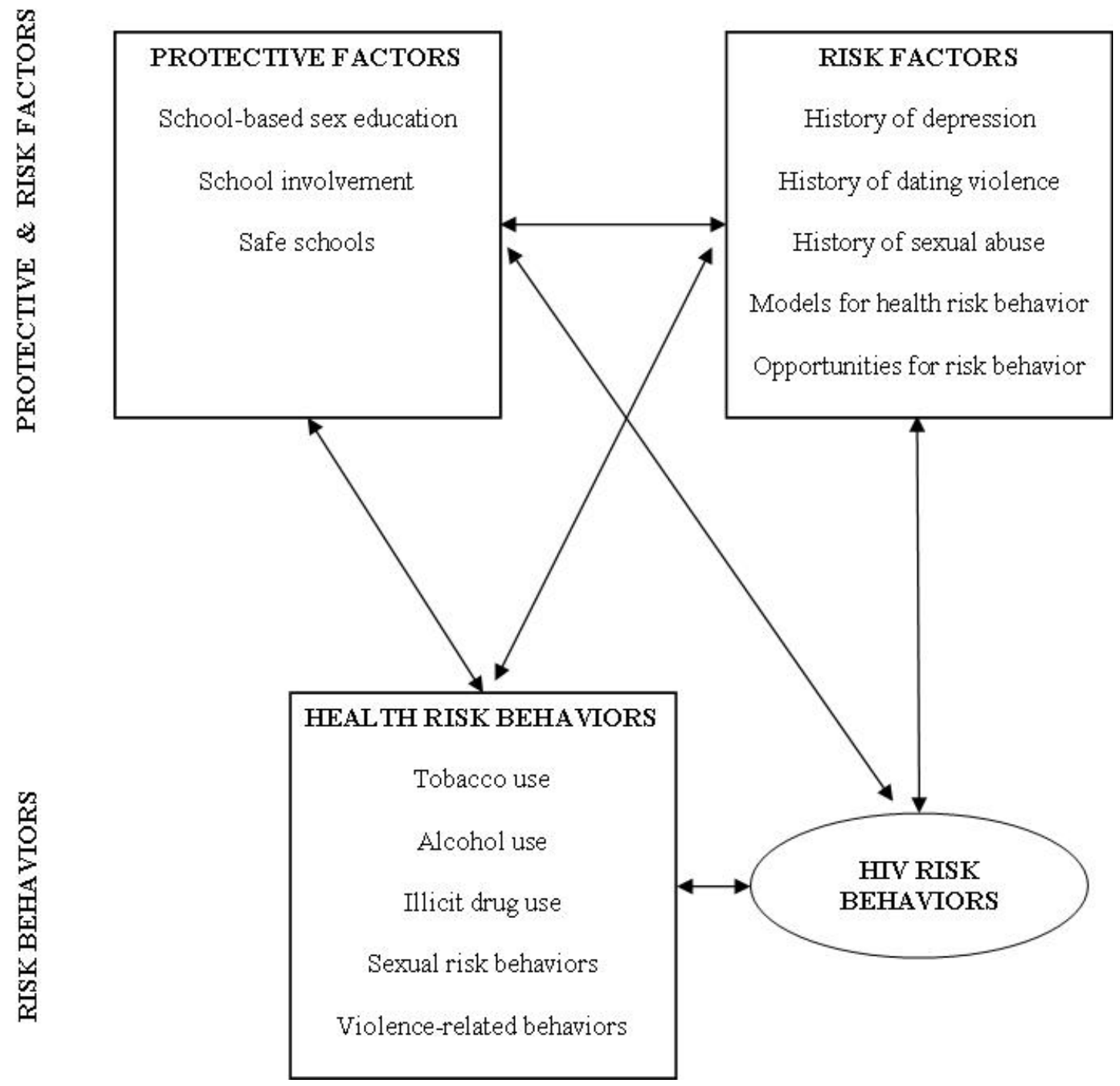

Figure 5. Conceptual model of factors influencing HIV Risk Behavior.

\section{HIV-related Risk Behaviors}

The sexual and reproductive health of adolescents is an important issue of concern in the United States, with responsible sexual behavior as a leading health indicator (IOM, 2011). The consequences of risky sexual behavior among adolescents include unintended pregnancies and the transmission of HIV and other STIs such as chlamydia, gonorrhea, and syphilis (Adler \& Rosengard, 1996; Malhotra, 2008). Several behaviors have been identified that increase risk for contracting HIV: unprotected sex with multiple sexual 
partners, the use of alcohol and other illicit substances, and injection drug use (IDU) (CDC, 1992, 2006, 2008d; Niyonsenga et al., 2008). The CDC currently uses the Youth Risk Behavior Surveillance System (YRBSS) to monitor these behaviors among adolescents in the United States.

Two other indices of adolescent sexual risk are often found in the literature: being sexually active (vs. non-active) and age at first sexual experience with another person. Some behaviors, including sexual behaviors, may be riskier than others (Luster \& Small, 1994; Miller et al., 1997), but may not necessarily be indicative of HIV risk (Marshall \& Werb, 2010). For instance, an adolescent may be sexually active, but may use condoms correctly and consistently. In the current study, sexual activity and age at first sexual experience are considered to be possible risk factors for HIV-related risk, rather than HIV risk behaviors themselves.

Unprotected sex. The American Academy of Pediatrics report (1990) entitled "Contraception and Adolescents" affirmed that the correct use of condoms was the best way to prevent the spread of STIs and HIV for sexually active teens. According to the National Longitudinal Study of Adolescent Health (Add Health), 36.1\% of young women and $48 \%$ of men aged $18-24$ years did not use a condom the last time they had sex (Pettifor et al., 2011), although there has been an increase in reported condom use among sexually active high school students from $46.2 \%$ in 1991 to $61.1 \%$ in 2009) (CDC, 2008b, 2010b).

Many young people fail to use condoms correctly and consistently, increasing their risk of exposure to HIV and other STIs (Santelli, Brener, Lowry, Bhatt, \& Zabin, 1998). Efforts to prevent HIV infection have focused on promoting the use of condoms, 
specifically, the male condom. Promoting the male condom makes male cooperation in sexual activity crucial, and many women face issues with negotiation skills, assertiveness, and powerlessness in relation to the use of protective barrier methods (Exner, Dworkin, Hoffman, \& Ehrhardt, 2003; Stein, 1990; Worth, 1989). Although there are other methods available to women that are under their control (e.g., microbicides, female condoms, etc.), little attention has been given to these viable options, and access to resources are limited.

Multiple sexual partners. An increase in the number of sexual partners increases the risk of exposure, especially when barrier methods are used infrequently or incorrectly. According to Add Health data, young women and men aged 18-24 years have an average of four lifetime partners (Pettifor et al., 2011). Between 1991 and 2009, the prevalence of high school students reporting four or more sexual partners in their lifetime decreased from $18.7 \%$ to $13.8 \%$ (CDC, 2008b, 2010b), although the prevalence is higher among sexually active boys $(16.2 \%)$ than of such girls $(11.2 \%)$.

Sex under the influence of drugs or alcohol. One of the most frequently cited HIV-related risk behaviors is engaging in alcohol or drug use prior to sexual intercourse (Newman \& Zimmerman, 2000). The influence of illicit substances may impair an individual's judgment and behavioral intentions (e.g., intent to use condoms) may be compromised (Adler \& Rosengard, 1996; Jemmott, 1996; Jemmott \& Jemmott, 1993). Santelli and colleagues (Santelli et al., 1998; Santelli, Robin, Brener, \& Lowry, 2001) found a strong association between substance use, unprotected sex, and multiple lifetime sexual partners. Among sexually active high school students nationwide, $21.6 \%$ reported using alcohol or drugs prior to sexual activity (CDC, 2010b). Overall, the prevalence of 
being under the influence of drugs or alcohol at last sexual intercourse was higher among males (25.9\%), White students (22.9\%), and 9th-grade students (24.7\%) than other comparable groups.

Injection drug use (IDU). In 2010, 14\% of females and 7\% of males diagnosed with HIV were infected by using injection drugs (CDC, 2012g). Adolescents are more likely to acquire HIV from heterosexual contact, however, youth who are injection drug users are at increased risk for HIV infection (CDC, 2008b). Potential transmission of STIs through contaminated needles is not the only risk associated with IDU. A study comparing Black and White adolescents found that $82 \%$ of injection drug users have had an average of four sexual partners (Halpern et al., 2004). Between 1995 and 2009, the prevalence of IDU among high school students remained below 4\%, although the rate peaked to $3.2 \%$ in 2003 (CDC, 2008b). In 2009, 2.1\% of students had ever used a needle to inject any illegal drug, however, the prevalence was higher among Black males (3.5\%), 11th-grade males (3.3\%), and Hispanics (3.1\%) (CDC, 2010b).

\section{Health Risk Behaviors}

Jessor and colleagues expanded the original formulation of PBT to include health risk behaviors (Jessor et al., 1991). The current framework lists multiple types of health and non-health risk behaviors in the domain of adolescent health behavior and lifestyles grouped into three categories: problem behavior, health-related behavior, and school behavior (Jessor, 1991). For the purpose of this study, sexual risk behaviors were also added to this domain since they fit the concept of health risk behaviors in both PBT (Madkour, Farhat, Halpern, Godeau, \& Gabhainn, 2010) and TGP (Wingood \& DiClemente, 2000). 
Sexual risk behaviors. Early age at first sexual experience, frequency sexual activity, infrequent or nonuse of contraceptives, multiple sexual partners, and combining intercourse with drugs or alcohol are all considered sexual risk behaviors. The latter three have been discussed previously as HIV-related risk behaviors. Sexual intercourse is the primary risk factor for unintended pregnancy, HIV, and other STIs (Morris et al., 1993; Westhoff et al., 1996). Nahom et al., (2011) compared the intentions of sexually experienced and inexperienced youth to engage in sexual activity and found that those who had already engaged in intercourse were significantly more likely to intend to have sex again. In 2009, 46\% of high school students reported ever having sexual intercourse, and with $34.2 \%$ reported recent sexual activity in the past three months, with somewhat different proportions by gender, race, and ethnicity (CDC, 2010b).

Researchers have examined the relationship between age at first sexual intercourse and other sexual and non-sexual risk behaviors (Cavazos-Rehg et al., 2011; Biro \& Dorn, 2006; Dillon et al., 2010; Schvaneveldt, Miller, Berry, \& Lee, 2001; Senn \& Carey, 2011; Stueve \& O'Donnell, 2005) and have found that younger age at initial sexual experience is predictive of the number of lifetime partners, unprotected intercourse, and increased risk for HIV (Coker et al., 1994; Morris et al., 1993; Sandfort, Orr, Hirsch, \& Santelli, 2008; Sieving, Eisenberg, Pettingell, \& Skay, 2006; Weiss et al., 2008; Werner-Wilson, 1998; Yarber et al., 2002). Early age at first sexual experience among youth has long-term health consequences and contributes to ongoing ethnic and racial disparities in rates of HIV, STIs, and unintended pregnancies (O'Donnell, O’Donnell, \& Stueve, 2001). 
There are inconsistent reports about the average reported age of first sexual intercourse for youth in the United States. One national report using YRBS data found an average age of initial sexual experience to be 14.4 years (Cavazos-Rehg et al., 2009), however, there are reports that sexual experience starts as young as 11 or 12 years of age among a significant proportion of youth (O’Donnell et al., 2001). Other studies report age of first sexual intercourse to be higher, between 15 and 17 years of age (Abma, Martinez \& Copen, 2010; Warren et al., 1998). If early sexual intercourse is defined as having sex before the age of 13 , then approximately $6 \%$ of U.S. high school students have initiated sex early, although, prevalence rates range from $2.2 \%$ (White females) to $24.9 \%$ (Black males), depending on race/ethnicity and gender (CDC, 2010b). YRBSS data indicate a downward trend in the percentage of high school students who report having sex before the age of 13, down from $10.2 \%$ in 1991 (CDC, 2010b).

Illicit substance use. The use of proscribed substances among youth, such as tobacco, alcohol, and illicit drugs, tend to co-occur and are identified as risk behaviors in both PBT and TGP (Jessor et al., 1991; Wingood \& DiClemente, 2000). The use of these substances, regardless of type, is a prominent determinant of sexual risk-taking among males and females (Lowry et al., 1994; Yarber et al., 2002). In a study examining risk behaviors among Florida adolescents, more males reported being frequent users than females in all illicit substances, however, experimental or infrequent use of any illicit drug was more common in females (Niyonsenga et al., 2008).

Approximately $45 \%$ of high school students have ever tried cigarette smoking, about $10 \%$ before the age of 13 (CDC, 2012g). In addition to its long-term health consequences, tobacco use, especially cigarette smoking, is also a risk factor for sexual 
risk behavior among adolescents (Everett, Malarcher, Sharp, Husten, \& Giovino, 2000; Kirby, 2002a; Yan, Chiu, Stoesen, \& Wang, 2007; Yarber et al., 2002). A study comparing Black and White adolescents found that $62 \%$ of adolescents who smoked cigarettes daily were sexually experienced as compared to adolescents who did not smoke (Halpern et al., 2004).

Adolescent alcohol and drug use has been studied at length since they are common predictors of substance abuse and addiction, participation in other risk behaviors, and rates of intentional and intentional injuries (Chatterji, Dave, Kaestner, \& Markowitz, 2004; Duarte et al., 2007; Fisher, Eke, Cance, Hawkins, \& Lam, 2008; Galaif et al., 2007; Guiao, Blakemore, \& Wise, 2004; Mulatu, Leonard, Godette, \& Fulmore, 2008; Peleg-Oren, Saint-Jean, Cardenas, Tammara, \& Pierre, 2009; Siegel, Naimi, Cremeens, \& Nelson, 2011; Tolou-Shams, Brown, Gordon, Fernandez, \& Group, 2007; Williams, Ayers, Bright, Abbott, \& Hawkins, 2007). As discussed previously, the use of the alcohol and drugs often precedes sexual events, and since sexual disinhibitors can impair cognitive function, individuals under the influence of these substances may be at risk for acquiring HIV through unprotected sex (Kirby, 2002a; Morrison et al., 2003; Wingood \& DiClemente, 2000). Substance use prior to sexual intercourse is also associated with having multiple sexual partners (Santelli et al., 2001; Yan et al., 2007) and is strongly associated with sexual victimization among adolescent females (Champion et al., 2004).

Despite the legal drinking age, $70.8 \%$ of adolescents nationwide have tried alcohol, $20.5 \%$ as early as 12 years of age (CDC, 2012g). An earlier study found that adolescents who reported misusing alcohol had increased odds of having initial sexual 
experience at an early age, multiple sex partners, and unprotected sex that were 6.1 to 23.0 times those of young people who did not misuse alcohol (Fergusson \& Lynskey, 1996). Studies assessing relationships between alcohol use and risky sexual behavior have found differences in the role of gender and race/ethnicity. Males had higher rates of consumption when they drank alcohol (Poulson, Eppler, Satterwhite, Wuensch, \& Bass, 1998), and binge drinking was found to be associated with having multiple sexual partners (Yarber et al., 2002). Analyses also indicate that African American adolescent females were less likely than other female adolescents to initiate alcohol use (Randolph, Torres, Gore-Felton, Lloyd, \& McGarvey, 2009; Williams et al., 2007). Nationally, Hispanic students were more likely than White and Black students to report ever using alcohol, however White students were more likely than their counterparts to report current alcohol use and binge drinking (CDC, 2010b).

Marijuana is the most common illicit drug used by adolescents. Nationwide, $36.8 \%$ of high school students had ever used marijuana in their lifetime, $20.8 \%$ in the last 30 days. More Hispanic students reported ever trying marijuana than students of other race/ethnicities, however, Black students were more likely than their counterparts to report current use of marijuana. Illicit drug use among youth is also linked to HIV risk behaviors and unintended pregnancies (Kirby, 2002a; Halpern et al., 2004).

Violence-related behaviors. According the CDC, violence-related behaviors among U.S. high school students decreased during 1991-2003, however, there was an increase in students that missed school because they felt too unsafe to attend (CDC, 2004b). Currently, $31.5 \%$ of high school students report being involved in a physical fight and $17.5 \%$ report carrying a weapon (CDC, 2010b). Males were more likely than 
females to carry a weapon $(27.1 \%$ vs. $7.1 \%)$, be involved in a physical fight $(39.3 \%$ vs. $22.9 \%$ ), or participate in other violent-related behaviors, possibly because boys are socialized into roles that encourage higher levels of physical aggression (Loeber \& Stouthamer-Loeber, 1998).

Studies examining violence-related behaviors found that they frequently co-occur with other health risks, including illicit substance use, early onset of sexual behavior, STDs, and teen pregnancy. With regard to HIV-related risk, carrying a weapon to school and engaging in physical fights were associated with early age of initial sexual experience, regardless of race or gender (Coker et al., 1994; Kirby, 2002a). Analyses of Add Health Wave III data found increased odds of having an STI, among young adults that had ever been involved in violence, regardless of role of victim or perpetrator (Doskoch, 2008).

\section{Risk Factors}

The conceptual framework for the present study identifies risk factors for HIVrelated risk behaviors as histories of depression, sexual or physical abuse, models for health risk behaviors, and opportunities to participate in health risk behaviors (Figure 5). Family members and peers are often models for unhealthy actions, such as cigarette smoking, use of illicit substances, and sexual risk behavior. The likelihood of participating in these behaviors increases when the opportunity is presented, such as being offered drugs or purchasing tobacco without proof of age.

Depression and depressive symptoms. Research examining the relationship between psychological distress and sexual behaviors has shown a clear link between the two. While there is a substantial body of research on the topic (Milhausen, Yarber, \& 
Crosby, 2003; Rector, Johnson, \& Noyes, 2003; Shrier et al., 2009; Waller et al., 2006; Wilson, Asbridge, Kisely, \& Langille, 2010), there still a debate as to whether depression is an antecedent or consequence of sexual behavior. Investigators have tried to establish the direction of causality from depression to risky sexual behaviors.

Much of this research suggests that adolescents with a history of depressive symptoms are more likely to initiate sex (Kirby, 2002a) and engage in risky sexual behaviors (Paxton, Valois, Watkins, Huebner, \& Drane, 2007), including having multiple partners (Khan et al., 2009; Rubin, Gold, \& Primack, 2009) and using condoms inconsistently (Brown et al., 2006; Shrier, Walls, Lops, \& Feldman, 2011). Conversely, there is a body of research that posits that risky sexual behavior can cause depression, even in the absence of sexual abuse or victimization (Ethier et al., 2006). The PBT framework designates depression as a risk outcome of problem behavior (Jessor et al., 1998b), whereas the TGP framework identifies depression as a personal risk factor (Wingood \& DiClemente, 2000). For the purpose of this study, depression was considered a risk factor for sexual and HIV-related risk behavior.

Analysis of Add Health data found that depressive symptoms predicted sexual risk behaviors for both genders, but particularly non-condom use and substance abuse for boys with high-level symptoms and substance abuse for girls with moderate depressive symptoms (Lehrer, Shrier, Gortmaker, \& Buka, 2006). Females are especially vulnerable to high risk behaviors (Kennedy et al., 1993; Kofler et al., 2011; Orr, Celentano, Santelli, \& Burwell, 1994; Paxton \& Robinson, 2008; Waller et al., 2006) as those with depressive symptoms may lack the self-esteem, self-efficacy, or assertiveness needed to negotiate safer sex (Brown, Danovsky, Lourie, DiClemente, \& Ponton, 1997). Depression may also 
inhibit an individual's perceived susceptibility to the risk of infection as it may impair cognitive function and memory (Khan et al., 2009).

Sexual and physical abuse. A history of sexual or physical abuse is identified as a risk factor for HIV in Wingood and DiClemente's (2000) application of TGP. Sexual violence and coerced sex are defined as sexual activity that occurs either without consent or with a person who consents by using contingent threats or physical force (Fantasia \& Fontenot, 2011; Marín, 1996). Many terms are used to describe such occurrences (e.g., rape, forced sex, coerced sex, sexual violence, etc.), however, for the purpose of this study, and in alignment with the TGP framework, they will be collectively referred to as "sexual abuse."

Survivors of sexual abuse may suffer from emotional and physical pain, which can potentially have long-term consequences, unintended pregnancies, eating disorders, substance abuse, low self-esteem, depression, and even STIs or HIV (Fantasia \& Fontenot, 2011; Shrier et al., 1998). Voison (2005) found that adolescents exposed to childhood sexual abuse were almost three times more likely than their peers to report a higher number of HIV-related risk behaviors. Sexual abuse during childhood or adolescence is also associated with involvement in sexual risk behaviors later in adulthood (DiIorio, Hartwell, Hansen, \& NIMH Multisite HIV Prevention Trial Group, 2002; Holmes, Foa, \& Sammel, 2005; Klein \& Chao, 1995; Senn, Carey, \& Vanable, 2008) and more severe sexual abuse is associated with riskier adult sexual behavior (Senn, Carey, Vanable, Coury-Doniger, \& Urban, 2007).

Adolescents who have experienced sexual abuse have been found to engage in HIV-related risk behaviors, including having multiple sexual partners and unprotected 
sex (Buzi et al., 2003; Holmes et al., 2005; Houck, Nugent, Lescano, \& Peters, 2010; Johnson, Rew, \& Sternglanz, 2006; Kenney, Reinholtz, \& Angelini, 1998; Kirby, 2002a; Yarber, Milhausen, Crosby, \& DiClemente, 2002), and are at greater risk for acquiring STIs or HIV. Risk of involvement in a teen pregnancy is strongly linked to sexual abuse, especially for adolescent males (Pierre, Shrier, Emans, \& DuRant, 1998; Saewyc, Magee, \& Pettingell, 2004). A study of pregnant teenagers found that over one-third (36\%) of them had been sexually abused prior to becoming pregnant (Kenney, Reinholtz, \& Angelini, 1997).

Dating violence has emerged as a prevalent problem among youth (Fantasia \& Fontenot, 2011). Draucker et al., (2010) identified several types of aggressive events that are characteristic of adolescent dating violence: tumultuous, explosive, scuffling, violating, threatening, controlling, disparaging, and rejecting, ignoring, or disrespecting. Victimization by intimate partner violence (IPV) may play an important role in sexual decision-making (Bauer et al., 2002) and is associated with high-risk health and sexual behaviors among both male and female adolescents, which increases their risk for HIV and STIs (Eaton, Davis, Barrios, Brener, \& Noonan, 2007; Silverman, Raj, Mucci, \& Hathaway, 2001).

Sexual abuse and IPV disproportionately affect women, making them more susceptible to negative outcomes related to such victimization. Women with a history of sexual abuse are more likely to engage in health-risk behaviors (Basile et al., 2006; Brener, McMahon, Warren, \& Douglas, 1999; Lang et al., 2011; Sundaram, Laursen, \& Helweg-Larsen, 2008), and less likely to use condoms or negotiate condom use, either for fear of provoking a threat of bodily harm or to avoid being raped or losing the partner 
(Muehlenhard \& Linton, 1987; Wingood \& DiClemente, 1997, 2000). He, McCoy, Stevens, and Stark (1998) found that violent experiences and threats of violence were associated with heightened risk for HIV in women. Female adolescents who reported IPV were more likely than others to report sexual risk behaviors, coercive sexual risk factors (i.e., partner sexual infidelity, fear and negative consequences of requesting condom use, and coerced condom nonuse), as well as depressive symptoms and use of illicit substances (Frye et al., 2011; Howard \& Wang, 2003; Littleton, Breitkopf, \& Berenson, 2007; Raiford, Wingood, \& DiClemente, 2007; Silverman et al., 2011; Silverman, Raj, \& Clements, 2004; Teitelman, Dichter, Cederbaum, \& Campbell, 2007).

Nationwide, roughly $7.4 \%$ of high school students reported ever being forced to have sex, however, females were more likely to report forced sex than males (10.5\% vs. 4.5\%). More students (10\%), however, reported that they had been hit, slapped, or physically hurt by their boyfriend or girlfriend, and this occurrence among adolescent males was almost as prevalent as among girls (10.3\% vs. 9.3\%) (CDC, 2010b), and is also associated with a cluster of other risk factors. Boys who reported feelings of hopelessness, physical fighting, weapon carrying, or having unprotected sex were more likely to report a history of IPV (Howard, Wang, \& Yan, 2008). Overall, the prevalence of dating violence was higher among Black (14.3\%) and Hispanic (11.5\%) than White (8.0\%) students (CDC, 2010b).

Opportunities to observe and participate in health risk behavior. When individuals in an adolescent's environment participate in risky behaviors (e.g., drinking and driving, smoking, illicit drug use, violent acts, etc.), they serve as a model for risk behavior (Jessor et al., 1998b). Parents and peers are important influences on adolescent 
risk behavior (Livaudais, Napoles-Springer, Stewart, \& Kaplan, 2007). Family was originally believed to be the model for most aspects of prosocial and proscribed behavior (Jessor et al., 1968), but later versions of PBT identify peers as powerful influence on adolescent behavior (Jessor \& Jessor, 1977).

The most common mode of direct influence is peer pressure, however, behavioral displays provide models for behavior that are reinforced through processes of social learning (Bandura, 2001). Peer influence plays an important role in explaining risky behavior during adolescence (Gardner \& Steinberg, 2005; Jaccard, Blanton, \& Dodge, 2005). Studies examining models of risk behavior found significant peer group influences on an adolescent's substance use, violence, truancy, and suicidal behavior (Duarte, Escario, \& Molina, 2007; Maxwell, 2002; Prinstein, Boergers, \& Spirito, 2001), and Kirby (2002a) found peer substance abuse and other problem behaviors to be risk factors for sexual behavior.

The opportunity to participate in risky behaviors, described by Jessor (1991) as an "illegitimate opportunity," is identified as a risk factor in the social environment system. An example of proscribed behavior for youth is the use of alcohol, and an opportunity to participate in such behavior exists when an individual is offered, given, or sold an alcoholic beverage. The opportunity to participate in risk behaviors has been associated with onset of first sexual experience (Abma, Martinez, \& Copen, 2010).

\section{Protective Factors}

Protective factors conceptualized as exposure to sex education, school involvement, and quality schools are thought to be predictive of HIV-related risk 
behaviors in adolescents, as well as related to participation in other health risk behaviors. The literature yielded reports of multiple studies involving protective factors.

School involvement. Adolescents in the United States have a large amount of unsupervised time on their hands, especially after school hours, presenting a window for potential risk and undesirable outcomes (Risisky et al., 1997). A greater involvement with school and extra-curricular activities is related to less sexual risk-taking, including later age at initial sexual experience and the use of contraception (Aspy et al., 2012; Kirby, 2002a). In a study analyzing self-reported sexual histories, adolescent girls who participated in extracurricular activities, volunteer clubs, and sports were less likely to be involved in sexual risk (Martyn \& Martin, 2003). School involvement is a protective factor under PBT's behavior system (Jessor et al., 1998a, 1998b) and is found to be associated with sexual risk behavior and mediated by the effect of family structure, class position, and race on youth sexual risk behavior (Ramirez-Valles et al., 1998).

In $2009,58 \%$ of high school students reported participating on at least on sports team. Males had higher rates of participation in sports (63.8\%) than females (52.3\%), but the level of participation declined with increased grade level (from $61.6 \%$ in 9 th grade to $51.1 \%$ in 12th grade) (CDC, 2010b). Participation in sports has been found to be related to lower rates of sexual behaviors (Habel, Dittus, De Rosa, Chung, \& Kerndt, 2010; Kulig, Brener, \& McManus, 2003) and may offer a protective effect, especially for females. Female athletes have a lower prevalence than non-athletes of sexual intercourse, multiple sexual partners, and teen pregnancies (Eitle \& Eitle, 2002; Miller, Sabo, Farrell, Barnes, \& Melnick, 1998; Savage \& Holcomb, 1999), however, male athletes have been 
found to have higher levels of sexual risk behaviors and substance use than male nonathletes (Forman, Dekker, Javors, \& Davison, 1995; J. Hoffman, 2006).

Safe schools. Quality schools are listed under the social environment system as a protective factor in PBT (Jessor et al., 1998b). Safe schools are considered quality schools, as there is less of an expectation for violence and substance abuse on school property. The Center for the Prevention of School Violence defines school violence as "any behavior that violates a school's educational mission or climate of respect or jeopardizes the intent of the school to be free of aggression against persons or property, drugs, weapons, disruptions, and disorder" (McDaniel, 2000, p. 2). Dunne, Humphreys, and Leach (2003) identified several categories of gender-based violence in schools that may act as barriers to school involvement, especially for girls; these include: bullying and intimidation, sexual harassment, physical and sexual assault, as well as verbal and psychological abuse. Few studies have specifically addressed the relationship between safe schools and sexual risk behaviors. Age at first sexual experience has been found to be associated with perceived school safety in adolescents (Marshall \& Werb, 2010).

Sex education exposure. Adolescents require accurate information about how to protect themselves against pregnancy, STIs, and HIV/AIDS (Fantasia \& Fontenot, 2011). Learning about HIV/AIDS helps adolescents acquire the knowledge and skills necessary to eliminate or reduce risks for infection (Morris et al., 1993). TGP states that the sexual division of power is manifested by conservative policies that may prohibit HIV prevention education and the distribution of condoms (Wingood \& DiClemente, 2000), and limited access to such resources has been identified as an acquired risk, especially for women (Barber, Axinn, \& Thornton, 1999; S. Hoffman, 2006; Keogh, 1988; Logan, 
Holcombe, Manlove, \& Ryan, 2007; Malhotra, 2008; Morris et al., 1993; Scott et al., 2011; Trussel, Koenig, Stewart, \& Darroch, 1997). Youth knowledgeable about HIV are more likely to exhibit HIV prevention behaviors.

In a review of HIV/AIDS and sex education programs in developing and developed countries, Kirby, Laris, and Rolleri (2005) found that, overall, these programs were more likely to have a positive impact on sexual behavior, including delaying the initial sexual experience, increasing condom use, and reducing the frequency of sexual activity and number of partners. School-based HIV prevention programs, specifically, have shown to increase HIV/AIDS knowledge, modify attitudes regarding susceptibility to infection, and increase likelihood of using contraception (Brown, Fritz, \& Barone, 1989; Kirby, 2002a; Newman, DuRant, Ashworth, \& Gaillard, 1993; Siegel, DiClemente, Durbin, Krasnovsky, \& Saliba, 1995). One study suggested that knowledge of HIV and school-based instruction may also play a role in maintaining lower levels of IDU behavior among high school students (Holtzman et al., 1991). A previous study found a very strong relationship between sex education classes and condom use on Hispanic adolescent males (Moran \& Corley, 1991).

The percentage of high school students who were taught about HIV/AIDS in school increased during 1991-1997 (83.3\% - 91.5\%) and then decreased during 19972009 (91.5\% - 87.8\%) (CDC, 2008c, 2010b). Although more girls (87.8\%) than boys $(86.3 \%)$ received HIV/AIDS instruction, there is little attention, as to whether sex education program outcomes differ for males and females (Carter \& Carter, 1993; DeLamater, 2007). 


\section{Sex Education Policy and Location of School District}

Location of residence is an important factor in studying adolescent risk behavior since the social environment surrounding and affecting adolescents may differ depending on where they live (Garfein et al., 2004; Marshall \& Werb, 2010; Milhausen et al., 2003). Local policies can have a substantial impact on adolescent risk behavior (Bishai et al., 2005; Roemer \& Paxman, 1985). For instance, local laws may regulate some aspects of the community's influence on sexuality since it allows individual school systems to determine the content of sex education curriculum (Satcher, 2001). Programs and policies designed to address sexual risk behavior are considered a protective factor, whereas restrictive policies regarding contraceptives are considered a risk factor (Kirby, 2002a).

Findings suggest that there is an association between sex education policies and adolescent sexual risk behaviors. Conservative states with the least comprehensive sexual education programs (e.g., Texas) have lower rates of reported condom use and higher rates of teen pregnancy. In comparison, states that have more comprehensive sexual education policies (e.g., California) have much lower rates of teen pregnancies (Guttmacher Institute, 2010). The increase in abstinence-only education policy and funding and the resulting decrease in contraceptive education in the mid-1990s may explain the decline of contraceptive use among youth after 2003 and the rise in teen birthrates after 2005 (Lindberg et al., 2006; Santelli \& Melnikas, 2010). Local sex education policies are important factors to consider when examining adolescent HIV-risk behaviors.

Sex education in South Florida. While Florida law requires abstinence to be taught in HIV/AIDS prevention units in health education courses across the state (Florida 
Legislature, 2011a, 2011b), it does not prohibit comprehensive sexual health curricula from being implemented as well (Florida Department of Education, n.d.). Currently, local school districts decide which health education course will meet the HIV/AIDS instruction mandate (SIECUS, 2011). The CDC's Division of Adolescent and School Health (DASH) currently funds four local school districts in Florida to provide HIV education as an aspect of their health education program (CDC, 2012d; SIECUS, 2010b). Three of these districts include Miami-Dade, Broward, and Palm Beach, which collectively make up the South Florida region, and are the 4th, 6th, and 11th largest school districts in the United States, respectively (American School \& University, 2012). Miami-Dade is the largest school district in Florida.

All three school districts have adopted more comprehensive sexual health curriculum (SIECUS 2010b), however, the policies, practices, and implementation of these programs vary. Funding recipients under DASH are part of the CDC's School Health Profiles (Profiles) report which has been conducted biennially since 1994 (CDC, 2008a). Profiles helps health departments and school districts monitor and assess characteristics of and trends in seven health areas, including policies related to HIV/AIDS prevention in schools (Brener et al., 2011). Despite the adoption of more comprehensive sex education policies, data indicate that programs are employed differently in each school district (Table 2).

Miami-Dade County Public Schools (MDCPS). The fundamental mission of Miami-Dade's HIV/AIDS education program is to decrease the prevalence of teen pregnancies, HIV/AIDS, and STIs among youth by fostering an increased awareness of healthy behaviors and practices that can help them become healthy adults. Prevention 
information is taught in a Human Growth and Development unit in middle school science classes and in the health education courses offered in 9th and 10th grades (MDCPS, 2012).

MDCPS has been part of the Profiles report since its inception in 1996. In 2008, $68.6 \%$ of middle schools and $78.8 \%$ high schools reported instruction in the 11 key HIV, STI, and pregnancy prevention topics. More specifically, about $69 \%$ of high schools reported teaching all three topics related to condom use: condom efficacy, importance of consistent and correct use, and how to obtain condoms (Table 2).

Table 2

Percentage of High Schools in South Florida That Taught HIV/STD and Pregnancy Prevention Topics, 2007-2008.

\begin{tabular}{lccc}
\hline & \multicolumn{3}{c}{ School District } \\
\cline { 2 - 4 } Topics Taught & Miami-Dade & Broward & Palm Beach \\
\hline 8 HIV, STI, and pregnancy prevention topics & 80.8 & 81.7 & 100.0 \\
3 condom use topics & 68.6 & 68.7 & 0.0 \\
All 11 topics & 78.8 & 80.0 & 0.0 \\
\hline
\end{tabular}

Note. From Brener et al., 2009, 2011

Broward County Public Schools (BCPS). Since 2007, six school districts in Florida have adopted more comprehensive sex education policies. Broward County, geographically located between Miami-Dade and Palm Beach, joined Brevard, Collier, Palm Beach, St. Lucie, and Volusia counties in expanding and improving their HIV/AIDS curriculum and teacher training (SIECUS, 2010b). BCPS currently offers Family Life/Human Sexuality and HIV/AIDS Prevention units as components of health education courses, and are offered in all grades (K-12) (BCPS, 2012b). In the Profiles 2008 , BCPS reported that $55.8 \%$ of middle schools and $78.8 \%$ of high schools taught the 
11 key prevention topics. Similar to MDCPS, about $69 \%$ of BCPS high schools taught all three topics related to condoms (Table 2).

School District of Palm Beach (SDPB). Palm Beach is the most recent of the South Florida school districts to revise its sex education policy by including a more comprehensive approach. This change was led mainly by Palm Beach health department's concern that the school district was not doing enough to prevent STIs and pregnancies among youth. The new changes went into effect in May 2008 (DeNardo, 2008b). SDPB's Human Growth and Development curriculum — which includes information on preventing pregnancy and STIs at age-appropriate intervals-was expanded to included grades K-10 (previously available only to 4th through 9th-graders) (Travis, 2008), and is taught as a special unit through Science departments (DeNardo, 2008c). Standardized lessons on condoms and other contraceptives were available in 6th and 7th grades, but none were planned for high school students as of 2008 (DeNardo, 2008a).

In Profiles $2008,8.8 \%$ of middle schools reported teaching all 11 key topics, including topics relating to condoms. Although $100 \%$ of SDPB high schools reported teaching eight key topics related to HIV/AIDS and pregnancy prevention, none of these schools included instruction on how to obtain condoms, and therefore scored $0 \%$ for teaching all three topics relating to condom usage (Table 2).

\section{Considerations of Gender, Culture, and Race}

While race, ethnicity, and gender usually convey biological attributes, they also represent socio-cultural aspects of an adolescent's identity. Patterns in adolescent risk behavior vary by race, cultural background, and gender (Halpern et al., 2004). Social and 
demographic factors have been found to be associated with early sexual risk behaviors and later reproductive health outcomes (Scott et al., 2011). Specifically, female gender and minority status are positively associated with risky sexual behaviors among youth (Manlove, Romano-Papillo, \& Ikramullah, 2004; Upchurch, Mason, Kusunoki, \& Kriechbaum, 2004). The Theory of Gender and Power places women, ethnic minorities, and those from conservative cultural backgrounds at a higher risk for negative outcomes related to HIV (Wingood \& DiClemente, 2000). PBT also lists racial disparities as risk factors in the social environment system (Jessor, 1991).

Gender and gendered roles. Gender differences have been observed in problem behaviors among youth (Epstein \& Spirito, 2010; Krantz et al., 2002; Kreiter et al., 1999; March \& Atav, 2010; Niyonsenga, 2007; Puente et al., 2011; Sacco et al., 1993; Schepis et al., 2011; Shrier et al., 1998; Tevendale et al., 2009). Gender is a key aspect of sexuality and a fundamental part of adolescent sexual behavior (Tolman, Striepe, \& Harmon, 2003), and also warrants consideration for this study. Gender stereotypes, as well as gender-specific behaviors are believed to contribute to gender inequalities and power imbalances (Connell, 1987; Froyum, 2010; Wingood \& DiClemente, 2000). Research on gender-role stereotypes in the United States — which usually encourage male dominance and female submissiveness - revealed that females are more likely to engage in safe behaviors whereas males are more apt to take risks. For instance, males are more likely than females to report having four or more sexual partners (CDC, 2010b) and are less likely than females to use a condom in unplanned, spontaneous situations (Jadack, Hyde, \& Keller, 1995). 
Gender roles stipulate how men and women are expected to behave in relation to their sexuality and other aspects of their lives and are usually learned at an early age (Marín, 1996). Gender-specific behaviors contribute to the rules of sexual identity and forms of femininity and masculinity (Dunne, et al., 2003). For instance, boys are supposed to like sex and be sexually competent and physically strong. Young men must often prove their manhood, and frequently do so with sex. Girls, on the other hand, are expected to be sexually submissive, not well-informed about sex, and should be primarily interested in matters of the home and children (Marín, 1996). Young women are encouraged to be sexy, yet not sexual, and must often find the right balance between seductive and prim (Pipher, 1994). In the Latino culture, these traditional gender roles for men and women are called machismo and marianismo, respectively (Hyde \& DeLamater, 2006).

Individuals who adhere to traditional, gender roles are more likely to engage in HIV risk-taking behaviors, like unprotected sex (Shannon et al., 2012), whereas a greater acceptance of non-traditional gender roles were a found to be protective factor (Kirby, 2002a). Men with traditional gender role beliefs were found to be more accepting of coercive sex and forcible rape than men with less traditional gender role beliefs (Burt, 1980; Fischer, 1987; Marín, 1996; Werner-Wilson, 1998). TGP contends that that sexual division of power and conservative gender norms place women at greater risk for HIV (Wingood \& DiClemente, 2000). Young girls may feel powerless (Koniak-Griffin, Nyamathi, Vasquez, \& Russo, 1994) and may be less able to refuse sex or insist on protective barrier methods, thereby increasing their risk for HIV (Salazar et al., 2010). 
The present study examined whether the constellation of problem and healthcompromising behaviors varied by gender.

Ethnicity and cultural influence. Social and cultural influences foster the development of attitudes about gender role expectations which can contribute to gender disparities in substance use, contraceptive behavior, and other health outcomes (Amaro, 1995; DePadilla et al., 2011; Gupta, 2000; Hitchcock et al., 2006; Marín, Gomez, Tschann, \& Gregorich, 1997). Broering (1991) defined sexual enculturation as a process where cultural meanings of sexuality and sexual norms were passed down from generation to generation. These teachings regulate values, rules, and acceptable behaviors related to sex (Brink, 1987). Cultural norms among Hispanics include gender inequalities and power imbalances within relationships that may influence age of first sexual experience (Dillon et al., 2010) and sexual behavior (Gilliam, Berlin, Kozloski, Hernandez, \& Grundy, 2007). Kirby identified "being Hispanic" as a risk factor for initial sexual experience and failure to use contraception (Kirby, 2002a).

The U.S. Hispanic population has increased 43\% from 2000 to 2010 (U.S. Census Bureau, 2012). Most Hispanics reside in just three states: California, Texas, and Florida. Hispanics make up $22.5 \%$ of the Florida population - a $57.4 \%$ increase in just 10 yearswith approximately 40\% (1.6 million) of all Florida Hispanics residing in Miami-Dade County alone. (U.S. Census Bureau, 2011b).

In addition to being the fastest growing demographic group in the United States, Latinos are also the largest and youngest ethnic minority group (Santelli, Abraido-Lanza, \& Melnikas, 2009). Hispanic youth are currently at a disproportionate risk for unplanned pregnancies and STIs, including HIV (Santelli et al., 2009; Vélez-Pastrana, González- 
Rodríguez, \& Borges-Hernández, 2005). Hispanic adolescents aged 13-19 years had the second highest rate of reported HIV infections in 2010 (CDC, 2012c). The high prevalence of sexual risk behaviors among Latinos is also concerning; more Hispanic high school students reported being sexually experienced, having multiple sexual partners, not wearing condoms, and using injection drugs than their White counterparts (CDC, 2010b).

Multiple factors are thought to be important in predicting sexual risk behaviors among Latinos, the most important of which may be the role of culture. U.S. Hispanic youth are more likely to come from larger families and hold general beliefs rooted in Hispanic traditions and cultural values (Westhoff, McDermott, \& Holcomb, 1996). Three important factors are the role of familismo, acculturation, and religion. Familismo is a one traditional Hispanic value that emphasizes reliance and interdependence on family and community and is believed to be the most important influence in the lives of Latino youth (Contreras, Mangelsdorf, Rhodes, Diener, \& Brunson, 1999), even in the context of sexual decision-making (Flores, Tschann, \& Marín, 2002; Muñoz-Laboy, 2008). Although it has been linked positive outcomes in children such as higher academic achievement and lower drug use (Vélez-Pastrana et al., 2005), it is also negatively associated with sexual behavior among girls (Guilamo-Ramos, Bouris, Jaccard, Lesesne, \& Ballan, 2009).

Acculturation - the process of relearning culture in order to adapt to a new or changing environment (DeSantis, Thomas, \& Sinnett, 1999) — is central to the experience of Latinos in the United States (Miranda, Bilot, Peluso, Berman, \& Van Meek, 2006). Studies have found that behaviors of acculturated Latino teenagers closely resemble those 
of non-Latino adolescents (McDonald, Manlove, \& Ikramullah, 2009), and that relationships exist between levels of acculturation and sexual risk behaviors. Higher levels of acculturation among Latino youth are associated with younger age at initial sexual experience and an increased likelihood of condom use (Afable-Munsuz \& Brindis, 2006; Ford \& Norris, 1993; Guilamo-Ramos, Jaccard, Pena, \& Goldberg, 2005), however, some studies have found evidence that acculturation is associated with unprotected sex, more sexual partners, and STIs (Lee \& Hahm, 2010; Guilamo-Ramos et al., 2009; Rapkin \& Erickson, 1994; Sabogal, Perez-Stable, Otero-Sabogal, \& Hiatt, 1995).

Catholicism, which forbids the use of birth control and contraception, is the predominant religion for many Latinos. Many young Latina women consider anal sex as an effective pregnancy prevention strategy and way to preserve virginity among Latina women, although it presents an even greater risk for HIV transmission for women than unprotected vaginal sex (Wingood \& DiClemente, 2000; CDC, 2011a).

In a study examining the generalizability of PBT among Latino and non-Latino college students, patterns of interrelations among problem (e.g., heavy drinking, marijuana use, etc.) and conventional (e.g., church attendance and good grades) behaviors were not found to be consistent across ethnic groups (Latino vs. non-Latino) and Latino subgroups (Cuban vs. non-Cuban) (Zamboanga et al., 2004). The potential influence of cultural norms on sexual behavior is an important consideration for research on adolescent HIV-risk behavior since problem behaviors may differ across ethnic groups.

Racial minority status. Although African Americans represent only $12.6 \%$ of the total U.S. population (U.S. Census Bureau, 2012), they account for almost 52\% of HIV 
infections (CDC, 2011c). HIV infection rates among 13-19 year-old adolescents were highest among Blacks (73\%) as compared to Hispanics (13\%) and Whites (12\%) (CDC, 2012c). The number of Black adolescents that engage in risky sexual behaviors has declined considerably in the past 20 years in the United States (CDC, 2012a). Over a 10year period in Florida, Black high school students reported a 10.9\% drop in the number who had engaged in sex, an $18.2 \%$ percent drop in ongoing sexual activity, and a $15.4 \%$ decline in those with multiple partners (Brochu, 2012). However, Black youth still report earlier onset of first intercourse, higher rates of sexual activity, less contraceptive use, more sexual partners, and higher rates of teenage pregnancy than their White counterparts (CDC, 2010b; Bartlett, Buck, \& Shattell, 2008; Kost, Henshaw, \& Carlin, 2010). This behavior places Blacks at greater risk for HIV/AIDS than adolescents of other races (Newman \& Zimmerman, 2000). However, differences in risk behaviors may exist across Black subgroups. For instance, in a study of HIV risk behaviors among young minority adults in Broward, Hlaing and Darrow (2006) found that condom use was more frequently reported by African Americans (60.0\%) than their Hispanic, Haitian, and Afro-Caribbean counterparts.

Factors other than individual risk behaviors may account for racial disparities in HIV and STIs as well. One study found that White young adults in the United States were at elevated risk for STIs and HIV when they engaged in high-risk behaviors, however, Black young adults were at considered at risk even when their behaviors were normative (Hallfors, Iritani, Miller, \& Bauer, 2007). Racial differences in sexual risk behaviors have been attributed to different cultural values and upbringing, as well as the effects of family dynamics and socioeconomic status (Brewster, 1994; Dancy, Crittenden, \& Freels, 2006; 
Furstenburg, Morgan, Moore, \& Peterson, 1987; Hayward, Grady, \& Billy, 1992;

Aneshensel \& Sucoff, 1996; Kapungu et al., 2010; Ramirez-Valles et al., 1998). Many African American adolescents face challenges at the neighborhood and individual levels that those from other racial and ethnic groups may not experience to the same degree. Many grow up with adverse neighborhood conditions that include such obstacles as limited financial resources and poverty at the community and family level, violence, drug and criminal activity, lack of positive role models, inadequate schooling, and limited access to care and preventative treatments (Sznitman, et al., 2010; Cornelius \& St. Lawrence, 2009; Corneille \& Belgrave, 2007).

In addition to gender and cultural background, the impact of race should also be considered in relation to HIV-related risk behaviors among youth. Both theories used to guide the current study identified racial minority status as a risk factor for problem behavior (Jessor, 1991; Wingood \& DiClemente, 2000).

Intersections of race ethnicity, and gender. While gender, race, or ethnicity may be considered separate factors for HIV-related risk, a combination of these factors may increase an individual's risk, especially for minority women. Black and Latina women are disproportionately affected by HIV/AIDS compared with women of other races and ethnicities (CDC, 2011a). In 2010, 82\% of HIV-infected females aged 13-24 years were either Black or Hispanic (CDC, 2012g). Most women are infected with HIV through heterosexual contact, almost $92 \%$ among female adolescents and young women.

In 2009, the prevalence of having ever had sexual intercourse was higher among Black (58.3\%) and Hispanic female (45.4\%) than White female (44.7\%) high school students (CDC, 2010b). More than twice as many Black adolescent females reported 
having sex before 13 years of age when compared to White females. One study observed that African American and Latina women were almost four times as likely to have unprotected sex compared with White women (Catania et al., 1992). Among female adolescents, only $52 \%$ of Black and $48 \%$ of Hispanic students reported using a condom at last intercourse, compared with 5.1\% of White female students (CDC, 2010b). Lack of condom use may not just be attributable to culture ethnicity or race alone, but could also be the results of having to cope with more immediate risks than just HIV, such as fear that their partner will emotionally, physically, or sexually abuse or leave them (Amaro, 1995; Higgins et al., 2010; Sobo, 1993).

Black and Hispanic males are also at significant risk for HIV and STIs. Similar to females, Black and Latino males account for $80 \%$ of HIV infected males aged 13-24 years (CDC, 2012c). Compared to White adolescent males, African American and Hispanic males are more likely to have had sexual intercourse and to initiate sex before age 13 (CDC, 2010b). Black adolescent males are 3.5 times as likely as White males and twice as likely as Hispanic males to have had four or more sexual partners in their lifetime. Fewer Hispanic male students (38.2\%) reported using a condom at last sexual intercourse than Black (27.5\%) and White (29\%) male students (CDC, 2010b).

Findings suggest that patterns of HIV-risk behaviors may differ for male and female adolescents across and within different racial and cultural/ethnic backgrounds (Amaro, 1995; Marín, 1996; Marín, Gomez, Tschann, \& Gregorich, 1997; Zamboanga et al., 2004). The present study assessed the relationship between these behaviors within the context of gender, race, and ethnicity. 


\section{Study Objectives}

The objectives of this research study were threefold. The first objective examined how protective factors, risk factors, and health risk behaviors were associated with HIVrelated risk behaviors among high school students in three South Florida school districts. The second objective assessed whether characteristics of district sex education policies were associated with students' participation in HIV risk behavior. The third objective investigated gender-specific differences in the predictors of participation in HIV-risk behavior among South Florida youth.

\section{Research Questions \& Hypotheses}

Based on the conceptual framework and the review of the literature, the following research questions guided the conduct of this study. The statement of hypotheses follows each related research question.

\section{Research Question 1}

What is the relationship between HIV risk behaviors (unprotected sex, multiple sexual partners, sex under the influence of drugs/alcohol, and injection drug use) and protective factors, risk factors, and health risk behaviors among high school students in South Florida?

Research Question 1 led to three hypotheses:

Hypothesis 1a: Protective factors (school involvement; safe schools; sex education) will be negatively associated with HIV risk behaviors.

Hypothesis 1b: Risk factors (histories of depressive symptoms, sexual abuse, and dating violence; models for risk behavior; opportunities to participate in risk behavior) will be positively associated with HIV risk behaviors. 
Hypothesis 1c: Health risk behaviors (sexual risk behaviors; tobacco, alcohol, and drug use; violence-related behaviors) will be positively associated with HIV risk behaviors.

\section{Research Question 2}

Do protective factors, risk factors, and health risk behaviors predict participation in HIV risk behaviors, when controlling for age, grade level, race/ethnicity, and school district?

Research Question 2 led to four hypotheses:

Hypothesis 2a: Students with protective factors will be less likely to report participation in HIV risk behavior compared to students without protective factors.

Hypothesis 2b: Students with risk factors will be more likely to report participation in HIV risk behavior compared to students without risk factors.

Hypothesis 2c: Students who engage in health risk behaviors will be more likely to report participation in HIV risk behavior compared to students who do not engage in health risk behaviors.

Hypothesis 2d: Protective factors will moderate the relationship between risk factors and HIV risk behaviors and health risk behaviors and HIV risk behaviors.

\section{Research Question 3}

Do characteristics of comprehensive sex education policies (length of policy implementation and course of sex education instruction) predict student participation in HIV risk behavior?

Research Question 3 led to two hypotheses: 
Hypothesis 3a: Students who received sex education in school districts with longer running comprehensive sex education policies will be less likely to report participation in HIV risk behaviors than students in school districts with shorter running policies.

Hypothesis 3b: Students who received sex education in a health education course will be less likely to report participation in HIV risk behavior than students who received sex education in a science course.

\section{Research Question 4}

What gender differences exist in the predictors of participation in HIV risk behavior among high school students in South Florida, when controlling for grade level, race/ethnicity, and school district?

Research Question 4 led to two hypotheses:

Hypothesis 4a: Gender differences will exist in the predictors of HIV risk behaviors. Hypothesis 4b: Risk factors will be a stronger predictor of HIV risk behavior for females than for males, and health risk behaviors will be a stronger predictor of HIV risk behavior for males than for females.

\section{Summary}

Adolescents engage in risk-taking behaviors, both sexual and non-sexual. The current state of the literature includes a wealth of information about protective factors, risk factors, and health risk behaviors that are related to sexual risk behaviors among youth, however, specific data is lacking with regards to predictors of HIV-related risk behaviors of adolescents in South Florida, a high risk area for HIV/AIDS. The diversity of the region's adolescents and large Hispanic population present a unique setting for examining HIV-related risk behavior among youth. Another consideration for this study 
is the influence that comprehensive sex education policies may have on students' participation in HIV risk behaviors.

Investigation of adolescent risk behaviors and the way these behaviors differ by gender are of great importance in efforts to reduce the incidence of unintended pregnancies, HIV, and other STIs among youth. It is imperative that these relationships be addressed with appropriate, theoretically-grounded research that recognizes the context in which adolescent sexual risk behavior occurs. Problem Behavior Theory and the Theory of Gender and Power frameworks were both used to guide the conceptual framework for this study.

The current chapter presented the theoretical and conceptual frameworks used in this study as well as the current state of the literature relevant to HIV risk behaviors among youth. Chapter 3 discusses the instrumentation, secondary data set, research design, methodology, and data analysis plan. The measurement and designation of the dependent and independent variables for the current study are also discussed. 


\section{CHAPTER III}

\section{METHODS}

This chapter presented the research and analytical method used to complete the current study and is divided into five sections. The first section described the instrument and discussed its overall reliability and validity. The next two sections explained the data collection methods for the three South Florida school districts and described the total study sample. In the fourth section, the demographic, independent, and dependent variables in the study were defined. The chapter concluded with the analysis plan used to evaluate the data and test each hypothesis, as well as assumptions and limitations of the current study.

\section{Instrumentation}

\section{Youth Risk Behavior Survey}

The Youth Risk Behavior Surveillance System (YRBSS) was designed by the CDC to monitor six categories of health risk behavior associated with major causes of morbidity and mortality among U.S. adolescents: behaviors that contribute to unintentional injuries and violence; alcohol and other drug use; tobacco use; sexual behaviors that contribute to unintended pregnancies and STIs; unhealthy dietary behaviors; and physical inactivity (CDC, 2010b). The YRBSS is the only national surveillance system that continually generates information about sexual behaviors among youth and related health outcomes throughout the United States (Morris et al., 1993).

The Youth Risk Behavior Survey (YRBS) is a school-based, anonymous, random survey of high school students that is conducted biennially through partnerships with state and local health departments. The questionnaire is the most representative source of 
information on risk behaviors of high school students in the United States (CDC, 2010a). YRBS surveys are also administered at the state and city levels since local data can be more useful in the assessment and planning of prevention efforts. Miami-Dade and Broward school districts in Florida were among the first few local departments of education to conduct the YRBS in 1990 (Kolbe, Kann, \& Collins, 1993). The School District of Palm Beach began its participation in 1999 (CDC, 2012e).

The goal of the YRBS is to describe the prevalence of risk behaviors that can be used to improve adolescent health and several of the national Healthy People objectives that are measured by the survey (CDC, 2004a; Morris et al., 1993). The instrument is also used by health and education agencies to create awareness, develop programs, inform professional development, support health-related policies and legislation, seek funding, and garner support for future surveys (Everett, Kann, \& McReynolds, 1997; Foti, Balaji, \& Shanklin, 2011; Kolbe et al., 1993).

\section{Instrument Reliability \& Validity}

The YRBS utilizes a self-report measure to gather data on health risk behaviors among adolescents. Any study that includes self-reported survey data has both strengths and weaknesses. An advantage of using self-report data is that a large numbers of people can be surveyed quickly, and closed-ended questions reduce researcher bias and are easier to analyze.

Sexual behaviors are generally measured by self-report scales (Obstfeld \& Meyers, 1984). With regard to reporting sexual behaviors, two types of errors are of particular importance: respondent error and instrument error. Respondent errors are those that include false reporting, social desirability bias, and memory recall, causing a 
participant to under-report or over-report a behavior. Instrument errors pertain to the reliability and validity of a survey that can be threatened by poor sentence structure, inadequate language translation, ambiguous wording, and sensitive or controversial topics (Smith, Steen, Spaulding-Givens, \& Schwendinger, 2003).

There have been several studies to date that have tested the validity and reliability of the YRBS questionnaire and data collection methods (CDC, 2004a). Reliability is the consistency of the instrument to achieve comparable results. The validity of an instrument establishes that the construct being tested is actually what is being measured. A literature review assessing the validity of self-report measures found that each of the six types of health-risk behaviors measured by the YRBS are affected by both cognitive and situational factors. The cognitive perspective stated that the adolescent must first understand the question and then be able remember the event before making a response. The situational perspective involved the external environment's influence on the adolescent's response in that perceived lack of privacy or confidentiality could cause an individual to answer dishonestly (Brener, Billy, \& Grady, 2003).

Overall, test-retest reliability studies of the YRBS have shown that students have reliably reported health risk behaviors over time (Brener et al., 2002; Brener, Collins, Kann, Warren, \& Williams, 1995) and their responses were found to be consistent with other surveys measuring adolescent risk (Kolbe et al., 1993). The questionnaire is written at the seventh-grade reading level so that students can accurately comprehend questions and response options (Brener, et al., 1995). Although social-desirability and recall bias may affect self-report data, Niyonsenga et al. (2008) contend that anonymous, selfadministered surveys may be one of the effective ways to obtain reliable information 
from adolescents. School-based surveys like the YRBS are more likely than householdbased surveys to reduce adolescents' concerns about privacy and confidentiality and increase their willingness to report health risk behaviors (Kandel \& Davies, 1991; Morris et al., 1993).

\section{Data Collection Procedures}

\section{Sampling and Weighting}

The source of data for this study is the 2009 State and Local Youth Risk Behavior Survey which uses a two-stage cluster probability sample design to produce representative samples of high school students (DOH, 2011d). Each local sample included public schools in each funded school district (e.g., School District of Palm Beach). In the first sampling stage, a random sample of public high schools was selected for participation in the survey. In the second sampling stage, a random sample of classrooms is selected within each selected school, and all students in those classes were eligible to participate. Some school districts have modified procedures to meet their individual needs. For example, Miami-Dade County Public Schools samples all high schools in their district rather than a sample of schools (CDC, 2004a; MDCPS, 2010).

Responses by survey participants were weighted in order to be representative of public high school students in each county. A response rate of $60 \%$ or greater was considered adequate for data to be weighted and generalizable to each particular school district's high school population. The overall response rate was acquired by multiplying the school response rate (percentage of district high schools sampled that participated in the YRBS) by the student response rate (percentage of students sampled that submitted questionnaires) (CDC, 2010a). Weights applied to each record adjusted for student non- 
response and the distribution of students by grade, sex, and race/ethnicity in each school district (CDC, 2004a).

\section{Survey Administration}

The 2009 state and local version of the YRBS consisted of 87 multiple-choice questions (the 2009 National YRBS had 98 questions) (CDC, 2012f). Data-collection procedures are similar for national, state, and local surveys (CDC, 2004a). All surveys were self-administered and responses were recorded directly on a scannable booklet or paper-and-pencil answer sheet (CDC, 2004a).

\section{Data-Processing Procedures for State and Local Surveys}

Data cleaning and preliminary analysis were performed by Westat, Inc. (Rockville, MD). In a collaborative with the CDC, a system of internal reliability checks, data processing, and data cleaning was completed (CDC, 2004a). The CDC identified a small percentage of students who falsified their answers, and inconsistent, conflicting responses were both set to "missing" and not imputed (Arizona Department of Education, 2004; North Dakota Department of Public Instruction, 2011). For example, if a student responded to one question that she had never had sexual intercourse, but then reported in a subsequent question that she had a sexual partner in the past 30 days, both responses would be set to "missing" since neither response can be assumed to be correct. Individual questionnaires with less than 20 valid responses are deleted from the dataset (CDC, 2004a).

\section{Protection of Human Subjects}

The YRBS protocol is approved by the CDC's Institutional Review Board (CDC, 2010b). Local school district procedures were followed for parental permission of student 
participation before survey administration (BCPS, 2012a; MDCPS, 2010; SDPB, 2012b).

Students were informed that the survey was about health behavior and that participation was both anonymous and voluntarily. The Youth Risk Behavior Survey is a pre-approved data set and did not require approval from Florida International University.

\section{Description of the Sample}

\section{Study Population}

Miami-Dade County Public Schools. The YRBS was conducted in 50 of 50 $(100 \%)$ MDCPS high schools in the spring of 2009. In this year, alternative and charter schools with large student populations also participated. Within each school, students from English classes were randomly selected (English is the only required course in all grades). All classes were selected using a computerized random selection procedure provided by the CDC. Overall, $81 \%$ of students in the sample completed questionnaires, providing a total sample of 2,256 participants (MDCPS, 2010).

Broward County Public Schools. The 2009 YRBS was completed by 1,526 students in 26 public high schools in Broward County Public Schools during the spring of 2009. The school response rate was $93 \%$, the student response rate was $76 \%$, and the overall response rate was $71 \%$. The results are representative of all 9 th through 12 thgraders in Broward County, Florida (BCPS, 2012a).

School District of Palm Beach. The Palm Beach YRBS was completed during the spring of 2009 by 2,087 high school students. Twenty-one of 23 high schools (91\%) participated in the survey (SDPB, 2010). Palm Beach sampled from all second period classes in all high schools (D. Fitzgerald, personal communication, October 9, 2011). The student response rate was $72 \%$, and the overall response rate was $66 \%$ (SDPB, 2010). 


\section{Study Sample}

In this study, secondary analyses were conducted from the combined 2009 YRBS dataset for Miami-Dade, Broward, and Palm Beach school districts. All male and female respondents in 9th through 12th grades were included. A total of 5,869 participants from the total combined public data sets were included in the data analysis. The minimum number of participants required was determined by an a priori power analysis using G*Power 3.1 (Faul, Erdfelder, Lang, \& Buchner, 2007). An effect size $\left(f^{2}\right)$ of 0.72 was calculated using the reported $R^{2}$ of 0.42 from previous research by Jessor and colleagues (1998a). Power analysis revealed that a sample size of at least 35 participants would be required to achieve $95 \%$ power and a two-sided Type I-error of 5\% $(\alpha=.05)$.

\section{Study Design}

In order to answer the research questions in this study, secondary analyses of the combined 2009 YRBS datasets were completed. The secondary analysis approach provides a mechanism for researchers to have access to large datasets and relevant measures, as well as conduct high-impact research with greater speed and less cost than primary data collection methods (Smith et al., 2011). The CDC has provided YRBS data for public use for over 20 years. As discussed earlier in this chapter, the YRBS has been shown to be both reliable and valid (Brener et al., 2002; Brener et al., 2003; Kolbe et al., 1993). Since 2009 datasets were available from each county, the current study was able to identify gender differences in factors related to HIV risk behaviors among adolescents from three South Florida school districts, where HIV is among the highest in the nation.

This study employed a non-experimental, cross-sectional research design with a correlational research component in order to test the research questions derived from the 
conceptual model. The non-experimental design was appropriate because none of the independent variables were manipulated (Cottrell \& McKenzie, 2011). The correlational component of the study examined the extent to which one or more independent variables were related to the outcome variable, HIV risk behavior. In addition, logistic regression analyses determined which variables in the study, when combined together, could best predict HIV risk behavior among South Florida adolescents.

\section{Variables and Measures}

This section defines the demographic, independent, and dependent variables used in the study. Questions from the YRBS study were regrouped and assigned to operationalize the variables of interest in order to reflect the conceptual model. Most conditions were dummy-coded and simplified into dichotomous variables in order to be used in the regression analyses (Drane \& Valois, 2002; Hardy, 1993). Instances where variables were not dummy-coded are noted. Some variables were recoded to provide

consistency with the model and, where necessary, individual variables were combined to create indices. Missing and "not sure" answers were excluded from analyses.

As mentioned in the previous chapter, gender is an important determinant in adolescent research. Previous studies have reported results by gender in order to explicate gender differences in particular risk factors and behaviors (Buzi et al., 2003; Kreiter et al., 1999; Halpern et al., 2004; Schepis et al., 2011; Shrier et al., 1998; Newman \& Zimmerman, 2000; Smith, Steen, Schwendinger, Spaulding-Givens, \& Brooks, 2005; Randolph et al., 2009; Waller et al., 2006; Wu, Rose, \& Bancroft, 2006). Therefore, the present study reported result by gender to illustrate how HIV-related risk 
behaviors, as well as protective factors, risk factors, health risk behaviors, differ by gender.

\section{Demographic Variables}

Although the demographic variables in this study were of interest in themselves (i.e., acquired risks), their primary function was to control for variation in HIV risk behavior. The 2009 YRBS data set provided few demographic variables: age, gender, race, ethnicity, and grade level (Table 3).

Table 3

Demographic Variables

\begin{tabular}{ll}
\hline \multicolumn{1}{c}{ Demographic } & \multicolumn{1}{c}{ Question } \\
\hline Age & How old are you? \\
Grade & In what grade are you? \\
Gender & What is your sex? \\
Ethnicity & Are you Hispanic or Latino? \\
Race & What is your race? \\
\hline
\end{tabular}

Age. Age was calculated using the subjects self-reported years of life at the time the survey was conducted and was recoded from a categorical variable (e.g., $1=\leq 12$ years; $2=13$ years; etc. $)$ into a scale variable $(13=13$ years $)$. Ages ranged from 12 years or younger ( $\leq 12$ years) to 18 years or older ( $\geq 18$ years).

Gender. Gender was a self-reported measure of either male or female.

Grade level. Grade level was also a self-reported measure of the current grade level during the academic year in which the questionnaire was completed. The grade levels were defined as 9th, 10th, 11th, or 12th grades. 
Location of school district. Since the datasets for each school district were collected separately, a variable for location of school district was created. School districts were defined as Miami-Dade, Broward, or Palm Beach.

Race/ethnicity. Race and ethnicity were computed from two questions: "Are you Hispanic or Latino?" and "What is your race?" (CDC, 2010a). Race/ethnicity was recoded as White, Black, Hispanic, and Others. Hispanics were defined as any students who identified themselves as Hispanic or Latino, regardless of race. Blacks included those who identified as Black or African American. Due to small sample sizes in the remaining subgroup categories, the "Other" category was created to include participants who identified as multiple-race non-Hispanics, Asians, American Indians/Alaska Natives, and Native Hawaiians/Pacific Islanders (Hlaing et al., 2007; Niyonsenga et al., 2008).

\section{Independent Variables}

Protective factors. The 2009 YRBS data set contained questions that corresponded to three protective factor variables in the conceptual framework for this study: sex education exposure, school involvement, and safe schools (Table 4). Detailed descriptions of measurement for each protective factor are addressed below.

Safe schools. Student perception of safe schools was assessed by developing a safe school index. The index was developed by adding the number responses questions to three questions about students' perceptions of safety at school: threatened or injured by someone at school, bullied by someone at school, and missed school due to unsafe feelings. A school was considered safe if a student answered "No" to any of the above questions. Possible scores ranged from zero to three. A score of zero indicated no safe conditions at school, while scores of one through three indicated safe school conditions. 
The internal consistency for this scale yielded a low Cronbach's alpha $(\alpha=.50)$, however, it is common to find low Cronbach values with short scales (e.g., scales with fewer than ten items) (Tavakol \& Dennick, 2011; Bernardi, 1994; Sijtsma, 2009). Since the safe school index had only three items, the mean inter-item correlation reported (.26) and found to be within the optimal range of .2 to .4 , as recommended by Briggs and Cheek (1986).

Table 4

Protective Factor Questions

\begin{tabular}{ll}
\hline Protective Factor & \\
\hline Sports teams & During the past 12 months, on how many sports teams did you play? \\
Sex education & Have you ever been taught about AIDS or HIV infection in school? \\
Felt unsafe & $\begin{array}{l}\text { During the past } 30 \text { days, on how many days did you not go to school because you } \\
\text { felt you would be unsafe at school or on your way to or from school? }\end{array}$ \\
Threatened/injured & $\begin{array}{l}\text { During the past } 12 \text { months, how many times has someone threatened or injured } \\
\text { you with a weapon such as a gun, knife, or club on school property? }\end{array}$ \\
Bullied & During the past 12 months, have you ever been bullied on school property? \\
\hline
\end{tabular}

School involvement. Memberships on sports teams were used as proxy measure for school involvement. Possible scores ranged from zero to three sports teams. A score of zero indicated no participation on a sports team in the past 12 months, while scores of one through three indicated number of sports team memberships.

Sex education. Exposure to sex education was measured by using a question about HIV/AIDS instruction at school. Receipt of sex education was defined as ever being taught about AIDS or HIV infection in school.

A protective factor index (PFI) (Jessor et al., 1995) was developed by adding the number of positive responses questions related to school involvement, safe schools, and sex education exposure. The internal consistency for this five-item scale was less than 
satisfactory as a reliability analyses yielded a low Cronbach's alpha $(\alpha=.26)$, and the mean inter-item correlation (.10) was also found to be outside the optimal range (Briggs \& Cheek, 1986). Since the PFI did not yield a reliable internal consistency, safe schools, sex education, and school involvement were analyzed separately.

Risk factors. The five risk factors variables that were explored in this study were depressive symptoms, histories of sexual abuse and dating violence, models for health risk behaviors, and opportunity to participate in risk behaviors (Table 5).

Table 5

\section{Risk Factor Questions}

\begin{tabular}{|c|c|}
\hline Risk Factor & Question \\
\hline Hopelessness & $\begin{array}{l}\text { During the past } 12 \text { months, did you ever feel so sad or hopeless almost every day } \\
\text { for two weeks or more in a row that you stopped doing some usual activities? }\end{array}$ \\
\hline Suicidal ideation & During the past 12 months, did you ever seriously consider attempting suicide? \\
\hline Suicide plan & $\begin{array}{l}\text { During the past } 12 \text { months, did you make a plan about how you would attempt } \\
\text { suicide? }\end{array}$ \\
\hline Suicide attempt & During the past 12 months, how many times did you actually attempt suicide? \\
\hline Dating violence & $\begin{array}{l}\text { During the past } 12 \text { months, did your boyfriend or girlfriend ever hit, slap, or } \\
\text { physically hurt you on purpose? }\end{array}$ \\
\hline Sexual abuse & $\begin{array}{l}\text { Have you ever been physically forced to have sexual intercourse when you did } \\
\text { not want to? }\end{array}$ \\
\hline Rode with drunk & $\begin{array}{l}\text { During the past } 30 \text { days, how many times did you ride in a car or other vehicle } \\
\text { driven by someone who had been drinking alcohol? }\end{array}$ \\
\hline Offered cigarettes & During the past 30 days, how did you usually get your own cigarettes? \\
\hline Offered alcohol & During the past 30 days, how did you usually get the alcohol you drank? \\
\hline Offered drugs & $\begin{array}{l}\text { During the past } 12 \text { months, has anyone offered, sold, or given you an illegal drug } \\
\text { on school property? }\end{array}$ \\
\hline
\end{tabular}

Depressive symptoms. Depressive symptomology was assessed by developing a depression index. The index used four questions about students' feelings of hopelessness, suicidal ideation, suicide plan, and suicide attempts. Suicide attempts were dichotomized into categories using yes/no responses (e.g., no suicide attempts/one or more suicide attempts). A summative index added all of the instances of depressive symptoms. 
Possible scores ranged from zero to four. Reliability analyses yielded an acceptable Cronbach's alpha $(\alpha=0.74)$.

Dating violence. To evaluate dating violence, students were asked if they had been hit, slapped, or physically hurt by a boyfriend or girlfriend. Dating violence was defined as ever being hit on purpose by a boyfriend or girlfriend in the past 12 months.

Sexual abuse. Sexual abuse was assessed by a question regarding forced sex. Sexual abuse was defined as ever being physically forced to have sexual intercourse.

Models for risk behavior. Models for health risk behavior was assessed by selfreport of students who rode in a vehicle with someone who had been drinking alcohol (Marshall \& Werb, 2010).

Opportunity to participate in risk behaviors. Opportunities to participate in health risk behaviors were measured using questions that addressed being offered, sold or given cigarettes, alcohol, or illicit drugs. Opportunities for risk behavior was defined as obtaining cigarettes, alcohol, or illicit drugs from someone in the past 30 days and was recoded into dichotomous categories using yes/no responses (e.g., no cigarettes/got cigarettes from someone, no alcohol/got alcohol from someone, and no drugs/got drugs from someone). The mean inter-item correlation (.30) was found to be within the optimal range.

A risk factor index (RFI) was developed by adding the responses to depressive symptoms, dating violence, sexual abuse, models for risk behavior, and opportunity to participate in risk behavior. Possible scores ranged from zero to ten, with higher scores indicating a greater the number of risk factors. Internal consistency for RFI was satisfactory, with reliability analyses yielding a Cronbach's alpha of .71. 
Health risk behaviors. The YRBS data set contained several questions about individuals risk behaviors that fit the current study's conceptual model. Students were asked 19 questions regarding sexual risk behaviors, violence-related behaviors (Table 6), and the use of tobacco, alcohol, and illicit drugs (Table 7).

Table 6

Health Risk Behavior Questions: Sexual Risk and Violence-Related Behaviors

\begin{tabular}{ll}
\hline \multicolumn{1}{c}{ Health Risk Behavior } & \multicolumn{1}{c}{ Question } \\
\hline Age at first sexual intercourse & How old were you when you had sexual intercourse for the first time? \\
Recent sexual activity & $\begin{array}{l}\text { During the past 3 months, with how many people did you have sexual } \\
\text { intercourse? }\end{array}$ \\
Weapon carrying & $\begin{array}{l}\text { During the past 30 days, on how many days did you carry a weapon such } \\
\text { as a gun, knife, or club? } \\
\text { During the past 12 months, how many times were you in a physical } \\
\text { fight? }\end{array}$ \\
\hline
\end{tabular}

Sexual risk behaviors. Sexual risk behaviors were defined by assessing early age at initial sexual experience and recent sexual activity. Early age at first sexual intercourse was defined as students who indicated they had first sexual intercourse before 13 years of age. Recent sexual activity was defined as having at least one sexual partner in the past three months (CDC, 2010a). Early age at initial sexual experience and recent sexual activity were recoded into dichotomous categories using yes/no responses (e.g. no sex before 13 years of age/having sex $<13$ years of age; no recent sexual partners/one or more recent sexual partners).

Violent behaviors. Violent behaviors were measured using questions about physical fighting and weapon carrying. Violent behavior was defined by reports of involvement in at least one fight in the past year or one more days of weapon carrying in the past month. 
Table 7

Health Risk Behavior Questions: Tobacco, Alcohol, and Illicit Drug Use

\begin{tabular}{|c|c|}
\hline Health Risk Behavior & Question \\
\hline Cigarettes & During the past 30 days, on how many days did you smoke cigarettes? \\
\hline Cigars & $\begin{array}{l}\text { During the past } 30 \text { days, on how many days did you smoke cigars, cigarillos, or } \\
\text { little cigars? }\end{array}$ \\
\hline Other tobacco & $\begin{array}{l}\text { During the past } 30 \text { days, on how many days did you use chewing tobacco, snuff, } \\
\text { or dip, such as Redman, Levi Garrett, Beechnut, Skoal, Skoal Bandits, or } \\
\text { Copenhagen? }\end{array}$ \\
\hline Alcohol & $\begin{array}{l}\text { During the past } 30 \text { days, on how many days did you have at least one drink of } \\
\text { alcohol? }\end{array}$ \\
\hline Binge drink & $\begin{array}{l}\text { During the past } 30 \text { days, on how many days did you have } 5 \text { drinks or more of } \\
\text { alcohol in a row, that is, within a couple of hours? }\end{array}$ \\
\hline Drink/drive & $\begin{array}{l}\text { During the past } 30 \text { days, how many times did you drive a car or other vehicle } \\
\text { when you had been drinking alcohol? }\end{array}$ \\
\hline Marijuana & During your life, how many times have you used marijuana? \\
\hline Recent marijuana & During the past 30 days, how many times did you use marijuana? \\
\hline Cocaine & $\begin{array}{l}\text { During your life, how many times have you used any form of cocaine, including } \\
\text { powder, crack, or freebase? }\end{array}$ \\
\hline Recent cocaine & $\begin{array}{l}\text { During the past } 30 \text { days, how many times did you use any form of cocaine, } \\
\text { including powder, crack, or freebase? }\end{array}$ \\
\hline Inhalants & $\begin{array}{l}\text { During your life, how many times have you sniffed glue, breathed the contents of } \\
\text { aerosol spray cans, or inhaled any paints or sprays to get high? }\end{array}$ \\
\hline Heroin use & $\begin{array}{l}\text { During your life, how many times have you used heroin (also called smack, junk, } \\
\text { or China White)? }\end{array}$ \\
\hline Methamphetamines & $\begin{array}{l}\text { During your life, how many times have you used methamphetamines (also called } \\
\text { speed, crystal, crank, or ice)? }\end{array}$ \\
\hline Ecstasy & During your life, how many times have you used ecstasy (also called MDMA)? \\
\hline Steroids & $\begin{array}{l}\text { During your life, how many times have you taken steroid pills or shots without a } \\
\text { doctor's prescription? }\end{array}$ \\
\hline
\end{tabular}

Recent tobacco use. Three items were used to evaluate recent tobacco use:

smoking cigarettes, smoking cigars, and using other tobacco products. Any student who indicated one or more days of use of any of these items during the last 30 days were considered recent tobacco users.

Recent alcohol use. To evaluate recent alcohol behaviors, students were asked on how many days did they drink alcohol or binge drank, and on how many times did they drive a vehicle when they had been drinking in the past 30 days. Responses that indicated one or more days/times during the last 30 days were considered recent alcohol users. 
Alcohol use items were recoded into dichotomous categories using yes/no responses (e.g. zero days/one or more days and zero times/one or more times).

Illicit drug use. Illicit drug use was assessed using nine questions about students' use or nonuse of seven different types of illicit drugs: marijuana, cocaine, inhalants, heroin, ecstasy, methamphetamines, and steroids without a prescription (Table 7). Questions were asked about both lifetime and recent drug use (past 30 days). Drug users were defined as students who reported the use of any of the abovementioned drugs one or more times (Niyonsenga et al., 2008). Illicit drug use items were recoded into dichotomous categories using yes/no responses (e.g. zero times/one or more times).

Since adolescent problem behaviors tend to co-vary, in what Jessor and others call a "problem behavior syndrome" (DiClemente et al., 2008; Donovan \& Jessor, 1985; Donovan et al., 1988; Jessor, 1991; Jessor \& Jessor, 1977), an overall health risk behavior index (HRBI) was created to examine the level of risk-taking behaviors of the participants. The score was developed by adding the responses to sexual risk behaviors, tobacco use, alcohol use, illicit drug use, violent behaviors. Possible scores ranged from zero to 19. Higher scores indicated a greater level of participation in health risk behaviors, whereas lower scores indicated a lower level of health risk behavior. Reliability analysis yielded an optimal Cronbach's alpha $(\alpha=.85)$ for the 19-item scale.

Comprehensive sex education policy implementation. The YRBS included an item asking participants about whether they had received HIV/AIDS instruction in school, however, there was no indication of the characteristics of the type of instruction they received. Although Miami-Dade, Broward, and Palm Beach school districts have all adopted more comprehensive sex education policies (SIECUS 2010b), data from Profiles 
2008 indicated that programs were employed differently in each school district (Brener et al., 2009). For the purpose of this study, sex education policy implementation was measured by length of time and course in which sex education was taught.

Length of policy implementation. Both Broward and Palm Beach counties implemented revised sex education policies after 2007. Since length of exposure to new policies may affect the impact of sex education on HIV risk behavior, a variable was created for length of time that the sex education policy had been in place. A dichotomous variable was created, coding Broward and Palm Beach districts for two years or less $(\leq 2$ years) and Miami-Dade for more than two years (3 or more years).

Sex education course. Sex education has been taught in a number of different courses (Clark \& Yarber, 1993; Denson et al., 1993). In Miami-Dade and Broward high schools, sex education is taught in health education courses, whereas, in Palm Beach, sex education is taught in science courses. A dichotomous variable was created for sex education course, coding for either health education or science.

\section{Dependent Variables}

Four measures identified from the 2009 YRBS were used to assess HIV risk behaviors in adolescents: unprotected sex, multiple sexual partners, substance abuse at last sex, and injection drug use (Table 8).

Unprotected sex. Unprotected sex was defined as students who reported condom nonuse at last sexual intercourse. Unprotected sex was recoded into dichotomous categories using yes/no responses (e.g. never had sex or used a condom/did not use a condom). 
Table 8

HIV Risk Behavior Questions

\begin{tabular}{ll}
\hline \multicolumn{1}{c}{ HIV Risk Behavior } & \multicolumn{1}{c}{ Question } \\
\hline Sexual partners & During your life, with how many people have you had sexual intercourse? \\
Unprotected sex & $\begin{array}{l}\text { The last time you had sexual intercourse, did you or your partner use a } \\
\text { condom? }\end{array}$ \\
Sex under influence & $\begin{array}{l}\text { Did you drink alcohol or use drugs before you had sexual intercourse the } \\
\text { last time? }\end{array}$ \\
Injection drug use & $\begin{array}{l}\text { During your life, how many times have you used a needle to inject any } \\
\text { illegal drug into your body? }\end{array}$ \\
\hline
\end{tabular}

Multiple sexual partners. To assess multiple sexual partners, a scale for lifetime sexual partners was created, with scores from ranging from zero (no partners) to six ( $\geq 6$ partners). Having multiple sexual partners was defined as having four or more sexual partners. The scale was recoded to a dichotomous category using yes/no responses (e.g., 0-3 sexual partners/ $\geq 4$ sexual partners).

Sex under influence of drugs/alcohol. Substance abuse at last sexual intercourse was defined as student's self-report of using alcohol or drugs at last sexual intercourse.

Injection drug use. An injection drug user was defined as any student who reported using a needle to inject any illegal drug into their body at any time during their life. Injection drug use was recoded into dichotomous categories using yes/no responses (e.g. zero times/one or more times).

A summative HIV risk behavior index was developed by adding the responses to unprotected sex, multiple sex partners, substance use at last intercourse, and injection drug use. Scores ranged from zero to four. Higher scores indicated a greater level of participation in HIV risk behaviors, whereas lower scores indicated lower levels of participation. The mean inter-item correlation (.26) was found to be in the optimal range for this four-item index. 
A composite dependent variable of "at least one HIV-risk behavior" was created for consistency with analyses in the study (Niyonsenga et al., 2008). Scores of zero on the index remained zero on the composite variable, indicating "no HIV risk." Participants who answered yes to any of the four HIV risk behavior questions (scores 1 to 4 ) were coded as one, which indicated participation in "at least one HIV risk behavior."

\section{Analytical Methods}

A series of statistical analyses were conducted to answer the research questions for this study. The statistical software SPSS 18 (SPSS, Inc.) was used for data management and analysis.

\section{Descriptive Analyses}

Preliminary analyses examined of frequency distributions for demographic variables, protective factors, risk factors, health risk behaviors, and characteristics of comprehensive sex education policy implementation, and were stratified by gender. Pearson Chi-square $\left(\chi^{2}\right)$ tests analyzed differences between males and females. Independent samples $t$ tests were conducted to determine whether significant differences existed in mean number of protective factors, risk factors, and health risk behaviors between genders.

Frequencies were calculated for individual HIV risk behavior items and were presented by age, gender, grade, race/ethnicity, and location of school district. Gender differences in HIV risk behaviors were calculated using Pearson Chi-square $\left(\chi^{2}\right)$ tests of independence. 


\section{Correlational Analyses}

Correlation analyses tested the hypotheses pertaining to the separate effects of protective factors, risk factors, and health risk behaviors (independent variables) on each HIV risk behavior (dependent variables) and HIV risk behavior index. Bivariate analyses were conducted among all independent variables (IVs) and each dependent variable (DV) and the HIV risk index. An alpha level of $p<.05$ was set for each hypothesis.

Phi coefficients $(\varphi)$ were used to compute the bivariate correlations between two dichotomous variables. Pearson correlation tests were conducted to calculate bivariate coefficients (Pearson's $r$ ) between dichotomous and continuous variables. Correlation coefficients $(-1$ to +1$)$ provided information regarding the strength and direction of the relationship between two variables. Relationships were considered weak if Pearson's $r$

was found to be less than .40 . Correlations ranging between .40 and .70 were considered moderate while correlations over .70 were considered to be strong relationships. All analyses were stratified by gender.

\section{Predictive Analyses}

Binary logistic regression analyses were conducted to examine predictors of students' participation in HIV risk behavior while controlling for grade level, race/ethnicity, and location of school district. Logistic regressions were used rather than linear regressions since the dependent variable (HIV risk) was a dichotomous variable with two values (no HIV risk behavior/at least one HIV risk behavior). Each analysis included the corresponding independent variable in the first block, demographic variables (e.g., grade level, race/ethnicity, and location of school district) in the second block, and interaction terms, if any, in the third block. All odds ratios presented were mutually 
adjusted for the other correlates. Wald $\chi^{2}$ statistics for significance testing of parameter estimates for adjusted odds ratios were also computed. All analyses were stratified by gender. To evaluate independent variables for multicollinearity, collinearity statistics were performed on the independent variables prior to the logistic regressions.

The first set of analyses consisted of three separate binary logistic regressions to examine whether each protective factor variable (sex education, safe schools, and school involvement) predicted HIV risk. The second set of analyses consisted of logistic regressions to examine whether the risk factor index (RFI) predicted participation in at least one HIV risk behavior, one for each gender. A third set of analyses examined whether the health risk behavior index (HRBI) predicted HIV risk.

Previous research (Jessor et al., 1995) suggests that protective factors may moderate the relationship between risk factors and risk-taking behavior. To examine this possibility in the present study, a logistic regression was conducted to examine the interaction effects of the independent variables. The demonstration of a moderator effect for protection from participation in HIV risk behavior required the demonstration of a significant interaction between each protective factor and the risk factors index (RFI) and the health risk behavior index (HRBI). The interaction terms were added as a final step in the respective regression models.

Predictive analyses also tested hypotheses the ability of comprehensive sex education policy variables to predict participation in HIV risk behavior. Since these variables were of interest in respect to the sex education received, analyses were restricted to students who reported receipt of HIV/AIDS education in school. Also, grade level was restricted to 9th and 10th grades since Palm Beach only offers sex education to 
9 th and 10th graders. Two sets of analyses were used. The first logistic regression determined whether length of policy implementation time (in years) predicted HIV risk. The second logistic regression included the course of instruction variable (health education vs. science).

In order to test for the influence of gender in the predictors of HIV risk, protective factors, risk factors (RFI), and health risk behaviors (HRBI) were entered into two separate logistic regressions as predictors of participation in HIV risk behavior, while controlling for demographic variables. Any significant interaction variables were added to the final block of the regression equations.

Lastly, to investigate initial findings that indicated significant effects in the full model, post-hoc analyses were also performed.

\section{Assumptions}

A number of assumptions have provided a foundation for the empirical analyses in the current study:

1. Participants in study had the ability to read and comprehend the questions.

2. Participants in the study responded honestly and accurately to the questionnaire.

3. The 2009 State and Local Youth Risk Behavior Survey data accurately reflect current trends in youth risk behavior in South Florida.

4. The 2009 Youth Risk Behavior Survey is a valid and reliable measure of youth risk behavior.

5. Data from the 2008 School Profiles report is a reliable measure of HIV, STD, and pregnancy prevention content in the high schools. 


\section{Delimitations}

The study was delimited by the following:

1. All school districts in the study had comprehensive sex education policies.

2. The study was limited to students in 9 th through 12 th grades enrolled in public high schools in Miami-Dade, Broward, and Palm Beach school districts.

3. The sample was delimited to students attending public high schools that participated in the 2009 Youth Risk Behavior Survey.

4. Surveys were eliminated if students did not complete questions regarding age, gender, race, and ethnicity.

\section{Limitations}

The study was limited by the following factors:

1. The study was limited to students attending school on the day the survey was distributed and collected.

2. The study was limited to students who had parental permission to participate in the study.

3. Self-report data may reflect reporting bias and social desirability bias.

4. As a cross-sectional study, causality could not be determined.

5. Secondary data were dependent on the accuracy in of survey administration by school districts and data collection methodology by the CDC.

6. The survey instrument did not provide a definition of "sexual intercourse" for participants and the interpretation of such term may result in different meanings for individuals. 
7. This version of the survey instrument did not include questions on sexual identity and gender of sexual partners.

8. Generalizations of the results are limited to students in South Florida public high schools.

\section{Summary}

A cross-sectional, non-experimental design was used in this study. Data were collected from public high schools in three South Florida school districts. Participants were 5,869 high school students 9th through 12th grades. The derived model, developed from the Problem Behavior Theory and the Theory of Gender and Power, organized the categories of independent variables in this study into protective factors, risk factors, and health risk behaviors. The main outcome variables in this study were HIV risk behaviors.

A subset of questions from 2009 State and Local YRBS was used to measure the variables in the study. The YRBS is one of the surveys developed by the CDC to monitor six categories of adolescent risk behaviors, including sexual behaviors that contribute to unintended pregnancy and sexually transmitted infections, including HIV. Hypotheses were tested using a series of statistical tests including correlational analyses and binary logistic regressions. Chapter 4 presents the findings of this study. 


\section{CHAPTER IV}

\section{RESULTS}

The purpose of this study was to examine gender differences in the influence of risk factors, protective factors, and health risk behaviors on the HIV-related risk behavior of adolescents in South Florida. The current study also explored how the implementation of comprehensive sex education policy affects HIV risk behavior. This chapter presents the results of the secondary analyses developed from the 2009 State and Local YRBS from three South Florida school districts.

\section{Description of the Sample}

The combined data set contained responses from 5,869 participants in MiamiDade, Broward, and Palm Beach school districts. Inclusion criteria for the study consisted of individuals in grades 9 through 12 only. Among these participants, students who identified themselves as being in an "ungraded or other grade" or were missing grade level, gender, age, or race/ethnicity information were excluded $(n=156)$. The total sample size was 5,713. Missing data were excluded and resulted in different sample sizes during testing of the models.

The majority of participants identified themselves as Black or Hispanic (69\%) and female $(51.3 \%)$. The average age was 16.1 years old (standard deviation $[S D]=1.23)$ (Table 9). The mean age at survey administration was $16.1(S D=1.21)$ for males and $16.0(S D=1.23)$ for females. An independent samples $t$ test did not reveal a significant difference in mean age between genders, $t(5711)=-1.78, p=.88$. 


\section{Table 9}

Demographic Characteristics of Survey Participants by Gender $(n=5,713)^{\mathrm{a}}$

\begin{tabular}{|c|c|c|c|c|}
\hline Demographic & $\begin{array}{c}\text { Females } \\
(n=2,933)\end{array}$ & $\begin{array}{c}\text { Males } \\
(n=2,780)\end{array}$ & $\chi^{2}$ & $p$ \\
\hline Age (years) & & & $11.18^{\mathrm{b}}$ & .08 \\
\hline$\leq 12$ & $10(0.3)$ & $5(0.2)$ & & \\
\hline 13 & $3(0.1)$ & $4(0.1)$ & & \\
\hline 14 & $287(9.9)$ & $217(7.8)$ & & \\
\hline 15 & $757(25.8)$ & 748 (26.9) & & \\
\hline 16 & 787 (26.8) & $751(27.0)$ & & \\
\hline 17 & $680(23.2)$ & $625(22.5)$ & & \\
\hline$\geq 18$ & 409 (13.9) & $430(15.5)$ & & \\
\hline Mean $( \pm S D)$ & $16.04( \pm 1.23)$ & $16.1( \pm 1.21)$ & 1.78 & .88 \\
\hline Race/Ethnicity & & & $2.95^{\mathrm{c}}$ & .40 \\
\hline Black & $756(25.8)$ & $666(24.0)$ & & \\
\hline Hispanic & $1280(43.6)$ & $1241(44.6)$ & & \\
\hline White & $714(24.2)$ & $684(24.6)$ & & \\
\hline Other & $182(6.2)$ & $189(6.8)$ & & \\
\hline Grade & & & $4.53^{\mathrm{d}}$ & .21 \\
\hline 9 & $829(28.3)$ & $844(30.4)$ & & \\
\hline 10 & 848 (28.9) & $817(29.4)$ & & \\
\hline 11 & $648(22.1)$ & $580(20.9)$ & & \\
\hline 12 & $608(20.7)$ & $539(19.4)$ & & \\
\hline School District & & & $.91^{\mathrm{c}}$ & .64 \\
\hline Broward & $770(26.3)$ & $702(25.3)$ & & \\
\hline Miami-Dade & $1115(38.0)$ & $1084(39.0)$ & & \\
\hline Palm Beach & $1048(35.7)$ & $994(35.8)$ & & \\
\hline
\end{tabular}

${ }^{a}$ All data are given as the number (percentage) of students unless otherwise specified.

${ }^{b}$ Degrees of freedom or $\mathrm{df}=6 ;{ }^{\mathrm{c}} \mathrm{df}=2 ;{ }^{\mathrm{d}} \mathrm{df}=3$

* $\mathrm{p}<.05$ (2-tailed)

Hispanic adolescents accounted for the highest percentage of the sample, while

Black and White students comprised the second and third largest groups. Most participants were in the 9th and 10th grades (58.4\%) and attended schools in either Miami-Dade (38.5\%) or Palm Beach (35.7\%). Pearson chi-square $\left(\chi^{2}\right)$ tests of 
independence revealed no significant differences in age group, race/ethnicity, grade level, or school district between genders.

\section{Descriptive Statistics}

Descriptive analyses were conducted to examine the occurrence of HIV risk behaviors as well as protective factors, risk factors, health risk behaviors, and among adolescents. Gender differences were calculated using Pearson chi-square $\left(\chi^{2}\right)$ tests of independence.

\section{HIV Risk Behaviors}

Items from the HIV risk behavior index were derived from the conceptual model and included unprotected sex, multiple lifetime partners, sex under the influence of drugs or alcohol, and lifetime injection drug use (Table 10). Significant gender differences were found for all HIV risk behaviors. Females (15.4\%) were more likely than males (12.2\%) to report unprotected sex (condom nonuse) at last sexual intercourse, $\chi^{2}(1, N=4,571)=$ $19.54, p=.002$.

Multiple sexual partners were defined as having four or more sexual partners in a lifetime. Twice as many males $(21.2 \%)$ than females $(11.3 \%)$ reported having four or more sexual partners their lifetime, $\chi^{2}(1, N=4,599)=83.59, p<.001$. The average number of sexual partners was $3.25(S D=2.00)$ for males and $2.55(S D=1.72)$ for females. An independent samples $t$ test revealed a significant gender difference in mean number of lifetime sexual partners, $t(2697.2)=-9.86, p<.001$.

Overall, reports of sex under the influence of drugs or alcohol at last sexual intercourse and lifetime injection drug use were low. Approximately $10.0 \%$ of male students and $6.5 \%$ of female students reported having sex under the influence, $\chi^{2}(1, N$ 
$=4,609)=17.70, p<.001$. Almost twice as many males $(2.5 \%)$ as females $(1.3 \%)$

reported using a needle at least once to inject any illegal drug into their body, $\chi^{2}(1, N=$ $3,468)=6.66, p=.01$.

Table 10

Descriptive Characteristics of HIV Risk Behaviors by Gender $(n=5,713)^{a}$

\begin{tabular}{|c|c|c|c|c|}
\hline HIV Risk Behavior & $\begin{array}{l}\text { Females } \\
(\mathrm{n}=2,933)\end{array}$ & $\begin{array}{c}\text { Males } \\
(\mathrm{n}=2,780)\end{array}$ & $\chi^{2}$ & $p$ \\
\hline Unprotected sex & $375(15.4)$ & $262(12.2)$ & $9.54^{\mathrm{b}}$ & $.002^{* *}$ \\
\hline \multicolumn{5}{|l|}{ No. of lifetime sexual partners } \\
\hline 1 & $505(39.3)$ & $412(29.0)$ & $113.12^{c}$ & $<.001^{* * *}$ \\
\hline 2 & $275(21.4)$ & 243(17.1) & & \\
\hline 3 & $176(13.7)$ & $184(12.9)$ & & \\
\hline 4 & $105(8.2)$ & $132(9.3)$ & & \\
\hline 5 & $73(5.7)$ & $64(4.5)$ & & \\
\hline$\geq 6$ & $150(11.7)$ & $387(27.2)$ & & \\
\hline Mean $( \pm S D)$ & $2.55( \pm 1.72)$ & $3.25( \pm 2.00)$ & -9.86 & $<.001^{* * *}$ \\
\hline$\geq 4$ sexual partners & $275(11.3)$ & $457(21.2)$ & $83.59^{\mathrm{b}}$ & $<.001^{* * *}$ \\
\hline $\begin{array}{l}\text { Sex under the influence } \\
\text { of drugs/alcohol }\end{array}$ & $159(6.5)$ & $214(9.9)$ & $17.70^{\mathrm{b}}$ & $<.001^{* * *}$ \\
\hline Lifetime injection drug use & $23(1.3)$ & $41(2.5)$ & $6.66^{\mathrm{b}}$ & $.01^{*}$ \\
\hline
\end{tabular}

The average number of HIV risk behaviors $.52(S D=0.86)$ for males and $.39(S D$ $=0.76$ ) for females, and an independent $t$ test found a significant gender difference, $t$ $(3792)=-4.87, p<.001$. Males $(33.8 \%)$ were more likely than females $(26.1 \%)$ to report at least one HIV risk behavior (Table 11). 
Table 11

Number of HIV Risk Behaviors by Gender $(n=5,713)^{a}$

\begin{tabular}{|c|c|c|c|c|}
\hline No. of HIV risk behaviors & $\begin{array}{c}\text { Females } \\
(\mathrm{n}=2,933)\end{array}$ & $\begin{array}{c}\text { Males } \\
(\mathrm{n}=2,780)\end{array}$ & $\chi^{2}$ & $p$ \\
\hline 0 & $1456(73.9)$ & $1207(66.2)$ & & \\
\hline 1 & $329(16.7)$ & $387(21.2)$ & & \\
\hline 2 & $140(7.1)$ & $159(8.7)$ & & \\
\hline 3 & $28(1.4)$ & $44(2.4)$ & & \\
\hline 4 & $18(0.9)$ & $26(1.4)$ & & \\
\hline Mean $( \pm \mathrm{SD})$ & $0.39( \pm 0.76)$ & $0.52( \pm 0.86)$ & -4.87 & $<.001^{* * *}$ \\
\hline At least one HIV risk behavior & & & 22.22 & $<.001^{* * *}$ \\
\hline No & $1456(73.9)$ & $1207(66.2)$ & & \\
\hline Yes & $515(26.1)$ & $616(33.8)$ & & \\
\hline
\end{tabular}

Separate analyses explored differences in each HIV risk behavior by age, race/ethnicity, grade level, and school district for females (Table 12) and males (Table 13). For cells with an expected count less than five, Monte Carlo exact tests were performed to calculate the exact $p$ value statistic.

HIV risk behaviors by age. The percentage of participants having unprotected sex increased with age. The average age of reported unprotected sex among females was $16.5(S D=1.2)($ Table 12$)$ and $16.4(S D=1.3)$ among males (Table 13). Independent $t$ tests revealed a significant differences in mean age for females, $t(2760)=-8.92, p<.001$, and males, $t(442.1)=-5.06, p<.001$, who engaged in unprotected sex. 
Table 12

HIV Risk Behaviors for Females by Demographics Characteristics $(n=2,762)^{a}$

\begin{tabular}{|c|c|c|c|c|}
\hline \multirow[b]{2}{*}{ Demographic } & \multicolumn{4}{|c|}{ HIV Risk Behavior } \\
\hline & $\begin{array}{l}\text { Unprotected } \\
\text { sex }\end{array}$ & $\begin{array}{c}4+\text { sexual } \\
\text { partners }\end{array}$ & $\begin{array}{c}\text { Sex under } \\
\text { the influence }\end{array}$ & $\begin{array}{l}\text { Injection } \\
\text { drug use }\end{array}$ \\
\hline \multicolumn{5}{|l|}{ Age (in years) ${ }^{b}$} \\
\hline$\leq 12$ & $6(1.4)$ & $7(2.1)$ & $5(2.5)$ & $5(10.9)$ \\
\hline 13 & $1(0.2)$ & -- & -- & -- \\
\hline 14 & $13(3.0)$ & $7(2.1)$ & $9(4.0)$ & $2(4.3)$ \\
\hline 15 & $70(15.9)$ & $41(12.5)$ & $37(18.6)$ & $9(19.6)$ \\
\hline 16 & $105(23.9)$ & $79(24.1)$ & $44(22.1)$ & $7(15.2)$ \\
\hline 17 & $148(33.6)$ & $112(34.1)$ & $60(30.2)$ & $15(32.6)$ \\
\hline$\geq 18$ & $97(22.0)$ & $82(25.0)$ & $45(22.6)$ & $8(17.4)$ \\
\hline Mean $( \pm S D)$ & $16.5( \pm 1.2)^{* * *}$ & $16.6( \pm 1.25)^{* * *}$ & $16.4( \pm 1.35)^{* * *}$ & $15.96( \pm 1.79)$ \\
\hline \multicolumn{5}{|l|}{ Race/Ethnicity ${ }^{\mathrm{c}}$} \\
\hline Black & $106(24.1)$ & $94(28.7)$ & $35(17.6)$ & $10(21.7)$ \\
\hline Hispanic & $206(46.8)$ & $123(37.5)$ & $79(39.7)$ & $18(39.1)$ \\
\hline White & $108(24.5)$ & $89(27.1)$ & $65(32.7)$ & $10(21.7)$ \\
\hline Other & $20(4.5)$ & $22(6.7)$ & $20(10.1)$ & $8(17.4)$ \\
\hline$\chi^{2}, p$ & $3.95, .27$ & $5.89, .12$ & $15.84, .001^{* *}$ & $11.85, .01^{*}$ \\
\hline \multicolumn{5}{|l|}{ Grade $^{c}$} \\
\hline 9 & $70(15.9)$ & $45(13.7)$ & $41(20.6)$ & $16(34.8)$ \\
\hline 10 & $106(24.1)$ & $75(22.9)$ & 43 (21.6) & $7(15.2)$ \\
\hline 11 & $131(29.8)$ & $112(34.1)$ & $50(25.1)$ & $12(26.1)$ \\
\hline 12 & $133(30.2)$ & $96(29.3)$ & $65(32.7)$ & $11(23.9)$ \\
\hline$\chi^{2}, p$ & $69.84,<.001^{* * *}$ & $67.90,<.001^{* * *}$ & $24.25,<.001^{* * *}$ & $4.54, .21$ \\
\hline \multicolumn{5}{|l|}{ School District $^{\mathrm{d}}$} \\
\hline Broward & $108(24.5)$ & $112(34.1)$ & $77(38.7)$ & $18(39.1)$ \\
\hline Miami-Dade & $174(39.5)$ & $94(28.7)$ & $47(23.6)$ & $10(21.7)$ \\
\hline Palm Beach & $158(35.9)$ & $122(37.2)$ & $75(37.7)$ & $18(39.1)$ \\
\hline$\chi^{2}, p$ & $.94, .63$ & $17.24,<.001^{* * *}$ & $23.97,<.001^{* * *}$ & $5.76, .06$ \\
\hline
\end{tabular}

${ }^{\mathrm{a}}$ All data are given as the number (percentage) of students unless otherwise specified.

${ }^{\mathrm{b}} \mathrm{df}=6 ;{ }^{\mathrm{c}} \mathrm{df}=3 ;{ }^{\mathrm{d}} \mathrm{df}=2$

${ }^{*} \mathrm{p}<.05 .{ }^{* *} \mathrm{p}<.01 .{ }^{* * *} \mathrm{p}<.001$. (2-tailed) 
Table 13

HIV Risk Behaviors for Males by Demographics Characteristics $(n=2,522)^{a}$

\begin{tabular}{|c|c|c|c|c|}
\hline \multirow[b]{2}{*}{ Demographic } & \multicolumn{4}{|c|}{ HIV Risk Behavior } \\
\hline & $\begin{array}{l}\text { Unprotected } \\
\text { sex }\end{array}$ & $\begin{array}{l}4+\text { sexual } \\
\text { partners }\end{array}$ & $\begin{array}{c}\text { Sex under } \\
\text { the influence }\end{array}$ & $\begin{array}{l}\text { Injection } \\
\text { drug use }\end{array}$ \\
\hline \multicolumn{5}{|l|}{ Age (in years) ${ }^{b}$} \\
\hline$\leq 12$ & $2(0.6)$ & $2(0.3)$ & $2(0.7)$ & $2(2.4)$ \\
\hline 13 & $2(0.6)$ & $2(0.3)$ & $2(0.7)$ & -- \\
\hline 14 & $17(14.9)$ & $19(3.3)$ & $8(2.8)$ & $3(3.5)$ \\
\hline 15 & $72(20.7)$ & $121(20.8)$ & $55(19.0)$ & $25(29.4)$ \\
\hline 16 & $83(23.9)$ & $131(22.5)$ & $70(24.1)$ & $16(18.8)$ \\
\hline 17 & $78(22.5)$ & $160(27.4)$ & $85(29.3)$ & $22(25.9)$ \\
\hline$\geq 18$ & $93(26.8)$ & $148(25.4)$ & $68(23.4)$ & $17(20.0)$ \\
\hline Mean $( \pm S D)$ & $16.4( \pm 1.3)^{* * *}$ & $16.5( \pm 1.22)^{* * *}$ & $16.5( \pm 1.22)^{* * *}$ & $16.2( \pm 1.36)$ \\
\hline \multicolumn{5}{|l|}{ Race/Ethnicity ${ }^{\mathrm{c}}$} \\
\hline Black & $78(22.5)$ & $212(36.4)$ & $55(19.0)$ & $20(23.5)$ \\
\hline Hispanic & $179(51.6)$ & $248(42.5)$ & $130(44.8)$ & $43(50.6)$ \\
\hline White & $69(19.9)$ & $82(14.1)$ & $81(27.9)$ & $9(10.6)$ \\
\hline Other & $21(6.1)$ & $41(7.0)$ & $24(8.3)$ & $13(15.3)$ \\
\hline$\chi^{2}, p$ & $8.61, .04^{*}$ & $101.07,<.001^{* * *}$ & $4.92, .18$ & $20.10,<.001^{* * *}$ \\
\hline \multicolumn{5}{|l|}{ Grade $^{c}$} \\
\hline 9 & $80(23.1)$ & $132(22.6)$ & $61(21.0)$ & $24(28.2)$ \\
\hline 10 & $93(26.8)$ & 159 (27.3) & $74(25.5)$ & $17(20.0)$ \\
\hline 11 & 75 (21.6) & $135(23.2)$ & $73(25.2)$ & $24(28.2)$ \\
\hline 12 & $99(28.5)$ & 157 (26.9) & $82(28.3)$ & $20(23.5)$ \\
\hline$\chi^{2}, p$ & $23.35,<.001^{* * *}$ & $39.48,<.001^{* * *}$ & $27.26,<.001^{* * *}$ & $6.83, .08$ \\
\hline \multicolumn{5}{|l|}{ School District $^{\mathrm{d}}$} \\
\hline Broward & $80(23.1)$ & $162(27.8)$ & $82(28.3)$ & $24(28.2)$ \\
\hline Miami-Dade & $138(39.8)$ & $241(41.3)$ & $112(38.6)$ & $34(40.0)$ \\
\hline Palm Beach & $129(37.2)$ & $180(30.9)$ & $96(33.1)$ & $27(31.8)$ \\
\hline$\chi^{2}, p$ & $0.46, .80$ & $10.29, .01^{* *}$ & $2.96, .23$ & $3.94, .14$ \\
\hline
\end{tabular}

${ }^{\mathrm{a}}$ All data are given as the number (percentage) of students unless otherwise specified.

${ }^{b} \mathrm{df}=6 ;^{\mathrm{c}} \mathrm{df}=3 ;{ }^{\mathrm{d}} \mathrm{df}=2$

${ }^{*} \mathrm{p}<.05 .{ }^{* *} \mathrm{p}<.01 .{ }^{* * *} \mathrm{p}<.001$. (2-tailed)

The average age for having four or more sexual partners was $16.6(S D=1.25)$ for females and $16.5(S D=1.22)$ for males. Independent $t$ tests found a significant difference 
in the mean age of students who reported four of more sexual partners for both females $(t$ $(2768)=-8.91, p<.001)$ and males $(t(927.8)=-8.95, p<.001)$.

Older students (15 years and older) were more likely to report sex under the influence of drugs/alcohol compared to their younger counterparts (14 years or younger). The average age for sex under the influence of alcohol/drugs was $16.4(S D=1.35)$ for females and $16.5(S D=1.22)$ for males. Independent $t$ tests found a significant age difference for females $(t(2775)=-4.25, p<.001)$ and males $(t(363.5)=-5.53, p<.001)$.

The average age of reported IDU was $16.2(S D=1.36)$ for males, however, the average age for IDU in females was younger $(M=16.0, S D=1.79)$. Among age groups, $33 \%$ of the females who reported IDU were 17 years of age and $29 \%$ of males who reported IDU were 15 years of age, however, independent $t$ tests did not find a significant age difference for IDU for either gender: males, $t(89.7)=-.97, p=.34$; females, $t(45.9)$ $=.31, p=.76$.

HIV risk behaviors by race/ethnicity. Unprotected sex was not found to be significantly different among race/ethnicities for females, $\chi^{2}(3, N=2,762)=3.95, p=$ .27. Males who had unprotected sex were significantly more likely to be Hispanic $(51.6 \%)$ than from any other race/ethnic group, $\left.\chi^{2}(3, N=2,522)=8.61, p=.04\right)$. Students who reported having multiple sexual partners were more likely to be Hispanic than other racial/ethnic groups, however a significant difference in students who reported multiple sexual partners among racial/ethnic groups was only found for males, $\chi^{2}(3, N=$ $2,522)=101.07, p<.001$

Females who had sex under the influence of drugs or alcohol were significantly more likely to be Hispanic (39.7\%) or White $(32.7 \%), \chi^{2}(3, N=2,762)=15.87, p=.001$. 
A significant difference in reports of sex under the influence among race/ethnicities, however, was not found for males, $\chi^{2}(3, N=2,522)=4.92, p=0.18$. Adolescent injection drug users were significantly more likely to be Hispanic than any other race/ethnicity: $50.6 \%$ of males that reported IDU were Hispanic, $\chi^{2}(3, N=2,522)=$ $20.10, p<.001 ; 39.1 \%$ of females that reported IDU were Hispanic, $\chi^{2}(3, N=2,762)=$ $11.85, p=0.003)$.

HIV risk behaviors by grade level. Most of the females (60\%) who reported unprotected sex were in 11th and 12th, and a significant difference in grade level was found, $\left.\chi^{2}(3, N=2,762)=69.84, p<.001\right)$. Also, 10th and 12th-grade males $(55.3 \%)$ were significantly more likely than 9 th and 11 th graders (44.7\%) to report not using a condom at last intercourse, $\left.\chi^{2}(3, N=2,522)=23.35, p<.001\right)$.

Students who had the highest reports of multiple sexual partners were more likely to be 11th and 12th-grade females (63.4\%) and 10th and 12th-grade males (54.2\%). A significant difference among grade levels was for both genders: males, $\chi^{2}(3, N=2,522)$ $=39.48, p<.001$; females, $\chi^{2}(3, N=2,762)=67.90, p<.001$.

Students who had sex under the influence were significantly more likely to be in the 12th-grade: females $(32.7 \%), \chi^{2}(3, N=2,762)=24.25$; males $(28.3 \%), \chi^{2}(3, N=$ $2,522)=27.26$. For injection drug use, there was no significant different found for grade level in either females, $\chi^{2}(3, N=2,762)=4.54, p=0.21$, or males, $\chi^{2}(3, N=2,030)=$ $6.83, p=0.08$.

HIV risk behaviors by school district. Unprotected sex was not significantly different among school district for females, $\chi^{2}(3, N=2,762)=0.94, p=0.63$, or males, $\left.\chi^{2}(3, N=2,522)=0.46, p=0.80\right)$. Females who had four or more sexual partners were 
significantly more likely to attend school in Palm Beach (37.2\%) or Broward (34.1\%), $\chi^{2}$ $(2, N=2,762)=17.24, p<.001$. Conversely, males with multiple sexual partners were significantly more likely to attend school in Miami-Dade $(41.3 \%), \chi^{2}(2, N=2,522)=$ $10.29, p=0.01)$.

Females who reported sex under the influence of drugs/alcohol at last sexual intercourse were significantly more likely to attend school in Broward (38.7\%) and Palm Beach (37.7\%) than Miami-Dade (23.6\%), $\chi^{2}(2, N=2,762)=23.97, p<.001$. Although Broward males were more likely than Miami-Dade and Palm Beach school districts to report sex under the influence, a significant difference was not found between school districts, $\chi^{2}(2, N=2,522)=2.96, p=0.23$. Also, chi-square tests did not find a significant difference in IDU among school districts for either gender: females, $\chi^{2}(2, N=$ $2,762)=5.76, p=0.06$; males, $\chi^{2}(2, N=2,522)=3.94, p=0.14$.

\section{Protective Factors}

Protective factors were derived from the conceptual framework of this study and included school involvement, receipt of sex education, and safe schools (Table 14). Membership on a sports team was used as a proxy measure for school involvement, while sex education was represented by reported receipt of HIV/AIDS instruction in school. Students' perceptions of safe school conditions were defined by students who reported none of the following unsafe conditions: threatened/injured with a weapon at school, bullied at school, and missed school due to safety concerns.

Overall, males had a higher number of protective factors than females, however this may be due to higher frequencies of males participating in more than one sports team. The average number of protective factors was $4.11(S D=.94)$ for males and 
4.02(SD = .82) for females. An independent samples $t$ test revealed a significant gender difference in the mean number of protective factors, $t(5308.5)=-3.97, p<.001$.

Table 14

Frequency Distribution of Protective Factors, by Gender $(n=5,713)^{\mathrm{a}}$

\begin{tabular}{|c|c|c|c|c|}
\hline Protective Factor & $\begin{array}{c}\text { Females } \\
(\mathrm{n}=2,933)\end{array}$ & $\begin{array}{c}\text { Males } \\
(\mathrm{n}=2,780)\end{array}$ & $\chi^{2}$ & $p$ \\
\hline \multicolumn{5}{|l|}{ Safe school conditions } \\
\hline $\begin{array}{l}\text { Did not miss school due to } \\
\text { safety concerns (past } 30 \mathrm{~d} \text { ) }\end{array}$ & $2726(93.0)$ & 2549 (91.9) & $2.55^{\mathrm{b}}$ & .11 \\
\hline $\begin{array}{l}\text { Was not threatened or injured } \\
\text { on school property (past } 30 \mathrm{~d} \text { ) }\end{array}$ & $2775(94.7)$ & $2482(89.5)$ & $53.71^{\mathrm{b}}$ & $<.001^{* *}$ \\
\hline $\begin{array}{l}\text { Was not bullied on school } \\
\text { property (past } 12 \text { mos.) }\end{array}$ & $2517(86.1)$ & $2450(88.3)$ & $6.02^{\mathrm{b}}$ & $.01^{* *}$ \\
\hline No. of safe conditions at school & & & $13.82^{\mathrm{c}}$ & $.003^{* *}$ \\
\hline 0 & $33(1.1)$ & $50(1.8)$ & & \\
\hline 1 & $107(3.7)$ & $145(5.2)$ & & \\
\hline 2 & $452(15.5)$ & $398(14.4)$ & & \\
\hline 3 & $2329(79.7)$ & $2174(78.6)$ & & \\
\hline Mean $( \pm S D)$ & $2.74( \pm .58)$ & $2.70( \pm .65)$ & 2.50 & $.01^{*}$ \\
\hline $\begin{array}{l}\text { Number of sports teams (past } 12 \\
\text { months) }\end{array}$ & & & $188.20^{\mathrm{c}}$ & $<.001^{* * *}$ \\
\hline 0 teams & $1717(59.7)$ & $1173(43.5)$ & & \\
\hline 1 team & $660(23.0)$ & $719(26.7)$ & & \\
\hline 2 teams & $344(12.0)$ & $460(17.1)$ & & \\
\hline 3 or more teams & $153(5.3)$ & $342(12.7)$ & & \\
\hline Mean $( \pm S D)$ & $.63( \pm .89)$ & $.99( \pm 1.06)$ & -13.73 & $<.001^{* * *}$ \\
\hline Received sex education in school & $2532(88.1)$ & $2296(85.1)$ & $10.82^{b}$ & $.001^{* *}$ \\
\hline \multicolumn{5}{|l|}{ No. of protective factors } \\
\hline Mean $( \pm S D)$ & $4.02( \pm .82)$ & $4.11( \pm .94)$ & -3.96 & $<.001^{* * *}$ \\
\hline
\end{tabular}

Safe schools. Approximately $79 \%$ of students reported all three safe conditions at school. The average number of reported safe conditions at school was $2.74(S D=.58)$ for females and $2.70(S D=.65)$ for males. An independent samples $t$ test revealed a 
significant difference in the average number of safe conditions at school between genders, $t(5521.89)=2.50, p=.012$.

There was no significance gender difference found for students that missed school due to safety concerns $\left(\chi^{2}(1, N=5,705)=2.55, p=.11\right)$. Male students $(10.5 \%)$ were more likely than female students (5.3\%) to report being threatened or injured with a weapon on school property in the past 12 months, however, females (13.9\%) were more likely than males (11.7\%) to report being bullied on school property. Chi-square analyses revealed significant gender differences for being threatened or injured with a weapon $\left(\chi^{2}\right.$ $(1, N=5,701)=53.71, p<.001)$ and being bullied at school $\left(\chi^{2}(1, N=5,700)=6.02, p\right.$ $=.01)$.

Sports team membership. Males were significantly more likely to report membership on a sports team than females $\left(\chi^{2}(1, N=5,568)=188.20, p<.001\right)$. The average number of sports teams that students reported were $.99(S D=1.06)$ for male students and $.63(S D=.89)$ for female students.

Receipt of sex education. Females (88.1\%) were more likely than males (85.1\%) to report receipt of sex education $\left(\chi^{2}(1, N=5,574)=10.82, p=.001\right)$.

\section{Risk Factors}

Risk factors identified by the conceptual model for this study included histories of depressive symptoms, dating violence, and sexual abuse, as well as models for and opportunities to participate in risk behavior (Table 15). The depression symptom index was derived from four variables relating to hopelessness and suicide ideation. Gender differences were calculated using Pearson chi-square $\left(\chi^{2}\right)$ tests of independence. 
Descriptive Characteristics of Risk Factors by Gender $(n=5,713)^{a}$

\begin{tabular}{|c|c|c|c|c|}
\hline Risk Factor & $\begin{array}{c}\text { Females } \\
(\mathrm{n}=2,933)\end{array}$ & $\begin{array}{c}\text { Males } \\
(\mathrm{n}=2,780)\end{array}$ & $\chi^{2}$ & $p$ \\
\hline \multicolumn{5}{|l|}{ Depressive symptoms } \\
\hline Felt sad or hopeless (past 12 mos.) & $1005(34.4)$ & $567(20.5)$ & $138.11^{\mathrm{b}}$ & $<.001^{* * *}$ \\
\hline Considered suicide (past 12 mos.) & $416(14.3)$ & $241(8.7)$ & $43.06^{\mathrm{b}}$ & $<.001^{* * *}$ \\
\hline Made suicide plan (past 12 mos.) & $293(10.1)$ & $211(7.7)$ & $10.27^{\mathrm{b}}$ & $.001^{* *}$ \\
\hline Attempted suicide (past 12 mos.) & $209(8.4)$ & $111(4.9)$ & $23.22^{\mathrm{b}}$ & $<.001^{* * *}$ \\
\hline No. of depressive symptoms & & & $108.35^{\mathrm{c}}$ & $<.001^{* * *}$ \\
\hline 0 & $1489(60.8)$ & $1669(74.7)$ & & \\
\hline 1 & $593(24.2)$ & $352(15.8)$ & & \\
\hline 2 & $149(6.1)$ & $87(3.9)$ & & \\
\hline 3 & $95(3.9)$ & $71(3.2)$ & & \\
\hline 4 & $124(5.1)$ & $55(2.5)$ & & \\
\hline Mean $( \pm S D)$ & $.68( \pm 1.09)$ & $.43( \pm .90)$ & 8.72 & $<.001^{* * *}$ \\
\hline Dating violence (past 12 mos.) & $316(10.8)$ & $312(11.3)$ & $.31^{\mathrm{c}}$ & .580 \\
\hline Sexual abuse & $260(8.9)$ & $176(6.4)$ & $13.17^{\mathrm{c}}$ & $<.001^{* * *}$ \\
\hline \multicolumn{5}{|l|}{ Model for risk behavior } \\
\hline Rode with drunk driver (past $30 \mathrm{~d}$ ) & 874 (29.9) & $781(28.2)$ & $2.04^{\mathrm{c}}$ & .15 \\
\hline \multicolumn{5}{|l|}{ Opportunities for risk behavior } \\
\hline Offered cigarettes (past 30 d) & $360(12.7)$ & 409 (15.4) & $8.38^{\mathrm{c}}$ & $.004^{* *}$ \\
\hline Offered alcohol (past $30 \mathrm{~d}$ ) & $1179(43.9)$ & $1045(41.7)$ & $2.51^{\mathrm{c}}$ & .11 \\
\hline Offered illegal drugs (past 12 mos.) & $615(21.2)$ & $760(27.8)$ & $33.13^{\mathrm{c}}$ & $<.001^{* * *}$ \\
\hline \multicolumn{5}{|l|}{ No. of risk factors } \\
\hline Mean $( \pm S D)$ & $1.9( \pm 1.98)$ & $1.7(1.85)$ & 4.46 & $<.001^{* * *}$ \\
\hline
\end{tabular}

${ }^{a}$ All data are given as the number (percentage) of students unless otherwise specified.

${ }^{\mathrm{b}} \mathrm{df}=4 ;{ }^{\mathrm{c}} \mathrm{df}=1 ;{ }^{\mathrm{d}} \mathrm{df}=10$

${ }^{*} \mathrm{p}<.05 .{ }^{* *} \mathrm{p}<.01 .{ }^{* * *} \mathrm{p}<.001 .(2$-tailed $)$

Overall, females were more likely than males to have a higher number of risk

factors, which may be due to more females reporting a higher number of depressive symptoms than males. The average number of risk factors was $1.9(S D=1.98)$ for female students and $1.7(S D=1.85)$ for male students, and an independent samples $t$ test revealed a significant gender difference, $t(4125.9)=4.46, p<.001$. 
History of depressive symptoms. Overall, females were more likely than males to report depressive symptoms, regardless of type, and significant gender differences were found in all four depressive symptoms More females (34.4\%) felt sad or hopeless for two or more weeks in a row in the last 12 months compared with males (20.5\%), $\chi^{2}$ $(1, N=5,695)=138.11, p<.001$. Approximately $14.3 \%$ and $8.7 \%$ of females and males, respectively, reported that they had seriously considered suicide in the past year, $\chi^{2}(1, N$ $=5,690)=43.06, p<.001$. Slightly higher proportions of females $(10.1 \%$ and $8.4 \%)$ made a suicide plan and attempted suicide at least once in the past year compared with males $(7.7 \%$ and $4.9 \%)$. Chi-square analyses revealed significant gender differences for planning a suicide $\left(\chi^{2}(1, N=5,658)=10.27, p=.001\right)$ and attempting a suicide $\left(\chi^{2}(1, N\right.$ $=4,738)=23.22, p<.001)$.

Females (5.1\%) were almost twice as likely as males (2.5\%) to report all four depressive symptoms, $\chi^{2}(4, N=5,713)=108.35, p<.001$. The mean number of items on the depressive symptom index was $.68(S D=1.09)$ for females and $.43(S D=.90)$ for males, and an independent samples $t$ test revealed a significant gender difference in mean number of items on the index, $t(4640.2)=8.72, p<.001$.

Histories of dating violence and sexual abuse. Similar proportions of males and females $(11 \%)$ reported a history of dating violence in the past 12 months $\left(\chi^{2}(1, N=\right.$ $5,695)=0.31, \mathrm{p}=.58$. Females $(8.9 \%)$ were significantly more likely to report a history of sexual abuse than males $(6.4 \%), \chi^{2}(1, N=5,674)=13.17, \mathrm{p}<.001$.

Models for risk behavior. Similar proportions of females and males (30\% and $28 \%$, respectively) reported riding in a car with someone who had been drinking alcohol 
at least once in the past 30 days. There was no significant gender difference found for students reporting riding in a car with a drunk driver, $\chi^{2}(1, N=5,700)=2.04, p=.15$.

Opportunities to participate in risk behavior. Males $(15.4 \%$ and $27.8 \%)$ were more likely than females $(12.1 \%$ and $21.2 \%)$ to report being offered, given, or sold cigarettes and illegal drugs, respectively. A significant gender difference was found for being offered cigarettes in the past 30 days $\left(\chi^{2}(1, N=5,485)=8.38, p=.004\right)$ and illegal drugs in the past 12 months $\left(\chi^{2}(1, N=5,636)=33.13, p<.001\right)$. Over $40 \%$ of males and females had been offered alcohol in the past 30 days, however, chi-square tests did not reveal a significant gender difference $\left(\chi^{2}(1, N=5,636)=2.51, p=.11\right)$.

\section{Health Risk Behaviors}

Health risk behaviors derived from the conceptual model included sexual behaviors, violence-related behaviors, and tobacco, alcohol, and drug use behaviors. Gender differences in health risk behaviors were calculated using Pearson chi-square $\left(\chi^{2}\right)$ tests of independence. Significant differences were found in 15 of the 19 health risk behaviors between genders.

Significant gender differences were found in the number of reported health risk

behaviors, $\chi^{2}(19, N=3,205)=48.72, p<.001$. The average number health risk behaviors was $3.0(S D=3.52)$ for males and $2.4(S D=2.87)$ for females. An independent $t$ test found a significant gender difference for average number of items on the health risk behavior index, $t(2905.2)=5.66, p<.001$.

Sexual risk behaviors. The average age of initial sexual experience for females $(n=1,289)$ who reported ever having sex was $14.63(S D=1.50)$, but the average age of first sexual experience for their male counterparts $(n=1,427)$ was younger $(M=13.9$, 
$S D=1.74)$ (Table 16). An independent samples $t$ test revealed a significant difference in mean age of first sexual intercourse between males and females who reported ever having sex, $t(2708.3)=12.2, p<.001$.

Table 16

Age at First Sexual Intercourse Among Students Who Reported Ever Having Sex, by Gender $(n=2,716)^{a}$

\begin{tabular}{|c|c|c|c|c|}
\hline $\begin{array}{l}\text { Age at first sexual } \\
\text { intercourse }\end{array}$ & $\begin{array}{l}\text { Females } \\
(\mathrm{n}=1,289)\end{array}$ & $\begin{array}{c}\text { Males } \\
(\mathrm{n}=1,427)\end{array}$ & $t$ & $P$ \\
\hline \multicolumn{5}{|l|}{ Age } \\
\hline$\leq 11$ years & $62(4.8)$ & $205(14.4)$ & & \\
\hline 12 years & $56(4.3)$ & $129(9.0)$ & & \\
\hline 13 years & $146(11.3)$ & $227(15.9)$ & & \\
\hline 14 years & $266(20.6)$ & $290(20.3)$ & & \\
\hline 15 years & $381(29.6)$ & $311(21.8)$ & & \\
\hline 16 years & $260(20.2)$ & $189(13.2)$ & & \\
\hline$\geq 17$ years & $118(9.2)$ & $76(5.3)$ & & \\
\hline Mean $( \pm S D)$ & $14.6( \pm 1.50)$ & $13.9( \pm 1.74)$ & 12.2 & $<.001^{* * *}$ \\
\hline \multicolumn{5}{|c|}{$\begin{array}{l}{ }^{a} \text { All data are given as the number (percentage) of students unless otherwise specified. } \\
{ }^{\mathrm{b}} \mathrm{df}=6 \\
{ }^{* * *} \mathrm{p}<.001 . \text { (2-tailed) }\end{array}$} \\
\hline \multicolumn{5}{|c|}{ Males $(13.1 \%)$ were more than three times as likely as females $(4.3 \%)$ to have } \\
\hline \multicolumn{5}{|c|}{ their initial sexual experience at a younger age $(\leq 13$ years $), \chi^{2}(1, N=5,328)=133.35, p$} \\
\hline \multicolumn{5}{|c|}{$<.001$ (Table 17). Over $35 \%$ of males and females reported recent sexual activity (at } \\
\hline \multicolumn{5}{|c|}{ least one sexual partner) in the past three months; no significant gender difference was } \\
\hline
\end{tabular}


Table 17

Descriptive Characteristics of Health Risk Behaviors, by Gender $(n=5,713)^{a}$

\begin{tabular}{lcccc}
\hline Health Risk Behavior & $\begin{array}{c}\text { Females } \\
(\mathrm{n}=2,933)\end{array}$ & $\begin{array}{c}\text { Males } \\
(\mathrm{n}=2,780)\end{array}$ & $\chi^{2}$ & $p^{\mathrm{b}}$ \\
\hline $\begin{array}{l}\text { Sexual risk behaviors } \\
\quad \begin{array}{l}\text { Early age at first sexual } \\
\text { experience }(\leq 13 \text { yrs.) }\end{array}\end{array}$ & $118(4.3)$ & $334(13.1)$ & 133.35 & $<.001^{* * *}$ \\
$\begin{array}{l}\text { Recent sexual activity (past } 3 \\
\text { mos.) }\end{array}$ & $983(35.4)$ & $948(37.2)$ & 1.83 & .18
\end{tabular}

Violent behaviors (past $30 \mathrm{~d}$ )

Carried a weapon

Involved in a physical fight

Recent tobacco use (past $30 \mathrm{~d}$ )

Smoked cigarettes

Smoked cigar

Chewing tobacco

Recent alcohol use (past $30 \mathrm{~d}$ )

Drank alcohol

Had $\geq 5$ drinks in a row

Drink-driving

Recent drug use (past $30 \mathrm{~d}$ )

Smoke marijuana

Used cocaine

Lifetime drug use

Marijuana

Cocaine

Inhalants

Heroin

Methamphetamine

Ecstasy

Steroids

$\begin{array}{rrrr}172(5.9) & 542(20.0) & 249.51 & <.001^{* * *} \\ 699(24.1) & 1005(37.3) & 113.42 & <.001^{* * *}\end{array}$

$\begin{array}{rrrr}360(12.7) & 405(15.3) & 7.76 & .005^{* *} \\ 213(7.3) & 354(12.9) & 48.69 & <.001^{* * *} \\ 62(2.1) & 172(6.3) & 61.37 & <.001^{* * *}\end{array}$

$\begin{array}{rrrc}1176(43.7) & 1023(41.2) & 3.30 & .07 \\ 568(19.7) & 585(21.7) & 3.35 & .07 \\ 175(8.4) & 231(11.6) & 12.31 & <.001^{* * *}\end{array}$

$\begin{array}{rrrr}526(18.2) & 671(24.9) & 36.62 & <.001^{* * *} \\ 70(2.4) & 131(4.8) & 23.03 & <.001^{* * *}\end{array}$

No. of health risk behaviors $2.38( \pm 2.87) \quad 3.03( \pm 2.87)$

$\begin{array}{rrrc}926(32.2) & 1035(38.5) & 24.38 & <.001^{* * *} \\ 166(5.7) & 230(8.4) & 15.76 & <.001^{*} \\ 218(10.4) & 177(8.7) & 3.26 & .07 \\ 50(2.4) & 96(4.7) & 16.69 & <.001^{* * *} \\ 69(3.3) & 107(5.3) & 10.02 & .002^{* *} \\ 223(7.7) & 280(10.2) & 11.32 & .001^{* *} \\ 62(2.1) & 118(4.3) & 21.48 & <.001^{* * *}\end{array}$

\section{Mean $( \pm S D)$}

\footnotetext{
${ }^{\mathrm{a}}$ All data are given as the number (percentage) of students unless otherwise specified.

${ }^{\mathrm{b}} \mathrm{df}=1$

${ }^{*} \mathrm{p}<.05 .{ }^{* *} \mathrm{p}<.01 .{ }^{* * *} \mathrm{p}<.001$. (2-tailed)
} 
Violence-related behaviors. Male students (20\%) were more than twice as likely to report carrying a weapon in the past 30 days compared to female students $(5.9 \%), \chi^{2}$ $(1, \mathrm{~N}=5,607)=249.51, \mathrm{p}<.001$. Significantly higher proportions of males $(37.3 \%)$ were involved in a physical fight in the past 30 days $\left(\chi^{2}(1, N=5,592)=113.42, p<\right.$ $.001)$ compared to their female counterparts (24.1\%).

Substance use behaviors. Substance use behaviors included the use of tobacco, alcohol, and illicit drugs. For recent tobacco use, $15.3 \%$ of males and $12.7 \%$ of females reported smoking cigarettes at least one day in the past 30 days $\left(\chi^{2}(1, N=5,494)=7.76\right.$, $p=.005$ ), while $12.9 \%$ of males and $7.3 \%$ of females reported smoking a cigar during the same time period $\left(\chi^{2}(1, N=5,655)=48.69, p<.001\right)$. Male students $(6.3 \%)$ were three times as likely as females (2.1\%) to have used chewing tobacco, snuff, or dip on at least one day in the past 30 days, $\chi^{2}(1, N=5,635)=61.37, p<.001$.

Similar proportions of females $(43.7 \%)$ and males $(41.2 \%)$ reported having at least one drink of alcohol in the past 30 days. Approximately $22 \%$ of males and $20 \%$ of females reported binge drinking in the past month. There was no gender difference found in recent alcohol use $\left(\chi^{2}(1, N=5,170)=3.30, p=.07\right)$ and binge drinking $\left(\chi^{2}(1, N=\right.$ $5,571)=3.35, p=.07)$, however, a significant gender difference was found for driving a vehicle when one had been drinking (past 30 days), $\chi^{2}(1, N=4,077)=12.31, p<.001$.

For recent drug use, more males (24.9\%) than females (18.2\%) reported smoking marijuana at least once in the past 30 days. Twice as many males (4.8\%) than females $(2.4 \%)$ reported using cocaine in the past month. The gender differences between recent marijuana use $\left(\chi^{2}(1, N=5,587)=36.62\right)$ and cocaine use $\left(\chi^{2}(1, N=5,630)=23.03\right)$ were found to be significant $(p<.001)$. 
Overall, student reports of lifetime drug use were low $(<7.0 \%)$, except for marijuana use (34.3\%). Chi-square analysis did not find a significant gender difference for use of inhalants $\left(\chi^{2}(1, N=4,126)=3.26, p=.07\right)$, however, for all other drug types, the prevalence of lifetime use was significantly higher in males than in females. Approximately $39 \%$ and $8.4 \%$ of males and $32 \%$ and $5.7 \%$ of females reported trying marijuana $\left(\chi^{2}(1, N=5,570)=24.38, p<.001\right)$ and cocaine $\left(\chi^{2}(1, N=5,620)=15.76, p\right.$ $<.001)$, respectively, at least once in their lifetime. Almost twice as many males $(4.7 \%$ and $4.3 \%)$ than females $(2.4 \%$ and $2.1 \%)$ reported using heroin $\left(\chi^{2}(1, N=4,122)=6.02\right.$, $p<.001)$ and steroid pills or shots without a doctor's prescription $\left(\chi^{2}(1, N=5,650)=\right.$ $21.48, p<.001)$, respectively. Twice as many males $(10.2 \%$ vs. $5.3 \%)$ used ecstasy than methamphetamines; similar proportions were found for female students (7.7\% vs. 3.3\%). Both lifetime ecstasy use $\left(\chi^{2}(1, N=5,644)=11.32, p=.001\right)$ and methamphetamine use $\left(\chi^{2}(1, N=4,124)=10.02, p=.002\right)$ were found to be significantly different by gender.

\section{Hypothesis Testing}

This section presents the results of testing the hypotheses for factors influencing HIV risk behaviors. Correlation analyses tested hypotheses pertaining to the relationship between each of the four HIV risk behaviors (dependent variables) and protective factors, risk factors, and health risk behaviors (independent variables). Phi coefficients $(\varphi)$ were used to compute the bivariate correlations between two dichotomous variables. Pearson correlation tests were conducted to calculate bivariate coefficients (Pearson's $r$ ) between dichotomous and continuous variables. 
Logistic regression analyses were then conducted to determine the whether protective factors, risk factors, and health risk behaviors predicted students' participation in HIV risk behavior when controlling for grade level, race/ethnicity, and school district.

\section{Research Question 1}

What is the relationship between HIV risk behaviors and protective factors, risk factors, and health risk behaviors among high school students in South Florida?

Hypothesis 1a. The hypothesis stated that protective factors would be negatively associated with HIV risk behaviors, and was partially supported.

Table 18

Bivariate Associations between Protective Factors and HIV Risk Behaviors, by Gender

\begin{tabular}{|c|c|c|c|c|}
\hline \multirow[b]{3}{*}{ Protective Factor } & \multicolumn{4}{|c|}{ Females $(n=2,933)$} \\
\hline & \multicolumn{4}{|c|}{ HIV Risk Behavior } \\
\hline & Unprotected sex & $\begin{array}{c}4+\text { sexual } \\
\text { partners }\end{array}$ & $\begin{array}{l}\text { Sex under } \\
\text { the influence }\end{array}$ & IDU \\
\hline Safe school conditions & $-.09^{* * *}$ & $-.12^{* * *}$ & $-.16^{* * *}$ & $-.18^{* * *}$ \\
\hline Sports team membership & $-.04^{*}$ & -.01 & .03 & $.07^{* *}$ \\
\hline \multirow[t]{2}{*}{ Sex education } & -.03 & $-.06^{* *}$ & $-.07^{* * *}$ & $-.16^{* * *}$ \\
\hline & \multicolumn{4}{|c|}{ Males $(\mathrm{n}=2,780)$} \\
\hline & \multicolumn{4}{|c|}{ HIV Risk Behavior } \\
\hline Protective Factor & Unprotected sex & $\begin{array}{c}4+\text { sexual } \\
\text { partners }\end{array}$ & $\begin{array}{l}\text { Sex under } \\
\text { the influence }\end{array}$ & IDU \\
\hline Safe school conditions & $-.15^{* * *}$ & $-.14^{* * *}$ & $-.22^{* * *}$ & $-.32^{* * *}$ \\
\hline Sports team membership & $-.06^{* *}$ & $.12^{* * *}$ & .01 & .04 \\
\hline Sex education & $-.11^{* * *}$ & $-.08^{* * *}$ & $-.10^{* * *}$ & $-.20^{* * *}$ \\
\hline
\end{tabular}

With a few exceptions, protective factors were negatively correlated with individual HIV risk behaviors (Table 18). The safe school index was negatively correlated $(p<.001)$ with all HIV risk behaviors for both genders. Sex education also exhibited significant negative relationships with HIV risk behaviors, with one exception. 
Unprotected sex was not significantly correlated with sex education for females, $\varphi=-.03$, $p=.09$. Sports team membership was negatively correlated with unprotected sex in males, $r(2478)=-.08, p<.001$, and females, $r(2731)=-.06, p=.004$, and positively correlated with having four or more sexual partners in males, $r(2498)=.07, p<.001$, and injection drug use in females, $r(2071)=.07, p=.001$.

Table 19

Bivariate Associations between Risk Factors and HIV Risk Behaviors, by Gender ${ }^{a}$

\begin{tabular}{|c|c|c|c|c|}
\hline \multirow[b]{3}{*}{ Risk Factor } & \multicolumn{4}{|c|}{ Females $(\mathrm{n}=2,933)$} \\
\hline & \multicolumn{4}{|c|}{ HIV Risk Behavior } \\
\hline & $\begin{array}{c}\text { Unprotected } \\
\text { sex }\end{array}$ & $\begin{array}{c}4+\text { sexual } \\
\text { partners }\end{array}$ & $\begin{array}{l}\text { Sex under } \\
\text { the influence }\end{array}$ & IDU \\
\hline Depression index & .20 & .20 & .15 & .25 \\
\hline Dating violence & .21 & .20 & .14 & .17 \\
\hline Sexual abuse & .25 & .30 & .22 & .20 \\
\hline Rode with drunk driver & .11 & .16 & .20 & .10 \\
\hline Offered cigarettes & .20 & .30 & .37 & .23 \\
\hline Offered alcohol & .14 & .18 & .25 & .13 \\
\hline \multirow[t]{4}{*}{ Offered illegal drugs } & .12 & .14 & .22 & .19 \\
\hline & \multicolumn{4}{|c|}{ Males $(\mathrm{n}=2,780)$} \\
\hline & \multicolumn{4}{|c|}{ HIV Risk Behavior } \\
\hline & $\begin{array}{c}\text { Unprotected } \\
\text { sex }\end{array}$ & $\begin{array}{c}+ \text { sexual } \\
\text { partners }\end{array}$ & $\begin{array}{l}\text { Sex under } \\
\text { the influence }\end{array}$ & IDU \\
\hline Depression index & .20 & .13 & .21 & .34 \\
\hline Dating violence & .20 & .19 & .20 & .21 \\
\hline Sexual abuse & .24 & .24 & .26 & .33 \\
\hline Rode with drunk driver & .14 & .17 & .26 & .15 \\
\hline Offered cigarettes & .23 & .23 & .40 & .32 \\
\hline Offered alcohol & .15 & .24 & .35 & .19 \\
\hline Offered illegal drugs & .16 & .12 & .22 & .23 \\
\hline
\end{tabular}

${ }^{\mathrm{a}}$ All correlations were statistically significant at $p<.001$ (2-tailed)

Hypothesis 1b. The hypothesis stated that risk factors would be positively associated with HIV risk behavior and was supported. 
All risk factors and HIV risk behaviors were found to have significant positive correlations $(\mathrm{p}<.001)$ (Table 19). Being offered cigarettes also had a moderate relationship with having sex under the influence of drugs or alcohol at last sex for males, $\varphi=.40$.

Hypothesis 1c. This hypothesis stated that health risk behaviors and HIV risk behaviors would be positively associated. As shown in Table 20, this prediction was supported. As expected, health risk behaviors had significant positive relationships ( $\mathrm{p}$ $<.001$ ) with individual HIV risk behaviors. A few moderate correlations were worth nothing. For females, recent sexual activity was moderately correlated with unprotected sex, $\varphi=.44$, and multiple sexual partners, $\varphi=.40$. Also, female IDU was moderately correlated with recent cocaine use, $\varphi=.48$, and lifetime methamphetamine use, $\varphi=.55$, and was highly correlated with lifetime heroin use, $\varphi=.71$.

Generally, HIV risk behaviors had stronger relationships with health risk behaviors for males. Early age at initial sexual experience was associated with multiple sexual partners, $\varphi=.46$. Sex under the influence of drugs or alcohol was moderately associated with the following illicit substance use behaviors: binge drinking: $\varphi=.45$; recent marijuana use: $\varphi=.43$; lifetime cocaine use: $\varphi=.42$; lifetime ecstasy use: $\varphi=.41$. Male IDU had the strongest relationships with health risk behaviors. Injection drug use was moderately correlated with recently use of: cigars, $\varphi=.48$, and cocaine, $\varphi=.64$; and lifetime use of: cocaine, $\varphi=.54$, inhalants, $\varphi=.46$, methamphetamine, $\varphi=.67$, ecstasy, $\varphi$ $=.53$; steroids, $\varphi=.64$; and heroin: $\varphi=.72$. 
Table 20

Bivariate Associations $^{a}$ between Health Risk Behaviors and HIV Risk Behaviors, by Gender ${ }^{b}$

\begin{tabular}{|c|c|c|c|c|c|c|c|c|}
\hline \multirow[b]{2}{*}{ Health Risk Behavior } & \multicolumn{4}{|c|}{ Females $(\mathrm{n}=2,933)$} & \multicolumn{4}{|c|}{ Males $(\mathrm{n}=2,780)$} \\
\hline & $\begin{array}{c}\text { Unprotected } \\
\text { sex }\end{array}$ & $\begin{array}{c}4+\text { sexual } \\
\text { partners }\end{array}$ & $\begin{array}{l}\text { Sex under } \\
\text { influence }\end{array}$ & IDU & $\begin{array}{c}\text { Unprotected } \\
\text { sex } \\
\end{array}$ & $\begin{array}{c}4+\text { sexual } \\
\text { partners }\end{array}$ & $\begin{array}{l}\text { Sex under } \\
\text { influence }\end{array}$ & IDU \\
\hline \multicolumn{9}{|l|}{ Sexual risk behaviors } \\
\hline Early age at first sexual experience & .22 & .34 & .21 & .32 & .29 & .46 & .26 & .25 \\
\hline Recent sex & .44 & .40 & .26 & .13 & .31 & .55 & .34 & 17 \\
\hline \multicolumn{9}{|l|}{ Violent-behaviors } \\
\hline Carried weapon & .09 & .14 & .13 & .25 & .15 & .22 & .26 & .28 \\
\hline Fighting & .21 & .17 & .17 & .17 & .09 & .25 & .26 & .18 \\
\hline \multicolumn{9}{|l|}{ Recent tobacco use } \\
\hline Smoked cigarettes & .21 & .31 & .36 & .22 & .23 & .22 & .39 & .31 \\
\hline Smoked cigar & .12 & .18 & .23 & .29 & .18 & .20 & .32 & .42 \\
\hline Chewing tobacco & .16 & .22 & .29 & .23 & .18 & .20 & .35 & .34 \\
\hline \multicolumn{9}{|l|}{ Recent alcohol use } \\
\hline Drank alcohol & .14 & .18 & .26 & .12 & .15 & .24 & .36 & .18 \\
\hline Binge drinking & .19 & .23 & .35 & .19 & 17 & .25 & .45 & .25 \\
\hline Drink-driving & .17 & .21 & .36 & .21 & .18 & .23 & .39 & .28 \\
\hline \multicolumn{9}{|l|}{ Recent drug use } \\
\hline Marijuana & .20 & .30 & .38 & .16 & .18 & .29 & .43 & .25 \\
\hline Cocaine & .16 & .26 & .31 & .48 & .23 & .21 & .37 & .64 \\
\hline \multicolumn{9}{|l|}{ Lifetime drug use } \\
\hline Marijuana & .26 & .30 & .32 & .14 & .20 & .29 & .36 & .22 \\
\hline Cocaine & .23 & .31 & .34 & .38 & .24 & .22 & .42 & .54 \\
\hline Inhalants & .15 & .15 & .22 & .26 & .15 & .12 & .23 & .46 \\
\hline Heroin & .20 & .24 & .32 & .71 & .26 & .24 & .32 & .72 \\
\hline Methamphetamine & 18 & .26 & .33 & .55 & .25 & .22 & .33 & .67 \\
\hline Ecstasy & .23 & .33 & .36 & .37 & .30 & .28 & .41 & .53 \\
\hline Steroids & .14 & .16 & .24 & .53 & .24 & .21 & .32 & .64 \\
\hline
\end{tabular}

${ }^{\mathrm{a}}$ All correlations were statistically significant at $p<.001$ (2-tailed) 


\section{Research Question 2}

Do protective factors, risk factors, and health risk behaviors predict participation in HIV-related risk behavior, when controlling for grade level, race/ethnicity, and school district?

Binary logistic regressions were used to assess the ability of protective factors (safe school index, sports team membership, and sex education), risk factors, and health risk behaviors to participation in HIV risk behavior, after controlling for demographic factors. Since the risk factor (RFI) and health risk behavior (HRBI) indices yielded satisfactory internal consistency, they were used as predictor variables in the logistic equations.

Each analysis included the corresponding independent variable in the first block, demographic variables (e.g., grade level, race/ethnicity, and location of school district) in the second block, and interaction terms, if applicable, in the third block. For race/ethnicity, the reference category was the "Other" race category. For school district, Broward was the reference category. All analyses were stratified by gender. Collinearity statistics were conducted to evaluate independent variables for multicollinearity prior to regression analysis. All correlations fell below .5, indicating that there was insufficient evidence to warrant concern about multicollinearity.

Hypothesis 2a. The hypothesis stated that students that report protective factors will be less likely to report participation in HIV risk behavior. This prediction was partially supported. To address this research question, three sets of binary logistic regressions were conducted as described above for each protective factor: safe schools, sports team membership, and sex education. Analyses were stratified by gender. 
Do safe conditions at school predict HIV risk behavior? Two logistic regression analyses were conducted, one for each gender, using the safe schools index (Block 1) and demographic controls (Block 2) as predictors (Table 21). The model contained four independent variables (safe schools index, grade level, race/ethnicity, and school district).

Table 21

Binary Logistic Regression Analyses Predicting Participation in At Least One HIV Risk Behavior from Safe School Index, by Gender ${ }^{a}$

\begin{tabular}{|c|c|c|c|c|c|c|c|c|}
\hline & \multicolumn{4}{|c|}{ Female } & \multicolumn{4}{|c|}{ Male } \\
\hline Variable & $\beta$ & SE & Wald & $\begin{array}{l}\text { Odds } \\
\text { ratio }\end{array}$ & $\beta$ & SE & Wald & $\begin{array}{l}\text { Odds } \\
\text { ratio }\end{array}$ \\
\hline \multicolumn{9}{|l|}{ Block 1: } \\
\hline Safe Schools & -.37 & .08 & $20.04^{* * *}$ & .69 & -.48 & .08 & $39.51^{* * *}$ & .62 \\
\hline \multicolumn{9}{|l|}{ Block 2: } \\
\hline Safe Schools & -.41 & .09 & $23.44^{* *}$ & .66 & -.56 & .08 & $48.42^{* * *}$ & .57 \\
\hline Grade level & .49 & .05 & $94.84^{* * *}$ & .64 & .35 & .05 & $54.46^{* * *}$ & .43 \\
\hline Race/ethnicity & & & 5.77 & & & & $44.74^{* * *}$ & \\
\hline Other & & & & 1 & & & & 1 \\
\hline Black & .17 & .26 & .46 & 1.19 & .58 & .23 & $6.22^{*}$ & 1.78 \\
\hline White & .47 & .26 & 3.39 & 1.60 & -.44 & .25 & 3.44 & .65 \\
\hline Hispanic & .31 & .25 & 1.55 & 1.37 & .17 & .23 & .58 & 1.18 \\
\hline School district & & & 1.04 & & & & 1.61 & \\
\hline Broward & & & & 1 & & & & 1 \\
\hline Miami-Dade & -.04 & .15 & .07 & .96 & -.09 & .14 & .39 & .92 \\
\hline Palm Beach & .10 & .14 & .48 & 1.10 & -.17 & .13 & 1.6 & .84 \\
\hline
\end{tabular}

For the female regression model, the overall model containing all predictors was statistically significant, $\chi^{2}(7, \mathrm{~N}=1967)=126.13, \mathrm{p}<.001$, indicating that the model was able to distinguish between respondents who reported and did not report participation in at least one HIV risk behavior. The model generated in the second block (with demographic controls) yielded a better fit to the data than the first block and correctly 
classified $74.1 \%$ of adolescents. This model also showed significant effects for safe schools and grade level. The strongest predictor of HIV risk was grade level, recording an odds ratio of 1.64. This indicated that for each grade level increase, female students were 1.64 times more likely to report participation in at least one HIV risk. According to this model, the odds ratio of .66 for the safe schools index was less than one, indicating that for each increase in a safe school condition, female students were .66 times less likely to report participation in an HIV risk behavior, controlling for other factors in the model.

For the male regression model, the overall model containing all predictors was statistically significant and fit the model well, $\chi^{2}(7, \mathrm{~N}=1815)=153.15, \mathrm{p}<.001$. The model generated in the second step (with demographic controls) correctly classified $67.7 \%$ of adolescents. This model also showed significant effects for safe schools, grade level, and race/ethnicity. The strongest predictor of HIV risk was Black race, recording an odds ratio of 1.78 . Black males were 1.78 time more likely to report HIV risk than males in the Other race category. For each grade level increase, male students were 1.43 times more likely to report participation in at least one HIV risk. According to this model, the odds ratio of .57 for the safe schools index was less than one, indicating that for each increase in a safe school condition, male students were .57 times less likely to report participation in an HIV risk behavior, controlling for other factors in the model.

In summary, results showed that the safe conditions at school predict HIV risk behavior in male and female students. Therefore, the hypothesis was supported. This model also showed that HIV risk increases with grade level, and Black male students were more likely to engage in HIV risk behavior than male students in the other race category. 


\section{Does sports team membership predict HIV risk behavior? Two logistic}

regression analyses were conducted, one for each gender, using the sports team membership (Block 1) and demographic controls (Block 2) as predictors (Table 22). The model contained four independent variables (number of sports teams, grade level, race/ethnicity, and school district).

Table 22

Binary Logistic Regression Analyses Predicting Participation in At Least One HIV Risk Behavior from Sports Team Membership, by Gender ${ }^{a}$

\begin{tabular}{cccccccccc}
\hline \multicolumn{1}{c}{ Female } & \multicolumn{1}{c}{ Male } \\
\hline Variable & $\beta$ & SE & Wald & $\begin{array}{c}\text { Odds } \\
\text { ratio }\end{array}$ & $\beta$ & SE & Wald & $\begin{array}{c}\text { Odds } \\
\text { ratio }\end{array}$ \\
\hline
\end{tabular}

Block 1:

$\begin{array}{lllllllll}\text { Sports teams } & -.06 & .06 & 1.12 & .94 & .15 & .05 & 10.36^{* *} & 1.16\end{array}$

Block 2:

\begin{tabular}{lcccccccc} 
Sports teams & -.06 & .06 & 1.15 & .94 & .16 & .05 & $10.23^{* *}$ & 1.17 \\
Grade level & .47 & .05 & $87.60^{* * *}$ & 1.6 & .35 & .05 & $55.22^{* * *}$ & 1.43 \\
Race/ethnicity & & & 6.11 & & & & $35.94^{* * *}$ & \\
$\quad$ Other & & & & 1 & & & & 1 \\
Black & .13 & .26 & .28 & 1.14 & .42 & .23 & .3 .39 & 1.53 \\
White & .45 & .25 & 3.19 & 1.58 & -.49 & .23 & $4.36^{*}$ & .62 \\
Hispanic & .28 & .25 & 1.22 & 1.32 & .06 & .22 & .08 & 1.06 \\
School district & & & 1.49 & & & & 1.35 & \\
$\quad$ Broward & & & & 1 & & & & 1 \\
Miami-Dade & -.09 & .15 & .38 & .91 & -.09 & .14 & .36 & .92 \\
$\quad$ Palm Beach & .08 & .14 & .30 & 10.8 & -.16 & .13 & 13.5 & .86 \\
\hline
\end{tabular}

For the female regression model, the overall model containing all predictors was statistically significant and fit the data well, $\chi^{2}(7, \mathrm{~N}=1957)=101.63, \mathrm{p}<.001$, indicating that the model was able to distinguish between respondents who reported and did not report participation in at least one HIV risk behavior. The model generated in the 
second block (with demographic controls) yielded a better fit to the data than the first block and correctly classified $73.9 \%$ of adolescents. This model showed significant effects for grade level only. Number of sports teams was not found to be significant.

For the male regression model, the overall model containing all predictors was statistically significant and fit the data well, $\chi^{2}(7, \mathrm{~N}=1797)=114.47, \mathrm{p}<.001$. The model generated in the second step (with demographic controls) correctly classified $67.3 \%$ of adolescents. This model also showed significant effects for number of sports teams, grade level, and race/ethnicity. Similar to females, the strongest predictor of HIV risk was grade level, recording an odds ratio of 1.43 . This model also revealed number of sports teams as a significant predictor, recording an odds ratio of 1.17. This indicated that for every increase in sports team membership, males were 1.17 times more likely to report HIV risk behavior. Also, White male students were .62 times less likely to report HIV risk than males in the Other race category.

In short, results showed that the sports team membership did significantly predict HIV risk behavior in males, but not in females. Therefore the hypothesis was partially supported.

Does receipt of sex education in school predict HIV risk behavior? Two logistic regression analyses were conducted, one for each gender, using the receipt of sex education in school $(0=$ No; $1=$ Yes $)($ Block 1$)$ and demographic controls (Block 2$)$ as predictors (Table 23). The model contained four independent variables (sex education, grade level, race/ethnicity, and school district). 
Table 23

Binary Logistic Regression Analyses Predicting Participation in At Least One HIV Risk Behavior from Receipt of Sex Education in School, by Gender ${ }^{a}$

\begin{tabular}{|c|c|c|c|c|c|c|c|c|}
\hline \multirow[b]{2}{*}{ Variable } & \multicolumn{4}{|c|}{ Female } & \multicolumn{4}{|c|}{ Male } \\
\hline & $\beta$ & SE & Wald & $\begin{array}{l}\text { Odds } \\
\text { ratio }\end{array}$ & $\beta$ & SE & Wald & $\begin{array}{l}\text { Odds } \\
\text { ratio }\end{array}$ \\
\hline \multicolumn{9}{|l|}{ Block 1: } \\
\hline Sex education & -.05 & .16 & .17 & .94 & -.54 & .14 & $16.00^{* * *}$ & .58 \\
\hline \multicolumn{9}{|l|}{ Block 2: } \\
\hline Sex education & -.16 & .16 & .94 & .85 & -.53 & .14 & $14.4^{* * *}$ & .59 \\
\hline Grade level & .47 & .05 & $89.94^{* * *}$ & 1.61 & .55 & .05 & $55.08^{* * *}$ & 1.4 \\
\hline Race/ethnicity & & & 6.36 & & & & $36.35^{* * *}$ & \\
\hline Other & & & & 1 & & & & 1 \\
\hline Black & .15 & .26 & .35 & 1.16 & .44 & .23 & 3.78 & 1.56 \\
\hline White & .47 & .26 & 3.48 & 1.61 & -.47 & .23 & $4.14^{*}$ & .63 \\
\hline Hispanic & .28 & .25 & 1.26 & 1.33 & .04 & .22 & .03 & 1.04 \\
\hline School district & & & 1.05 & & & & .99 & \\
\hline Broward & & & & 1 & & & & 1 \\
\hline Miami-Dade & -.07 & .15 & .23 & .93 & -.09 & .14 & .38 & .92 \\
\hline Palm Beach & .07 & .14 & .25 & 1.07 & -.13 & .13 & .98 & .88 \\
\hline
\end{tabular}

For the female regression model, the overall model containing all predictors was statistically significant and fit the data well, $\chi^{2}(7, \mathrm{~N}=1959)=102.74, \mathrm{p}<.001$, indicating that the model was able to distinguish between respondents who reported and did not report participation in at least one HIV risk behavior. The model generated in the second block (with demographic controls) yielded a better fit to the data than the first block and correctly classified $74.0 \%$ of female adolescents. This model only revealed significant effects for grade level, recording an odds ratio of 1.61 and indicating that probability of participation in HIV risk increased with grade level. Receipt of sex education was not found to be significant, 
For the male regression model, the overall model containing all predictors was statistically significant and fit the data well, $\chi^{2}(7, \mathrm{~N}=1801)=117.77, \mathrm{p}<.001$. The model generated in the second step (with demographic controls) correctly classified $67.6 \%$ of adolescents. This model also showed significant effects for sex education, grade level, and race/ethnicity. Similar to females, the strongest predictor of HIV risk was grade level, recording an odds ratio of 1.42 . The odds ratio of .59 for receipt of sex education indicated that male students who received sex education were .59 times less likely to participate in HIV risk behavior than male students who did not receive sex education. This model also showed White males were .63 times less likely to report HIV risk than males in the Other race category.

In short, results showed that the sex education was a significant predictor of HIV risk behavior for males, but not for females. Therefore the hypothesis was partially supported. This model also showed that HIV risk increases with grade level, and compared to males in Other race/ethnicities, White males were less likely to engage in HIV risk behavior.

Hypothesis $\mathbf{2 b}$. The hypothesis stated that students with risk factors will be more likely to report participation in HIV risk behavior. This prediction was supported. To address this research question, two logistic regression analyses were conducted, one for each gender, using the risk factor index (RFI) (Block 1) and demographic controls (Block 2) as predictors (Table 24). The model contained four independent variables (RFI, grade level, race/ethnicity, and school district). 
Table 24

Binary Logistic Regression Analyses Predicting Participation in At Least One HIV Risk Behavior from the Risk Factor Index, by Gender ${ }^{a}$

\begin{tabular}{|c|c|c|c|c|c|c|c|c|}
\hline \multirow[b]{2}{*}{ Variable } & \multicolumn{4}{|c|}{ Female } & \multicolumn{4}{|c|}{ Male } \\
\hline & $\beta$ & SE & Wald & $\begin{array}{l}\text { Odds } \\
\text { ratio }\end{array}$ & $\beta$ & SE & Wald & $\begin{array}{l}\text { Odds } \\
\text { ratio }\end{array}$ \\
\hline \multicolumn{9}{|l|}{ Block 1: } \\
\hline RFI & .13 & .03 & $172.94^{* * *}$ & .53 & .50 & .04 & $156.76^{* * *}$ & 1.64 \\
\hline \multicolumn{9}{|l|}{ Block 2: } \\
\hline RFI & .45 & .03 & $174.41^{* * *}$ & 1.57 & .52 & .04 & $152.35^{* * *}$ & 1.68 \\
\hline Grade level & .56 & .06 & $67.71^{* * *}$ & 1.69 & .35 & .06 & 30.17 & 1.41 \\
\hline Race/ethnicity & & & 5.50 & & & & $43.54^{* * *}$ & \\
\hline Other & & & & 1 & & & & 1 \\
\hline Black & .50 & .32 & 2.41 & 1.66 & .98 & .32 & $9.22^{* *}$ & 2.66 \\
\hline White & .55 & .31 & 3.14 & 1.74 & -.35 & .32 & 1.21 & .71 \\
\hline Hispanic & .26 & .31 & .68 & 1.29 & .21 & .31 & .45 & .67 \\
\hline School district & & & 1.49 & & & & .76 & \\
\hline Broward & & & & 1 & & & & 1 \\
\hline Miami-Dade & -.001 & .19 & .00 & 1.00 & .03 & .19 & .02 & .97 \\
\hline Palm Beach & .18 & .17 & 1.05 & 1.19 & -.14 & .18 & .63 & .87 \\
\hline
\end{tabular}

For the female regression model, the overall model containing all predictors was statistically significant, $\chi^{2}(7, \mathrm{~N}=1478)=287.82, \mathrm{p}<.001$, but did not fit the data well (H-L statistic, $\mathrm{p}<.05$ ). The model generated in the second block (with demographic controls) yielded a better fit to the data than the first block and correctly classified $77.9 \%$ of female adolescents. This model also showed significant effects for RFI and grade level. The strongest predictor of HIV risk was grade level, recording an odds ratio of 1.69. The odds ratio for RFI was 1.57 , indicating that for every increase in risk factors, female students were 1.57 times more likely to report participation in at least one HIV risk. 
For the male regression model, the overall model containing all predictors was statistically significant and fit the data well, $\chi^{2}(7, \mathrm{~N}=1304)=282.88, \mathrm{p}<.001$. The model generated in the second step (with demographic controls) correctly classified $75.2 \%$ of adolescents. This model showed significant effects for RFI, grade level, and race/ethnicity. The strongest predictor of HIV risk was Black race (2.66), indicating that Black male students were 2.66 times more likely to report HIV risk behavior compared to male students in the Other race category. RFI recorded an odds ratio of 1.68. This indicated that for each increase in number of risk factors, male students were 1.68 times more likely to report participation in at least one HIV risk.

In summary, results showed that the risk factors predicted HIV risk behavior in both male and female students, however, the probability of risk was higher for males (1.68) than for females (1.57). This hypothesis was supported. This model also showed that HIV risk increases with grade level, and Black males students are more likely to engage in HIV risk behavior compared to males in the Other race category.

Hypothesis 2c. The hypothesis stated that students who reported participation in health risk behaviors would be more likely to report participation in HIV risk behaviors compared to students who did not engage in health risk behaviors. This prediction was supported. To address this research question, two logistic regression analyses were conducted, one for each gender, using the health risk behavior index (HRBI) (Block 1) and demographic controls (Block 2) as predictors (Table 25). The model contained four independent variables (HRBI, grade level, race/ethnicity, and school district). 
Table 25

Binary Logistic Regression Analyses Predicting Participation in At Least One HIV Risk Behavior from the Health Risk Behavior Index, by Gender ${ }^{a}$

\begin{tabular}{|c|c|c|c|c|c|c|c|c|}
\hline \multirow[b]{2}{*}{ Variable } & \multicolumn{4}{|c|}{ Female } & \multicolumn{4}{|c|}{ Male } \\
\hline & $\beta$ & SE & Wald & $\begin{array}{l}\text { Odds } \\
\text { ratio }\end{array}$ & $\beta$ & SE & Wald & $\begin{array}{l}\text { Odds } \\
\text { ratio }\end{array}$ \\
\hline \multicolumn{9}{|l|}{ Block 1: } \\
\hline HRBI & .46 & .03 & $299.28^{* * *}$ & 1.58 & .38 & .02 & $269.13^{* * *}$ & 1.53 \\
\hline \multicolumn{9}{|l|}{ Block 2: } \\
\hline HRBI & .47 & .03 & $275.82^{* * *}$ & 1.59 & .43 & .03 & $272.06^{* * *}$ & 1.46 \\
\hline Grade level & .37 & .07 & $33.25^{* * *}$ & 1.45 & .28 & .06 & $19.53^{* * *}$ & 1.32 \\
\hline Race/ethnicity & & & $10.71^{*}$ & & & & $78.75^{* * *}$ & \\
\hline Other & & & & 1 & & & & 1 \\
\hline Black & 1.07 & .38 & $8.09^{* *}$ & 2.94 & .87 & .33 & $7.10^{* *}$ & 2.39 \\
\hline White & .81 & .37 & 4.67 & 2.24 & -.99 & .34 & $8.39^{* *}$ & .37 \\
\hline Hispanic & .66 & .37 & 3.07 & 1.94 & -.08 & .32 & .07 & .92 \\
\hline School district & & & 3.07 & & & & .95 & \\
\hline Broward & & & & 1 & & & & 1 \\
\hline Miami-Dade & .29 & .20 & 2.15 & 1.33 & .03 & .19 & .03 & 1.03 \\
\hline Palm Beach & .29 & .18 & 2.63 & 1.34 & -.12 & .18 & .48 & .88 \\
\hline
\end{tabular}

For the female regression model, the overall model containing all predictors was statistically significant, $\chi^{2}(7, \mathrm{~N}=1679)=484.81, \mathrm{p}<.001$, but did not fit the data well (H-L statistic, $\mathrm{p}<.05)$. The model generated in the second block (with demographic controls) correctly classified $80.9 \%$ of female adolescents. This model also showed significant effects for HRBI, grade level, and race/ethnicity. The strongest predictor of HIV risk was HRBI, recording an odds ratio of 1.58. This indicated that for every increase in number of health risk behaviors, female students were 1.58 times more likely to report participation in at least one HIV risk behavior. This model also showed that 
Black females were 2.94 times more likely to participate in HIV risk behavior compared to females in the Other race/ethnicity category.

For the male regression model, the overall model containing all predictors was statistically significant and fit the data well, $\chi^{2}(7, \mathrm{~N}=1475)=513.93, \mathrm{p}<.001$. The model generated in the second step (with demographic controls) correctly classified $79.1 \%$ of adolescents. This model showed significant effects for HRBI, grade level, and race/ethnicity. The strongest predictor of HIV risk was Black race, recording an odds ratio of 2.4, indicating that Black male students were 2.4 times more likely than males in the Other race category to report HIV risk behavior, while White males were .37 times less likely to report HIV risk behavior. HRBI recorded an odds ratio of 1.53 , indicating that for each increase in number of health risk behaviors, male students were 1.53 times more likely to report participation in at least one HIV risk.

In summary, results showed that the health risk behaviors predicted HIV risk behavior in both male and female students, however, the probability of risk was higher for females (1.59) than for males (1.53), when controlling for grade level, race/ethnicity, and school district location. Therefore the hypothesis was supported. This model also showed that HIV risk increases with grade level, and Black students were more likely than Other race/ethnicity students to engage in HIV risk behavior when controlling for other factors. Conversely, White male students were less likely than Other male students to report HIV risk behavior.

Hypothesis 2d. The hypothesis stated that protective factors will moderate the relationships between risk factors and HIV risk behaviors and between health risk behaviors and HIV risk behaviors. This prediction was partially supported. To address 
this research question, two sets of logistic regression analyses were conducted using and interaction variable with protective factors and RFI (Table 26). Although sports team membership was found to be a significant predictor of HIV risk in males, it was found to increase the probability of HIV risk, therefore it was excluded from further analysis as a protective factor.

Table 26

Binary Logistic Regression Analyses Predicting Participation in HIV Risk Behavior from Interactions for Protective Factors and RFI/HRBI

\begin{tabular}{ccccccccc}
\hline & \multicolumn{4}{c}{ Female } & \multicolumn{5}{c}{ Male } \\
\hline Variable & $\beta$ & SE & Wald & $\begin{array}{c}\text { Odds } \\
\text { ratio }\end{array}$ & $\beta$ & SE & Wald & $\begin{array}{c}\text { Odds } \\
\text { ratio }\end{array}$ \\
\hline Safe Schools x RFI & .04 & .02 & .03 & 1.00 & -.01 & .03 & .05 & .99 \\
Safe Schools x HRBI & .02 & .03 & .89 & 1.02 & .02 & .02 & 1.25 & 1.02 \\
Sex Education x RFI & - & - & - & - & -.11 & .07 & $2.75^{*}$ & .89 \\
Sex Education x HRBI & - & - & - & - & -.08 & .05 & 2.46 & .92 \\
\hline \multicolumn{2}{l}{ Two-tailed tests of significance: ${ }^{*} \mathrm{p}<.05 .{ }^{* *} \mathrm{p}<.01 .^{* * *} \mathrm{p}<.001}$. & & &
\end{tabular}

Do safe schools moderate the relationship between risk factors and HIV risk

behavior? Two logistic regression analyses were conducted, one for each gender, using the interaction term for safe schools and RFI in Block 3 (Table 26). The model contained four independent variables (RFI, grade level, race/ethnicity, and school district) and one interaction term (safe schools x RFI)

For the female regression model, the overall model containing all predictors was statistically significant and fit the data well, $\chi^{2}(8, \mathrm{~N}=1476)=288.23, \mathrm{p}<.001$. The model generated in the third step (with interaction terms) correctly classified $78 \%$ of female adolescents. The interaction term of safe schools X RFI was not found to be statistically significant in the model. For the male regression model, the overall model containing all predictors was statistically significant and fit the data well, $\chi^{2}(8, N=1302)$ 
$=282.41, \mathrm{p}<.001$. The model generated in the second step (with demographic controls) correctly classified $75.5 \%$ of male students. The interaction term for safe schools was not found to be statistically significant in this model.

In summary, results showed that the safe schools index did not significantly moderate the relationship between risk factors and HIV risk behavior for either gender.

\section{Do safe schools moderate the relationship between health risk behaviors and}

HIV risk behavior? Two logistic regression analyses were conducted, one for each gender, using the interaction term for safe schools and HRBI in Block 3 (Table 26). The model contained four independent variables (HRBI, grade level, race/ethnicity, and school district) and one interaction term (safe schools $\mathrm{x} \mathrm{HRBI}$ )

For the female regression model, the overall model containing all predictors was statistically significant, $\chi^{2}(8, \mathrm{~N}=1696)=480.60, \mathrm{p}<.001$, but did not fit the data well (H-L statistic, $\mathrm{p}<.05)$. The model generated in the third step (with interaction terms) correctly classified $80.9 \%$ of female adolescents. The interaction term of safe schools X HRBI was not found to be statistically significant in the model. For the male regression model, the overall model containing all predictors was statistically significant and fit the data well, $\chi^{2}(8, \mathrm{~N}=1472)=509.54, \mathrm{p}<.001$. The model generated in the second step (with demographic controls) correctly classified $79.1 \%$ of male students. The interaction term for safe schools was not found to be statistically significant in this model.

In summary, results showed that the safe schools index did not significantly moderate the relationship between health risk behaviors and HIV risk behavior for either gender. Therefore, the hypothesis was not supported. 


\section{Does receipt of sex education moderate the relationship between risk factors}

and HIV risk behavior? Since sex education was not found to predict HIV risk behavior in females, logistic regression analysis was conducted for males only using the interaction term for sex education and RFI in Block 3 (Table 26). The model contained four independent variables (RFI, grade level, race/ethnicity, and school district) and one interaction term (sex education $\mathrm{x}$ RFI)

For the male regression model, the overall model containing all predictors was statistically significant and fit the data well, $\chi^{2}(8, N=1298)=285.02, p<.001$. The model generated in the second step (with demographic controls) correctly classified $75.6 \%$ of male students. The interaction term for sex education $\mathrm{x}$ RFI was found to be statistically significant in this model, recording an odds ratio of .89 , indicating that it reduce the likelihood of males reporting HIV risk behavior. Therefore this hypothesis was supported.

Does receipt of sex education moderate the relationship between health risk behaviors and HIV risk behavior? Since sex education was not found to predict HIV risk behavior in females, logistic regression analysis was conducted for males only using the interaction term for sex education and HRBI in Block 3 (Table 26). The model contained four independent variables (HRBI, grade level, race/ethnicity, and school district) and one interaction term (sex education $\mathrm{x} \mathrm{HRBI}$ ).

For the male regression model, the overall model containing all predictors was statistically significant and fit the data well, $\chi^{2}(8, N=1465)=515.83, p<.001$. The model generated in the second step (with demographic controls) correctly classified 
$79.2 \%$ of male students. The interaction term for sex education $\mathrm{x}$ HRBI was not found to be statistically significant in this model. Therefore, the hypothesis was not supported.

\section{Research Question 3}

Do characteristics of comprehensive sex education policies predict students' participation in HIV risk behavior?

The two characteristics of sex education policy examined in this study were length of comprehensive sex education policy implementation and course of instruction in which sex education topics were taught (health education vs. science course). Because these variables were of interest in respect to comprehensive sex education students received, analyses were restricted to 9th-10th grade students who reported receipt of HIV/AIDS education in school $(n=2,808)$.

Table 27

Descriptive Characteristics of Sex Education Policy Implementation Among 9th-10th Grade Students Who Reported Receipt of HIV/AIDS Education in School $(n=2,808)^{a}$

\begin{tabular}{lcccc}
\hline Characteristic & $\begin{array}{c}\text { Females } \\
(\mathrm{n}=1,436)\end{array}$ & $\begin{array}{c}\text { Males } \\
(\mathrm{n}=1,372)\end{array}$ & $\chi^{2}$ & $p$ \\
\hline $\begin{array}{l}\text { Length of time policy implemented } \\
\quad 2 \text { years }\end{array}$ & & & $1.74^{\mathrm{b}}$ & .68 \\
$\quad 865(60.2)$ & $837(61.0)$ & & \\
$\quad \begin{array}{l}\text { or more years } \\
\text { Course of instruction }\end{array}$ & $571(39.8)$ & $535(39.0)$ & & \\
$\quad \begin{array}{l}\text { Health education } \\
\text { Science }\end{array}$ & $870(60.6)$ & $819(59.7)$ & & $.23^{\mathrm{b}}$ \\
\hline
\end{tabular}

${ }^{\mathrm{a}}$ All data are given as the number (percentage) of students unless otherwise specified.

${ }^{b} \mathrm{df}=1$

* $\mathrm{p}<.05 .(2$-tailed $)$

Preliminary analyses tested for gender differences in characteristics of sex education policy characteristics. Similar proportions of males and females (60-61\%) attended schools in districts that had implemented comprehensive sex education policies within two years of survey administration (Table 27). Similar proportions of students in 
both genders $(60 \%)$ reported receiving sex education topics in a health education course.

Chi-square analyses did not reveal significant gender differences for either length of time $\left(\chi^{2}(1, N=2,808)=1.74, p=.68\right)$ or course of instruction $\left(\chi^{2}(1, N=2,808)=.23, p=\right.$ $.63)$.

To test the hypotheses, bivariate analyses first were performed to test for correlations between HIV risk behaviors and independent variables. Phi $(\varphi)$ correlation coefficients were computed for each HIV risk behavior with length of policy implementation ( $\leq 2$ years vs. $\geq 3$ years) and course in which sex education was taught (health education vs. science) (Table 28). The only significant correlation found was between course of instruction and lifetime injection drug use for males, $\varphi(1020)=.07, \mathrm{p}$ $=.03$.

Table 28

Bivariate Associations of Characteristics of Sex Education Policy Implementation and HIV Risk Behavior for 9th-10th Grade Students Who Reported Receipt of HIV/AIDS Education ${ }^{\mathrm{a}}$

\begin{tabular}{|c|c|c|c|c|}
\hline \multirow[b]{3}{*}{ Variable } & \multicolumn{4}{|c|}{ Females $(\mathrm{n}=1,436)$} \\
\hline & \multicolumn{4}{|c|}{ HIV Risk Behavior } \\
\hline & Unprotected sex & $4+$ sexual partners & $\begin{array}{l}\text { Sex under } \\
\text { the influence }\end{array}$ & IDU \\
\hline Length of policy implementation & -.02 & -.03 & -.03 & -.02 \\
\hline \multirow[t]{4}{*}{ Course of instruction } & -.02 & -.04 & -.02 & .004 \\
\hline & \multicolumn{4}{|c|}{ Males $(n=1,372)$} \\
\hline & \multicolumn{4}{|c|}{ HIV Risk Behavior } \\
\hline & Unprotected sex & $4+$ sexual partners & $\begin{array}{l}\text { Sex under } \\
\text { the influence }\end{array}$ & IDU \\
\hline Length of policy implementation & -.008 & .04 & .008 & .06 \\
\hline Course of instruction & -.03 & .05 & -.005 & $.07^{*}$ \\
\hline
\end{tabular}

${ }^{\mathrm{a}}$ All data are given as the $\mathrm{Phi}(\varphi)$ coefficient.

Two-tailed tests of significance: ${ }^{*} \mathrm{p}<.05$.

Hypothesis 3a. The hypothesis stated that students who received sex education in school districts with longer running comprehensive sex education policies (Miami-Dade) 
would be less likely to report HIV risk behaviors than students in school districts with shorter running policies (Broward and Palm Beach). Bivariate analysis revealed that there were no significant associations between length of policy implementation time and any of the individual HIV risk behaviors, therefore this hypothesis was not supported.

Hypothesis $\mathbf{3 b}$. This hypothesis stated that students who received sex education in a health education course will be less likely to report HIV risk behaviors than students who received sex education in a science course. This hypothesis was also not supported.

Since course of instruction was not found to be significantly correlated to any of the HIV risk behaviors in the bivariate analyses for females, analysis was performed for males only. A logistic regression analyses was conducted using course of instruction $(0=$ science; 1 = health education) (Block 1) and demographic controls (Block 2) as predictors (Table 29). The model contained three independent variables (course of instruction, grade level, and race/ethnicity). Since IDU was the only HIV risk behavior found to be significantly correlated with course of instruction, it was used as the dependent variable in this logistic regression. Collinearity statistics were conducted to evaluate independent variables for multicollinearity prior to regression analysis. All correlations fell below .5 , indicating that there was insufficient evidence to warrant concern about multicollinearity. 
Table 29

Binary Logistic Regression Analyses Predicting Lifetime Injection Drug Use from Course of Instruction for 9th-10th Grade Males Who Received Sex Education ${ }^{a}$

\begin{tabular}{lcccc}
\hline \multicolumn{1}{c}{ Variable } & $\beta$ & SE & Wald & Odds ratio \\
\hline Block 1: & & & \\
Course of Instruction & & & & 1 \\
Science & 1.01 & .48 & $4.51^{*}$ & 2.75 \\
Health education & & & & \\
Block 2: & & & & 1 \\
Course of Instruction & & & & 2.48 \\
Science & .91 & .520 & 3.56 & .56 \\
Health education & -.59 & .44 & 1.76 & 1 \\
Grade level & & & $12.72^{* *}$ & .28 \\
Race/ethnicity & & & & .09 \\
Other & -1.29 & .59 & $4.8^{*}$ & .19 \\
Black & -2.46 & .84 & $8.67^{* *}$ & $8.82^{* *}$ \\
White & -1.67 & .56 &
\end{tabular}

Two-tailed tests of significance: ${ }^{*} \mathrm{p}<.05{ }^{* *} \mathrm{p}<.01$.

For the male regression model, the overall model containing all predictors was statistically significant and fit the data well, $\chi^{2}(5, N=1020)=18.60, p<.001$. The model in the first step (without demographic controls) revealed that 9th-10th grade male students who received sex education in a health education course (vs. science course) were 2.75 times more likely to report lifetime IDU. The model generated in the second step (with demographic controls) correctly classified $97.6 \%$ of adolescents. This model showed significant effects for race/ethnicity only. Results revealed that 9th-10th grade White males were .09 times less likely to report IDU compared to males in the Other race category. Also, compared to the reference category, Black students and Hispanic students, respectively, were .28 and .19 times less likely to report HIV risk behavior. 
In summary, when controlling for demographic factors, results did not show that 9th-10th grade students that received sex education in a health education course were less likely to report HIV risk behavior than students that received sex education in a science course. Therefore the hypothesis was not supported.

\section{Research Question 4}

What gender differences exist in the predictors of participation in HIV risk behavior among high school students in South Florida when controlling for grade level, race/ethnicity, and school district?

To test this research question, two logistic regressions (one for each gender) were performed to assess the ability of protective factors, risk factors, and health risk behaviors to predict students' participation in HIV risk behavior, after controlling for demographic factors (e.g., grade level, race/ethnicity) (Table 30). School district location was not found to be a significant predictor of HIV risk in any of the previous models, and was therefore omitted from the full regression model. Collinearity statistics were conducted to evaluate independent variables for multicollinearity prior to regression analysis. All correlations fell below .5, indicating that there was insufficient evidence to warrant concern about multicollinearity.

The female model contained five independent variables. The protective factor variable that was included was safe schools (safe schools index). The RFI was used for risk factors and the HRBI was used for health risk behaviors. Demographic factors included grade level and race/ethnicity. For race/ethnicity, the reference category was the "Other" race category. 
Table 30

Female Logistic Regression Analyses of Predictors of Participation in At Least One HIV Risk Behavior

\begin{tabular}{lcccc}
\hline \multicolumn{1}{c}{ Variable } & $\beta$ & SE & Wald & Odds ratio \\
\hline Safe schools index & .09 & .14 & .38 & 1.10 \\
RFI & .11 & .05 & $5.10^{*}$ & 1.12 \\
HRBI & .41 & .04 & $127.27^{* * *}$ & 1.51 \\
Grade level & .41 & .07 & $34.25^{* * *}$ & 1.54 \\
Race/ethnicity & & & $12.03^{* *}$ & \\
$\quad$ & & & 1 \\
$\quad$ Other & 1.16 & .41 & $8.11^{* *}$ & 3.18 \\
$\quad$ Black & .86 & .40 & $4.73^{*}$ & 2.36 \\
$\quad$ White & .63 & .39 & 2.54 & 1.87 \\
\hline \multicolumn{2}{l}{ Hispanic } & & &
\end{tabular}

The overall model containing all predictors was statistically significant and fit the data well, $\chi^{2}(7, \mathrm{~N}=1402)=413.62, \mathrm{p}<.001$, indicating that the model was able to distinguish between respondents who reported and did not report participation in at least one HIV risk behavior. The model correctly classified $81.2 \%$ of adolescents. This model showed significant effects for RFI, HRBI, grade level, and race/ethnicity. Safe schools were not found to be a significant predictor.

The strongest predictor of HIV risk behavior in the model was race/ethnicity. Compared with the reference category (Other race/ethnicity), Black and White female students, respectively, were 3.18 and 2.36 times more likely to engage in HIV risk behavior. HRBI recorded an odds ratio of 1.51. This indicated that for every increase in number of health risk behaviors, female students were 1.51 times more likely to report participation in at least one HIV risk behavior. RFI reported an odds ratio of 1.12 , indicating that for every increase in number of risk factors, female students were 1.12 times more likely to report participation in at least one HIV risk behavior. For each grade 
level increase, female students were 1.51 times more likely to report participation in at least one HIV risk.

Table 31

Male Logistic Regression Analyses of Predictors of Participation in At Least One HIV Risk Behavior

\begin{tabular}{lcccc}
\hline \multicolumn{1}{c}{ Variable } & $\beta$ & SE & Wald & Odds ratio \\
\hline Safe schools index & -.001 & .16 & .000 & 1.00 \\
Sex education & -.09 & .39 & .05 & .92 \\
Sports team membership & .10 & .08 & 1.80 & 1.11 \\
RFI & .16 & .15 & 1.09 & 1.19 \\
HRBI & .43 & .04 & $135.40^{* * *}$ & 1.54 \\
Grade level & .32 & .07 & $19.11^{* * *}$ & 1.38 \\
Race/ethnicity & & & $57.94^{* * *}$ & \\
$\quad$ Other & .90 & .37 & $.57^{* *}$ & 1 \\
$\quad$ Black & -.96 & .38 & $6.25^{* *}$ & .39 \\
$\quad$ White & -.001 & .36 & .00 & 1.00 \\
$\quad$ Hispanic & -.17 & .16 & 1.18 & .85 \\
Sex education x RFI & ${ }^{* *} \mathrm{p}<.01^{* * *} \mathrm{p}<.001$ & & \\
\hline Two-tailed tests of significance: & & & \\
\end{tabular}

The male model (Table 31) contained seven independent variables and one interaction variable (sex education $\mathrm{x}$ RFI). The overall model containing all predictors was statistically significant and fit the model well, $\chi^{2}(11, \mathrm{~N}=1206)=431.53, \mathrm{p}<.001$, indicating that the model was able to distinguish between respondents who reported and did not report participation in at least one HIV risk behavior. The model correctly classified $80.8 \%$ of adolescents. This model showed significant effects for HRBI, grade level, and race/ethnicity. Neither RFI nor any of the protective factor variables were found to be significant in the regression equation. The interaction term (sex education $\mathrm{x}$ RFI) was also not significant. 
The strongest predictor of HIV risk behavior among males was Black race. Compared with the reference category (Other race), Black males were 2.4 times more likely to engage in HIV risk behavior. The second strongest predictor of HIV risk behavior was HRBI, recording an odds ratio of 1.54 . This indicated that for every increase in number of health risk behaviors, male students were 1.54 times more likely to report participation in at least one HIV risk behavior. For each grade level increase, male students were 1.38 times more likely to report participation in at least one HIV risk. This model also showed that White males recorded an odds ratio of .39, indicating that they were .39 times less likely to engage in HIV risk behavior compared to males of the Other race/ethnicity category.

Hypothesis 4a. The research hypothesis that gender differences will exist in the predictors of HIV risk was supported. For females, RFI, HRBI, grade level, and race/ethnicity were found to be predictors of HIV risk behavior. For males, however, the only significant predictors of HIV risk behavior were HRBI, grade level, and race/ethnicity. Grade level was a stronger predictor of HIV risk for females (1.54) than males (1.38). Also, Black race was a stronger predictor of risk for females (3.18) than for males (2.4). Furthermore, White females (2.36) were more likely to engage in HIV risk behavior than females in the Other race category, however, White males (.39) were less likely to engage in HIV risk behavior than the reference category.

Hypothesis $\mathbf{4 b}$. This hypothesis stated that risk factors will be a stronger predictor of HIV risk behavior in females than in males, and health risk behaviors will be a stronger predictor of HIV risk behavior for males than in females. This hypothesis was 
supported. HRBI was found to be stronger in males (1.54) than in females (1.51). RFI was not found to be a significant predictor of HIV risk in males.

\section{Post-Hoc Analyses}

To further examine the significant findings in the full model (Hypothesis 4), posthoc analyses were conducted to determine the separate effects of individual risk factor and health risk behavior variables on each HIV risk behavior. Four separate sets of logistic regressions were performed to assess the ability of individual risk factors and health risk behaviors to predict students' participation in each of the four HIV risk behaviors, after controlling for demographic factors. All analyses were stratified by gender. Collinearity statistics were conducted to evaluate independent variables for multicollinearity prior to regression analysis.

Each model contained 26 independent variables, including five risk factors and 19 health risk behaviors. The risk factors "offered cigarettes" and "offered alcohol" were omitted from the regression equation because they were highly correlated with the health risk behaviors "cigarette use" and "alcohol use." All other correlations fell below .5, indicating that there was insufficient evidence to warrant concern about multicollinearity. Demographic factors included grade level and race/ethnicity. School district was omitted from this model since it was not found to be significant in the previous logistic regression models. For race/ethnicity, the reference category was the "Other" race category.

\section{Predictors of Unprotected sex}

Table 32 presents the significant predictors of unprotected sex at last intercourse $(0=$ No, $1=$ Yes $)$. For females, the overall model containing all predictors was statistically significant and fit the model well, $\chi^{2}(28, \mathrm{~N}=1429)=371.70, \mathrm{p}<.001$. This 
model correctly classified $85.3 \%$ of adolescents. There were seven significant predictors found in the female regression model, including grade level, one risk factors, and five health risk behaviors. For males, the overall model containing all predictors was statistically significant and fit the model well, $\chi^{2}(28, \mathrm{~N}=1228)=192.40, \mathrm{p}<.001$. The model correctly classified $89.3 \%$ of adolescents. There were also seven significant predictors found in the male regression equation, including grade level, race/ethnicity, two risk factors, and three health risk behaviors.

Table 32

Significant Predictors of Unprotected Sex at Last Sexual Intercourse, by Gender ${ }^{a}$

\begin{tabular}{|c|c|c|c|c|}
\hline & \multicolumn{4}{|c|}{ Females } \\
\hline Variable & $\beta$ & SE & Wald & Odds ratio \\
\hline Grade level & .24 & .09 & $7.43^{* *}$ & 1.27 \\
\hline Sexual abuse & .97 & .26 & $13.97^{* *}$ & 2.64 \\
\hline Recent sexual activity & 2.19 & .21 & $108.24^{* * *}$ & 8.94 \\
\hline Smoked cigarettes & .72 & .29 & $6.32^{*}$ & 2.06 \\
\hline Recent marijuana & -.69 & .27 & $6.62^{*}$ & .50 \\
\hline Inhalants & .56 & .28 & $4.08^{*}$ & 1.17 \\
\hline \multirow[t]{2}{*}{ Physical fighting } & .74 & .20 & $13.69^{* * *}$ & 2.10 \\
\hline & \multicolumn{4}{|c|}{ Males } \\
\hline Variable & $\beta$ & SE & Wald & Odds ratio \\
\hline Grade level & .21 & .10 & $7.00^{* *}$ & 1.31 \\
\hline Race/ethnicity & & & $8.47^{*}$ & \\
\hline Sexual abuse & .90 & .43 & $4.37^{*}$ & 2.45 \\
\hline Dating violence & .55 & .28 & $3.85^{*}$ & 1.73 \\
\hline Early age at first sex & 1.09 & .30 & $12.94^{* * *}$ & 2.97 \\
\hline Recent sexual activity & 1.23 & .23 & $27.95^{* * *}$ & 3.43 \\
\hline Smoked cigarettes & .97 & .32 & $9.08^{* *}$ & 2.65 \\
\hline
\end{tabular}

The strongest predictor of unprotected sex for both genders was recent sexual activity. Female students who had sexual intercourse in the last three months were 8.94 
times more likely to report not using a condom at last sexual intercourse than females who did not engage in sexual activity, and male students were 3.43 times more likely to report having unprotected sex compared to males that did not recently have sex. Male students who had their first sexual intercourse before the age of 13 were 2.97 times more likely to not use a condom at last sexual intercourse than male students who practiced abstinence or had their first sexual intercourse at a later age.

Females and males who reported a history of sexual abuse were 2.64 and 2.45 times more likely, respectively, to report unprotect sex compared to females and males without a history of sexual abuse. Male victims of dating violence were 1.73 times as likely to report unprotected sex.

Smoking cigarettes was also found to be a significant predictor of unprotected sex, and males who smoked cigarettes were about 2.6 times as likely to report unprotected sex and females who smoked cigarettes were 2.06 times as likely to report unprotected sex, compared to students who did not smoke cigarettes. Also, female students who reported lifetime use of inhalants were 1.76 times as likely not use a condom at last sexual intercourse. Interestingly, females who reported smoking marijuana in the past 30 days were .50 times less likely to report unprotected sex than females who did not smoke marijuana. For males, there were no drug or alcohol use behaviors found to be significant predictors of unprotected sex.

Finally, female students who reported being in a physical fight were 2.10 times more likely to report not using a condom at last sex than females who did not engage in a physical fight. 


\section{Predictors of Having Multiple Sexual Partners}

Table 33 presents the significant predictors of having multiple (4 or more) sexual partners $(0=$ No, $1=$ Yes $)$. For females, the overall model containing all predictors was statistically significant and fit the model well, $\chi^{2}(28, \mathrm{~N}=1436)=366.80, \mathrm{p}<.001$. This model correctly classified $90.7 \%$ of adolescents.

Table 33

Significant Predictors of Four or More Sexual Partners, by Gender ${ }^{a}$

\begin{tabular}{lcccc}
\hline \multicolumn{1}{c}{ Variable } & $\beta$ & SE & Wald & Odds ratio \\
\hline Grade level & .31 & .11 & $8.01^{* *}$ & 1.36 \\
Race/ethnicity & & & $10.07^{*}$ & \\
Sexual abuse & 1.10 & .28 & $15.56^{* * *}$ & 3.01 \\
Early age at first sex & 1.05 & .49 & $4.06^{*}$ & 2.85 \\
Recent sexual activity & 1.91 & .27 & $50.98^{* * *}$ & 6.74 \\
Smoked cigarettes & .93 & .31 & $9.32^{* *}$ & 2.55 \\
Lifetime marijuana & .85 & .29 & $8.78^{* *}$ & 2.34 \\
Ecstasy & .83 & .36 & $5.28^{*}$ & 2.29 \\
\hline \multicolumn{1}{c}{ Variable } & & & Males & \\
\hline Grade level & $\beta$ & SE & Wald & Odds ratio \\
White race & .45 & .10 & $20.01^{* * *}$ & 1.57 \\
Early age at first sex & -1.50 & .49 & $9.28^{* *}$ & .22 \\
Recent sexual activity & 2.27 & .31 & $54.08^{* * *}$ & 9.66 \\
Weapon carrying & 2.36 & .23 & $107.43^{* * *}$ & 10.55 \\
Physical fighting & .60 & .27 & $5.01^{*}$ & 1.81 \\
\hline Two-tailed tests of significance: ${ }^{*} \mathrm{p}<.05 .{ }^{* *} \mathrm{p}<.01 .^{* * *} \mathrm{p}<.001$. \\
\end{tabular}

There were eight significant predictors found in the female regression model, including grade level, race/ethnicity, one risk factors, and five health risk behaviors. For males, the overall model containing all predictors was statistically significant and fit the model well, $\chi^{2}(28, \mathrm{~N}=1237)=513.37, \mathrm{p}<.001$. The model correctly classified $87.9 \%$ 
of adolescents. There were six significant predictors found in the male regression equation, including grade level, White race, and four health risk behaviors.

The strongest predictor of having multiple sexual partners was recent sexual activity. Female students who had sexual intercourse in the last three months were 6.74 times more likely to having for or more sexual partners than females who did not have sex recently. Male students who had sex in the past three months, however, were 10.55 times more likely to report having multiple sexual partners compared to males that did not recently have sex.

Male students who had their first sexual intercourse before the age of 13 were 9.66 times more likely to report having four or more sexual partners than male students who practiced abstinence or had their first sexual intercourse at a later age. The odds ratio for females who had their first sexual experience before 13 years of age was 2.85 . Females who reported a history of sexual abuse were 3 times more likely, to have multiple sexual partners compared to females without a history of sexual abuse.

Smoking cigarettes was also found to be a significant predictor of multiple sexual partners, and females who smoked cigarettes were 2.55 times more likely to report having four or more sexual partners compared to female students who did not smoke cigarettes. Also, female students who reported lifetime use of marijuana and ecstasy were 2.3 times more likely to have four or more sexual partners than female students who never used marijuana or ecstasy.

Finally, male students who reported being in a physical fight or carrying a weapon were 1.8 times more likely to have multiple sexual partners than males who did not engage in a physical fighting or weapon carrying. White male students were also .22 
times less likely to report four or more sexual partners than males in the Other race category.

\section{Predictors of Sex Under the Influence of Alcohol/Drugs}

Table 34 presents the significant predictors of having sex under the influence of drugs or alcohol at last sexual intercourse $(0=$ No, $1=$ Yes $)$. For females, the overall model containing all predictors was statistically significant and fit the model well, $\chi^{2}(28$, $\mathrm{N}=1437)=294.560, \mathrm{p}<.001$. This model correctly classified $94.2 \%$ of adolescents. There were three significant predictors found in the female regression model. For males, the overall model containing all predictors was statistically significant and fit the model well, $\chi^{2}(28, \mathrm{~N}=1241)=349.23, \mathrm{p}<.001$. The model correctly classified $92.4 \%$ of adolescents. There were seven significant predictors found in the male regression equation, all of which were health risk behaviors.

The strongest predictor of having sex under the influence in females was lifetime use of marijuana. Female students who smoked marijuana at least once in their lifetime were 3.93 times more likely to report sex under the influence of drugs/alcohol than females who never used marijuana. The strongest predictor of sex under the influence in male students was involvement in a physical fight. Males who reported engaging in a fight were 3.2 times more likely to have sex under the influence of drugs or alcohol than male students who did not engage in a physical fight.

Table 34

Significant Predictors of Sex Under the Influence of Drugs/Alcohol at Last Sexual Intercourse, by Gender ${ }^{a}$

Females

Variable

$\beta$

SE

Wald

Odds ratio 


\begin{tabular}{lcccc} 
Recent sexual activity & 1.09 & .32 & $11.85^{* *}$ & 2.98 \\
Drank alcohol & 1.07 & .47 & $5.16^{*}$ & 2.91 \\
Lifetime marijuana & 1.37 & .47 & $8.84^{* *}$ & 3.93 \\
\cline { 2 - 5 } & & & Males & \\
\hline \multicolumn{1}{c}{ Variable } & $\beta$ & SE & Wald & Odds ratio \\
\hline Offered drugs & .84 & .27 & $9.81^{* *}$ & 2.31 \\
Recent sexual activity & .90 & .30 & $9.40^{* *}$ & 2.47 \\
Smoked cigarettes & .76 & .33 & $5.35^{*}$ & 2.13 \\
Drank alcohol & 1.00 & .48 & $4.35^{*}$ & 2.72 \\
Binge drinking & 1.07 & .36 & $8.78^{* *}$ & 2.91 \\
Drink-driving & .77 & .33 & $5.34^{*}$ & 2.16 \\
Physical fighting & 1.16 & .31 & $14.48^{* * *}$ & 3.20 \\
\hline Two-tailed tests of significance: ${ }^{*} \mathrm{p}<.05 .^{* *} \mathrm{p}<.01 .^{* * *} \mathrm{p}<.001$. &
\end{tabular}

Compared with students who never had sex or were not recently sexually active, male and female students who were recently sexual active (past 3 months) were 2.98 and 2.47 times more likely to report sex under the influence, respectively. Recent alcohol use (past 30 days) was also found to be a significant predictor of sex under the influence for both genders. Females who drank alcohol were 2.91 times more likely and males who drank alcohol were 2.72 times more likely to report last sexual intercourse under the influence of drugs or alcohol compared with students who did not drink alcohol in the last 30 days. Binge drinking (2.91) and driving under the influence (2.16) were also found to be significant predictors of sex under the influence of drugs/alcohol in males.

Finally, cigarette smoking and being offered or sold illicit drugs were found to be significant predictors of sex under the influence of drugs/alcohol.

\section{Predictors of Injection Drug Use}

For females, the overall model containing all predictors was statistically significant and fit the model well, $\chi^{2}(28, \mathrm{~N}=1439)=210.76, \mathrm{p}<.001$, however, there 
were no significant predictors of IDU found in the female regression model. For males, the overall model containing all predictors was statistically significant and fit the model well, $\chi^{2}(28, \mathrm{~N}=1241)=282.62, \mathrm{p}<.001$. For the male regression model, there were no significant predictors for IDU found when controlling for all factors in the model.

\section{Overall Predictors of HIV risk behavior}

When controlling for demographic factors (grade level, race/ethnicity, and school district location), the safe schools index, risk factor index, and health risk behavior index were all found to predict HIV risk behavior in both genders. Receipt of sex education and sports team membership were found to predict participation in HIV risk behavior in males only.

In the full regression models, gender differences were found in the predictors of participation in HIV risk behavior (Figure 6). HRBI was found to significantly predict HIV risk in both genders, however, RFI was only found to significantly predict HIV risk in females. Grade level was a consistent significant predictor of HIV risk in all of the individual regression models as well as the full regression model. Black and White race were also important predictors of HIV risk, however, gender differences were found in the magnitude of influence. 


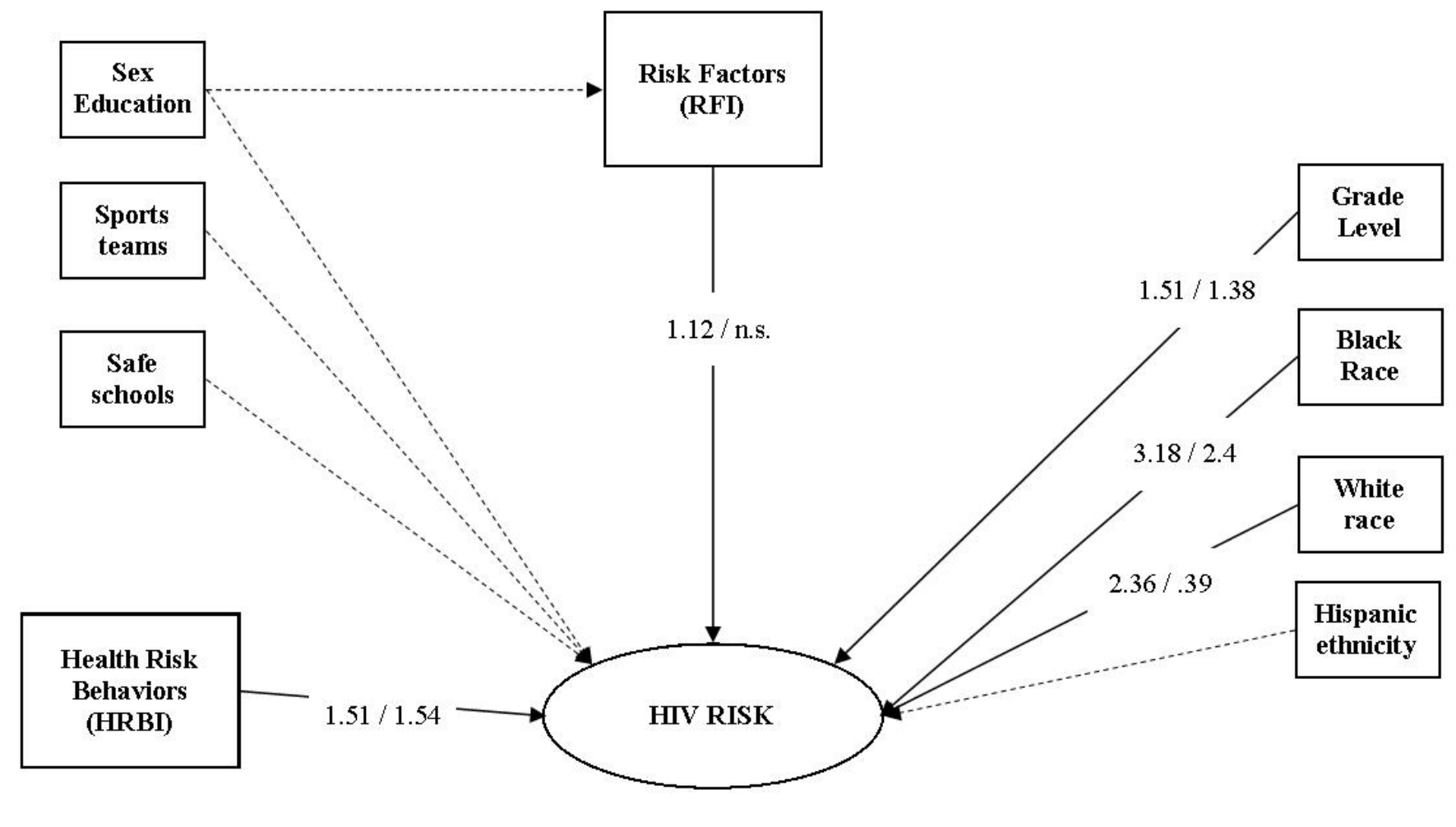

Figure 6. Logistic regression for the conceptual model of factors influencing adolescent participation in HIV risk behavior. Bold arrows indicate statistically significant relationships. Dashed lines indicate relationships that were not significant (n.s.). Odd ratios values for both genders (females/males) are reported. 
Post-hoc analyses examined predictors of individual HIV risk behaviors for both genders. Recent sexual activity (past 3 months) was found to be a strong, significant predictor of the HIV risk behaviors. Other common predictors among genders were early age at first sexual intercourse and cigarette smoking, however, gender differences were found in the significant predictors of having unprotected sex, multiple sexual partners, and sex under the influence of drugs/alcohol.

\section{Summary}

This chapter presented the findings from a secondary analysis of the combined 2009 State and Local YRBS for Miami-Dade, Broward, and Palm Beach school districts, as guided by the conceptual model for protective factors, risk factors, and health risk behaviors that influence adolescent HIV risk behavior. Results from the tests of the hypotheses were presented and findings were summarized. The final chapter contains a summary of the current study, a discussion of the findings in comparison with the current state of the literature, as well as implications for public health and recommendations for future research. 


\section{Chapter V \\ DISCUSSION}

The final chapter summarizes the present study and reviews its problem, purpose, and findings. Comparisons with the current state of the literature are discussed, implications for public health are presented, and, finally, future research recommendations are listed.

\section{Summary of the Study}

This study investigated gender differences in the influence of factors associated with adolescent HIV-related risk behaviors, as predicted by a guiding framework derived from Jessor's Theory of Problem Behavior (PBT) (Jessor et al., 1998a) and Wingood and DiClemente's (2000) adaption of Theory of Gender and Power (TGP). A secondary analysis of the combined 2009 State and Local YRBS data set from three South Florida school districts tested the conceptual model for factors affecting HIV-related risk behavior among high school students. The variables identified from the conceptual model included protective factors, risk factors, health risk behaviors, as well as sex education policy characteristics.

\section{Problem Statement}

Adolescents engage in a range of risk behaviors during their transition from childhood to adulthood (DiClemente et al., 2008; Jessor, 1991). Of special concern are behaviors that have health and life-compromising outcomes such as unintended pregnancies and STIs, including HIV, which affect individuals as well as communities as a whole. Several behaviors have been identified that put adolescents at increased risk for HIV: unprotected sexual intercourse, multiple sexual partners, sex under the influence of 
alcohol or drugs, and injection drug use (CDC, 1992, 2006, 2008d; Niyonsenga et al., 2008).

Rates of adolescent sexual activity in the state of Florida are higher than national rates for high school students who reported ever having sex (50.6\% vs. $46.0 \%)$, initiating sex before age 13 ( $8.3 \%$ vs. 5.9\%), and having four or more lifetime sexual partners (16.6\% vs. 13.5\%) (CDC, 2010b). Miami-Dade, Broward, and Palm Beach counties, which collectively make up the South Florida region, are the top three areas for HIV/AIDS and STI cases in Florida (Bandiera et al., 2008). Young people living in this region have been especially hit hard by the HIV/AIDS epidemic. Of the 3,840 reported HIV/AIDS cases among the state's adolescents and young adults through 2010, almost half (47.4\%) were from South Florida (DOH, 2011a, 2011b, 2011c). Despite high prevalence rates of HIV/AIDS among South Florida youth, research on adolescent sexual risk behaviors in this region is limited.

The social and financial burdens of preventable health problems due to risky adolescent behavior are considerable and possibly long-lasting (HHS, 2012a), and can have negative implications for mental health, missed opportunities, or even loss of life. Identifying and understanding individual and socio-environmental factors that may influence risk-taking among youth is crucial in order for researchers, health educators, and policy makers to inform HIV prevention programs and policies.

\section{Purpose of the Study}

The primary goal of this study was to investigate gender differences in the predictors of participation in HIV-related risk behaviors among high school students in three South Florida school districts. These predictors included risk factors, protective 
factors, and health risk behaviors. Another objective assessed whether characteristics of sex education policy were associated with students' participation in HIV risk behavior.

\section{Discussion}

\section{HIV Risk Behaviors}

Results revealed that $26 \%$ of female and $34 \%$ of male high school students in South Florida reported participation in at least one HIV risk behavior. This finding was consistent with another study of Florida high school students - using a similar HIV risk index as the present study — which found that $27 \%$ of females and $33.7 \%$ of males had participated in at least on HIV risk behavior (Niyonsenga et al., 2008). Males reported significantly more HIV risk behaviors than females. A greater number of HIV risk behaviors for males may exist due to a higher frequency of engaging in sexual intercourse at younger ages and having more sexual partners and illicit substance use than females.

Results from the present study showed that twice as many males as females had four or more lifetime sexual partners ( $21.2 \%$ vs. $11.3 \%)$, and females were more likely than males to have unprotected sex. These findings were comparable with previous research with Florida high school students (CDC, 2010b; Niyonsenga et al., 2008). Although reasons for gender differences in condom use in this sample were unknown, previous research has cited barriers of female condom use to include difficulty negotiating protected sex with partners, low perceived need with a single partner, and use of other contraceptives, such as the birth control pill (Wingood \& DiClemente, 2000).

Most adolescents in this study did not have sex under the influence of drugs or alcohol or inject illegal drugs; however, males were more likely than females to report these behaviors. A small proportion of students placed themselves at risk for HIV 
infection through IDU, however, this estimate presented an upper bound on the number of high school students at risk for HIV due to injecting illegal substances given that not all intravenous drug users share needles. Hispanic females were more likely to inject drugs and have sex under the influence than females of other race/ethnic groups. These finding supported results from the nationally-representative, school-based 2009 YRBS survey (CDC, 2010b) with regards to IDU, but contrary to the YRBS with regards to sex under the influence. Nationally, White females were more likely than Black and Hispanic females to report using drugs or alcohol prior to sexual intercourse.

In the present study, Hispanic males were more likely than males of other race/ethnic groups to engage in unprotected sex, have multiple sexual partners, and inject drugs. These findings were inconsistent with national results from the 2009 YRBS: Black males were more likely that White and Hispanic males to having multiple sexual partners, and equal proportions of Black and Hispanic males reported IDU (CDC, 2010b).

Miami-Dade males and Palm Beach females were more likely than males and females of other races/ethnicities to report multiple sexual partners, and females in both Broward and Palm Beach were more likely to have sex under the influence of drugs and alcohol than females in Miami-Dade. There is a paucity of research studies comparing risk behaviors of adolescents by county/school district in Florida (Hall \& Camejo, 2004), and the present study was the first to compare HIV-related risk behaviors among MiamiDade, Broward, and Palm Beach high school students.

Although the purpose of this study was to examine HIV-related risk behaviors among youth, it should be noted that the majority of South Florida adolescents either abstained from sex or used condoms and with fewer partners. The prevalence of HIV risk 
behaviors examined in this study was consistent with both Florida state and national results from the 2009 YRBS (CDC, 2010b).

\section{Protective Factors}

Safe schools. Most high school students $(>80 \%)$ in South Florida reported feeling safe at school. Females were more likely to be bullied at school than males, but were less likely to be threatened or injured with a weapon. Previous research (Crick \& Grotpeter, 1995; Valois et al., 2002) found that females were more likely than males to display relational aggression with other females, usually through the means of bullying, such as character defamation, gossip, and exclusion of peers.

Safe conditions at schools were negatively correlated with all HIV risk behaviors, suggesting a protective effect. Results from logistic regression analysis found that, when controlling for demographic factors, safe schools predicted participation in at least one HIV risk behavior in both male and female students. Odds ratios $(<1.0)$ indicated that an increased number of safe conditions at school were protective of students' participation in HIV risk behavior. Quality schools are listed as a protective factor against problem behavior in PBT's social environment system (Jessor et al., 1991). Although few studies have specifically addressed the relationship between safe schools and HIV risk behaviors, Kirby and Lepore (2007) found that greater school attendance was protective of initial sexual experience and frequency of sex, and lower rates of school safety was associated with increased risk for unprotected sex and teen pregnancy.

School involvement. Consistent with previous findings (CDC, 2010b), males in the present study were more likely than females to participate in sports. Athletic participation was inversely related to unprotected sex in both genders, suggesting a 
protective effect, as noted by Kirby and Lepore (2007). For males, a positive relationship was found between sports team membership and having multiple sexual partners. This gender-specific effect of sports participation on sexual behavior was consistent with the Miller et al. (1998) study that assessed gender differences in the influence of sports and exercise on sexual risk.

According to the behavior system of PBT, involvement in school activities, like sports, is a protective factor against risky adolescent behavior (Jessor et al., 1991). While sports team membership suggested a protective effect against unprotected sex in both genders, it was not found to be protective when demographic factors were controlled for. For males, results revealed that increased participation in sports increased the likelihood that males would engage in HIV risk behavior.

Previous research has shown that participation in sports is associated with lower rates of sexual behaviors and was protective, especially for females. (Habel, Dittus, De Rosa, Chung, \& Kerndt, 2010; Kulig, Brener, \& McManus, 2003; Miller, Sabo, Farrell, Barnes, \& Melnick, 1998), however, other studies indicated that athletic participation is associated with earlier age at first sexual intercourse and higher levels of sexual risk taking, especially for Black males (Forman et al., 1995; Miller, Barnes, Melnick, Sabo, \& Farrell, 2002; Miller, et al., 2005).

Sex education. Most students ( $>85 \%)$ in South Florida received sex education in school, however, females were more likely than males to have received instruction. These results supported Florida state and national data from the 2009 YRBS (CDC, 2010b). Most 9th and 10th-grade students (60\%) in the current study learned about sex education topics in health education courses, and less than $40 \%$ of these students were in school 
districts that had been teaching comprehensive sex education topics for three or more years at time of survey administration.

Similar to safe schools, sex education had negative associations with all HIV risk behaviors, suggesting a protective effect. Results from logistic regression analyses for all students revealed odds ratios $(<1.0)$ that also suggested a protective effect, however, sex education was only found to significantly predict HIV risk behavior in males, when controlling for grade level, race/ethnicity, and school district.

When analyzing characteristics of sex education policy implementation among 9th and 10th grade students who received sex education, a significant positive correlation was found between course of instruction and IDU among males. Further analysis revealed that students who received sex education in a health education course were significantly more likely to report IDU than students who received sex education in a science course, however, this relationship was not found to be significant when controlling for demographic factors.

According to TGP (Wingood \& DiClemente, 2000), limited access to sex education in schools is a risk factor for HIV, and previous research has indicated that receipt of sex education has a protective effect for HIV and sexual risk behaviors among youth (Armstrong et al., 2009; Kirby, 2002a; Kirby \& Lepore, 2007; Holtzman, et al., 1991; Mueller et al., 2008). Kirby, Laris, and Rolleri (2005) found that sex education programs have a positive impact on sexual behavior, including delaying the initial sexual experience and reducing the frequency of sexual activity and number of partners. Schoolbased programs have also been shown to increase contraceptive use (Brown, Fritz, \& Barone, 1989; Kirby, 2002a; Newman, DuRant, Ashworth, \& Gaillard, 1993; Siegel, 
DiClemente, Durbin, Krasnovsky, \& Saliba, 1995), and may also play a role in maintaining lower levels of IDU behavior among high school students (Holtzman et al., 1991).

\section{Risk Factors}

Depressive symptoms. Over $34 \%$ of females and $20 \%$ of males reported feelings of sadness or hopelessness within 12 months of survey administration, and over $14 \%$ of females and $8 \%$ of males had thoughts of suicide. Consistent with findings Florida adolescents (CDC, 2010b) and non-Florida adolescents (Elkington, Bauermeister, \& Zimmerman, 2010; Khan et al., 2009; Waller et al., 2006), females were more likely to have depressive symptoms than males. Nolen, Hoeksema and Girgus (1994) found that after the age of 15 , females were twice as likely as males to be depressed.

Students with higher levels of depressive symptoms were more likely to have unprotected sex than students who had less depressive symptoms. The relationship between depressive symptoms and multiple sexual partners was stronger in females than in males, but depressed males were more likely to have sex under the influence of drugs or alcohol and inject illegal drugs than depressed females. In a previous analysis of Add Health data, Lehrer et al. (2006) found high levels of depressive symptoms predicted substance abuse in males. A more recent study (Rubin et al., 2009) examining the association between depression and sexual risk in female adolescents found that increased levels of depression were associated with an increased number of sexual partners.

Contrary to findings from the present study, Khan et al. (2009) did not find a gender difference in the association between depression symptoms and multiple sexual 
partners; the study, however, only examined White and Black young adults. According to the TGP, females with a history of psychological distress or depression are at an increased risk HIV, which may reflect inequalities of power within within relationships (Wingood \& DiClemente, 2000). Previous studies (Brown et al., 1997; Filson et al., 2010) suggest that women who felt powerless in relationships had higher levels of depression, and depressed females may lack the self-esteem, self-efficacy, or assertiveness needed to refuse sex or negotiate safer sex.

Sexual abuse and dating violence victimization. Females more likely than males to report a history of sexual abuse. This finding was consistent with Florida state findings (CDC, 2010b), as well as findings from non-Florida studies that report higher frequencies of sexual abuse in females (Basile et al., 2006; Shrier et al., 1998). Results from the current study also suggest that sexually-abused females were at increased risk for HIV than females who did not have a history of sexual abuse. As predicted by TGP (Wingood \& DiClemente, 2000) and cited by others (Basile et al., 2006; Brener, McMahon, Warren, \& Douglas, 1999; Lang et al., 2011; Sundaram, Laursen, \& HelwegLarsen, 2008), women are disproportionately affected by sexual abuse, and sexuallyabused females were more likely to engage in health-risk behaviors, were more susceptible to IPV, and less likely to use condoms or negotiate condom use. Victims of sexual abuse may submit to risky behavior for fear of provoking a threat of bodily harm or to avoid being raped or losing the partner (Muehlenhard \& Linton, 1987; Wingood \& DiClemente, 1997).

Although the correlation between sexual abuse and HIV-related risk was weaker in males than in females, the relationship should not be discounted. A recent meta- 
analysis assessing the strength of association between histories of sexual abuse and risky sexual behaviors among adolescent males found that sexually-abused males were significantly more likely than males who were not abused to report unprotected sexual intercourse, multiple sex partners, and pregnancy involvement (Homma, Wang, Saewyc, \& Kishor, 2012).

Opportunities to observe and participate in health risk behavior. Consistent with national results (CDC, 2010b), males were more likely than females to be offered, sold, or given cigarettes or illegal drugs. Similar proportions of adolescents in the current study rode in a vehicle with a driver that had been drinking. Drink-driving is an example of modeling risk behavior, a risk factor in the perceived environment system of PBT (Jessor et al., 1991).

Correlational analyses revealed significant, positive relationships between riding with a drunk driver and being offered, sold, or given any illicit substance. These findings suggest a strong relationship between an "illegitimate opportunity" and participation in risk behaviors, as illustrated by the PBT framework (Jessor \& Jessor, 1977). A direct opportunity and access to the tools needed to engage in risk behavior can lead youth to believe that such behavior is not as socially undesirable or proscribed as it seems.

Risk Factor Index (RFI). Overall, females were more likely than males to have a higher number of risk factors, however, the relationship between risk factors and HIV risk behavior was stronger for males. An increase in number of risk factors was found to increase the probability in engaging in HIV risk behavior. This was true for both males and females. Safe conditions at school were not found to moderate the relationship between RFI and participation in HIV risk behavior, however, sex education was found 
to moderate the relationship between RFI and HIV risk behavior in males. The odds ratio of .89 indicated that the interaction between sex education and RFI reduced the likelihood of males reporting HIV risk behavior. Conceptually, the role of protective factors is to enhance the likelihood of socially desirable and positive outcomes, whereas risk factors have the reverse effect (Jessor et al., 1998b). Previous research also suggests that protective factors may moderate the relationship between risk factors and risk-taking behavior (Jessor et al., 1995).

\section{Health Risk Behaviors}

Sexual behaviors. The majority of sexually-experienced adolescents had their first sexual experience at 14 years of age or older. The current study supported findings by the Cavazos-Rehg et al. (2011) and March \& Atav (2010) studies that found the average age of sexual initiation was 14.4 years, but conflicted with findings by Abma et al. (2010) and Warren et al. (1998) which found age at first sexual experience to be older. The average age at first sexual experience in the present study was 13.9 years for males and 14.6 years for females. The literature consistently reports that males initiate sex at younger ages than females, and the current study supports those findings (Abma et al., 2010; March \& Atav, 2010).

More than $35 \%$ of participants in the present study had sexual intercourse at least three months prior to survey administration, which was similar to $37 \%$ of Florida high school students in the 2009 YRBS school-based survey (CDC, 2010b). Other results of the present study showed that twice as many males as females had four or more lifetime sexual partners $(21.2 \%$ vs. $11.3 \%)$, and females were more likely than males to have 
unprotected sex. These findings were comparable with previous research with Florida high school students (CDC, 2010b; Niyonsenga et al., 2008).

Consistent with the current literature, sexually active females were more likely to have unprotected sex than sexually active males (CDC, 2010a; Howard \& Wang, 2007). Also, adolescents who initiated sex at early ages were more likely to be sexually active and have multiple lifetime sexual partners, however, this was more apparent in males than in females. Previous research consistently states that early age at first sexual intercourse is predictive of a greater number of lifetime sexual partners (Coker et al., 1994; Sandfort et al., 2008; Weiss et al., 2008).

Illicit substance use behaviors. Overall, males reported significantly more participation in tobacco and illicit drug use behaviors than females, with one exception. Females were significantly more likely to report lifetime use of inhalants (e.g., sniffing glue to get high, etc.). There was no significant gender difference found for current alcohol use and binge drinking among youth, however, male students were more likely to report drink-driving than female students.

Interestingly, cigarette smoking was moderately correlated with HIV risk behaviors. Kirby (2002a) and colleagues (Kirby \& Lepore, 2007) list tobacco use and cigarette smoking as a risk factor for various adolescent sexual risk behaviors, including initiating sex, having an increase number of sexual partners, and not using contraceptives. With the exception of cigarette smoking and lifetime marijuana use, males who used illicit substances were at increased risk for HIV-related risk behavior than their female counterparts. Binge-drinking males, and males who recently smoked marijuana or had ever tried cocaine or ecstasy were more likely to have sex under the influence of drugs 
and alcohol than males who did not engage these illicit substance use behaviors. Wen, Balluz, and Town (2012) study found a strong link between HIV risk behavior and binge drinking among youth.

Adolescent illicit substance use was found to be a strong predictor of participation in other risk behaviors, including HIV risk behavior. This finding supported previous research that has shown a relationship between illicit substance use and increased risk for HIV through unprotected sex (Kirby, 2002a; Kirby \& Lepore, 2007; Morrison et al, 2003; Wingood \& DiClemente, 2000), multiple sexual partners (Santelli et al., 2001; Yan et al., 2007), and other risky behaviors (Benotsch et al., 2011; Everett et al., 2000; Halpern et al., 2004; Wilke et al., 2005; Yarber et al., 2002).

Having sex under the influence of drugs or alcohol was more strongly related to having four or more sexual partners than not using a condom at last sex. This was true for both male and females. When examining the use of individual illicit substances, they, too, were more strongly linked to the likelihood of multiple sexual partners than unprotected sex. Previous research by Santelli and colleagues (Santelli et al., 1998, 2001) found a strong association between substance use, unprotected sex, and multiple sexual partners. The influence of illicit substances may impair an individual's judgment and behavioral intentions (e.g., the intent to use condoms) may be compromised (Adler \& Rosengard, 1996; Jemmott, 1996; Jemmott \& Jemmott, 1993). In the current study, results suggest that adolescents under the influence of drugs or alcohol may be more at risk for having more sexual partners than unprotected sex.

Violent behaviors. Males engaged in more physical fighting than females, and were more than three times as likely to carry a weapon. These results are consistent with 
the prevalence of violence-related behaviors among adolescents in Florida state (CDC, 2010b). A higher prevalence of violent behaviors among males adolescents may exist since they are often socialized into roles that promote higher levels of agression (Valois et al., 2002).

Overall, physical fighting and weapon carrying among males has stronger correlations with HIV risk behaviors than females, with one exception. Physical fighting among females was more strongly correlated with reports of unprotected sex than among males. Studies examining violence-related behaviors found that they frequently co-occur with other health risks, including sexual risk behaviors and STIs (Coker et al., 1994; Doskoch, 2008; Kirby, 2002a).

Health Risk Behavior Index (HRBI). Males engaged in more health risk behaviors than females, which could suggest a syndrome of risky behavior as described by PBT (Jessor, 1991). Similar to RFI, HRBI had a positive influence on the likelhood of participating in an HIV risk behavior. Increased participation in health risk behaviors increased the probability that an adolescent would engage in HIV risk behavior. The odds of doing so, however, was stronger for females than for males when controlling for grade level, race/ethnicity, and school district.

As noted previously, adolescent participation in risk behaviors have been shown to co-occur in what Jessor and others call a "problem behavior syndrome" (DiClemente et al., 2008; Donovan \& Jessor, 1985; Donovan et al., 1988; Jessor, 1991; Jessor \& Jessor, 1977). Problem behaviors, like physical fighting and illicit substance use behaviors, tend to be positively correlated to other problem behaviors, like HIV-related risk behaviors (Lugoe, Klepp, Rise, Skutle, \& Biswalo, 1995). Basen-Engquist et al. 
(1996) found several clustering behaviors among youth, one which included smoking, drinking, substance use before sex, multiple partners, unprotected sex, and not wearing seatbelts. A study comparing Black and White adolescents found clusters of co-occurring behaviors, one of which was labeled "heavy dabblers" to describe sexually-experienced participants who all smoked, binge drank, and used marijuana and other illicit drugs (Halpern et al., 2004).

\section{Predictors of HIV Risk Behavior}

Results of the logistic regression analyses provide some support for the importance of interpersonal and socio-environmental factors associated with HIV risktaking. Grade level was a consistent positive predictor of HIV risk behavior. As grade level increased, so did the odds of participating in HIV risk behavior. School district was not found to be a significant predictor of HIV risk behavior in any of the regression models, and was not included in the full regression model. Gender differences were also found in relation to the influence of race/ethnicity on HIV risk. White female adolescents were at increased odds for HIV compared with female adolescents in the Other race category, however, White male adolescents were found to be at decreased odds for HIV risk compared to male adolescents in the Other race category. Black race was found to increase the likelihood of participation in HIV risk behavior for both genders, however, the odds of increased risk was higher for females (3.18) than it was for males (2.45). This finding is consistent with TGP, which lists ethnic minority status as a risk factor (Wingood \& DiClemente, 2000).

For both genders, increased participation in health risk behaviors increased the odds of classification in the HIV-risk group. Although the risk factors were found to 
directly increase the odds of HIV risk for both male and females in previous regression models, when controlling for demographic factors and health risk behaviors, risk factors were only found to significantly predict HIV risk in females. The findings that risk factors and health risk behaviors increase adolescents' odds of participating in HIV risk behavior were consistent with both TGP (Wingood \& DiClemente, 2000) and PBT frameworks (Jessor et al., 1995, 1998b).

To further examine the significance of risk factors and health risk behaviors in the previous logistic regression models, post-hoc analyses were conducted to determine the effects of particular aspects on individual HIV risk behaviors. Results from each set of analyses revealed gender differences in the predictors of unprotected sex, multiple sexual partners, and sex under the influence of drugs/alcohol (there were no significant predictors found for IDU). Some risk factors and health risk behaviors were found to predict several HIV risk behaviors, while others were found to only significantly predict certain HIV risk behaviors.

Recent sexual activity (past 3 months) was found to be the strongest predictor of HIV risk behavior for both genders, increasing the odds of participation in HIV risk behavior. This was expected since three of the four HIV risk behaviors involved sexual intercourse. When controlling for all other factors, recent sexual activity was a stronger predictor of unprotected sex for female students compared to male students, but was a stronger predictor of having multiple sexual partners and sex under the influence of drugs/alcohol for male students. Sexual intercourse is a primary risk factor for unintended pregnancies and HIV/STIs (Morris et al., 1993; Westhoff et al., 1996), and adolescents 
who had already engaged in intercourse were significantly more likely to intend to have sex again, increasing their risk for HIV (Nahom et al., 2011).

Early age at first sexual experience ( $<13$ years) was found to increase the odds of having four or more lifetime sexual partners for both genders and unprotected sexual intercourse for males. These findings are consistent with previous studies that have found that younger ages at initial sexual experience are predictive of the number of lifetime partners, unprotected intercourse, and increased risk for HIV (Coker et al., 1994; Morris et al., 1993; Sandfort, Orr, Hirsch, \& Santelli, 2008; Sieving, Eisenberg, Pettingell, \& Skay, 2006; Weiss et al., 2008; Werner-Wilson, 1998; Yarber et al., 2002).

A history of sexual abuse was found to increase the likelihood of not using a condom in both males and females, and having multiple sexual partners in females. A history of dating violence, however, was only found to predict the likelihood of having unprotected sex in males. Adolescents who have experienced sexual abuse have been found to engage in HIV-related risk behaviors, including having multiple sexual partners and unprotected sex (Buzi et al., 2003; Holmes et al., 2005; Houck, Nugent, Lescano, \& Peters, 2010; Johnson, Rew, \& Sternglanz, 2006; Kenney, Reinholtz, \& Angelini, 1998; Kirby, 2002a; Yarber, Milhausen, Crosby, \& DiClemente, 2002), and are at greater risk for acquiring STIs or HIV.

Cigarette smoking in the past 30 days was found to increase the probability of having unprotected sex in both genders, as well as multiple sexual partners in females, and having sex under the influence of drugs/alcohol. Cigarette smoking is also a risk factor for sexual risk behavior among adolescents (Everett, Malarcher, Sharp, Husten, \& Giovino, 2000; Kirby, 2002a; Yan, Chiu, Stoesen, \& Wang, 2007; Yarber et al., 2002). 
Participation in a physical fight was found to increase the odds of unprotected sex in females, and having multiple sexual partners and sex under the influence of drugs/alcohol in males. Weapon carrying was found to increase the odds of having multiple sexual partners in males. These results are consistent with previous studies that found violent behaviors among youth frequently co-occurred illicit substance use (Melzer-Lang, 1998; Valois, McKeown, Garrison, and Vincent, 1995) and sexual risk behavior, including having multiple partners and not using condoms (Sosin, Koepsell, Rivara, \& Mercy, 1995).

For females, lifetime use of inhalants was found to increase the odds of unprotected sex, however, recent marijuana use (past 30 days) was found to decrease the odds of not using a condom. Lifetime marijuana and ecstasy use were found to increase the odds of having multiple sexual partners. The finding that recent marijuana use suggests a protective effect for unprotected sex is contrary to previous findings that illicit drug use among youth is be related to HIV risk behaviors, including contraceptive nonuse (Kirby, 2002a; Kirby \& Lepore, 2007; Halpern et al., 2004).

Post-hoc analyses were also able to identify the substance use behaviors that predicted adolescents' report of having sex under the influence of drugs or alcohol. For males, recent alcohol use (past 30 days), binge drinking, drink-driving, and being offered, given, or sold drugs increased the odds that a male students would have sex under the influence. For females, only lifetime marijuana use and recent alcohol use predicted increased odds of having sex under the influence. As discussed previously, illicit substance abuse often precedes sexual events, and youth under the influence of these substances may be at increased risk for HIV since these sexual disinhibitors may impair 
decision making, such as the intention to wear condoms (Kirby, 2002a; Morrison et al., 2003; Wingood \& DiClemente, 2000).

\section{Key Findings}

Participation in HIV-related risk behavior is associated with a complex of other behaviors, as well as interpersonal and socio-environmental factors that place adolescents at an increased vulnerability for risk. This constellation of factors vary depending on gender and the HIV risk behavior being studied. Results from the current study suggest that protective factors, such as sex education and students' perceptions of safe conditions at school, may decrease likelihood of participating in HIV risk behaviors. Conversely, risk factors and participation in health risk behaviors increased the probability of participation in HIV risk behaviors. Students in higher grades (compared with students in lower grades) and Black students (compared with students in the "Other" race category) were more likely to engage in HIV risk behavior as well. Findings suggest that attention to gender, grade level, and race/ethnicity should be made when examining HIV risk behaviors among youth.

\section{Limitations}

The present study has a few notable limitations. This study relied on the YRBSS which utilizes a self-report survey instrument. The measures used in this study could be biased for several reasons. First, participants may have provided responses to questions that reflected social-desirability bias. Second, recall bias may also be a factor due to the number of questions on the state and local YRBS survey (87 questions) and questions that ask participants to remember behaviors at different time periods (e.g., past 30 days, past 3 months, past 12 months). Third, measures may not have collected accurate data 
due to the sensitive nature of the some questions (i.e., illicit drug use or sexual activity) and participants' perceptions of their experiences or behaviors. Finally, the possibility for non-participation or non-response bias may exist since the only students that contributed to the YRBS had to be present on the day of survey administration and attend one of the public schools that were chosen to participate. Students who missed school that day due to an illness or truancy did not participate in the survey. Truant adolescents are likely to be at higher risk for participation in risky behaviors. Also, most students who attended alternative schools in South Florida were not surveyed, even though they likely represent a group of high-risk youth as well. Despite the use of a self-report instrument, the YRBS has shown to be a reliable instrument over time (Brener et al., 2002; Brener, Collins, Kann, Warren, \& Williams, 1995) and adolescent responses were consistent with other surveys measuring adolescent risk (Kolbe et al., 1993).

The cross-sectional nature of this study does not allow for causal inference of protective factors, risk factors, and health risk behaviors with HIV-related risk behavior. It is possible that a reciprocal influence in the model could exist. That is, HIV risk behavior itself might be influencing variables that were used as predictors. For example, the present study found positive correlations between depressive symptoms and sexual risk behaviors, however, previous research has debated whether depression is an antecedent to (Brown et al., 2006; Khan et al., 2009; Kirby, 2002a; Paxton et al., 2007; Rubin et al., 2009; Shrier et al., 2011) or a result of sexual behavior (Ethier et al., 2006; Hallfors et al., 2005).

Furthermore, a secondary data set limits the analyses related to the research questions available. Some variables that may have better clarified relationships between 
variables were not available in the data set. For instance, questions about academic achievement (i.e., grades in school) and history of HIV testing are available on the national YRBS survey instrument, but are not available on the state and local YRBS instrument (CDC, 2012f).

Also, the YRBS is a multiple choice instrument, and its use of closed-ended questions may affect responses if the participant did not understand the questions properly. For instance, the YRBS did not provide a definition of "sexual intercourse" and the interpretation of such term may result in different meanings for individuals (i.e., vaginal, oral, anal, etc.). Also, an increasing number of states and local districts are including questions on sexual identity (e.g., gay, lesbian, bisexual, etc.) and gender of sexual partners on their YRBS instrument, however, the school districts in the present study did not. Although it would have been preferable to include these questions about sexual identity and sexual partners, it should be noted that across the nine sites that assessed sexual identity, most students $(>90 \%)$ reported a heterosexual identity and having sex with opposite sex partners (CDC, 2011e).

Analyses in this study relied on a composite, summative index of HIV-related risk behavior as an outcome measure. Four questions about risky sexual and drug-injecting behaviors were chosen from the YRBS since they had a common factor of being related to the identified risks for HIV (CDC, 2008b). Generalizations drawn from the HIV risk index, however, may not apply equally to all of its components, and individual components may not completely be indicative of HIV risk. Meaning, the estimates present an upper bound on the number of high school students at risk for HIV. For instance, although injection drug use is a mode of HIV transmission due to contaminated 
or shared needles (CDC, 2008b), not all injection drug users in this current study may share needles. Future items on the YRBS instrument should include more elaborate measurements or follow-up questions to better measure HIV risk among youth.

In the current study, some measures have multiple-item indexes (e.g., depression index), however, some measures only had a single item (e.g., dating violence). The inadequacy of the single item may account for some insignificant findings or may limit the predictability of the measure. For instance, intimate partner violence can include physical, verbal, sexual, and emotional abuse, but the YRBS only addressed its physical component (i.e., being hit or slapped by boy/girlfriend). Therefore, the prevalence of IPV among youth may have been underestimated.

The measurement of both protective and risk factors could have been made more extensive with regards to family dynamics, neighborhood characteristics (e.g., crime statistics), and institutional factors (e.g., availability of school nurses or psychologists). If additional factors could be directly measured in the various settings of the adolescent life — independent of self-report - they may have strengthened the outcomes of the study. Also, the YRBS was not designed to evaluate the effectiveness of specific interventions, including school curricula. With respect to sex education, the measure of HIV/AIDS instruction in school is narrow and based on whether instruction was received. There was no measure regarding the quantity, quality, content, or duration of instruction received, which may differ by school district or school.

Finally, while the each school district's survey sample composed a representative sample of high school students (BCPS, 2012a; MDCPS, 2010; SDPB, 2010), the final sample did not illustrate a proportionate sample of the school populations in reference to 
each other. For example, the sample included 1,472 students from Broward and 2,412 students from Palm Beach, although Broward is a larger school district and has more high school students (69,350 students) than Palm Beach (48,998 students) (BCPS, 2012; SDPB, 2012a).

Despite these limitations, the present study has its strengths, in that it adds to the literature examining HIV risk behavior among youth guided by a conceptual framework derived from both Problem Behavior Theory and the Theory of Gender and Power. This study is the first known attempt to study Problem Behavior Theory with attention to gender differences in adolescent HIV risk behavior among a sample of South Florida youth. Also, this study examined protective factors, risk factors, and health risk behaviors that may be associated with adolescent HIV-related risk-taking. Therefore, this study has theoretical implications as well as practical implications for public health professionals interested in the prevention of HIV/STIs and unintended pregnancies among youth.

\section{Implications for Public Health}

The present findings have implications for adolescent HIV risk prevention programs and interventions. Negative outcomes related to HIV risk are easy to demonstrate (e.g., the state of Florida ranks first for rates of new HIV cases among 13-19 year-olds), however, health educators, public health professionals, and policy makers should be aware of gender differences in the predictors of HIV risk behaviors that exist among youth. Programs should be gender-sensitive and culturally-specific. Current HIV/AIDS prevention and sex education programs may not be sufficient if these risk factors are not considered. 
Screening adolescents for risk factors (e.g., history of sexual abuse), should be implemented in order to identify youth at risk for health risk and HIV-related risk behaviors. Recognition of these at-risk youth can present an opportunity to help them by providing counseling services or referrals to mental health professionals. Schools are an appropriate setting for HIV and other risk prevention (Constantine, 2008), especially with the likelihood of available school counselors, peer mentors, and other resources. Since schools are the only institution that has contact with the vast majority of a population's youth over prolonged periods of time, they have the potential to effectively reach a large number of children and adolescents at once. School-based programs also have a better stability and sustainability than individual program interventions (Meyer \& Farrell, 1998; Farrell, Valois, \& Meyer, 2002).

Although findings from this study suggested that school-based sex education was protective against HIV risk behaviors, when controlling for demographic factors, it was only found to be protective for males. This finding indicates that sex education may not sufficiently address factors that influence HIV risk, such as condom use by females. Discussion topics regarding gendered social norms should be included for both males and females. Also, due to the increasing HIV risk behaviors with increase in grade level, sex education programs should be taught at all grade levels. The APHA (2005), among others (DiClemente, 1989; Kirby, 2006; Ott \& Santelli, 2007b; Santelli, 2008; Brooks, 2004), recommends that age-appropriate, evidence-based, comprehensive sexuality education should be an integral part of K-12 health education in order to decrease risky behavior among youth. 
Finally, findings from the current study indicate that students' perceptions of safe schools may protect against HIV risk. Efforts to reducing adolescent risk behaviors may be enhanced by strengthening and increasing protective factors. Overall, protective factors in this study were found to exist in the school environment (i.e., sex education and safe schools). Health professionals and school administrators can help decrease adolescent risk by improving school safety and increasing students' connectedness to schools.

In summary, HIV risk prevention interventions should be tailored to account for differences between groups of adolescents, especially by gender and race/ethnicity. Adolescents should be screened for risk factors that may incline them to participate in health and HIV-related risk behaviors. Finally, efforts should be made to increase and strengthen protective factors that may help reduce the risk of HIV among youth.

\section{Implications for Theory Development}

The current study supports Problem Behavior Theory as a guiding framework for identifying factors that may influence adolescent involvement in risk behaviors. Overall findings suggest that protective factors identified by the conceptual model reduced the likelihood of HIV risk behaviors. Conversely, results indicate that risk factors and participation in health risk behaviors increased the likelihood of risk behavior. The present study adds to the Problem Behavior Theory by assessing the influence gender, race/ethnicity, sex education, and location of school district on HIV risk behavior. These additional factors were identified from the Theory of Gender and Power and were added to the study's conceptual model of risk and protective factors that influence adolescent 
HIV risk behavior. This model was used for testing the identified factors of HIV risk, and was consistent with previous research.

The current study also adds to the knowledge base of the Theory of Gender and Power by adding findings specific to gender differences in factors associated with HIVrelated risk behaviors. Although Wingood and DiClemente's (2000) application of TGP for HIV risk was designed to identify contextual factors that may affect women's risk for HIV, the current study applied TGP for both genders. Gender differences were found in the relationship between exposure to sex education and HIV risk behaviors. The significant negative associations between sex education and all HIV risk behaviors were found to be stronger in males than in females, suggesting that sex education was more protective for males.

The conceptual framework guided by Problem Behavior Theory and the Theory of Gender and Power was found to be useful in understanding protective factors, risk factors, and health risk behaviors as they relate to HIV risk behaviors. This framework can be used guide HIV risk prevention efforts among youth by increasing identified protective factors and decreasing risk factors. These findings can also be used to inform areas in which gender-tailoring may be appropriate or necessary for prevention program planning among youth in South Florida.

\section{Recommendations for Future Research}

It is recommended that future studies be conducted in order to further explore the underlying variations in HIV-related risk behaviors of male and female adolescents. Future research should also explore possible risk and protective factors particular to certain race/ethnicities and investigate how these factors work to increase or decrease 
risk. For example, acculturation has been found to be associated with unprotected sex, more sexual partners, and STIs in Hispanic adolescents (Lee \& Hahm, 2010; GuilamoRamos et al., 2009; Rapkin \& Erickson, 1994; Sabogal, Perez-Stable, Otero-Sabogal, \& Hiatt, 1995).

Also, research combining the YRBS with other locally-administered tools could also add demographic and other factors of risk and protection to the analyses as defined by the Problem Behavior Theory or the Theory of Gender and Power. For instance, overall school grades from the Florida Comprehensive Assessment Test (FCAT) could serve as a proxy measure for the "quality schools" variable in the social environment system.

In the future, evaluation studies are necessary to determine the strengths and weaknesses of each school district's comprehensive sex education curriculum. Randomized, controlled studies in which youth are enrolled and followed over time can give evidence of the impact of sex education. This way, multiple predictors can be addressed and risky behavior can be quantified. With evidence-based findings, researchers and health professionals can influence policy and practice in order to support funding and programming for effective HIV prevention and school-based sex education interventions designed to increase protective factors and decrease risk for HIV.

\section{Conclusion}

Despite the limitations of a cross-sectional, secondary data analysis study, the current study contributed to prior knowledge about factors associated with adolescent HIV risk behavior. Consistent with other studies, factors such as safe schools and exposure to sex education were found to be negatively associated with HIV risk behavior, 
suggesting a protective effect. Conversely, being exposed to risk factors (e.g., sexual abuse) and participating in health risk behaviors (e.g., illicit substance use) suggest an increase risk for involvement in HIV risk behavior.

This study was the first known attempt to use a sample of South Florida high school students in order to identify gender differences protective factors and risk factors for HIV-related risk behaviors. Overall, this study provides new evidence about adolescents who are underrepresented in the research literature, despite living in the geographical region with the most HIV/AIDS cases in the top-ranking state for new HIV cases among 13-19 year-old youth in the United States. This study uncovers new questions that can be explored in order to bring a better understanding about how to effectively reduce HIV risk among this population of adolescents.

Adolescent participation in HIV-related risk behavior is associated with involvement in a constellation of other behaviors, as well as risk factors that place adolescents at an increased vulnerability for risk. Common predictors of HIV risk behavior included increased grade level, Black race, risk factors, and health risk behaviors. Also, Black students in South Florida were more likely to participate in HIV risk behaviors than students of other racial/ethnic groups. Recent sexual activity was the strongest predictor of participation in sexual risk behaviors, however, gender differences were identified in the specific predictors of not using a condom, having multiple sexual partners, and having sex under the influence of drugs or alcohol.

Although gender differences in HIV-related risk behaviors were found, HIV risk behavior was low within this population, with fewer than $40 \%$ of adolescents reporting participation in any HIV-related risk. Interventions aimed to reduce HIV risk behavior 
should focus on enhancing protective factors in addition to decreasing risky behaviors. It is also imperative for future prevention efforts to be gender-specific and culturallyappropriate.

\section{Summary}

This chapter summarized the current study including the problem, purpose, and results. Also included was a discussion of the findings in comparison with the current state of the literature, implications for public health, and recommendations for future research. 


\section{REFERENCES}

Abma, J. C., Martinez, G. M., \& Copen, C. E. (2010). Teenagers in the United States: Sexual activity, contraceptive use, and childbearing, National Survey of Family Growth 2006-2008. Vital and Health Statistics, 23(30), 1-57. Retrieved June 9, 2012, from http://www.cdc.gov/nchs/data/series/sr_23/sr23_030.pdf

Adler, N. E., \& Rosengard, C. (1996). Adolescent contraceptive behavior: Raging hormones or rational decision making. In S. Oskamp, \& S. C. Thompson (Eds.), Understanding and Preventing HIV Risk Behavior: Safer Sex and Drug Use (pp. 31-56). Thousand Oaks, CA: Sage Publications.

Ajzen, I. (1991). The theory of planned behavior. Organizational Behavior and Human Decision Processes, 50, 179-211.

Allensworth, D. D., \& Symons, C. W. (1989). A theoretical approach to school-based HIV prevention. Journal of School Health, 59(2), 59-65.

Amaro, H. (1995). Love, sex, and power. Considering women's realities in HIV prevention. American Psychologist, 50(6), 437-47.

American Academy of Pediatrics. (1990). Contraception and adolescents. Pediatrics, 86, $134-138$

American Public Health Association. (2005). Sexuality Education As Part of a Comprehensive Health Education Program in K-12 Schools. Retrieved April 2, 2012, from

http://www.apha.org/advocacy/policy/policysearch/default.htm?id=1304

American School \& University. (2012). 2011 AS\&U 100: Largest School Districts by Enrollment. Retrieved June 14, 2012, from http://asumag.com/asu100/2011/enrollment/

American School Health Association. (1995). ASHA takes a stand. The Pulse of the American School Health Association, 16(1), 4.

Aneshensel, C. S., \& Sucoff, C. A. (1996). The neighborhood context of adolescent mental health. Journal of Health and Social Behavior, 37, 293-310.

Arizona Department of Education. (2004). 2003 Arizona Youth Risk Behavior Survey (YRBS) FAQ Sheet. Retrieved June 9, 2012, from http://www.ade.az.gov/sa/health/matrix/chss/FAQsheet.pdf

Armstrong, S., Ashford, A., López, I. A., \& Brown, C. P. (2009). Exploring the effect of sexual education on sexual health risk behaviors: Analysis of the 2003 and 2007 Youth Risk Behavior Surveys in Florida and Alabama. Florida Public Health Review, 6, 68-74. 
Askew, J. (2007). Breaking the taboo: An exploration of female university students' experiences of attending a feminist informed sex education course. Sex Education: Sexuality, Society and Learning, 7(3), 251-264.

Aspy, C. B., Vesely, S. K., Oman, R. F., Tolma, E., Rodine, S., Marshall, L., \& Fluhr, J. (2012). School-related assets and youth risk behaviors: alcohol consumption and sexual activity. Journal of School Health, 82(1), 3-10.

Bandiera, F., Jeffries, W., Dodge, B., Reece, M., \& Herbenick, D. (2008). Regional differences in sexuality education on a state level: The case of Florida. Sex Education, 8(4), 451-463.

Bandura, A. (1992). A social cognitive approach to exercise control over AIDS infection. In R. J. DiClemente (Ed.), Adolescents \& AIDS: A Generation in Jeopardy (pp. 89-116). Newbury Park, CA: Sage Publications.

Bandura, A. (2001). Social cognitive theory: An agentic perspective. Annual Review of Psychology, 52, 1-26.

Barber, J. S., Axinn, W. G., \& Thornton, A. (1999). Unwanted childbearing, health, and mother-child relationships. Journal of Health and Social Behavior, 40(3), 231-57.

Bartlett, R., Buck, R., \& Shattell, M. M. (2008). Risk and protection for HIV/AIDS in African-American, Hispanic, and White adolescents. Journal of National Black Nurses' Association, 19(1), 19-25.

Basen-Engquist, K., Edmundson, E. W., \& Parcel, G. S. (1996). Structure of health risk behavior among high school students. Journal of Consulting and Clinical Psychology, 64(4), 764-75.

Basile, K. C., Black, M. C., Simon, T. R., Arias, I., Brener, N. D., \& Saltzman, L. E. (2006). The association between self-reported lifetime history of forced sexual intercourse and recent health-risk behaviors: Findings from the 2003 National Youth Risk Behavior Survey. Journal of Adolescent Health, 39(5), 752.e1-7.

Bauer, H. M., Gibson, P., Hernandez, M., Kent, C., Klausner, J., \& Bolan, G. (2002). Intimate partner violence and high-risk sexual behaviors among female patients with sexually transmitted diseases. Sexually Transmitted Diseases, 29(7), 411-6.

Bay-Cheng, L. Y., \& Lewis, A. E. (2006). Our "ideal girl" : Prescriptions of female adolescent sexuality in a feminist mentorship program. Affilia: Journal of Women and Social Work, 21(1), 71-83. doi:10.1177/0886109905283137

Becker, M. H. (1974). The Health Belief Model and personal health behavior. Health Education Monographs, 2, 324-473. 
Benotsch, E. G., Koester, S., Luckman, D., Martin, A. M., \& Cejka, A. (2011). Nonmedical use of prescription drugs and sexual risk behavior in young adults. Addictive Behaviors, 36(1-2), 152-5.

Bernardi, R. A. (1994). Validating research results when Cronbach's alpha is below .70: A methodological orocedure. Educational and Psychological Measurement, 54(3), 766-775.

Bersamin, M., Todd, M., \& Remer, L. (2011). Does distance matter? Access to family planning clinics and adolescent sexual behaviors. Journal of Maternal and Child Health, 15(5), 652-9.

Biro, F. M., \& Dorn, L. D. (2006). Puberty and adolescent sexuality. Psychiatric Annals, $36(10), 685-690$.

Bishai, D. M., Mercer, D., \& Tapales, A. (2005). Can government policies help adolescents avoid risky behavior? Preventative Medicine, 40(2), 197-202.

Boonstra, H. D. (2009). Advocates Call for a New Approach after the Era of "Abstinence-Only" Sex Education. Guttmacher Policy Review, 12(1), 6-12.

Brener, N. D., Billy, J. O., \& Grady, W. R. (2003). Assessment of factors affecting the validity of self-reported health-risk behavior among adolescents: Evidence from the scientific literature. Journal of Adolescent Health, 33(6), 436-57.

Brener, N. D., Collins, J. L., Kann, L., Warren, C. W., \& Williams, B. I. (1995). Reliability of the Youth Risk Behavior Survey questionnaire. American Journal of Epidemiology, 141, 575-80.

Brener, N. D., Demissie, Z., Foti, K., McManus, T., Shanklin, S. L., Hawkins, J., \& Kann, L. (2011). School Health Profiles 2010: Characteristics of Health Programs Among Secondary Schools. Atlanta: Centers for Disease Control and Prevention.

Brener, N. D., Kann, L., McManus, T., Kinchen, S. A., Sundberg, E. C., \& Ross, J. G. (2002). Reliability of the 1999 youth risk behavior survey questionnaire. Journal of Adolescent Health, 31(4), 336-42.

Brener, N. D., McMahon, P. M., Warren, C. W., \& Douglas, K. A. (1999). Forced sexual intercourse and associated health-risk behaviors among female college students in the United States. Journal of Consulting and Clinical Psychology, 67(2), 252-259.

Brener, N. D., McManus, T., Foti, K., Shanklin, S. L., Hawkins, J., Kann, L., \& Speicher, N. (2009). School Health Profiles 2008: Characteristics of Health Programs Among Secondary Schools. Atlanta: Centers for Disease Control and Prevention. 
Brewer, N. T., \& Rimer, B. K. (2008). Perspectives on theories of health behavior that focus on individuals. In K. Glanz, B. K. Rimer, \& V. Viswanath (Eds.), Health Behavior and Health Education: Theory, Research and Practice (4th ed.). San Francisco, CA: Jossey Bass.

Briggs, S. R., \& Cheek, J. M. (1986). The role of factor analysis in the development and evaluation of personality scales. Journal of Personality, 54, 106-48.

Brink, P. J. (1987). Cultural aspects of sexuality. Holistic Nursing Practice, 1(4), 12-20.

Brochu, N. (2012, August 5). Black Teens Get Message on Safer Sex. Sun-Sentinel. Retrieved August 21, 2012, from http://articles.sun-sentinel.com/2012-0804/health/fl-teen-sexual-behaviors-20120802_1_black-teens-aids-epidemic-southflorida-s-hiv

Broering, J. M. (1991). Childhood sexual learning and sex education in schools. NAACOG's Clinical Issues in Perinatal and Women's Health Nursing, 2(2), 17989.

Brooks, L. A. (2004). Influencing adolescent behaviors: a need for comprehensive sex education. AWHONN Lifelines, 8(4), 296-8.

Broward County Public Schools. (2012, November 19). District Overview. Retrieved from http://www.browardschools.com/about/overview.htm

Broward County Public Schools. (2012a). 2009 Broward County Public High School Youth Risk Behavior Survey Results. Retrieved October 5, 2011, from Health Education Services, Broward County Public Schools:

http://www.broward.k12.fl.us/studentsupport/healthedservices/documents/YRBS. pdf

Broward County Public Schools. (2012b). Health Education Services. Retrieved May 9, 2012, from Broward County Public Schools:

http://www.broward.k12.fl.us/studentsupport/healthedservices/hivaids.htmL

Brown, L. K., Danovsky, M. B., Lourie, K. J., DiClemente, R. J., \& Ponton, L. (1997). Adolescents with psychiatric disorders and the risk of HIV. Journal of the American Academy of Child and Adolescent Psychiatry, 36(11), 1609-1617.

Brown, L. K., Danovsky, M. B., Lourie, K. J., DiClemente, R. J., \& Ponton, L. E. (1997). Adolescents with psychiatric disorders and the risk of HIV. Journal of the American Academy of Child and Adolescent Psychiatry, 36(11), 1609-1617.

Brown, L. K., Fritz, G. K., \& Barone, V. J. (1989). The impact of AIDS education on junior and senior high school students. A pilot study. Journal of Adolescent Health Care, 10(5), 386-92. 
Brown, L. K., Tolou-Shams, M., Lescano, C., Houck, C. D., Zeidman, J., Pugatch, D., . . . Group, P. S. (2006). Depressive symptoms as a predictor of sexual risk among African American adolescents and young adults. Journal of Adolescent Health, 39(3), 444.e1-8.

Burt, M. (1980). Cultural myths and supports for rape. Journal of Personality and Social Psychology, 38, 217-230.

Buzi, R. S., Tortolero, S. R., Roberts, R. E., Ross, M. W., Addy, R. C., \& Markham, C. M. (2003). The impact of a history of sexual abuse on high-risk sexual behaviors among females attending alternative schools. Adolescence, 38(152), 595-605.

Carter, S. M., \& Carter, D. S. (1993). Gender differentiated receptivity to sexuality education curricula by adolescents. Health Education Research, 8(2), 233-43.

Carvajal, S. C., Hanson, C. E., \& Romero, A. J. (2002). Behavioural risk factors and protective factors in adolescents: A comparison of Latinos and non-Latino Whites. Ethnicity \& Health, 7(3), 181-93.

Catania, J. A., Coates, T. J., Kegeles, S., Fullilove, M. T., Peterson, J., Marín, B., . . . Hulley, S. (1992). Condom use in a multi-ethnic neighborhoods of San Francisco: The population based AMEN (AIDS in Multi-Ethnic Neighborhoods) study. American Journal of Public Health, 82, 284-287.

Catania, J. A., Kegeles, S. M., \& Coates, T. J. (1990). Towards an understanding of risk behavior: An AIDS Risk Reduction Model (ARRM). Health Education Quarterly, 17(1), 53-72.

Cates, W., \& McPheeters, M. (1997). Adolescents and Sexually Transmitted Diseases: Current Risks and Future Consequences. Prepared for the Workshop on Adolescent Sexuality and Reproductive Health in Developing Countries: Trends and Interventions. Washington, DC: National Research Council.

Cavazos-Rehg, P. A., Krauss, M. J., Spitznagel, E. L., Schootman, M., Bucholz, K. K., Peipert, J. F., . . B Bierut, L. J. (2009). Age of sexual debut among U.S. adolescents. Contraception, 80(2), 158-62.

Cavazos-Rehg, P. A., Krauss, M. J., Spitznagel, E. L., Schootman, M., Cottler, L. B., \& Bierut, L. J. (2011). Number of sexual partners and associations with initiation and intensity of substance use. AIDS and Behavior, 15(4), 869-74.

Centers for Disease Control and Prevention. (1992). Selected behaviors that increase risk for HIV infection among high school students - United States, 1990. MMWR Weekly, 41(14), 237-240. Retrieved from MMWR Weekly.

Centers for Disease Control and Prevention. (2004a). Methodology of the Youth Risk Behavior Surveillance System. MMWR, 53(RR-12), 1-14. 
Centers for Disease Control and Prevention. (2004b). Violence-Related Behaviors Among High School Students—United States, 1991-2003. MMWR, 53(29), 651674.

Centers for Disease Control and Prevention. (2006). Trends in HIV-Related Risk Behaviors Among High School Students - United States, 1991-2005. MMWR, $55(31), 851-854$.

Centers for Disease Control and Prevention. (2008a). HIV Prevention Education and HIV-Related Policies in Secondary Schools - Selected Sites, United States, 2006. $M M W R, 57,822-825$. Retrieved February 1, 2012, from http://www.cdc.gov/mmwr/preview/mmwrhtml/mm5730a2.htm

Centers for Disease Control and Prevention. (2008b). Trends in HIV- and STD-Related Risk Behaviors Among High School Students — United States, 1991-2007. $M M W R, 817-822$.

Centers for Disease Control and Prevention. (2008c). Youth Risk Behavior Surveillance — United States, 2007. MMWR, 57(SS-4), 1-130.

Centers for Disease Control and Prevention. (2008d). Youth Risk Behavior Survey (YRBS) Item rationale for the 2009 core questions. Retrieved July 2, 2012, from http://www.cdc.gov/healthyyouth/yrbs/pdf/questionnaire/2009ItemRationale.pdf

Centers for Disease Control and Prevention. (2009a). Sexual and Reproductive Health of Persons Aged 10-24 Years, 2002-2007. MMWR, 58(SS-6), 1-64.

Centers for Disease Control and Prevention. (2009b). SISTA. Retrieved July 9, 2012, from

http://www.cdc.gov/hiv/topics/prev_prog/ahp/resources/guidelines/pro_guidance/ print/sista.htm

Centers for Disease Control and Prevention. (2010a). 2009 National YRBS Data Users Manual. Retrieved May 12, 2011, from ftp://ftp.cdc.gov/pub/data/yrbs/2009/YRBS_2009_National_User_Guide.pdf

Centers for Disease Control and Prevention. (2010b). Youth Risk Behavior Surveillance — United States, 2009. MMWR, 59(SS-5), 1-142.

Centers for Disease Control and Prevention. (2011a). HIV among Women. Retrieved January 19, 2012, from http://www.cdc.gov/hiv/topics/women/pdf/women.pdf

Centers for Disease Control and Prevention. (2011b). HIV Among Youth. Retrieved from www.cdc.gov/hiv/youth/pdf/youth.pdf 
Centers for Disease Control and Prevention. (2011c). HIV Surveillance Report, 2009. Retrieved April 9, 2012, from http://www.cdc.gov/hiv/topics/surveillance/resources/reports/

Centers for Disease Control and Prevention. (2011d). Sexually Transmitted Disease Surveillance, 2010. Retrieved July 9, 2012, from http://www.cdc.gov/std/stats10/surv2010.pdf

Centers for Disease Control and Prevention. (2011e). Sexual identity, sex of sexual contacts, and health-risk behaviors among students in grades 9-12 --- Youth Risk Behavior Surveillance, selected sites, United States, 2001-2009. MMWR, 60(SS07), 1-133.

Centers for Disease Control and Prevention. (2012a). Dramatic Decline in Sexual Risks among Black Youth since 1991. Retrieved August 1, 2012, from http://www.cdc.gov/nchhstp/newsroom/2012/IAC-YRBS-PressRelease.html

Centers for Disease Control and Prevention. (2012b). Genital HPV Infection - Fact Sheet. Retrieved August 30, 2012, from http://www.cdc.gov/std/HPV/STDFactHPV.htm

Centers for Disease Control and Prevention. (2012c). HIV Surveillance in Adolescents and Young Adults. Retrieved July 5, 2012, from http://www.cdc.gov/hiv/topics/surveillance/resources/slides/adolescents/index.ht $\mathrm{m}$

Centers for Disease Control and Prevention. (2012d). Palm Beach County, Florida Funded Partners - Adolescent and School Health. Retrieved August 15, 2012, from http://www.cdc.gov/healthyyouth/states/locals/fl-palm-beach.htm

Centers for Disease Control and Prevention. (2012e). Participation History \& Data Quality, 1991-2011 - High School. Retrieved August 15, 2012, from http://www.cdc.gov/healthyyouth/yrbs/history-states.htm

Centers for Disease Control and Prevention. (2012f). Questionnaires \& Item Rationales. Retrieved July 15, 2012, from http://www.cdc.gov/healthyyouth/yrbs/questionnaire_rationale.htm

Centers for Disease Control and Prevention. (2012g). Youth Risk Behavior Surveillance — United States, 2011. MMWR, 61(SS-4), 1-162.

Centers for Population Options. (1989). Adolescents, AIDS and HIV: A Community-Wide Responsibility. Washington, DC: Centers for Population Options.

Champion, H. L., Foley, K. L., DuRant, R. H., Hensberry, R., Altman, D., \& Wolfson, M. (2004). Adolescent sexual victimization, use of alcohol and other substances, and other health risk behaviors. Journal of Adolescent Health, 35(4), 321-8. 
Chatterji, P., Dave, D., Kaestner, R., \& Markowitz, S. (2004). Alcohol abuse and suicide attempts among youth. Economics \& Human Biology, 2(2), 159-80.

Chesson, H. W., Blandford, J. M., Gift, T., Tao, G., \& Irwin, K. (2004). The estimated direct medical cost of sexually transmitted diseases among American youth, 2000. Perspectives on Sexual and Reproductive Health, 36(1), 11-9.

Choudhury, S., Blakemore, S., \& Charman, T. (2006). Social cognitive development during adolescence. Social Cognitive and Affective Neuroscience, 1(3), 165-174. doi:10.1093/scan/ns1024

Clark, J. K., \& Yarber, W. L. (1993). Two curricular settings of an HIV education unit related to secondary school students HIV knowledge and attitude. Journal of Health Education, 24(1), 4-10.

Coker, A. L., Richter, D. L., Valois, R. F., McKeown, R. E., Garrison, C. Z., \& Vincent, M. L. (1994). Correlates and consequences of early initiation of sexual intercourse. Journal of School Health, 64(9), 372-7.

Connell, R. (1987). Gender and Power. Stanford, CA: Stanford University Press.

Constantine, N. A. (2008). Converging evidence leaves policy behind: Sex education in the United States. Journal of Adolescent Health, 42(4), 324-6.

Contreras, J. M., Mangelsdorf, S. C., Rhodes, J. E., Diener, M. L., \& Brunson, L. (1999). Parent-child interaction among Latina adolescent mothers: The role of family and social support. Journal of Research on Adolescence, 9(4), 417-439.

Corbie-Smith, G., Akers, A., Blumenthal, C., Council, B., Wynn, M., Muhammad, M., \& Stith, D. (2010). Intervention mapping as a participatory approach to developing an HIV prevention intervention in rural African American communities. AIDS Education and Prevention, 23(3), 184-202.

Corneille, M. A., \& Belgrave, F. Z. (2007). Ethnic identity, neighborhood risk, and adolescent drug and sex attitudes and refusal efficacy: the urban African American girls' experience. Journal of Drug Education, 37(2), 177-190.

Cornelius, J. B., \& St. Lawrence, J. S. (2009). Receptivity of African American adolescents to an HIV-prevention curriculum enhanced by text messaging. Journal for Specialists in Pediatric Nursing, 14(2), 123-131.

Costa, F. M. (2008). Problem Behavior Theory - A Brief Overview. Retrieved January 9, 2012, from Institute of Behavioral Science, University of Colorado at Boulder: http://www.colorado.edu/ibs/jessor/pb_theory.html 
Cothran, M. M., \& White, J. P. (2002). Adolescent behavior and sexually transmitted diseases: The dilemma of human papillomavirus. Health Care for Women International, 23, 306-319.

Cottrell, R. R., \& McKenzie, J. F. (2011). Health Promotion and Education Research Methods: Using the Five Chapter Thesis/Dissertation Model (2nd ed.). Boston: Jones \& Bartlett Publishers.

Cox, M. F. (2007). Maternal demandingness and responsiveness as predictors of adolescent abstinence. Journal of Pediatric Nursing, 22(3), 197-205.

Crick, N. R., \& Grotpeter, J. K. (1995). Relational aggression, gender, and socialpsychological adjustment. Child Development, 66, 710-722.

Crosby, R. A., \& Danner, F. (2008). Adolescents' sexually transmitted disease protective attitudes predict sexually transmitted disease acquisition in early adulthood. Journal of School Health, 78(6), 310-3.

Cull-Wilby, B. L., Alcoe, S. Y., \& Taylor, P. G. (1985). The relationship between sex education and knowledge in grade eight students. Canadian Journal of Public Health, 76(3), 163-6.

Dancy, B. L., Crittenden, K. S., \& Freels, S. (2006). African-American adolescent females' predictors of having sex. Journal of National Black Nurses' Association, 17(2), 30-8.

Dariotis, J. K., Sifakis, F., Pleck, J. H., Astone, N. M., \& Sonenstein, F. L. (2011). Racial and ethnic disparities in sexual risk behaviors and STDs during young men's transition to adulthood. Perspectives on Sexual and Reproductive Health, 43(1), 51-59.

Darroch, J. E., Landry, D. J., \& Singh, S. (2000). Changing emphases in sexuality education in U.S public secondary schools, 1988-1999. Family Planning Perspectives, 32(5), 204-211, 265.

DeLamater, J. (2007). Gender equity in formal sexuality education. In S. S. Klein, B. Richardson, D. A. Grayson, L. H. Fox, \& C. Kramarae (Eds.), Handbook for Achieving Gender Equity through Education (2nd ed., pp. 411-420). New York: Taylor \& Francis.

DeNardo, C. (2008, Feburary 14). Sixth-graders will learn about contraceptives. Palm Beach Post. Retrieved August 9, 2011, from http://www.palmbeachpost.com/

DeNardo, C. (2008b, February 14). Palm Beach County, Fla., School District Plans to Begin Comprehensive Sex Education Program. Palm Beach Post. Retrieved August 9, 2011, from http://www.palmbeachpost.com 
DeNardo, C. (2008c, Feburary 14). Sixth-graders will learn about contraceptives. Palm Beach Post. Retrieved August 9, 2011, from http://www.palmbeachpost.com/

Denson, D. R., Voight, R., \& Eisenman, R. (1993). Factors that influence HIV/AIDS instruction in schools. Adolescence, 28(110), 309-14.

DePadilla, L., Windle, M., Wingood, G., Cooper, H., \& DiClemente, R. J. (2011). Condom use among young women: Modeling the theory of gender and power. Health Psychology, 30(3), 310-9.

DeSantis, L., \& Thomas, J. T. (1987). Parental attitudes toward adolescent sexuality: Transcultural perspectives. Nurse Practitioner, 12(8), 43-8.

DiClemente, C. C., \& Prochaska, J. O. (1982). Self-change and therapy change of smoking behavior: A comparison of processes of change in cessation and maintenance. Addictive Behaviors, 7(2), 133-42.

DiClemente, R. J. (1989). Prevention of human immunodeficiency virus infection among adolescents: The interplay of health education and public policy in the development and implementation of school-based AIDS education programs. AIDS Education and Prevention, 1(1), 70-8.

DiClemente, R. J. (1996). Adolescents at risk for acquired immune deficiency syndrome: epidemiology of AIDS, HIV prevalence and HIV incidence. In S. Oskamp, \& S. Thompson (Eds.), Understanding and Preventing HIV Risk Behavior (pp. 13-30). Newbury Park, CA: Sage Publications.

DiClemente, R. J., \& Wingood, G. M. (2003). Human immunodeficiency virus prevention for adolescents: Windows of opportunity for optimizing intervention effectiveness. Archives of Pediatric and Adolescent Medicine, 157(4), 319-20.

DiClemente, R. J., Crittenden, C. P., Rose, E., Sales, J. M., Wingood, G. M., Crosby, R. A., \& Salazar, L. F. (2008). Psychosocial predictors of HIV-associated sexual behaviors and the efficacy of prevention interventions in adolescents at-risk for HIV infection: What works and what doesn't work? Psychosomatic Medicine, 70, 598-605. doi:10.1097/PSY.0b013e3181775edb

DiClemente, R. J., Crosby, R., \& Kegler, M. (Eds.). (2002). Emerging Theories in Health Promotion Practice and Research: Strategies for Improving Public Health. San Francisco: Jossey Bass.

DiClemente, R. J., Wingood, G. M., Crosby, R. A., Sionean, C., Cobb, B. K., Harrington, K., ... Oh, M. K. (2002). Sexual risk behaviors associated with having older sex partners: A study of black adolescent females. Sexually Transmitted Diseases, 29(1), 20-4. 
DiClemente, R. J., Wingood, G. M., Harrington, K. F., Lang, D. L., Davies, S. L., Hook, E. W., . . . Robillard, A. (2004). Efficacy of an HIV prevention intervention for African American adolescent girls: A randomized controlled trial. Journal of the American Medical Association, 292(2), 171-179.

Dilorio, C., Hartwell, T., Hansen, N., \& Group, N. M. (2002). Childhood sexual abuse and risk behaviors among men at high risk for HIV infection. American Journal of Public Health, 92(2), 214-9.

Dillon, F. R., De La Rosa, M., Schwartz, S. J., Rojas, P., Duan, R., \& Malow, R. M. (2010). U.S. Latina age of sexual debut: Long-term associations and implications for HIV and drug abuse prevention. AIDS Care, 22(4), 431-40.

Doan, A. E., \& McFarlane, D. R. (2012). Saying no to abstinence-only education: An analysis of state decision-making. Publius. doi:10.1093/publius/pjr052

Doljanac, R. F., \& Zimmerman, M. A. (1998). Psychosocial factors and high-risk sexual behavior: Race differences among urban adolescents. Journal of Behavioral Medicine, 21(5), 451-67.

Donovan, J. E. (2005). Problem Behavior Theory. In C. B. Fisher, \& R. M. Lerner (Eds.), Encyclopedia of Applied Developmental Science (Vol. 2, pp. 872-877). Thousand Oaks, CA: Sage Publications.

Donovan, J. E., \& Jessor, R. (1985). Structure of problem behavior in adolescence and young adulthood. Journal of Consulting and Clinical Psychology, 53, 890-904.

Donovan, J. E., Jessor, R., \& Costa, F. M. (1988). Syndrome of problem behavior in adolescence: A replication. Journal of Consulting and Clinical Psychology, 56(5), 762-765.

Donovan, J. E., Jessor, R., \& Costa, F. M. (1991). Adolescent health behavior and conventionality-unconventionality: An extension of problem-behavior theory. Health Psychology, 10(1), 52-61.

Doskoch, P. (2008). STDs among young adults linked to childhood and reenage risk factors. Perspectives on Sexual and Reproductive Health, 40(3), 182-183.

Drane, J. W., \& Valois, R. F. (2002). Risk behavior data analysis: ordinal or dichotomous the choice is yours. American Journal of Health Behavior, 26(6), 465-72.

Draucker, C. B., Martsolf, D., Stephenson, P., Risko, J., Heckman, T., Sheehan, D., . . . Ferguson, C. (2010). Aggressive events in adolescent dating violence. Issues in Mental Health Nursing, 31(9), 599-610.

Duarte, R., Escario, J.-J., \& Molina, J. A. (2007). Peer Effects, Unobserved Factors and Risk Behaviours: An Analysis of Alcohol Abuse and Truancy Among Adolescents 
(January 2007). IZA Discussion Paper No. 2589. Retrieved July 12, 2012, from http://ssrn.com/abstract $=964975$

Duffy, K., Lynch, D. A., \& Santelli, J. (2008). Government support for abstinence-onlyuntil-marriage education. Clinical Pharmacology \& Therapeutics, 84(6), 746-8.

Dunn, P. (1982). Reduction of teenage pregnancy as a rationale for sex education: a position paper. Journal of School Health, 52(10), 611-3.

Dunne, M., Humphreys, S., \& Leach, F. (2003). Gender and Violence in Schools. UNESCO. Retrieved July 7, 2012, from http://unesdoc.unesco.org/images/0014/001467/146763e.pdf

DuRant, R. H., Smith, J. A., Kreiter, S. R., \& Krowchuk, D. P. (1999). The relationship between early age of onset of initial substance use and engaging in multiple health risk behaviors among young adolescents. Archives of Pediatriatric and Adolescent Medicine, 153(3), 286-91.

Dworkin, S., \& Santelli, J. (2007). Do abstinence-plus interventions reduce sexual risk behavior among youth? PLoS Medicine, 4(9), e276.

Eaton, D. K., Davis, K. S., Barrios, L., Brener, N. D., \& Noonan, R. K. (2007). Associations of dating violence victimization with lifetime participation, cooccurrence, and early initiation of risk behaviors among U.S. high school students. Journal of Interpersonal Violence, 22(5), 585-602.

Edberg, M. (2007). Essentials of Health Behavior: Social and Behavioral Theory in Public Health. Boston: Jones \& Bartlett Publishers.

Eitle, T., \& Eitle, D. (2002). Just don't do it: high school sports participation and young female adult sexual behavior. Sociology of Sport Journal, 19(4), 403-418.

Elkind, D. (1967). Egocentrism in adolescence. Child Development, 38(4), 1025-1034.

Elkington, K. S., Bauermeister, J. A., \& Zimmerman, M. A. (2010). Psychological distress, substance use, and HIV/STI risk behaviors among youth. Journal of Youth and Adolescence, 39, 514-527.

Epstein, J. A. (2006). Pro: Does abstinence-only education put adolescents at risk? American Journal of Maternal \& Child Nursing, 31(6), 348.

Epstein, J. A., \& Spirito, A. (2010). Gender-specific risk factors for suicidality among high school students. Archives of Suicide Research, 14(3), 193-205. doi:10.1080/13811118.2010.494130

Ethier, K. A., Kershaw, T. S., Lewis, J. B., Milan, S., Niccolai, L. M., \& Ickovics, J. R. (2006). Self-esteem, emotional distress and sexual behavior among adolescent 
females: Inter-relationships and temporal effects. Journal of Adolescent Health, $38(3), 268-74$.

Everett, S. A., Kann, L., \& McReynolds, L. (1997). The Youth Risk Behavior Surveillance System: policy and program applications. Journal of School Health, 67(8), 333-5.

Everett, S. A., Malarcher, A. M., Sharp, D. J., Husten, C. G., \& Giovino, G. A. (2000). Relationship between cigarette, smokeless tobacco, and cigar use, and other health risk behaviors among U.S. high school students. Journal of School Health, $70(6), 234-40$.

Exner, T. M., Dworkin, S. L., Hoffman, S., \& Ehrhardt, A. A. (2003). Beyond the male condom: the evolution of gender-specific HIV interventions for women. Annual Review of Sex Research, 14, 114-36.

Fantasia, H. C., \& Fontenot, H. B. (2011). The sexual safety of adolescents. Journal of Obstetric, Gynecologic, and Neonatal Nursing, 40(2), 217-24.

Farrell, A. D., Valois, R. F., \& Meyer, A. L. (2002). Impact of the RIPP violence prevention program: A one school design. American Journal of Health Education, 33(3), 167-172.

Faul, F., Erdfelder, E., Lang, A. G., \& Buchner, A. (2007). G*Power 3: A flexible statistical power analysis program for the social, behavioral, and biomedical sciences. Behavior Research Methods, 39, 175-191.

Fergusson, D. M., \& Lynskey, M. T. (1996). Alcohol misuse and adolescent sexual behaviors and risk taking. Pediatrics, 98(1), 91-6.

Filson, J., Ulloa, E., Runfola, C., \& Hokoda, A. (2010). Does powerlessness explain the relationship between intimate partner violence and depression? Journal of Interpersonal Violence, 25(3), 400-415.

Finklea, L., Gruendemann, G., \& Harris, D. C. (2004). Abstaining from abstinence. American Journal of Health Education, 35(2), 100-102.

Fischer, G. J. (1987). Hispanic and majority student attitudes towards forcible date rape as a function of differences in attitudes towards women. Sex Roles, 17, 93-101.

Fisher, H. H., Eke, A. N., Cance, J. D., Hawkins, S. R., \& Lam, W. K. (2008). Correlates of HIV-related risk behaviors in African American adolescents from substanceusing families: Patterns of adolescent-level factors associated with sexual experience and substance use. Journal of Adolescent Health, 42(2), 161-9.

Flores, E., Tschann, J. M., \& Marín, B. V. (2002). Latina adolescents: predicting intentions to have sex. Adolescence, 37(148), 659-79. 
Florida Department of Education. (n.d.). HIV/STD Prevention, Teen Pregnancy Prevention and Sexual Health Education. Retrieved January 19, 2012, from http://www.fldoe.org/BII/CSHP/Education/HIV_STD/Default.asp

Florida Department of Health. (2007). HIV and AIDS Epidemic among Adolescents \& Young Adults. Retrieved March 12, 2011, from http://www.doh.state.fl.us/Disease_ctrl/aids/trends/epiprof/epiprof_adol_2007.pdf

Florida Department of Health. (2011a). Epidemiolgical Profile: Palm Beach County. Retrieved October 25, 201, from http://www.doh.state.fl.us/Disease_ctrl/aids/trends/epiprof/Epi_10_stats/Part09_0 910b.pdf

Florida Department of Health. (2011b). Epidemiological Profile: Broward County. Retrieved October 25, 2011, from http://www.doh.state.fl.us/Disease_ctrl/aids/trends/epiprof/Epi_10_stats/Part10_0 910b.pdf

Florida Department of Health. (2011c). Epidemiological Profile: Miami Dade County. Retrieved October 25, 2011, from http://www.doh.state.fl.us/Disease_ctrl/aids/trends/epiprof/Epi_10_stats/Part11

Florida Department of Health. (2011d). Youth Risk Behavior Survey. Retrieved October 2, 2011, from http://www.doh.state.fl.us/disease_ctrl/epi/Chronic_Disease/YRBS/Intro.htm

Florida Legislature. (2011). Fla. Stat. § 1003.46 Health education; instruction in Acquired Immune Deficiency Syndrome. Retrieved April 13, 2012, from http://www.leg.state.fl.us/statutes/index

Florida Legislature. (2011b). Fla. Stat. \$ 1003.46 Health education; instruction in Acquired Immune Deficiency Syndrome. Retrieved April 13, 2012, from http://www.leg.state.fl.us/statutes/index

Ford, K., \& Norris, A. E. (1993). Urban Hispanic adolescents and young adults: Relation of acculturation to sexual behavior. Journal of Sex Research, 30, 316-323.

Forhan, S. E., Gottlieb, S. L., Sternberg, M. R., Xu, F., Datta, S. D., McQuillan, G. M., . . . Markowitz, L. E. (2009). Prevalence of sexually transmitted infections among female adolescents aged 14 to 19 in the United States. Pediatrics, 124(6), 15051512 .

Forman, E. S., Dekker, A. H., Javors, J. R., \& Davison, D. T. (1995). High-risk behaviors in teenage male athletes. Clinical Journal of Sports Medicine, 5(1), 36-42. 
Foti, K., Balaji, A., \& Shanklin, S. (2011). Uses of Youth Risk Behavior Survey and School Health Profiles data: applications for improving adolescent and school health. Journal of School Health, 81(6), 345-54.

Froyum, C. M. (2010). Making 'good girls': sexual agency in the sexuality education of low-income black girls. Culture, Health and Sexuality, 12(1), 59-72.

Frye, V., Ompad, D., Chan, C., Koblin, B., Galea, S., \& Vlahov, D. (2011). Intimate partner violence perpetration and condom use-related factors: Associations with heterosexual men's consistent condom use. AIDS and Behavior, 15(1), 153-62.

Furstenburg, F. F., Morgan, P. S., Moore, K. A., \& Peterson, J. L. (1987). Race Differences in the Timing of Adolescent Intercourse. American Sociological Review, 52, 511-18.

Galaif, E. R., Sussman, S., Newcomb, M. D., \& Locke, T. F. (2007). Suicidality, depression, and alcohol use among adolescents: a review of empirical findings. International Journal of Adolescent Medicine and Health, 19(1), 27-35.

Gardner, M., \& Steinberg, L. (2005). Peer influence on risk taking, risk preference, and risky decision making in adolescence and adulthood: an experimental study. Developmental Psychology, 41(4), 625-35.

Garfein, R. S., Monterroso, E. R., Tong, T. C., Vlahov, D., Des Jarlais, D. C., Selwyn, P., ... Holmberg, S. D. (2004). Comparison of HIV infection risk behaviors among injection drug users from East and West Coast US cities. Journal of Urban Health, 81(2), 260-7.

Gilliam, M. L., Berlin, A., Kozloski, M., Hernandez, M., \& Grundy, M. (2007). Interpersonal and personal factors influencing sexual debut among MexicanAmerican young women in the United States. Journal of Adolescent Health, 41, 495-503.

Gonzalez, J., Field, T., Yando, R., Gonzalez, K., Lasko, D., \& Bendell, D. (1994). Adolescents' perceptions of their risk-taking behavior. Journal of Adolescence, 29(115), 701-9.

Greydanus, D. E., Bashe, P., \& American Academy of Pediatrics. (2003). Caring for Your Teenager: The Complete and Authoritative Guide. New York: Bantam Books.

Gruber, J. (2001). Introduction. In J. Gruber, Risky Behavior among Youths: An Economic Analysis (pp. 1-28). Chicago: University of Chicago Press.

Guiao, I. Z., Blakemore, N. M., \& Wise, A. B. (2004). Predictors of teen substance use and risky sexual behaviors: Implications for advanced nursing practice. Clinical Excellence for Nurse Practitioners, 8(2), 52-59. 
Guilamo-Ramos, V., Bouris, A., Jaccard, J., Lesesne, C., \& Ballan, M. (2009). Familial and cultural influences on sexual risk behaviors among Mexican, Puerto Rican, and Dominican youth. AIDS Education and Prevention, 21(5 Suppl), 61-79.

Guilamo-Ramos, V., Jaccard, J., Pena, J., \& Goldberg, V. (2005). Acculturation-related variables, sexual initiation, and subsequent sexual behavior among Puerto Rican, Mexican, and Cuban youth. Health Psychology, 24, 88-95.

Gupta, G. R. (2000). Gender, sexuality, and HIV/AIDS: the what, the why, and the how. HIV/AIDS Policy \& Law Review, 5(4), 86-93.

Guttmacher Institute. (2010). U.S. teenage pregnancies, births, and abortions: National and state trends and trends by race and ethnicity. Retrieved January 29, 2012, from http://www.guttmacher.org/pubs/USTPtrends.pdf

Guttmacher Institute. (2012a). Facts on American Teens' Sexual and Reproductive Health. Retrieved from http://www.guttmacher.org/pubs/FB-ATSRH.pdf

Guttmacher Institute. (2012b). Facts on American Teens' Sources of Information About Sex. Retrieved from http://www.guttmacher.org/pubs/FB-Teen-Sex-Ed.html

Habel, M. A., Dittus, P. J., De Rosa, C. J., Chung, E. Q., \& Kerndt, P. R. (2010). Daily participation in sports and students' sexual activity. Perspectives on Sexual and Reproductive Health, 42(4), 244-250.

Haffner, D. W. (1988). AIDS and adolescents: School health education must begin now. Journal of School Health, 58(4), 154-5.

Haffner, D. W. (1995). Facing facts: Sexual health for America's adolescents. SIECUS Report, 23(6), 2-8.

Haffner, D. W., \& Wagoner, J. (1999). Vast majority of Americans support sexuality education. SIECUS Report, 27(6), 22-23.

Hajcak, F., \& Garwood, P. (1988). What parents can do to prevent pseudo hypersexuality in adolescents. Family Therapy, 15(2), 99-105.

Hall, J. N., \& Camejo, M. (2004). Drug abuse in Miami and Ft. Lauderdale, Florida. Epidemiologic Trends in Drug Abuse, 3, 108-122. Retrieved October 5, 2012, from http://archives.drugabuse.gov/pdf/cewg/Vol2_604.pdf\#page=116

Hallfors, D. D., Iritani, B. J., Miller, W. C., \& Bauer, D. J. (2007). Sexual and drug behavior patterns and HIV and STD racial disparities: the need for new directions. American Journal of Public Health, 97(1), 125-32. 
Hallfors, D. D., Waller, M. W., Bauer, D., Ford, C. A., \& Halpern, C. T. (2005). Which comes first in adolescence - sex and drugs or depression? American Journal of Preventive Medicine, 29(3), 163-70.

Halpern, C. T., Hallfors, D., Bauer, D. J., Iritani, B., Waller, M. W., \& Cho, H. (2004). Implications of racial and gender differences in patterns of adolescent risk behavior for HIV and other sexually transmitted diseases. Perspectives on Sexual and Reproductive Health, 36(6), 239-47.

Hardy, M. A. (1993). Regression with Dummy Variables. Newbury Park, CA: Sage Publications.

Harrison, A. (2002). The social dynamics of adolescent risk for HIV: Using research findings to design a school-based intervention. Agenda, 53, 43-52.

Harvey, S. M. (2000). New kinds of data, new options for HIV prevention among women: A public health challenge. Health Education \& Behavior, 27(5), 566-569.

Hayward, M. D., Grady, W. R., \& Billy, J. O. (1992). The influence of socioeconic status on adolescent pregnancy. Social Science Quarterly, 73, 751- 72.

He, H., McCoy, H. V., Stevens, S. J., \& Stark, M. J. (1998). Violence and HIV sexual risk behaviors among female sex partners of male drug users'. Women \& Health, 21(1), 161-175.

Higgins, J. A., Hoffman, S., \& Dworkin, S. L. (2010). Rethinking gender, heterosexual men, and women's vulnerability to HIV/AIDS. American Journal of Public Health, 100(3), 435-45.

Hillier, L., Harrison, L., \& Bowditch, K. (1999). Neverending love and blowing your load: The meanings of sex to rural youth. Sexualities, 2(1), 69-88.

Hitchcock, J. H., Sarkar, S., Nastasi, B., Burkholder, G., Varjas, K., \& Jayasena, A. (2006). Validating culture and gender-specific constructs: A mixed-method approach to advance assessment procedures in cross-cultural settings. Journal of Applied School Psychology, 22(2), 13-33.

Hlaing, W. M., \& Darrow, W. W. (2006). HIV risk reduction among young minority adults in Broward County. Journal of Health Care for the Poor and Underserved, 17(2 Suppl), 159-73.

Hlaing, W. M., de la Rosa, M., \& Niyonsenga, T. (2007). Human immunodeficiency virus (HIV) and substance use risk behaviors among tri-ethnic adolescents of Florida. AIDS and Behavior, 11(2), 239-51. 
Hoffman, J. P. (2006). Extracurricular activities, athletic participation, and adolescent alcohol use: Gender-differentiated and school-contextual effects. Journal of Health and Social Behavior, 47(3), 275-29.

Hoffman, S. D. (2006). By the numbers: The public costs of adolescent childbearing. Retrieved March 23, 2012, from http://www.thenationalcampaign.org/resources/pdf/pubs/btn_full.pdf

Holmes, W. C., Foa, E. B., \& Sammel, M. D. (2005). Men's pathways to risky sexual behavior: role of co-occurring childhood sexual abuse, posttraumatic stress disorder, and depression histories. Journal of Urban Health, 82(1, Suppl 1), 8999.

Holtzman, D., Anderson, J. E., Kann, L., Arday, S. L., Truman, B. I., \& Kolbe, L. J. (1991). HIV instruction, HIV knowledge, and drug injection among high school students in the United States. American Journal of Public Health, 81(12), 15961601 .

Homma, Y., Wang, N., Saewyc, E., \& Kishor, N. (2012). The relationship between sexual abuse and risky sexual behavior among adolescent boys: A meta-analysis. Journal of Adolescent Health, 51(1), 18-24.

Houck, C. D., Nugent, N. R., Lescano, C. M., \& Peters, A. (2010). Sexual abuse and sexual risk behavior: Beyond the impact of psychiatric problems. Journal of Pediatric Psychology, 35(5), 473-483.

Howard, D. E., \& Wang, M. Q. (2003). Risk profiles of adolescent girls who were victims of dating violence. Adolescence, 38(149), 1-14.

Howard, D. E., Wang, M. Q., \& Yan, F. (2008). Psychosocial factors associated with reports of physical dating violence victimization among U.S. adolescent males. Adolescence, 43(171), 449-60.

Howard-Barr, E. M., Wiley, D., Moore, M. J., Lang, D., \& Zipperer, K. (2011). Addressing sexual health in Florida youth: Improving communication, collaboration, and consensus building among providers. Health Promotion Practice, 12(4), 600-609.

Howell, M. (2007). The History of Federal Abstinence-Only Funding. Retrieved March 27,2012 , from http://www.advocatesforyouth.org/storage/advfy/documents/fshistoryabonly.pdf

Hubbard, B. M., Giese, M. L., \& Rainey, J. (1998). A replication study of Reducing the Risk, a theory-based sexuality curriculum for adolescents. Journal of School Health, 68(6), 243-7. 
Hyde, J. S., \& DeLamater, J. D. (2006). Understanding Human Sexuality (9th ed.). Boston: McGraw Hill.

Igra, V., \& Irwin, C. E. (1996). Theories of adolescent risk-taking behavior. In R. J. DiClemente, W. B. Hansen, \& L. E. Ponton (Eds.), Handbook of adolescent risk behavior (pp. 35-51). New York: Plenum Press.

Institute of Medicine. (2011). Leading Health Indicators for Healthy People 2020: Letter Report. Retrieved March 18, 2012, from http://www.iom.edu/

Jaccard, J., Blanton, H., \& Dodge, T. (2005). Peer influences on risk behavior: An analysis of the effects of a close friend. Developmental Psychology, 41(1), 13547.

Jadack, R. A., Hyde, J. S., \& Keller, M. L. (1995). Gender and knowledge about HIV, risky sexual behavior, and safer sex practices. Research in Nursing \& Health, 18(4), 313-24.

Janz, N. K., \& Becker, M. H. (1984). The Health Belief Model: a decade later. Health Education Quarterly, 11(1), 1-47.

Jeffries, W. L., Dodge, B., Bandiera, F. C., \& Reece, M. (2010). Beyond abstinence-only: Relationships between abstinence education and comprehensive topic instruction. Sex Education: Sexuality, Society and Learning, 10(2), 171-185.

Jemmott, J. B., \& Jemmott, L. S. (1993). Alcohol and drug use during sexual activity: Predicting the HIV-risk related behaviors of inner-city Black male adolescents. Journal of Adolescent Research, 8(1), 41-57.

Jemmott, J. B., Jemmott, L. S., Fong, G. T., \& Morales, K. H. (2010). Effectiveness of an HIV/STD risk-reduction intervention for adolescents when implemented by community-based organizations: a cluster-randomized controlled trial. American Journal of Public Health, 100(4), 720-6.

Jessor, R. (1991). Risk behavior in adolescence: a psychosocial framework for understanding and action. Journal of Adolescent Health, 12(8), 597-605.

Jessor, R., \& Jessor, S. L. (1977). Problem Behavior and Psychosocial Development: A Longitudinal Study of Youth. New York: Academic Press.

Jessor, R., Donovan, J. E., \& Costa, F. M. (1991). Beyond adolescence: Problem behavior and young adult development. New York: Cambridge University Press.

Jessor, R., Graves, T. D., Hanson, R. C., \& Jessor, S. L. (1968). Society, personality, and deviant behavior: A study of a tri-ethnic community. New York: Holt, Rinehart \& Winsto. 
Jessor, R., Turbin, M. S., \& Costa, F. M. (1998a). Protective factors in adolescent health behavior. Journal of Personality and Social Psychology, 75(3), 788-800.

Jessor, R., Turbin, M. S., \& Costa, F. M. (1998b). Risk and protection in successful outcomes among disadvantaged adolescents. Applied Developmental Science, 2(4), 194-208.

Jessor, R., Van Den Bos, J., Vanderryn, J., Costa, F. M., \& Turbin, M. S. (1995). Protective factors in adolescent problem behavior: Moderator effects and developmental change. Development Psychology, 31(6), 923-933.

Johnson, B. T., Scott-Sheldon, L. A., Huedo-Medina, T. B., \& Carey, M. P. (2011). Interventions to reduce sexual risk for human immunodeficiency virus in adolescents: A meta-analysis of trials, 1985-2008. Archives of Pediatric and Adolescent Medicine, 165(1), 77-84.

Johnson, R. J., Rew, L., \& Sternglanz, R. W. (2006). The relationship between childhood sexual abuse and sexual health practices of homeless adolescents. Adolescence, 41(162), 221-34.

Kandel, D. B., \& Davies, M. (1991). Decline in the use of illicit drugs by high school students in New York State: A comparison with national data. American Journal of Public Health, 81, 1064-1067.

Kapungu, C. T., Baptiste, D., Holmbeck, G., McBride, C., Robinson-Brown, M., Sturdivant, A., .. . Paikoff, R. (2010). Beyond the "birds and the bees": gender differences in sex-related communication among urban African-American adolescents. Family Process, 49(2), 251-64.

Kendall, N. (2008a). Sexuality education in an abstinence-only era: A comparative case study of two U.S. states. Sexuality Research \& Social Policy, 5(2), 23-44. doi:10.1525/srsp.2008.5.2.23

Kendall, N. (2008b). The state(s) of sexuality education in America. Sexuality Research \& Social Policy, 5(2), 1-11.

Kennedy, C., Skurnick, J., Wan, J., Quattrone, G., Sheffet, A., Quinones, M., . . Louria, D. (1993). Psychcological distress, drug and alcohol use as correlates of consom use in HIV-serodiscordant heterosexual couples. AIDS, 7, 1493-1499.

Kenney, J. W., Reinholtz, C., \& Angelini, P. J. (1997). Ethnic differences in childhood and adolescent sexual abuse and teenage pregnancy. Journal of Adolescent Health, 21(1), 3-10.

Kenney, J. W., Reinholtz, C., \& Angelini, P. J. (1998). Sexual abuse, sex before age 16, and high-risk behaviors of young females with sexually transmitted diseases. Journal of Obstetric, Gynecologic, \& Neonatal Nursing, 27(1), 54-63. 
Keogh, J. J. (1988). Sex counselling of the male adolescent. Part 3. Clinical conditions in the sexually active male. Nursing RSA, 3(11-12), 14-5, 21.

Khan, M. R., Kaufman, J. S., Pence, B. W., Gaynes, B. N., Adimora, A. A., Weir, S. S., \& Miller, W. C. (2009). Depression, sexually transmitted infection, and sexual risk behavior among young adults in the United States. Archives of Pediatric \& Adolescent Medicine, 163(7), 644-52.

Kirby, D. (1985). Sexuality education: a more realistic view of its effects. Journal of School Health, 55(10), 421-4.

Kirby, D. (2000). School-based interventions to prevent unprotected sex and HIV among adolescents. In J. Peterson, \& R. DiCLemente, Handbook of HIV Prevention (pp. 103-128). New York, NY: Kluwer/Plenum Press.

Kirby, D. (2001). Emerging Answers: Research findings on programs to reduce teen pregnancy. American Journal of Health Education.

Kirby, D. (2002a). Antecedents of adolescent initiation of sex, contraceptive use, and pregnancy. American Journal of Health Behavior, 26(6), 473-85.

Kirby, D. (2002b). Effective approaches to reducing adolescent unprotected sex, pregnancy, and childbearing. Journal of Sex Research, 39(1), 51-7.

Kirby, D. (2006). Comprehensive sex education: strong public support and persuasive evidence of impact, but little funding. Archives of Pediatrics \& Adolescent Medicine, 160(11), 1182-4.

Kirby, D. (2008). The impact of abstinence and comprehensive sex and STD/HIV education programs on adolescent sexual behavior. Sexuality Research \& Social Policy, 5(3), 18-27.

Kirby, D. (2011). Sex Education: Access and Impact on Sexual Behavior of Young People. Retrieved from http://www.un.org/esa/population/meetings/egmadolescents/p07_kirby.pdf

Kirby, D., \& Laris, B. A. (2009). Effective curriculum-based sex and STD/HIV education programs for adolescents. Child Development Perspectives, 3(1), 21-29.

Kirby, D., \& Lepore, G. (2007). Sexual risk and protective factors: Factors affecting teen sexual behaviour, pregnancy, childbearing and sexually transmitted disease: Which are important? Washington, DC: National Campaign to Prevent Teen Pregnancy.

Kirby, D., Barth, R., Leland, N., \& Fetro, J. (1991). Reducing the risk: impact of a new curriculum on sexual risk-taking. Family Planning Perspectives, 23(6), 253-63. 
Kirby, D., Laris, B. A., \& Rolleri, L. A. (2007). Sex and HIV education programs: their impact on sexual behaviors of young people throughout the world. Journal of Adolescent Health, 40(3), 206-17.

Kirby, D., Laris, B., \& Rolleri, L. (2005). Impact of Sex and HIV Education Programs on Sexual Behaviors of Youth in Developing and Developed Countries. [Youth Research Working Paper, No. 2]. Research Triangle Park, NC: Family Health International.

Klein, H., \& Chao, B. S. (1995). Sexual abuse during childhood and adolescence as predictors of HIV-related sexual risk during adulthood among female sexual partners of injection drug users. Violence Against Women, 1(1), 55-76.

Kohler, P. K., Manhart, L. E., \& Lafferty, W. E. (2008). Abstinence-only and comprehensive sex education and the initiation of sexual activity and teen pregnancy. Journal of Adolescent Health, 42(4), 344-51.

Kolbe, L. J., Kann, L., \& Collins, J. L. (1993). Overview of the Youth Risk Behavior Surveillance System. Public Health Reports, 108(Suppl 1), 2-10.

Koniak-Griffin, D., Nyamathi, A., Vasquez, R., \& Russo, A. A. (1994). Risk-taking behaviors and AIDS knowledge: experiences and beliefs of minority adolescent mothers. Health Education Research, 9(4), 449-63.

Kost, K., Henshaw, S., \& Carlin, L. (2010). U.S. Teenage Pregnancies, Births and Abortions: National and State Trends and Trends by Race and Ethnicity. Retrieved March 12, 2012, from http://www.guttmacher.org/pubs/USTPtrends.pdf

Krantz, S. R., Lynch, D. A., \& Russell, J. M. (2002). Gender-specific profiles of selfreported adolescent HIV risk behaviors. Journal of the Association of Nurses in AIDS Care, 13(6), 25-33. doi:10.1177/1055329002238023

Kreiter, S. R., Krowchuk, D. P., Woods, C. R., Sinal, S. H., Lawless, M. R., \& DuRant, R. H. (1999). Gender differences in risk behaviors among adolescents who experience date fighting. Journal of Pediatrics, 104(6), 1286-92.

Kulig, K., Brener, N., \& McManus, T. (2003). Sexual activity and substance use among adolescents by category of physical activity plus team sports participation. Archives of Pediatrics \& Adolescent Medicine, 157(9), 905-912.

Landry, D. J., Kaeser, L., \& Richards, C. L. (1999). Abstinence promotion and the provision of information about contraception in public school district sexuality education policies. Family Planning Perspectives, 31(6), 280-6.

Lang, D. L., Sales, J. M., Salazar, L. F., Hardin, J. W., DiClemente, R. J., Wingood, G. M., \& Rose, E. (2011). Rape victimization and high risk sexual behaviors: 
longitudinal study of african-american adolescent females. Western Journal of Emergency Medicine, 12(3), 333-42.

Lee, J., \& Hahm, H. C. (2010). Acculturation and sexual risk behaviors among Latina adolescents transitioning to young adulthood. Journal of Youth and Adolescence, $39(4), 414-27$.

Lehrer, J. A., Shrier, L. A., Gortmaker, S., \& Buka, S. (2006). Depressive symptoms as a longitudinal predictor of sexual risk behaviors among US middle and high school students. Pediatrics, 118(1), 189-200.

Lewis, C. C. (1981). How adolescents approach decisions: Changes over grades seven to twelve and policy implications. Child Development, 52, 538-544.

Lightfoot, M. A., \& Milburn, N. G. (2009). HIV prevention and African American youth: examination of individual-level behaviour is not the only answer. Culture, Health \& Sexuality, 11(7), 731-42.

Lindberg, L. D., Santelli, J. S., \& Singh, S. (2006). Changes in Formal Sex Education: 1995-2002. Perspectives on Sexual and Reproductive Health, 38(4), 182-189.

Lindley, L. L., Reininger, B. M., Vincent, M. L., Richter, D. L., Saunders, R. P., \& Shi, L. (1998). Support for school-based sexuality education among South Carolina voters. Journal of School Health, 68(5), 205-12.

Littleton, H., Breitkopf, C. R., \& Berenson, A. (2007). Sexual and physical abuse history and adult sexual risk behaviors: Relationships among women and potential mediators. Child Abuse \& Neglect, 7, 757-768.

Livaudais, J. C., Napoles-Springer, A., Stewart, S., \& Kaplan, C. P. (2007). Understanding Latino adolescent risk behaviors: parental and peer influences. Ethnicity \& Disease, 17(2), 298-304.

Loeber, R., \& Stouthamer-Loeber, M. (1998). Development of juvenile aggression and violence: Some common misconceptions and controversies. American Psychologist, 53(2), 242-59.

Logan, C., Holcombe, E., Manlove, J., \& Ryan, S. (2007). The Consequences of Unintended Childbearing: A White Paper. Retrieved March 18, 2012, from www.thenationalcampaign.org/resources/pdf/consequences.pdf

Lowry, R., Holtzman, D., Truman, B. I., Kann, L., Collins, J. L., \& Kolbe, L. J. (1994). Substance use and HIV-related sexual behaviors among U.S. high school students: are they related? American Journal of Public Health, 84(7), 1116-1120. 
Lugoe, W. L., Klepp, K. I., Rise, J., Skutle, A., \& Biswalo, P. M. (1995). Relationship between sexual experience and non-sexual behaviours among secondary school students in Arusha, Tanzania. East African Medical Journal, 72(10), 635-40.

Luster, T., \& Small, S. A. (1994). Factors associated with sexual risk-taking behaviors among adolescents. Journal of Marriage and Family, 56(3), 622-632.

Madkour, A. S., Farhat, T., Halpern, C. T., Godeau, E., \& Gabhainn, S. N. (2010). Early adolescent sexual initiation as a problem behavior: a comparative study of five nations. Journal of Adolescent Health, 47(4), 389-98.

Malhotra, S. (2008). Impact of the sexual revolution: consequences of risky sexual behaviors. Journal of American Physicians and Surgeons, 13(3), 88-90.

Malow, R. M., Rosenberg, R., Donenberg, G., \& Dévieux, J. G. (2006). Interventions and patterns of risk in adolescent HIV/AIDS prevention. American Journal of Infectious Diseases, 2(2), 80-89.

Mane, P., \& Lawson, L. (2007). HIV prevention, gender and sexual health. International Journal of Sexual Health, 19, 47-52. doi:10.1300/J514v19n03_06

Manlove, J., Romano-Papillo, A., \& Ikramullah, E. (2004). Not Yet: Programs to Delay First Sex among Teens. Retrieved March 26, 2012, from http://www.thenationalcampaign.org/resources/pdf/pubs/notyet.pdf

March, A. L., \& Atav, A. S. (2010). Social environment and problem behavior: perceived school safety, gender and sexual debut. Journal of School Nursing, 26(2), 121-30. doi: $10.1177 / 1059840509343112$

Marín, B. V. (1996). Cultural Issues in HIV Prevention for Latinos: Should we be changing gender roles. In S. Oskamp, \& S. C. Thompson (Eds.), Understanding and Preventing HIV Risk Behavior (pp. 157-176). Thousand Oaks, CA: Sage Publications.

Marín, B. V., Gomez, A. A., Tschann, J. M., \& Gregorich, S. E. (1997). Condom use in unmarried Latino men: a test of cultural constructs. Health Psychology, 6(5), 458467.

Marshall, B. D., \& Werb, D. (2010). Health outcomes associated with methamphetamine use among young people: a systematic review. Addiction, 105(6), 91-1002.

Martyn, K. K., \& Martin, R. (2003). Adolescent sexual risk assessment. Journal of Midwifery \& Womens Health, 48(3), 213-9.

Maxwell, K. A. (2002). Friends: The Role of Peer Influence across Adolescent Risk Behaviors. Journal of Youth and Adolescence, 31(4), 267-77. 
McDaniel, J. (2000). Testimony of the Center for the Prevention of School Violence on A Vision for Safer Schools. Retrieved July 7, 2012, from http://www.ncdjjdp.org/cpsv/pdf_files/testimony.pdf

McDonald, J. A., Manlove, J., \& Ikramullah, E. N. (2009). Immigration Measures and Reproductive Health Among Hispanic Youth: Findings from the National Longitudinal Survey of Youth, 1997-2003. Journal of Adolescent Health, 44, 1424.

Melzer-Lang, M. D. (1998). Violence and associated high-risk health behavior in adolescents. Substance abuse, sexually transmitted diseases, and pregnancy of adolescents. Pediatric Clinics of North America, 45(2), 307-17.

Meyer, A., \& Farrell, A. D. (1998). Social skills training to promote residence in urban sixth grade students: One product of an action research strategy. Education and Treatment of Children, 21, 461-488.

Miami-Dade County Public Schools. (2010). 2009 Youth Risk Behavior Survey: Senior High School Results. Retrieved October 6, 2011, from http://oer.dadeschools.net/YRBS/P_R_REPORTS/2009YRBSProgressReport.pdf

Miami-Dade County Public Schools. (2012). HIV/AIDS Education Program. Retrieved May 9, 2012, from http://aidseducation.dadeschools.net/

Middleman, A. B. (1999). Review of sexuality education in the United States for health professionals working with adolescents. Current Opinion in Pediatrics, 11(4), 283-6.

Milhausen, R. R., DiClemente, R. J., Lang, D. L., Spitalnick, J. S., Sales, J. M., \& Hardin, J. W. (2008). Frequency of sex after an intervention to decrease sexual risk-taking among African-American adolescent girls: Results of a randomized, controlled clinical trial. Sex Education: Sexuality, Society and Learning, 8(1), 4757.

Miller, K. E., Barnes, G. M., Melnick, M. J., Sabo, D. F., \& Farrell, M. P. (2002). Gender and racial/ethnic differences in predicting adolescent sexual risk: athletic participation versus exercise. Journal of Health and Social Behavior, 43(4), 436450.

Miller, K. E., Hoffman, J. H., Barnes, G. M., Sabo, D., Melnick, M. J., \& Farrell, M. P. (2005). Adolescent anabolic steroid use, gender, physical activity, and other problem behaviors. Substance Use \& Misuse, 40(11), 1637-57.

Miller, K. E., Sabo, D. F., Farrell, M. P., Barnes, G. M., \& Melnick, M. J. (1998). Athletic participation and sexual behavior in adolescents: the different worlds of boys and girls. Journal of Health and Social Behavior, 39(2), 108-123. 
Miller, K. S., Clark, L. F., Wendell, D. A., Levin, M. L., Gray-Ray, P., Velez, C. N., \& Webber, M. P. (1997). Adolescent heterosexual experience: a new typology. Journal of Adolescent Health, 20(3), 179-86.

Miller, S., Exner, T., Williams, S., \& Ehrhardt, A. (2000). A gender-specific intervention for at-risk women in the USA. AIDS Care, 12(5), 603-12.

Miranda, A. O., Bilot, J. M., Peluso, P. R., Berman, K., \& Van Meek, L. G. (2006). Latino families: The relevance of the connection among acculturation, family dynamics, and health for family counseling research and practice. The Family Journal, 14, 268-273.

Montemayor, M. (1983). Parents and adolescents in conflict: All families some of the time and some families most of the time. Journal of Early Adolescence, 3(1-2), 83-103. doi:10.1177/027243168331007

Moran, J. R., \& Corley, M. D. (1991). Sources of sexual information and sexual attitudes and behaviors of Anglo and Hispanic adolescent males. Adolescence, 26(104), 857-864.

Morris, L., Warren, C. W., \& Aral, S. O. (1993). Measuring adolescent sexual behaviors and related health outcomes. Public Health Reports, 108(1 Suppl), 31-36.

Morrison, D. M., Gillmore, M. R., Hoppe, M. J., Gaylord, J., Leigh, B. C., \& Rainey, D. (2003). Adolescent drinking and sex: Findings from a daily diary study. Perspectives on Sexual and Reproductive Health, 35(4), 162-168.

Muehlenhard, C., \& Linton, M. (1987). Date rape and sexual aggression in dating situations: Incidence and risk factors. Journal of Counseling Psychology, 34, 186196.

Mueller, T. E., Castaneda, C. A., Sainer, S., Martinez, D., Herbst, J. H., Wilkes, A. L., \& Villarruel, A. M. (2009). The implementation of a culturally based HIV sexual risk reduction program for Latino youth in a Denver area high school. AIDS Education and Prevention, 21(5 Suppl), 164-70.

Mulatu, M. S., Leonard, K. J., Godette, D. C., \& Fulmore, D. (2008). Disparities in the patterns and determinants of HIV risk behaviors among adolescents entering substance abuse treatment programs. Journal of the National Medical Association, 100(2), 1405-16.

Muñoz-Laboy, M. (2008). Familism and sexual regulation among bisexual Latino men. Archives of Sexual Behavior, 37, 773-782.

Nahom, D., Wells, E., Gillmore, M. R., Hoppe, M., Morrison, D. M., Archibald, M., .. . Graham, L. (2011). Differences by gender and sexual experience in adolescent 
sexual behavior: implications for education and HIV prevention. Journal of School Health, 71(4), 153-8.

Neinstein, L. (1996). Adolescent Health Care: A Practical Guide. Baltimore: Williams \& Wilkins.

Neutens, J. J., Drolet, J. C., DuShaw, M. L., \& Jubb, W. (1991). Sexuality Education Within Comprehensive School Health Education. Kent, Ohio: American School Health Association.

Newman, C., DuRant, R. H., Ashworth, C. S., \& Gaillard, G. (1993). An evaluation of a school-based AIDS/HIV education program for young adolescents. AIDS Education and Prevention, 5(4), 327-39.

Newman, P. A., \& Zimmerman, M. A. (2000). Gender differences in HIV-related sexual risk behavior among urban African American youth: A multivariate approach. AIDS Education and Prevention, 12(4), 308-25.

Niyonsenga, T. (2007). Prevalence and correlates of sexual risk behaviors by gender among multi-ethnic adolescents. Annals of Epidemiology, 17(9), 742-743. doi:10.1016/j.annepidem.2007.07.061

Niyonsenga, T., Hlaing, W. M., \& McCormack Brown, K. R. (2008). Health compromising behaviors by gender among Florida adolescents. Florida Public Health Review, 5, 22-35.

Noar, S. M., Carlyle, K., \& Cole, C. (2006). Why communication is crucial: Metaanalysis of the relationship between safer sexual communication and condom use. Journal of Health Communication, 11, 365-390.

Nolen-Hoeksema, S., \& Girgus, J. S. (1994). The emergence of gender difference in depression during adolescence. Psychological Bulletin, 115(3), 424-443.

North Dakota Department of Public Instruction. (2011). Do Students Tell the Truth on the Youth Risk Behavior Survey (YRBS)? Retrieved June 9, 2012, from http://www.dpi.state.nd.us/health/yrbs/truth.pdf

Nsuami, M. J., Sanders, L. S., \& Taylor, S. N. (2010). Knowledge of sexually transmitted infections among high school students. American Journal of Health Education, 41(4), 206-217.

Obstfeld, L. S., \& Meyers, A. W. (1984). Adolescent sex education: a preventive mental health measure. Journal of School Health, 54(2), 68-70.

O'Donnell, L., O'Donnell, C. R., \& Stueve, A. (2001). Early sexual initiation and subsequent sex-related risks among urban minority youth: The reach for health study. Family Planning Perspectives, 33, 268-275. 
O'Donnell, L., Stueve, A., Wilson-Simmons, R., Dash, K., Agronick, G., \& JeanBaptiste, V. (2006). Heterosexual risk behaviors among urban young adolescents. The Journal of Early Adolescence, 26, 87-109. doi:10.1177/0272431605282653

Orr, S. T., Celentano, D. D., Santelli, J., \& Burwell, L. (1994). Depressive symptoms and risk factors for HIV acquisition among Black women attending urban health centers in Baltimore. AIDS Education and Prevention, 6, 230-236.

Ott, M. A., \& Santelli, J. S. (2007a). Abstinence and abstinence-only education. Current Opinion in Obstetrics and Gynecology, 19, 446-452.

Ott, M. A., \& Santelli, J. S. (2007b). Approaches to adolescent sexuality education. Adolescent Medicine: State of the Art Reviews, 18(3), 558-70, viii.

Paxton, K. C., \& Robinson, W. L. (2008). Depressive symptoms, gender, and sexual risk behavior among African-American adolescents: implications for prevention and intervention. Journal of Prevention \& Intervention in the Community, 35(2), 4962.

Paxton, R. J., Valois, R. F., Watkins, K. W., Huebner, E. S., \& Drane, J. W. (2007). Associations between depressed mood and clusters of health risk behaviors. American Journal of Health Behavior, 31(3), 272-83.

Pedlow, C. T., \& Carey, M. P. (2003). HIV sexual risk-reduction interventions for youth: A review and methodological critique of randomized control trials. Behavior Modification, 27, 35-190.

Pedlow, C. T., \& Carey, M. P. (2004). Developmentally appropriate sexual risk reduction interventions for adolescents: rationale, review of interventions, and recommendations for research and practice. Annals of Behavioral Medicine, $27(3), 172-84$.

Peleg-Oren, N., Saint-Jean, G., Cardenas, G. A., Tammara, H., \& Pierre, C. (2009). Drinking alcohol before age 13 and negative outcomes in late adolescence. Alcoholism: Clinical and Experimental Research, 33(11), 1966-72.

Pettifor, A. E., Levandowski, B. A., Macphail, C., Miller, W. C., Tabor, J., Ford, C., . . . Cohen, M. (2011). A tale of two countries: rethinking sexual risk for HIV among young people in South Africa and the United States. Journal of Adolescent Health, 49(3), 237-243.

Pierre, N., Shrier, L. A., Emans, S. J., \& DuRant, R. H. (1998). Adolescent males involved in pregnancy: associations of forced sexual contact and risk behaviors. Journal of Adolescent Health , 23(6), 364-9.

Pipher, M. (1994). Reviving Ophelia: Saving the Selves of Adoelscent Girls. New York: Ballantine Books. 
Poulson, R. L., Eppler, M. A., Satterwhite, T. N., Wuensch, K. L., \& Bass, L. A. (1998). Alcohol consumption, strength of religious beliefs, and risky sexual behavior in college students. Journal of American College Health, 46(5), 227-32.

Prinstein, M. J., Boergers, J., \& Spirito, A. (2001). Adolescents' and their friends healthrisk behavior: Factors that alter or add to peer influence. Journal of Pediatric Psychology, 26(5), 287-298.

Puente, D., Zabaleta, E., Rodríguez-Blanco, T., Cabanas, M., Monteagudo, M., Pueyo, M. J., . . group, ". i. (2011). Gender differences in sexual risk behaviour among adolescents in Catalonia, Spain. Gaceta Sanitaria, 25(1), 13-9.

Raiford, J. L., Wingood, G. M., \& DiClemente, R. J. (2007). Prevalence, incidence, and predictors of dating violence: a longitudinal study of African American female adolescents. Journal of Women's Health, 16(6), 822-32.

Raj, A., Reed, E., Miller, E., Decker, M. R., Rothman, E. F., \& Silverman, J. G. (2007). Contexts of condom use and non-condom use among young adolescent male perpetrators of dating violence. AIDS Care, 19(8), 970-3.

Raj, A., Silverman, J. G., Wingood, G. M., \& DiClemente, R. J. (1999). Prevalence and correlates of relationship abuse among a community-based aample of low-income African American women. Violence Against Women, 5(3), 272-291.

Ramirez-Valles, J., Zimmerman, M. A., \& Newcomb, M. D. (1998). Sexual risk behavior among youth: modeling the influence of prosocial activities and socioeconomic factors. Journal of Health and Social Behavior, 39(3), 237-53.

Randolph, M. E., Torres, H., Gore-Felton, C., Lloyd, B., \& McGarvey, E. L. (2009). Alcohol use and sexual risk behavior among college students: understanding gender and ethnic differences. American Journal of Drug and Alcohol Abuse, $35(2), 80-4$.

Rapkin, A. J., \& Erickson, P. I. (1994). Differences in knowledge of and risk factors for AIDS between Hispanic and non-Hispanic women attending an urban family planning clinic. AIDS, 4(9), 889-899.

Raymond, M., Bogdanovich, L., Brahmi, D., Cardinal, L. J., Fager, G. L., Frattarelli, L. C., ... Santelli, J. S. (2008). State refusal of federal funding for abstinence-only education. Sexuality Research and Social Policy, 5(3), 44-55.

Rector, R. E., Johnson, K. A., \& Noyes, L. R. (2003). Sexually Active Teenagers Are More Likely to Be Depressed and to Attempt Suicide. Retrieved May 11, 2012, from http://www.heritage.org/research/reports/2003/06/sexually-active-teenagersare-more-likely-to-be-depressed 
Rickenback, C. (2006). Con: Does abstinence-only education put adolescents at risk? American Journal of Maternal \& Child Nursing, 31(6), 349.

Risisky, D., Caldwell, L. L., \& Fors, S. W. (1997). The prevention of HIV among adolescents: A leisure education intervention. Journal of Health Education, 28(6), 350-356.

Roemer, R., \& Paxman, J. M. (1985). Sex education laws and policies. Studies in Family Planning, 16(4), 219-30.

Romer, D., \& Hornik, R. (1992). HIV education for youth: the importance of social consensus in behaviour change. AIDS Care, 4(3), 285-303.

Rotheram-Borus, M. J., Mahler, K. A., \& Rosario, M. (1995). AIDS prevention with adolescents. AIDS Education and Prevention, 7(4), 320-36.

Rubin, A. G., Gold, M. A., \& Primack, B. A. (2009 ). Associations between depressive symptoms and sexual risk behavior in a diverse sample of female adolescents. Journal of Pediatric and Adolescent Gynecology, 22(5), 306-12.

Sabia, J. J. (2006). Does sex education affect adolescent sexual behaviors and health? . Journal of Policy Analysis and Management, 25(4), 783-802.

Sabogal, F., Perez-Stable, E. J., Otero-Sabogal, R., \& Hiatt, R. A. (1995). Gender, ethnic, and acculturation differences in sexualbehaviors: Hispanic and non-Hispanic white adults. Hispanic Journal of Behavioral Sciences, 17(2), 139-159.

Sacco, W. P., Rickman, R. L., Thompson, K., Levine, B., \& Reed, D. L. (1993). Gender differences in AIDS-relevant condom attitudes and condom use. AIDS Education and Prevention, 5(4), 311-26.

Saewyc, E. M., Magee, L. L., \& Pettingell, S. E. (2004). Teenage pregnancy and associated risk behaviors among sexually abused adolescents. Perspectives on Sexual and Reproductive Health, 36(3), 98-105.

Salazar, L. F., Bradley, E. L., Younge, S. N., Daluga, N. A., Crosby, R. A., Lang, D. L., \& DiClemente, R. J. (2010). Applying ecological perspectives to adolescent sexual health in the United States: Rhetoric or reality? Health Educucation Research, 25(4), 552-562. doi:10.1093/her/cyp065

Sandfort, T. G., Orr, M., Hirsch, J. S., \& Santelli, J. (2008). Long-term health correlates of timing of sexual debut: Results from a national U.S. study. American Journal of Public Health, 98(1), 155-161.

Santelli, J. S. (2008). Medical accuracy in sexuality education: Ideology and the scientific process. American Journal of Public Health, 98(10), 1786-1792. 
Santelli, J. S., \& Melnikas, A. J. (2010). Teen fertility in transition: recent and historic trends in the United States. Annual Review of Public Health, 31, 371-83.

Santelli, J. S., Abraido-Lanza, A. F., \& Melnikas, A. J. (2009). Migration, acculturation, and sexual and reproductive health of Latino adolescents. Journal of Adolescent Health, 44(1), 3-4.

Santelli, J. S., Brener, N. D., Lowry, R., Bhatt, A., \& Zabin, L. S. (1998). Multiple sexual partners among U.S. adolescents and young adults. Family Planning Perspectives, $30(6), 271-275$.

Santelli, J. S., Robin, L., Brener, N. D., \& Lowry, R. (2001). Timing of alcohol and other drug use and sexual risk behaviors among unmarried adolescents and young adults. Family Planning Perspective, 33(5), 200-5.

Satcher, D. (2001). The Surgeon General's Call to Action to Promote Sexual Health and Responsible Sexual Behavior. American Journal of Health Education, 32(6), 35668.

Savage, M., \& Holcomb, D. (1999). Adolescent female athlete's sexual risk-taking behaviors. Journal of Youth and Adolescence, 28(5), 595-602.

Schaalma, H. P., Abraham, C., Gillmore, M. R., \& Kok, G. (2004). Sex education as health promotion: what does it take? Archives of Sexual Behavior, 33(3), 259-69.

Schepis, T. S., Desai, R. A., Cavallo, D. A., Smith, A. E., McFetridge, A., Liss, T. B., . . . Krishnan-Sarin, S. (2011). Gender differences in adolescent marijuana use and associated psychosocial characteristics. Journal of Addiction Medicine, 5(1), $65-$ 73. doi:10.1097/ADM.0b013e3181d8dc62

School District of Palm Beach County. (2010). The 2009 Youth Risk Behavior Survey Results: The School District of Palm Beach County Florida. Retrieved November 1, 2011, from http://www.palmbeachschools.org/sc/documents/2009_YRBS_Report.pdf

School District of Palm Beach County. (2012). Directory of Schools and Principals, 2012-2013. Retrieved November 19, 2012, from http://www.palmbeachschools.org/Community/PDFs/Schools_Prin_Photos.pdf

School District of Palm Beach County. (2012). Student Participation in Authorized Surveys. Retrieved November 1, 2012, from http://www.palmbeachschools.org/Forms/Documents/2027.pdf

Schvaneveldt, P. L., Miller, B. C., Berry, E. H., \& Lee, T. R. (2001). Academic goals, achievement, and age at first sexual intercourse: Longitudinal, bidirectional influences. Adolescence, 36(144), 767-787. 
Scott, M. E., Wildsmith, E., Welti, K., Ryan, S., Schelar, E., \& Steward-Streng, N. R. (2011). Risky adolescent sexual behaviors and reproductive health in young adulthood. Perspectives on Sexual and Reproductive Health, 43(2), 110-118.

Senn, T. E., \& Carey, M. P. (2011). Age of partner at first adolescent intercourse and adult sexual risk behavior among women. Journal of Women's Health, 20(1), 616.

Senn, T. E., Carey, M. P., \& Vanable, P. A. (2008). Childhood and adolescent sexual abuse and subsequent sexual risk behavior: Evidence from controlled studies, methodological critique, and suggestions for research. Clinical Psychology Review, 28, 711-735.

Senn, T. E., Carey, M. P., Vanable, P. A., Coury-Doniger, P., \& Urban, M. (2007). Characteristics of sexual abuse in childhood and adolescence influence sexual risk behavior in adulthood. Archives of Sexual Behavior, 36(5), 637-45.

Sexuality Information and Education Council of the United States. (2001a). Issues and Answers: Fact Sheet on Sexuality Education. SIECUS Report, 29(6), 30-37.

Sexuality Information and Education Council of the United States. (2001b). Toward a Sexually Healthy America: Roadblocks Imposed by the Federal Government's Abstinence-Only-Until-Marriage Education Program. Retrieved April 12, 2012, from http://www.advocatesforyouth.org/storage/advfy/documents/abstinenceonly.pdf

Sexuality Information and Education Council of the United States. (2003). The Truth about STDs. Retrieved March 13, 2012, from http://www.santacruzhealth.org/pdf/FS_truth_about_stds.pdf

Sexuality Information and Education Council of the United States. (2010a). A History of Federal Abstinence-Only-Until-Marriage Funding FY10. Retrieved October 15, 2011, from http://ww.siecus.org

Sexuality Information and Education Council of the United States. (2010b). Florida State Profile Fiscal Year 2009. Retrieved April 13, 2012, from http://www.siecus.org/_data/global/images/State\%20Profile\%20FY\%2009/FLOR IDA.pdf

Sexuality Information and Education Council of the United States. (2011). Florida State Profile Fiscal Year 2010. Retrieved April 9, 2012, from http://http://www.siecus.org

Shannon, K., Leiter, K., Phaladze, N., Hlanze, Z., Tsai, A. C., Heisler, M., . . W Weiser, S. D. (2012). Gender inequity norms are associated with increased male-perpetrated 
rape and sexual risks for HIV infection in Botswana and Swaziland. PLoS ONE, $7(1)$, e 28739.

Shrier, L. A., Pierce, J. D., Emans, S. J., \& DuRant, R. H. (1998). Gender differences in risk behaviors associated with forced or pressured sex. Archives of Pediatric and Adolescent Medicine, 152(1), 57-63.

Shrier, L. A., Schillinger, J. A., Aneja, P., Rice, P. A., Batteiger, B. E., Braslins, P. G., . . . Fortenberry, J. D. (2009). Depressive symptoms and sexual risk behavior in young, chlamydia-infected, heterosexual dyads. Journal of Adolescent Health, 45(1), 63-9.

Shrier, L. A., Walls, C., Lops, C., \& Feldman, H. A. (2011). Correlates of incorrect condom use among depressed young women: An event-level analysis. Journal of Pediatric and Adolescent Gynecology, 24(1), 10-14.

Siegel, D. M., DiClemente, R. J., Durbin, M., Krasnovsky, F., \& Saliba, P. (1995). Change in junior high school students' AIDS-related knowledge, misconceptions, attitudes, and HIV-preventive behaviors: Effects of a school-based intervention. AIDS Education and Prevention, 7(6), 534-43.

Siegel, M. B., Naimi, T. S., Cremeens, J. L., \& Nelson, D. E. (2011). Alcoholic beverage preferences and associated drinking patterns and risk behaviors among high school youth. American Journal of Preventative Medicine, 40(4), 419-26.

Sieving, R., Eisenberg, M., Pettingell, S., \& Skay, C. (2006). Friends' influence on adolescents' first sexual intercourse. Perspective on Sexual and Reproductive Health, 38(1), 3-19.

Sijtsma, K. (2009). On the use, the misuse, and the very limited usefulness of Cronbach's alpha. Psychometrika, 74(1), 107-120. doi:10.1007/s11336-008-9101-0

Silverman, J. G., McCauley, H. L., Decker, M. R., Miller, E., Reed, E., \& Raj, A. (2011). Coercive Forms of Sexual Risk and Associated Violence Perpetrated by Male Partners of Female Adolescents. Perspectives on Sexual and Reproductive Health, 43(1), 60-65.

Silverman, J. G., Raj, A., \& Clements, K. (2004). Dating violence and associated sexual risk and pregnancy among adolescent gin the United States. Pediatrics, 114(2), e220-e225.

Silverman, J. G., Raj, A., Mucci, L. A., \& Hathaway, J. E. (2001). Dating violence against adolescent girls and associated substance use, unhealthy weight control, sexual risk behavior, pregnancy, and suicidality. Journal of the American Medical Association, 286(5), 572-9. 
Silverman, J. G., Raj, A., Mucci, L. A., \& Hathaway, J. E. (2001). Dating violence against adolescent girls and associated substance use, unhealthy weight control, sexual risk behavior, pregnancy, and suicidality. Journal of the American Medical Association, 286(5), 572-9.

Smart, R., Adlaf, E., \& Walsh, G. (1994). Neighbourhood socio-economic factors in relation to student drug use and programmes. Journal of Child and Adolescent Substance Abuse, 3, 37-46.

Smith, A. K., Ayanian, J. Z., Covinsky, K. E., Landon, B. E., McCarthy, E. P., Wee, C. C., \& Steinman, M. A. (2011). Conducting high-value secondary dataset analysis: an introductory guide and resources. Journal of General Internal Medicine, 26(8), 920-9.

Smith, M. B., Canter, W. A., \& Robin, A. L. (1989). A path analysis of an adolescent drinking behavior model derived from problem behavior theory. Journal of Studies on Alcohol and Drugs, 50(2), 128-42.

Smith, T. E., Steen, J. A., Schwendinger, A., Spaulding-Givens, J., \& Brooks, R. G. (2005). Gender differences in adolescent attitudes and receptivity to sexual abstinence education. Children \& Schools, 27(1), 45-50.

Smith, T. E., Steen, J. A., Spaulding-Givens, J., \& Schwendinger, A. (2003).

Measurement in abstinence education: Critique and recommendations. Evaluation \& the Health Professions, 26(2), 180-205.

Sobo, E. J. (1993). Inner-city women and AIDS: the psycho-social benefits of unsafe sex. Culture, Medicine, and Psychiatry, 17(4), 455-85.

Solomon-Fears, C. (2004, Oct 2004). Reducing Teen Pregnancy: Adolescent Family Life and Abstinence Education. Retrieved March 12, 2012, from Congressional Research Service Reports: http://digital.library.unt.edu/ark:/67531/metacrs5749/

Sosin, D. M., Koepsell, T. D., Rivara, F. P., \& Mercy, J. A. (1995). Fighting as a marker for multiple problem behaviors in adolescents. Journal of Adolescent Health, 16(3), 209-215.

Starkman, N., \& Rajani, N. (2002). The case for comprehensive sex education. AIDS Patient Care and STDs, 16(7), 313-8.

Stein, Z. A. (1990). HIV prevention: The need for methods women can use. American Journal of Public Health., 80(4), 460-2.

Steinberg, L., \& Cauffman, E. (1996). Maturity of judgement in adolescence:

Psychosocial factors in adolescent decision making. Law and Human Behavior, 20, 249-272. 
Stout, J. W., \& Kirby, D. (1993). The effects of sexuality education on adolescent sexual activity. Pediatric Annals, 22(2), 120-6.

Stueve, A., \& O'Donnell, L. N. (2005). Early alcohol initiation and subsequent sexual and alcohol risk behaviors among urban youths. American Journal of Public Health, 95(5), 887-93.

Sundaram, V., Laursen, B., \& Helweg-Larsen, K. (2008). Is sexual victimization gender specific?:The prevalence of forced sexual activity among men and women in Denmark, and self-reported well-being among survivors. Journal of Interpersonal Violence, 23(10), 1414-1440.

Sznitman, S. R., Carey, M. P., Vanable, P. A., DiClemente, R. J., Brown, L. K., Valois, R. F., . . Romer, D. (2010). The impact of community-based sexually transmitted infection screening results on sexual risk behaviors of African American adolescents. Journal of Adolescent Health, 47(1), 12-19.

Tavakol, M., \& Dennick, R. (2011). Making sense of Cronbach's alpha. International Journal of Medical Education, 2, 53-55. doi:10.5116/ijme.4dfb.8dfd

Teitelman, A. M., Dichter, M., Cederbaum, J., \& Campbell, J. C. (2007). Intimate partner violence, condom use and HIV risk for adolescent girls: Gaps in the literature and future directions for research and intervention. Journal of HIV/AIDS Prevention in Children and Youth, 8(2), 65-93.

Tevendale, H. D., Lightfoot, M., \& Slocum, S. L. (2009). Individual and environmental protective factors for risky sexual behavior among homeless youth: an exploration of gender differences. AIDS and Behavior, 13(1), 154-164. doi:10.1007/s10461$008-9395-z$

Tolman, D. L., Striepe, M. I., \& Harmon, T. (2003). Gender matters: constructing a model of adolescent sexual health. Journal of Sex Research, 40(1), 4-12.

Tolou-Shams, M., Brown, L. K., Gordon, G., Fernandez, I., \& Group, P. S. (2007). Arrest history as an indicator of adolescent/young adult substance use and HIV risk. Drug and Alcohol Dependence, 88(1), 87-90.

Travis, S. (2008, Feburary 13). 'Age-appropriate' sex education to begin in kindergarten. Sun Sentinel. Retrieved April 1, 2011, from http://articles.sun-sentinel.com/200802-13/news/0802120597_1_curriculum

Trenholm, C., Devaney, B., Fortson, K., Quay, L., Wheeler, J., \& Clark, M. (2007). Impacts of Four Title V, Section 510 Abstinence Education Programs. Retrieved September 28, 2010, from www.mathematicampr.com/publications/pdfs/impactabstinence.pdf 
Trussel, 1. J., Koenig, J., Stewart, F., \& Darroch, J. E. (1997). Medical care cost savings from adolescent contraceptive use. Family Planning Perspectives , 29(6), 248-55, 295.

Turbin, M. S., Jessor, R., \& Costa, F. M. (2000). Adolescent cigarette smoking: healthrelated behavior or normative transgression? Prevention Science, 1(3), 115-24.

U.S. Census Bureau. (2011a). Age and Sex Composition 2010. Retrieved June 6, 2012, from http://www.census.gov/prod/cen2010/briefs/c2010br-03.pdf

U.S. Census Bureau. (2011b). The Hispanic Population: 2010 - Census Bureau. Retrieved June 21, 2012, from http://www.census.gov/prod/cen2010/briefs/c2010br-04.pdf

U.S. Census Bureau. (2012). 2010 Census: Unites States Profile. Retrieved June 29, 2012, from http://www2.census.gov/geo/maps/dc10_thematic/2010_Profile/2010_Profile_Ma p_United_States.pdf

U.S. Department of Health and Human Services. (2011). Directory of Program Services. Retrieved April 13, 2012, from http://www.acf.hhs.gov/ebrochure2011/directory_of_program_services.pdf

U.S. Department of Health and Human Services. (2012a). Healthy People 2020 Objectives. Retrieved June 9, 2012, from http://www.healthypeople.gov/2020/topicsobjectives2020/pdfs/HP2020objectives .pdf

U.S. Department of Health and Human Services. (2012b). Title XX Funding History. Retrieved April 13, 2012, from http://www.hhs.gov/opa/about-opa-andinitiatives/title-xx-afl/what-is-title-xx/title-xx-funding-history/

U.S. House of Representatives Committee on Government Reform. (2004). The Content of Federally Funded Abstinence-Only Education Programs. Retrieved October 9, 2011, from http://www.democrats.reform.house.gov/Documents/20041201102153-50247.pdf

Underhill, K., Operario, D., \& Montgomery, P. (2009). Abstinence-only programs for HIV infection prevention in high-income countries. Retrieved January 18, 2012, from http://onlinelibrary.wiley.com/doi/10.1002/14651858.CD005421.pub2/full

United Nations. (2003). General Comment No. 4: Adolescent health and development in the context of the Convention on the Rights of the Child. CRC/GC/2003/4.

Retrieved April 2, 2012, from

http://www.unhcr.org/refworld/docid/4538834f0.html 
United Nations. (2010). Report of the United Nations Special Rapporteur on the right to education. Retrieved April 2, 2012, from http://daccess-ddsny.un.org/doc/UNDOC/GEN/N10/462/13/PDF/N1046213.pdf?OpenElement

Upchurch, D. M., Mason, W. M., Kusunoki, Y., \& Kriechbaum, M. J. (2004). Social and behavioral determinants of self-reported STD among adolescents. Perspectives on Sexual and Reproductive Health, 36(6), 276-287.

Valois, R. F., MacDonald, J. M., Bretous, L., Fischer, M. A., \& Drane, J. W. (2002). Risk factors and behaviors associated with adolescent violence and aggression. American Journal of Health Behavior, 26(6), 454-64.

Valois, R. F., McKeown, R. E., Garrison, C. Z., \& Vincent, M. L. (1995). Correlates of aggressive and violent behaviors among public high school adolescents. Journal of Adolescent Health, 16(1), 26-34.

van den Akker, O. B., Andre, J., Lees, S., \& Murphy, T. (1999). Adolescent sexual behaviour and knowledge. British Journal of Midwifery,, 7(12), 765 - 769.

Vélez-Pastrana, M. C., González-Rodríguez, R. A., \& Borges-Hernández, A. (2005). Family functioning and early onset of sexual intercourse in Latino adolescents. Adolescence, 40, 777-791.

Waller, M. W., Hallfors, D. D., Halpern, C. T., Iritani, B. J., Ford, C. A., \& Guo, G. (2006). Gender differences in associations between depressive symptoms and patterns of substance use and risky sexual behavior among a nationally representative sample of U.S. adolescents. Archives of Women's Mental Health, $9(3), 139-50$.

Warren, C. W., Santelli, J. S., Everett, S. A., Kann, L., Collins, J. L., Cassell, C., . . Kolbe, L. J. (1998). Sexual behavior among U.S. high school students, 19901995. Family Planning Perspectives, 30(4), 170-2, 200.

Wattleton, F. (1987). American teens: sexually active, sexually illiterate. Journal of School Health, 57(9), 379-80.

Weinstein, E., \& Rosen, E. (1991). Adolescents' knowledge of AIDS and behavior change: Implications for education. Journal of Health Education, 22(5), 313-18.

Weinstock, H., Berman, S., \& Cates, W. J. (2004). Sexually transmitted diseases among American youth: incidence and prevalence estimates, 2000. Perspectives on Sexual and Reproductive Health, 36(1), 6-10.

Weiss, J. A., Jampol, M. L., Lievano, J. A., Smith, S. M., \& Wurster, J. L. (2008). Normalizing risky sexual behaviors: a grounded theory study. Pediatric Nursing, 34(2), 163-9. 
Weiss, U. K., \& Tillman, K. H. (2009). Risky sexual behaviors among Hispanic young adults in South Florida: Nativity, age at immigration and gender differences. Perspectives on Sexual and Reproductive Health, 41(4), 202-209.

Wen, X. J., Balluz, L., \& Town, M. (2012). Prevalence of HIV risk behaviors between binge drinkers and non-binge drinkers aged 18- to 64-years in U.S., 2008. Journal of Community Health, 37(1), 72-79.

Werner-Wilson, R. J. (1998). Gender differences in adolescent sexual attitudes: The influence of individual and family factors. Adolescence, 33(131), 519-532.

Westhoff, W. W., McDermott, R. J., \& Holcomb, D. R. (1996). HIV risk behaviors: A comparison of U.S. Hispanic and Dominican Republic youth. AIDS Education and Prevention, 8(2), 106-14.

Wierson, M., \& Bright, J. (1996). Educational policy, adolescent knowledge of HIV risk, and sexual behavior in Zimbabwe and the United States. In S. Oskamp, \& S. Thompson (Eds.), Understanding HIV Risk Behavior (pp. 237-268). New York: Sage Publications.

Wilke, D. J., Siebert, D. C., Delva, J., Smith, M. P., \& Howell, R. L. (2005). Gender differences in predicting high-risk drinking among undergraduate students. Journal of Drug Education, 35(1), 79-94.

Williams, J. H., Ayers, C. D., Bright, C. L., Abbott, R. D., \& Hawkins, J. D. (2007). Understanding race and gender differences in delinquent acts and alcohol and marijuana use: A developmental analysis of initiation. Social Work Research, 31(2), 71-81.

Wilson, K., Asbridge, M., Kisely, S., \& Langille, D. (2010). Associations of risk of depression with sexual risk taking among adolescents in Nova Scotia high schools. Canadian Journal of Psychiatry, 55(9), 577-585.

Wilson, S. N. (2000). Sexuality education: our current status, and an agenda for 2010. Family Planning Perspectives, 32(5), 252-4.

Wingood, G. M., \& DiClemente, R. J. (1997). Consequences of having a physically abusive partner on the condum use and sexual negotiation practices of young adult African American women. American Journal of Public Health, 87, 10161018.

Wingood, G. M., \& DiClemente, R. J. (2000). Application of the theory of gender and power to examine HIV-related exposures, risk factors, and effective interventions for women. Health Education \& Behavior, 27(5), 539-565.

Wingood, G. M., \& DiClemente, R. J. (2002). The Theory of Gender and Power: A Social Structureal Theory for Guiding Public Health Interventions. In R. J. 
DiClemente, R. A. Crosby, \& M. C. Kegler (Eds.), Emerging Theories in Health Promotion Practice and Research: Strategies for Improving Public Health (pp. 313-346). San Francisco: Jossey-Bass.

Wingood, G. M., \& DiClemente, R. J. (2006). Enhancing adoption of evidence-based HIV interventions: Promotion of a Suite of HIV prevention interventions for African American women. AIDS Education and Prevention, 18(Suppl A), 161170.

Wingood, G. M., DiClemente, R. J., Mikhail, I., Lang, D. L., McCree, D. H., Davies, S. L., . . Saag, M. (2004). A randomized controlled trial to reduce HIV transmission risk behaviors and sexually transmitted diseases among women living with HIV: The WiLLOW Program. Journal of Acquired Immune Deficiency Syndrome, 37(2 Suppl), S58-67.

Wingood, G. M., Seth, P., DiClemente, R. J., \& Robinson, L. S. (2009). Association of sexual abuse with incident high-risk human papillomavirus infection among young African-American women. Sexually Transmitted Diseases, 36(12), 784-6.

Worth, D. (1989). Sexual decision-making and AIDS: Why condom promotion among vulnerable women is likely to fail. Studies in Family Planning, 20(6), 297-307.

Wu, T.-Y., Rose, S. E., \& Bancroft, J. M. (2006). Gender differences in health risk behaviors and physical activity among middle school students. The Journal of School Nursing, 22(1), 25-31.

Yan, A. F., Chiu, Y.-W., Stoesen, C. A., \& Wang, M. Q. (2007). STD-/HIV-related sexual risk behaviors and substance use among U.S. rural adolescents. Journal of the National Medical Association, 99(12), 1386-1394.

Yarber, W. L., Milhausen, R., Crosby, R. A., \& DiClemente, R. J. (2002). Selected risk and protective factors associated with two or more lifetime sexual intercourse partners and non-condom use during last coitus among U.S. rural high school students. American Journal of Health Education, 33(4), 206-213.

Zamboanga, B. L., Carlo, G., \& Raffaelli, M. (2004). Problem Behavior Theory: An examination of the behavior structure system in Latino and non-Latino college students. Interamerican Journal of Psychology, 38(2), 253-262. 
VITA

CHRISTI M. NAVARRO

\section{EDUCATION}

Ph.D. (Candidate) in Public Health

2013

Florida International University, Miami, FL

Graduate Certificate in Women's Studies

2008

Florida International University, Miami, FL

Nova Southeastern University, Ft. Lauderdale, FL

B.S. in Biological Sciences

1998

Florida International University, Miami, FL

HONORS \& AWARDS

Dissertation Year Fellowship

2012

Florida International University

Greg Alexander Outstanding Student Author (2nd place)

Maternal \& Child Health, American Public Health Association

2008-2013

McKnight Doctoral Fellowship

2008-2011

Graduate Assistantship

Women's Studies Center, Florida International University

2009-2012

Fall 2011

\section{SCHOLARSHIP}

$\underline{\text { Professional Presentations }}$

Navarro, C. M., HIV Risk Behaviors in a Gendered Context Among Youth, presented at the Greg Alexander Outstanding Student Papers in Maternal \& Child Health 
Session at the $139^{\text {th }}$ Annual Meeting of the American Public Health Association, Washington, DC, October 2011

Navarro, C. M. and McCoy, H. V. Sexual Risk Behaviors in a Gendered Context Among Youth in Florida, presented at $139^{\text {th }}$ Annual Meeting of the American Public Health Association, Washington, DC, October 2011

Navarro, C. M., Gender Differences in Protective Sexual Health Behaviors among High School Students in Florida, presented at the 2011 McKnight Doctoral Mid-Year Research and Writing Conference, Tampa, FL, February 2011

Navarro, C. M., Young Women \& MENA: Sexuality and Reproductive Health Challenges in Contemporary Morocco, presented at the Women, Sexuality, and Gender Studies Student Conference at Florida International University, Miami, FL, November 2010

Poster Presentations

Abreu-Pérez, R., Navarro, C. M., Beck-Sagué, C., Lerebours-Nadal, L., Soto, S., Nicholas, S., and Malow, R. M. Characteristics Associated with HIV Status Disclosure to HIV-Infected Youth Receiving Antiretroviral Therapy (ARV) in the Dominican Republic (DR), presented at the 140th Annual Meeting of the American Public Health Association, San Francisco, CA, October 2012

Navarro, C. M., Gender Differences in Sexual Risk Behaviors Highlight Need for Attention to Gendered Context, presented at the 139th Annual Meeting of the American Public Health Association, Washington, DC, October 2011

Navarro, C. M., Sexual Risk Behaviors in a Gendered Context Among High School Students, presented at the 2011 National HIV Prevention Conference, Atlanta, GA, August 2011

$\underline{\text { Publications }}$

Navarro, C. M. (2009). "Interrogating the birthing experience: A feminist perspective of women's choice in childbirth." Making Waves Journal, 8:29-37.

Navarro, C. M., (2009). "The social importance of looking good: Media images and selfobjectification in women." Making Waves Journal, 7:13-19.

PROFESSIONAL AFFILIATIONS

American Public Health Association, APHA

Society for Adolescent Health \& Medicine, SAHM 